\title{
Evaluation of hillslope failure and community adjustment after extreme weather event, Waimarama 26-27 April, 2011
}

\author{
Albert E Frampton \\ A thesis submitted to Victoria University of Wellington \\ In partial fulfilment of requirements for the degree of \\ Master of Science in Physical Geography
}

School of Geography, Environment and Earth

Sciences

Victoria University of Wellington

November 2018 


\section{ABSTRACT}

In 2011, Waimarama received $80 \%$ of its annual rainfall in 48 hours. This extreme event with a return period of $>100$ years caused saturated hillslopes to collapse forming 100s of shallow landslides in the Puhokio Valley.

This study collected soil samples from 54 exposed slip scarp horizons for laboratory analysis of soil mechanical properties. Field measurements of slip and slope angles, length, width and depth to determine that $23,212 \mathrm{~m}^{3}$ of sediment was volume lost, from the 54 landslides. The field and lab measurements were used to generate a coherent understanding of landsliding at Waimarama. Laboratory analysis for liquid limits water content showed a high of $88.5 \%$ to a low of $18.8 \%$ and plastic limit water content had a high of $51 \%$ in the A horizon (organics) and low of $16.1 \%$. Specific gravity also indicated a high reading $1.74 \mathrm{~g} / \mathrm{cm}^{3}$ with a low of $1.16 \mathrm{~g} / \mathrm{cm}^{3}$. The A horizon was able to tolerate high levels of water content in most tests, while the B horizon was capable of coping with some increase in water content. The $\mathrm{C}$ horizon was only able to handle low volumes of water, and was the main initiator of regolith collapse. The laboratory results indicated high saturation levels within the horizons of weak lithology of marine regolith that over caps impervious marine bedrock. The main cause for hillslope collapse and exposure of multiple translational and debris flow landslides was extreme saturation. However, towards the height of the rainfall event a 4.5 magnitude earthquake was recorded with unknown collateral consequences. Most slip locations were found in the aspects of east, south-east, west, and northwest, and on slope angles $15-25^{\circ}$.

The study confirmed previous surveys that regolith depth $80-100 \mathrm{~cm}$ on impervious sandstone, siltstone/mudstone, when saturated over lengthy wet spells or from extreme precipitation, will collapse.

In addition to the physical geographic study a survey was included to record individual and family accounts of the weather phenomenon. A questionnaire was prepared with specific questions that required yes or no answers. These questions dealt with loss of buildings, loss of land, animals, financial loss and recovery, economic loss, insurance and mitigation plans. The most affected were farmers and the next affected were householders while the holiday park was the worst affected of small businesses. Insurance was a significant help in most recoveries. Land rehabilitation was mitigated with new plantings and some aerial sowing, otherwise many slips 
were left to revegetate naturally. Economic and financial loss was severe for most farmers, due to pasture loss and animal relocation.

Extreme rainfall causes slips that affect humans, but they can be mitigated.

The Waimarama event is one of many events that can happen countrywide, the results can be a disastrous loss of personal, economic and financial assets, loss of infrastructure, including roading, bridges and communication. These are factors that many people and communities only realise when it happens to them. Mitigation against such events might include adequate insurance and knowledge of what to do, and where to go should an event happen unexpectedly and without warning.

Keywords: Waimarama April 2011; extreme event; multiple landslides; human survey. 


\section{Acknowledgements:}

There are quite a number of people who indulged their time, support and patience that helped get this research started, developed and finished in an understandable form.

Dr Kevin Norton, my one and only supervisor has spent many hours helping me to gain the necessary skills to carry out the tasks needed to become proficient at understanding that dirt moves downhill in many forms. Thank you Kevin, I'm truly grateful.

To Dr Nick Preston (deceased) who gave me the encouragement to move from geology to geomorphology and continue to where I am today.

Dr Brent Alloway whose suggestion sparked the idea that there was a need to follow up on a severe rainstorm at Waimarama - I did, no regrets.

Ben Hines, $\mathrm{PhD}$ candidate who over the years has reviewed and helped me come to terms with academic writing, and also read and corrected this text. Thanks Ben.

Prof. Joe D'Orio Rtd. who has spent many hours reviewing my texts - especially on how to write correct citations within the text. Really appreciate your help Joe.

Rohini Biradavolu, librarian who gave me hours of tuition on the End Note system; Jane Chewings, for her help in the lab and Dez Tessler for getting me the right field equipment necessary to carry out field research; Andrew Rae for sorting out the GIS programme that caused me so many headaches.

David Lim, my workmate who is a guru on computers, especially when I stuffed up. Thanks

To the farming Families of Te Apiti Road, McNeur, McKay, and Chesterman who so generously allowed access to their farms so I could carry out my field work. Thank you.

Then finally to my family, especially to my field assistant wife, Hilda, who has endured months of silence, home alone, heard my complaints and shared in my disappointments when lab work screwed up and I had to redo an entire exercise. However, she also spent time choosing words that made more sense than mine.

To my very best family friends, Ian and Caroline Brickell, for the most generous offer of their beautiful home in Taradale, I always slept well and the numerous meals their daughter Kaylene cooked for me, Kevin and his father-in-law.

To my PhD candidate daughter Felicity who has shared inordinate amounts of info, some of her short cuts, many hours into shaping my text to look appealing and for that I'm truly grateful.

My two daughters-in-law, Catherine for the numerous meals, Jessica for her counselling when things got a bit bad and the countless interruptions from my grandchildren, where would you be without them.

My two younger sons Dean and Blair who kept their dad with-I-need-to-have-a-break conversations on fishing and flying.

To Wayne, son and boss, who has allowed me days off to get this thesis together, I owe you.

Nearly time for a drink. Thank-you to everyone. 


\section{Table of Contents}

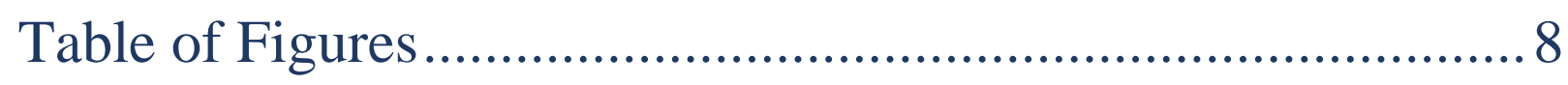

List of tables ...................................................................... 11

Chapter 1: Introduction...................................................... 12

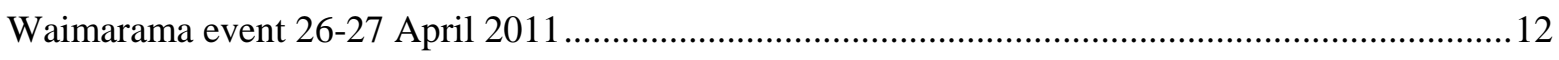

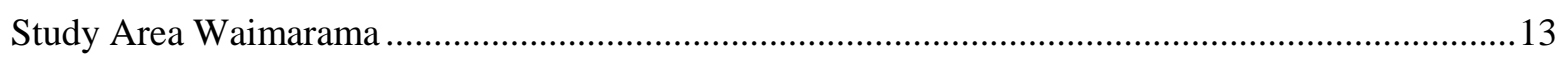

1.1 Aims and Objectives .................................................. 16

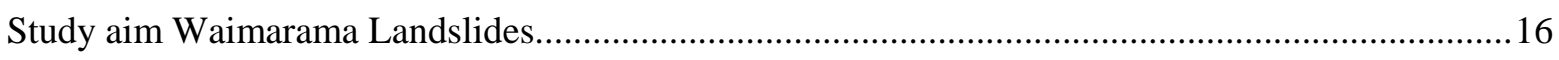

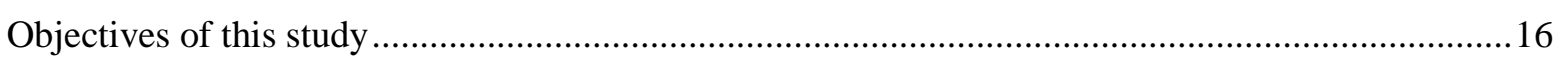

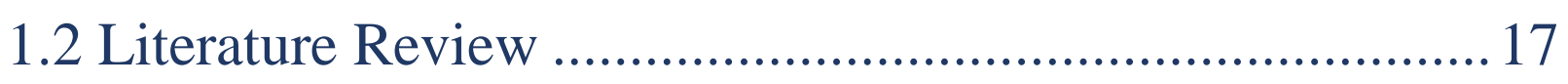

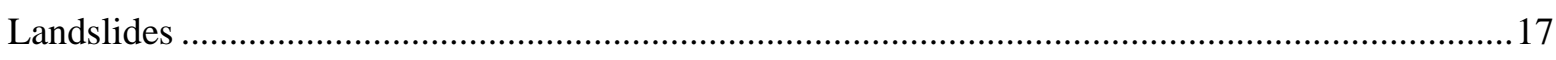

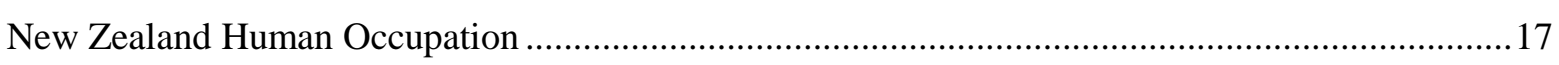

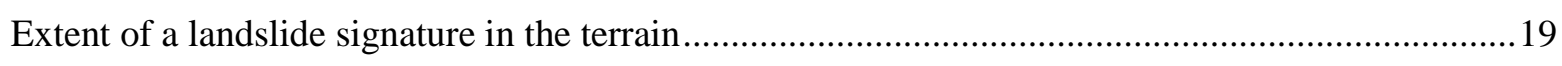

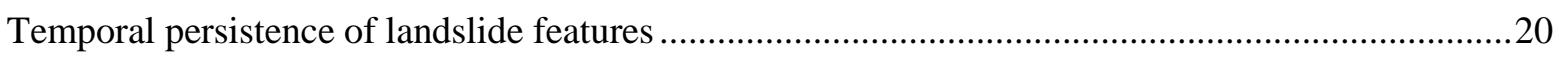

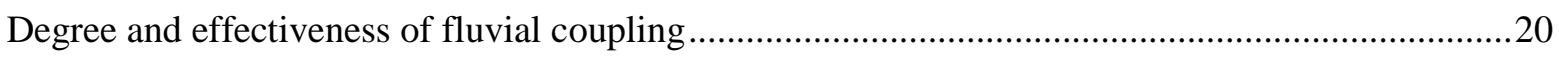

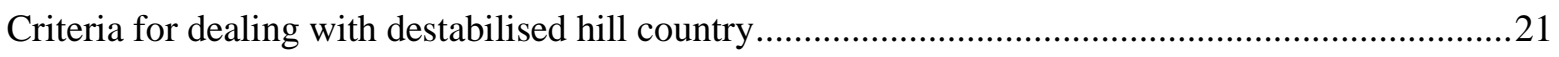

Chapter 2: Anthropogenic Influence on Landscape .................34

2.1: Land Mitigation and Assessment ......................................34

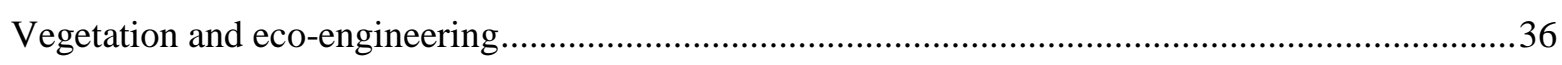

Evaluating how small scale, soil fixation can have large scale consequences....................................38

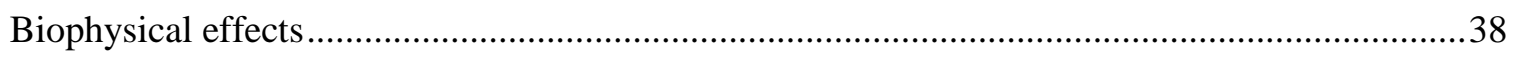

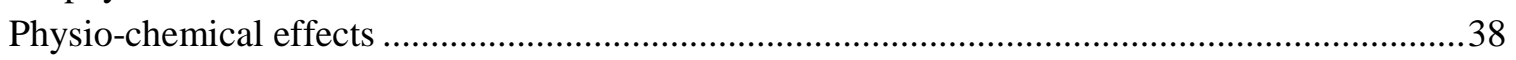

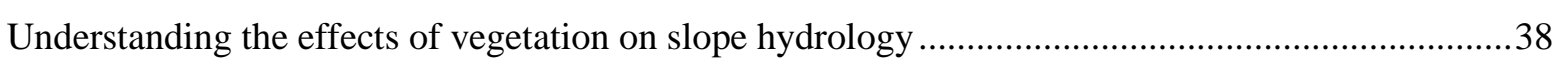

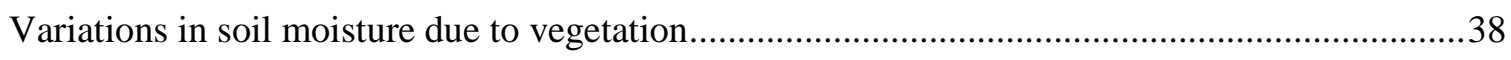

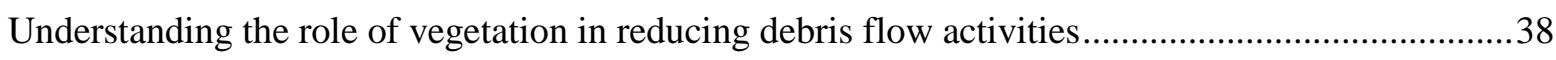

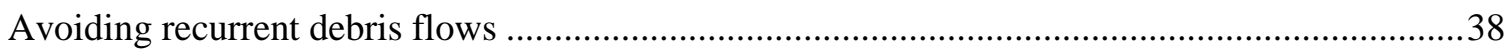

Understanding the impact of trees on the stability of dikes (Levees) ................................................39

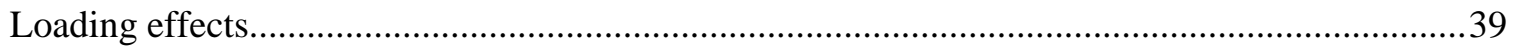

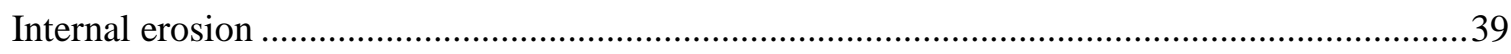

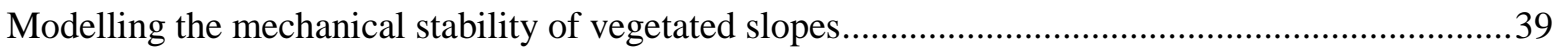

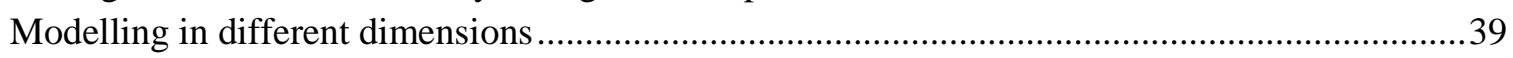


Alternative models 39

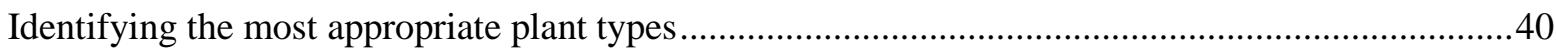

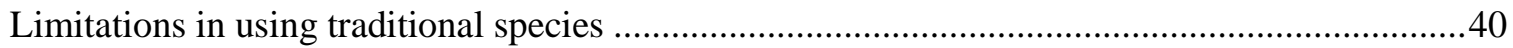

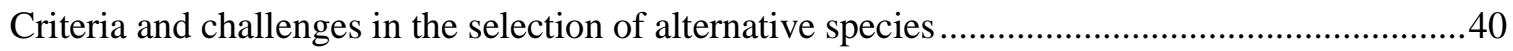

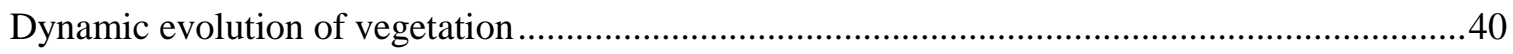

Using inert engineering structures and live plant material: efficacy over time................................40

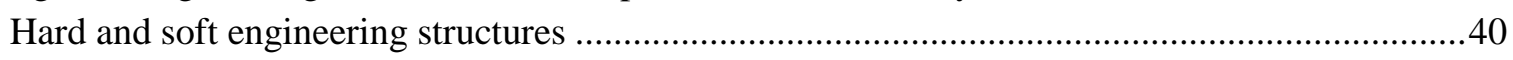

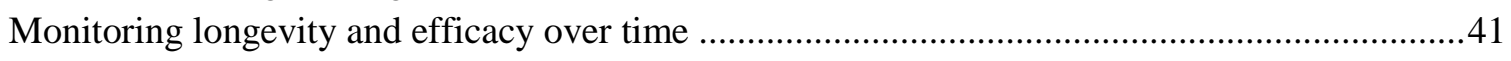

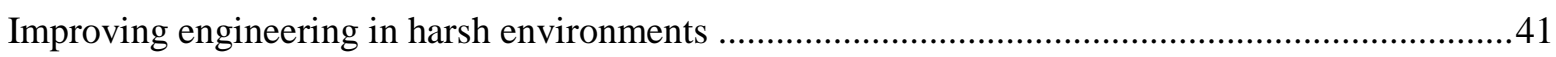

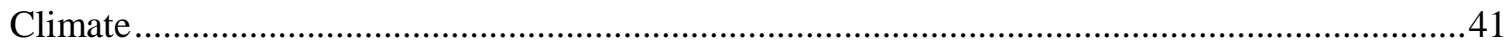

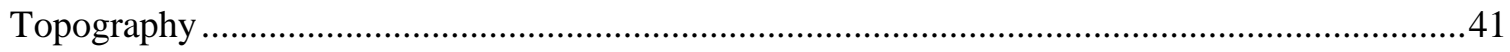

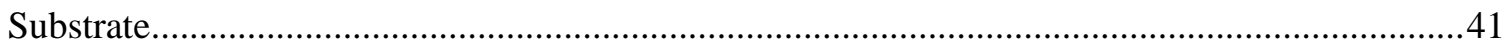

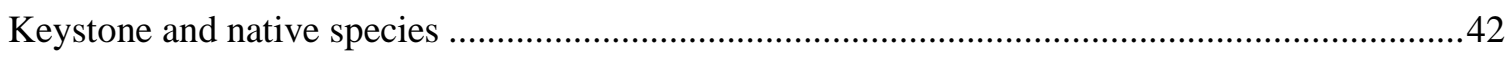

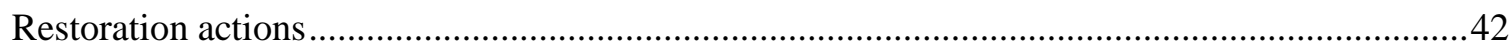

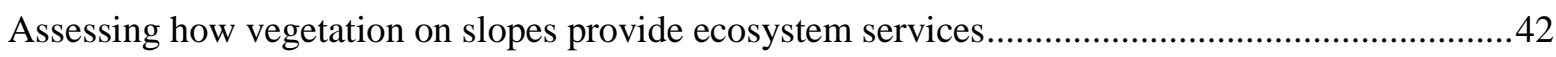

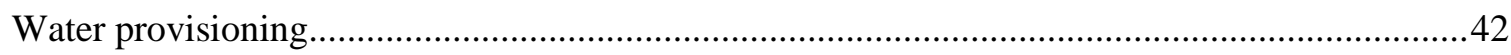

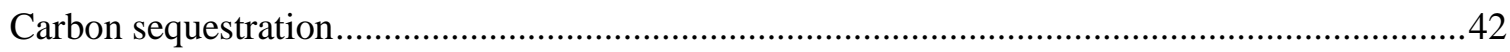

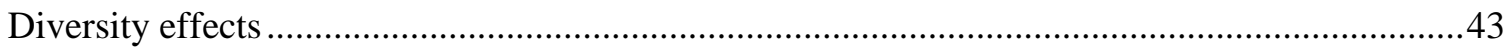

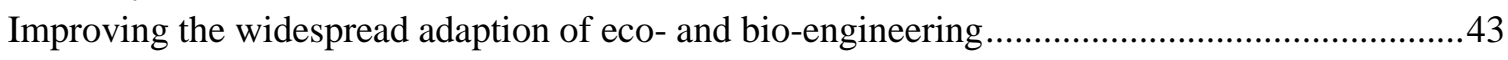

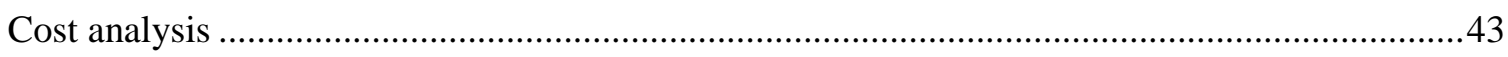

Benefits …

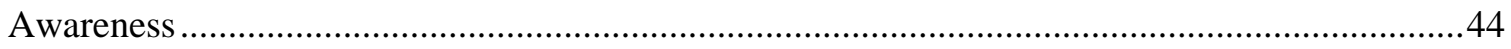

\section{2: Modelling Landslides .................................................45}

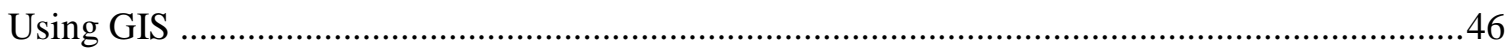

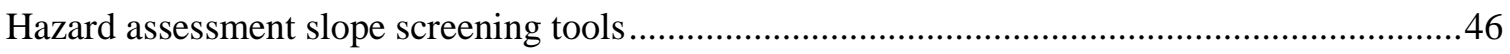

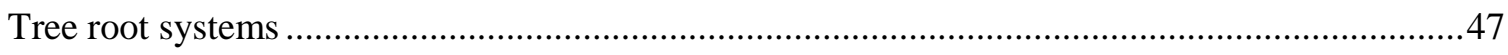

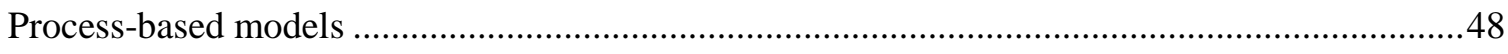

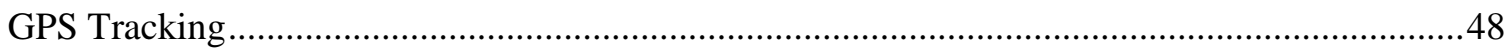

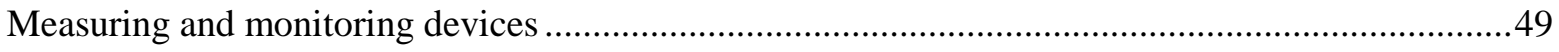

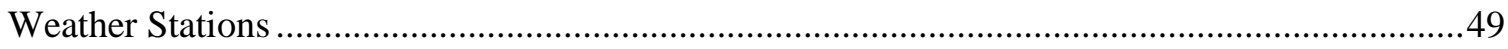

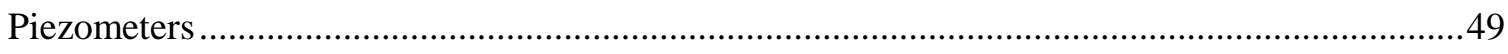

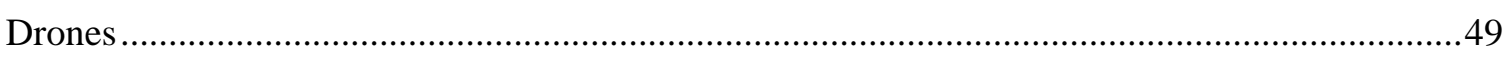

Chapter 3: Area Geology, Soils and Location .........................51

3.1: Tectonics and Geology ................................................51

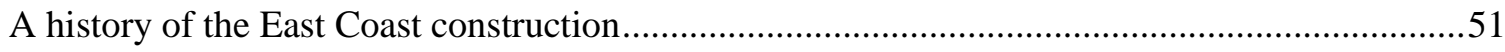

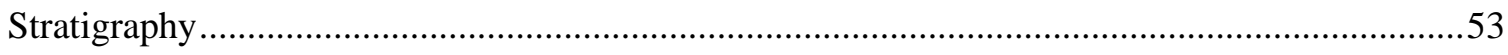

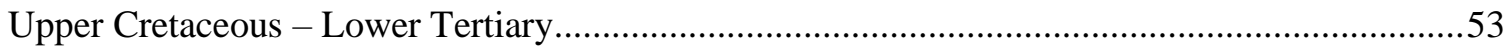

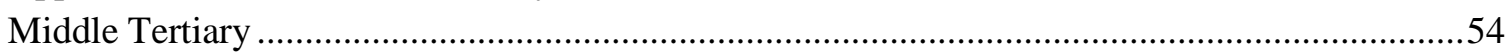

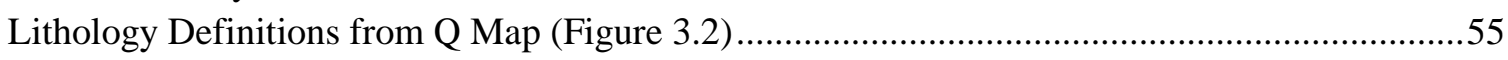

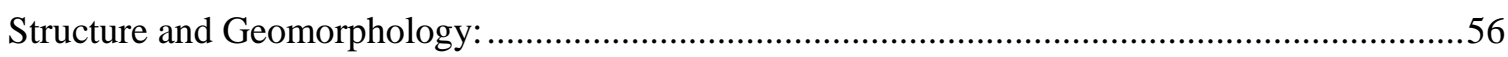

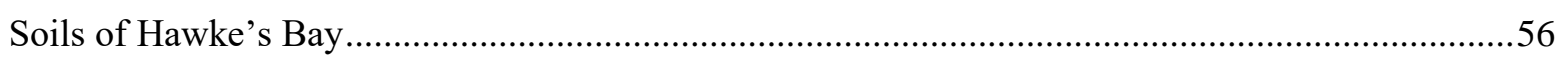

Age 


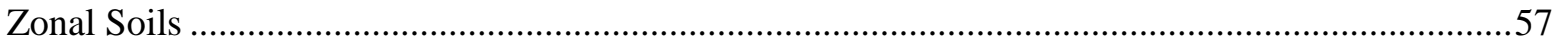

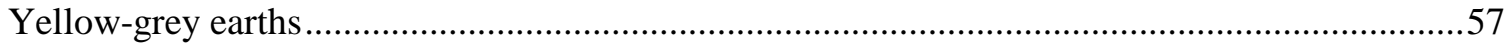

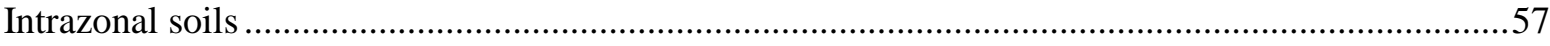

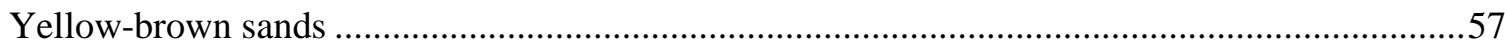

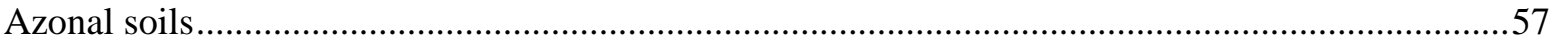

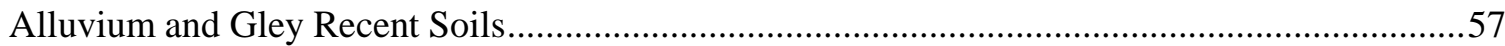

3.2: Puhokio Valley .............................................................62 62

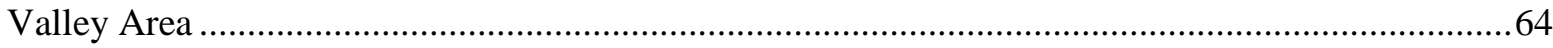

Chapter 4: Methods and Results ..........................................66

4.1: Field work..................................................................... 66

4.2: Laboratory Analysis: ...................................................76

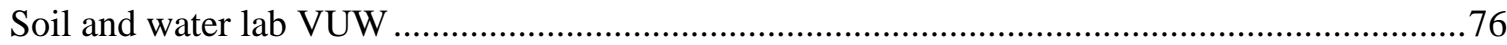

Liquid Limit Determination (Cone penetrometer); Plastic Limit Determination; Soil Moisture

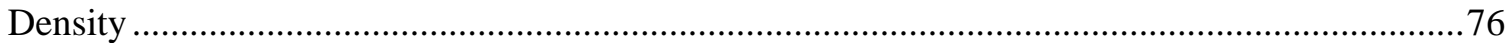

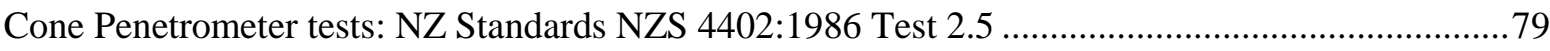

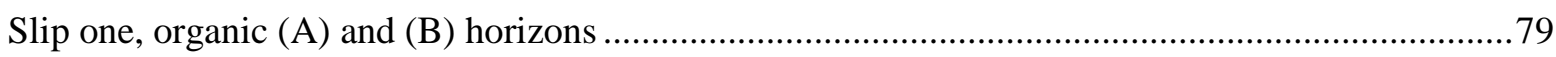

Plastic Limit Determination: NZ Standards NZS 4402:1986 Test 2.3...........................................80

Soil Moisture Density: NZ Standards NZS 4402: 1986 Tests 2.1 and 5.1.3......................................81

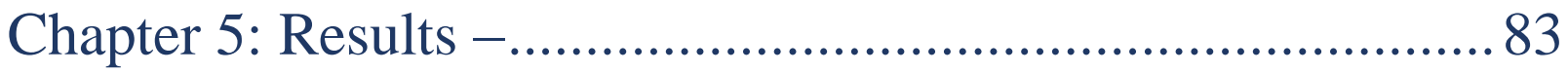

Physical attributes of Waimarama Landslides .......................8 83

5.1: Slip characteristics: ..................................................... 83

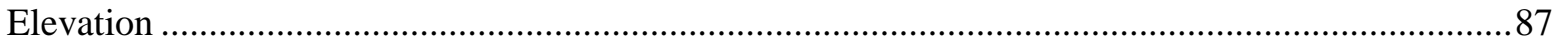

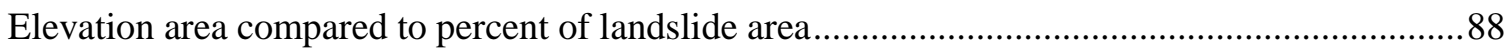

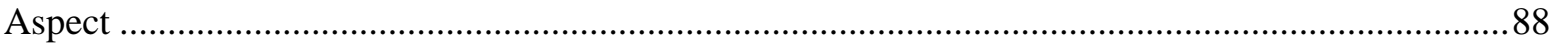

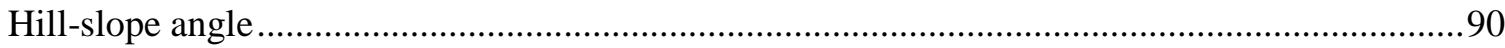

Laboratory results: ....................................................... 92

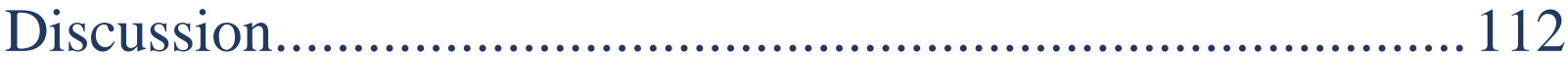

Developments in the use of Atterberg limits....................... 115 
Chapter 6: Community perceptions and response to the Waimarama Landslides .................................................. 117

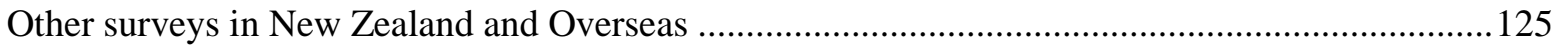

Chapter 7: Conclusions ..................................................... 133

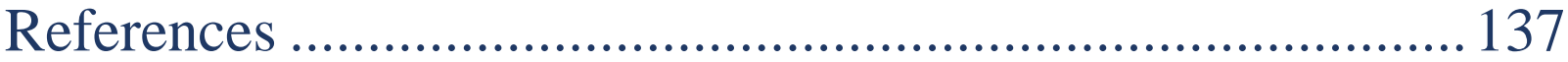

Appendix …................................................................ 147 


\section{Table of Figures}

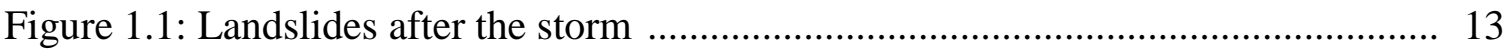

Figure 1.2: Location of Waimarama in North Island, New Zealand ............................ 13

Figure 1.3: Waimarama village, residential and holiday seaside resort ....................... 14

Figure 1.4: Beef farming, Waimarama .............................................................. 14

Figure 1.5: Forestry blocks are a factor in the Waimarama economy ......................... 15

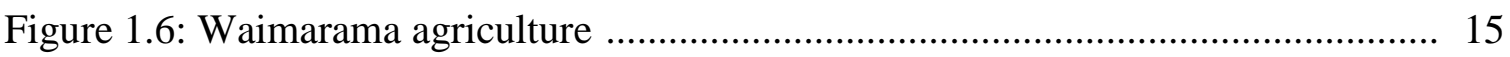

Figure 1.7: Ariel view of landslides after storm 2011 ............................................ 19

Figure 1.8: New Zealand land erosion chart ......................................................... 23

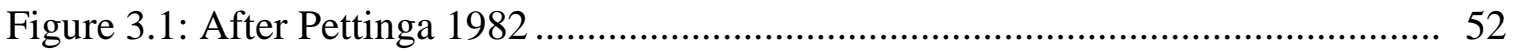

Figure 3.2: Hikurangi Trough Plate Boundary East Coast NZ ................................. 54

Figure 3.3: Q map of lithology structures within the Waimarama region...................... 55

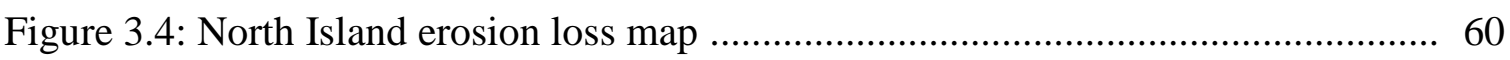

Figure 3.5: Average annual precipitation chart for Waimarama ............................... 62

Figure 3.6: North Island Hawke's Bay annual precipitation .......................................... 63

Figure 3.7: Multiple landslides on grassland pastures ................................................. 64

Figure 3.8: Quad bike transport with associated survey equipment ............................. 65

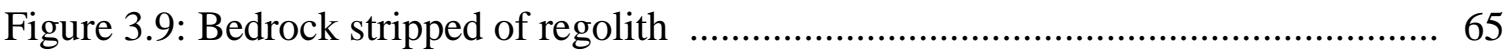

Figure 4.1: 54 sample plots shown inside research border....................................... 66

Figure 4.2: GPS location and site information of 54 landslides.................................6 67

Figure 4.3: Landslides after the storm. McNeur photo ............................................... 68

Figure 4.4: Rope and peg slip length measuring ........................................................ 69

Figure 4.5: Tools used for obtaining regolith samples ........................................... 70

Figure 4.6: Collecting regolith samples with stainless steel cores ............................... 70

Figure 4.7: Slip head scarp measuring, 80 $\mathrm{cm}$ to grass line ....................................... 71

Figure 4.8: $1 \mathrm{~m}$ to grass line. Note levels of horizons .............................................. 71

Figure 4.9: Clusters of slip sites in relation to Te Apiti Road North, Waimarama ......... 72

Figure 4.10: The hypothetical nine-unit land surface model....................................... 73

Figure 4.11: This dome appeared after Kaikoura earthquake .................................... 74

Figure 4.12: Large fissure after Kaikoura earthquake November 2016 ........................ 74

Figure 4.13: Depth over $1 \mathrm{~m}$ in earthquake fissure ................................................... 75

Figure 4.14: Small erupting Bentonite mud volcano, Kaikoura ................................. 75 
Figure 4.15: Slip showing result of older landslide

Figure 4.16: Friable breakdown of marine bedrock 78

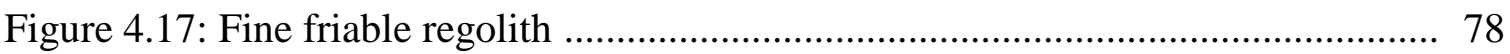

Figure 4.18: New cone penetrometer alongside practice penetrometer ....................... 79

Figure 4.19: Liquid limit determination sample ................................................... 80

Figure 4.20: Plastic Limit soil with organics removed ........................................... 81

Figure 4.21: Cone Penetrometer core tubes for soil moisture density …...................... 82

Figure 5.1: Google Earth boundary showing pre storm slips .................................... 84

Figure 5.2: Post storm, Slip sites drawn with polygon coloured yellow ....................... 85

Figure 5.3: Results from elevation of landslides and land area ................................ 87

Figure 5.4: Land area percent vs slip area percent ............................................. 88

Figure 5.5: Structural tectonic map of Waimarama-Mangakuri Coastal High .............. 89

Figure 5.6: Results of slope and landslide area ...................................................... 90

Figure 5.7: Chart showing comparisons of slope and slip angles .............................. 91

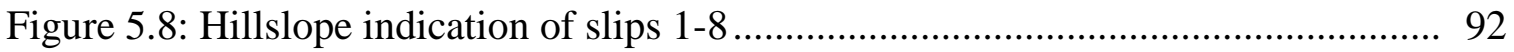

Figure 5.9: Plastic limit, specific gravity and liquid limit, laboratory results ................ 93

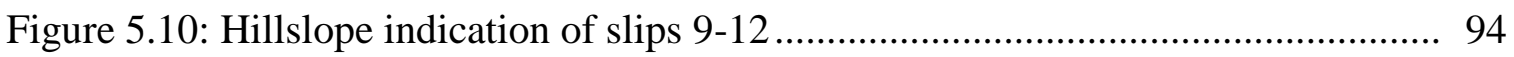

Figure 5.11: Plastic limit, specific gravity and liquid limit, laboratory results .............. 95

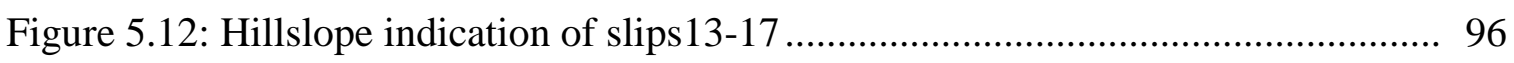

Figure 5.13: Plastic limit, specific gravity and liquid limit, laboratory results .............. 97

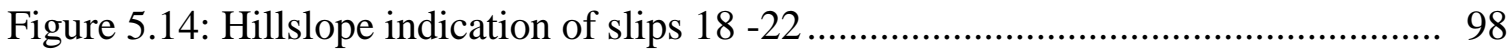

Figure 5.15: Plastic limit, specific gravity and liquid limit, laboratory results ............. 99

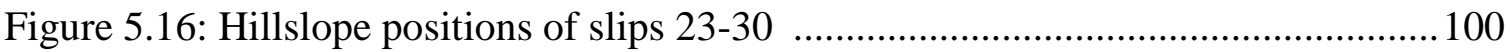

Figure 5.17: Plastic limit, specific gravity and liquid limit, laboratory results ............... 101

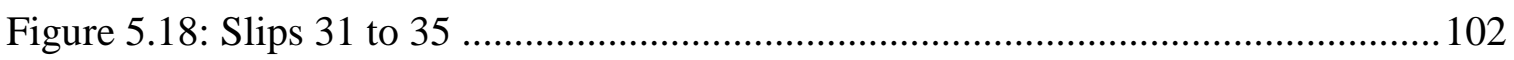

Figure 5.19: Plastic limit, specific gravity and liquid limit, laboratory results ............... 103

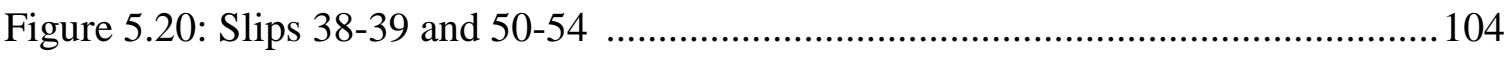

Figure 5.21: Plastic limit, specific gravity and liquid limit, laboratory results ............... 105

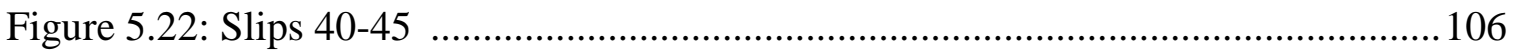

Figure 5.23: Plastic limit, specific gravity and liquid limit, laboratory results ............... 107

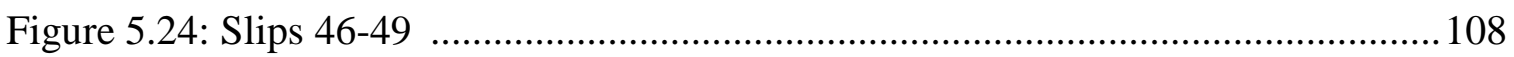

Figure 5.25: Plastic limit, specific gravity and liquid limit, laboratory results .............. 109

Figure 5.26: NIWA return period calculation for extreme event precipitation ...............114

Figure 5.27: Plasticity chart for classification of cohesive soils (Casagrande) ..............115

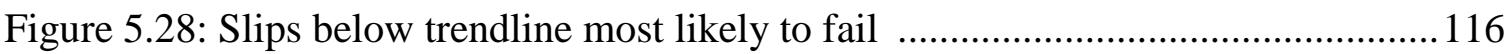


Figure 6.1: Siltation of agricultural land, fence with flood debris. McNeur photo 118

Figure 6.2: Montage four photos 119

Figure 6.3: Mitigation planting 120

Figure 6.4: 18 months after first visit, regrowth signs visible 120

Figure 6.5: New tree plantings by community have removed all traces of the slip 122

Figure 6.6: Local contractor to the rescue, helping Angel. McNeur photo 123

Figure 6.7: Replacing damaged fence line 123

Figure 6.8: Rehabilitated farmland, ploughed and resown 124

Figure 6.9: Landslides showing slow recovery, west facing 125 


\section{List of tables}

Table 1: Varnes 1978 Landslide Classification ........................................................... 17

Table 2: Comparisons for field measurements and GIS measurements ...................... 86

Table 3: Laboratory analysis of all site measured slips .................................................. 111

Table 4: Questions with frequency and percentages ................................................... 121 


\section{Chapter 1: Introduction}

From high mountain ranges to lowland flood plains there are designated terms to describe the processes of landslides. Depending on the rock type, the primary processes that contribute to landslide development are either mechanical or chemical. Earthquakes and tectonics can also contribute to the mechanical disturbance of hillslopes. Mechanical processes consist of climatebased action and time, precipitation, ice, wind and solar energy; while chemical processes require a combination of precipitation and mineral reaction over time.

Globally, deforestation of indigenous forests on hillslopes and river valleys since early anthropogenic settlement, along with natural process (e.g. precipitation, wind, tectonics and solar energy) combine or act individually to reduce hillslopes and aggrade river plains. Through these physical attributes of nature, the evolution of landslide geomorphic processes change the value and nature of hillslope morphology (Crozier, 2010).

Shallow landslides in New Zealand have resulted from the same human activities as in the rest of the world; clear felling of pristine forests, burn off, and turning the land into pasture, agriculture and residential uses, along with road building and industrial development.

The bedrock of the east coast of the North Island is unique; soils are formed from weakly lithified Tertiary marine sediments, siltstone/mudstone and sandstone uplifted by plate tectonics, with Kamp (1992)tephra mixed in from volcanic activity. In the central plateau, volcanism and air fall tephra are added soil components. The weak structure of the marine sediments and the steep hillslopes are the primary reason for shallow landslides. Often during lengthy periods of precipitation or short duration high intensity rainfall, saturated weak regolith sitting on impermeable bedrock is a classic situation for the occurrence of multiple shallow landslides.

\section{Waimarama event 26-27 April 2011}

In 2011, 26, 27 $7^{\text {th }}$ April a severe storm event triggered multiple landslides in the Waimarama region of Hawke's Bay. The loss of regolith from these multiple landslides had a significant impact on agricultural activity from flood debris and siltation, and on farm animal production through loss of pasture, grazing land and animals (Figure 1.1). 


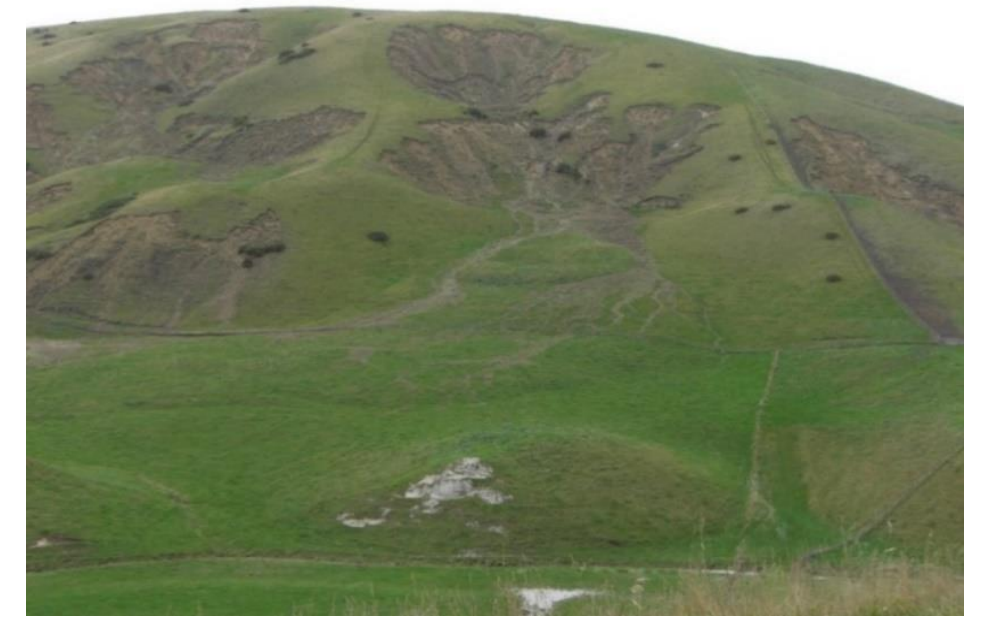

Figure 1.1: Landslides after the storm. McNeur photo

The Napier and Hastings region, including the coastal villages of Ocean Beach and Waimarama (Figure 1.2), received most of their average annual rainfall of $(800-1000 \mathrm{~mm})$ over a $48 \mathrm{hr}$ period from 1:00am 26th to midnight 27th April, 2011. A measurement of $850 \mathrm{~mm}$ was recorded in Waimarama (Research, 2011). At the same time an Mw 4.5 earthquake was recorded (GeoNet). The flooding and hillslope failure caused by this event and the consequent damage to farm and residential property, are the basis for this research.

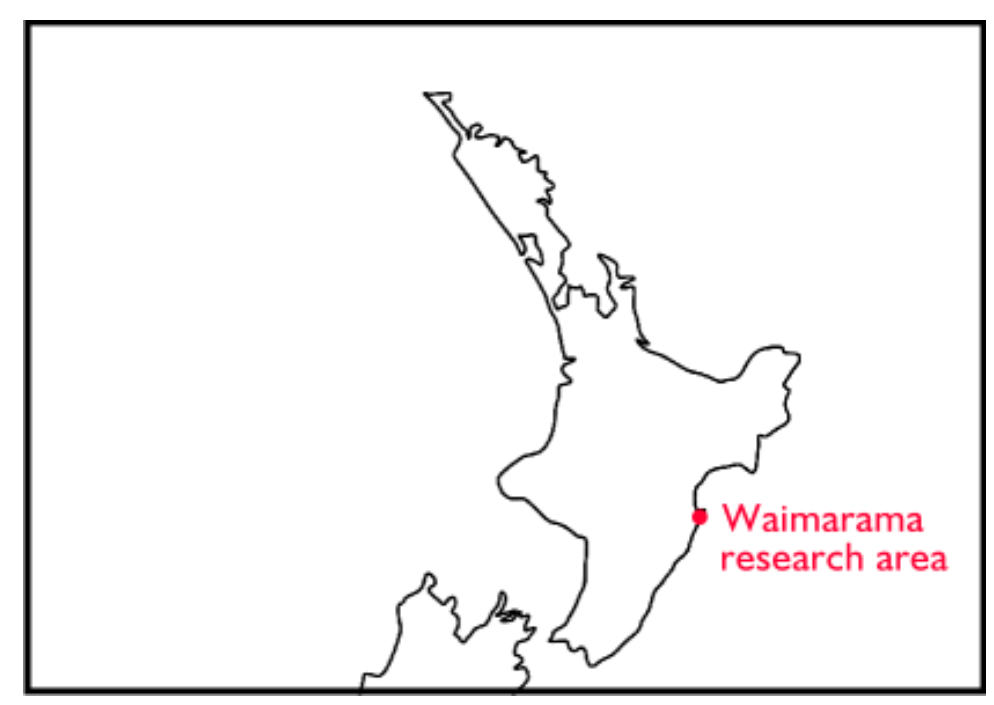

Figure 1.2 Location of Waimarama in North Island, New Zealand

\section{Study Area Waimarama}

Waimarama (Figure 1.3) is situated approximately 20 minutes' drive east from Havelock North, and $27 \mathrm{~km}$ from Hastings in the Hawkes Bay. The road runs in an easterly direction under the limestone bluffs of Te Mata Peak and crosses the Tuki Tuki River where it branches to the right, 
then left, winding up into the hills and out to the east coast. The landscape is rugged and scarred with multiple slips caused by the severe weather event on 26-27 April, 2011.

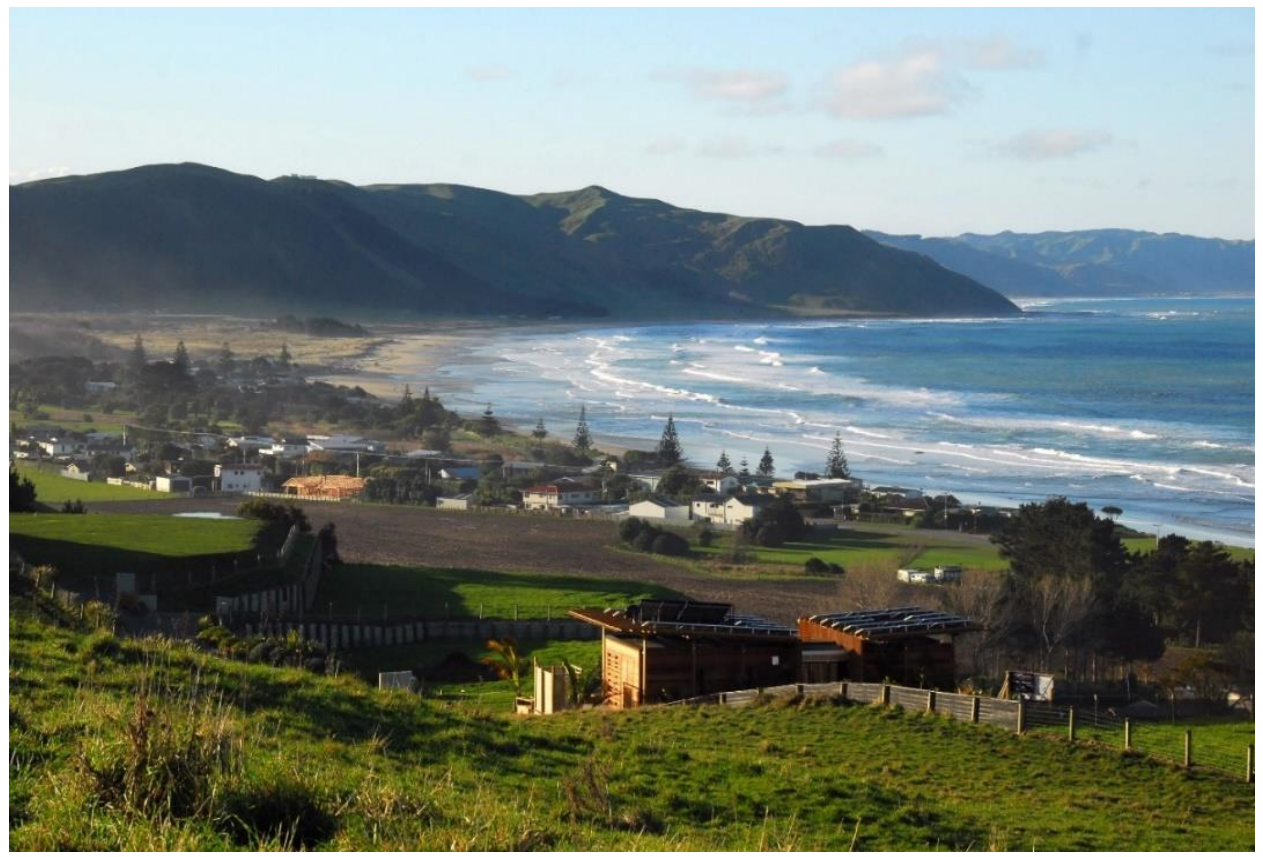

Figure 1.3: Waimarama village, residential and holiday seaside resort

The permanent residents either work locally on farms or travel over the hill to Havelock North, Hastings and Napier. Travelling each day is non-confrontational without traffic congestion. The main production of the Waimarama basin is beef and sheep farming, exotic forestry blocks, and some agricultural plantings with a limited amount of tourism (Figures 1.4, 1.5 and 1.6).

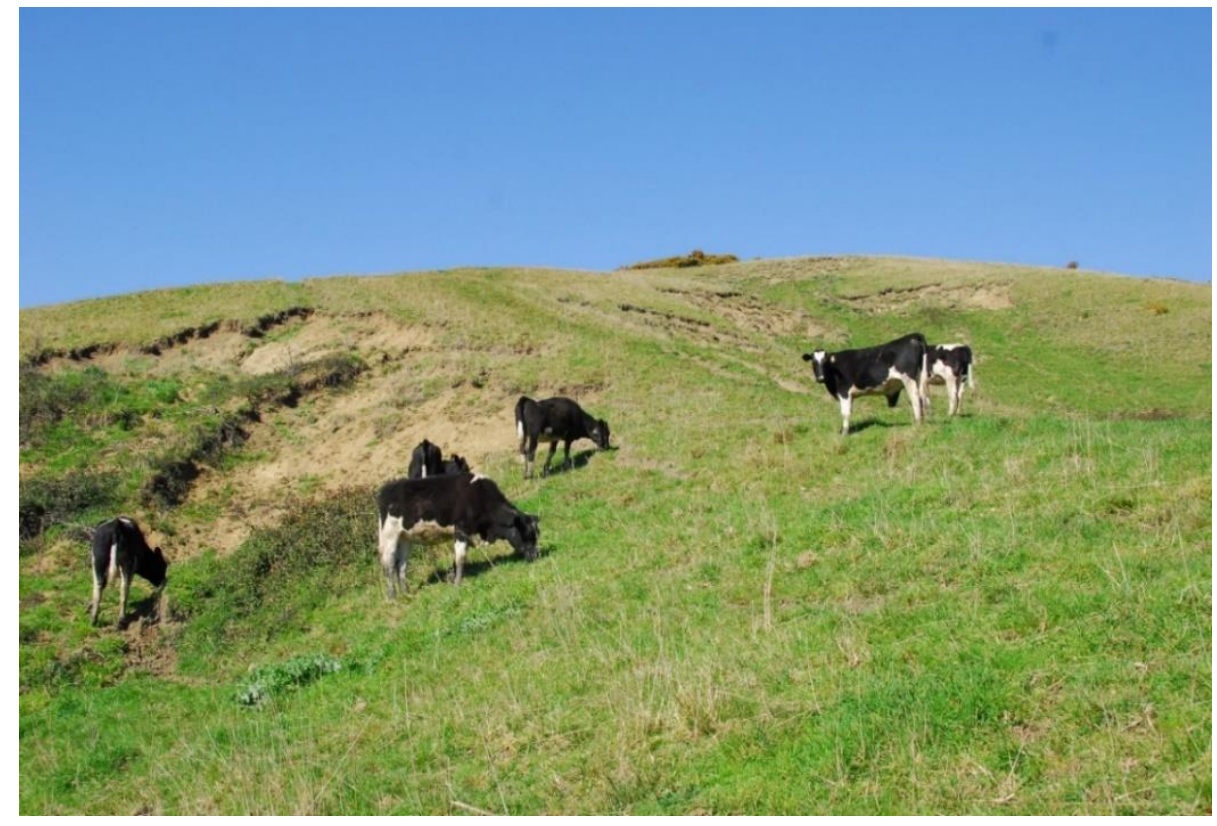

Figure 1.4: Beef farming, Waimarama 


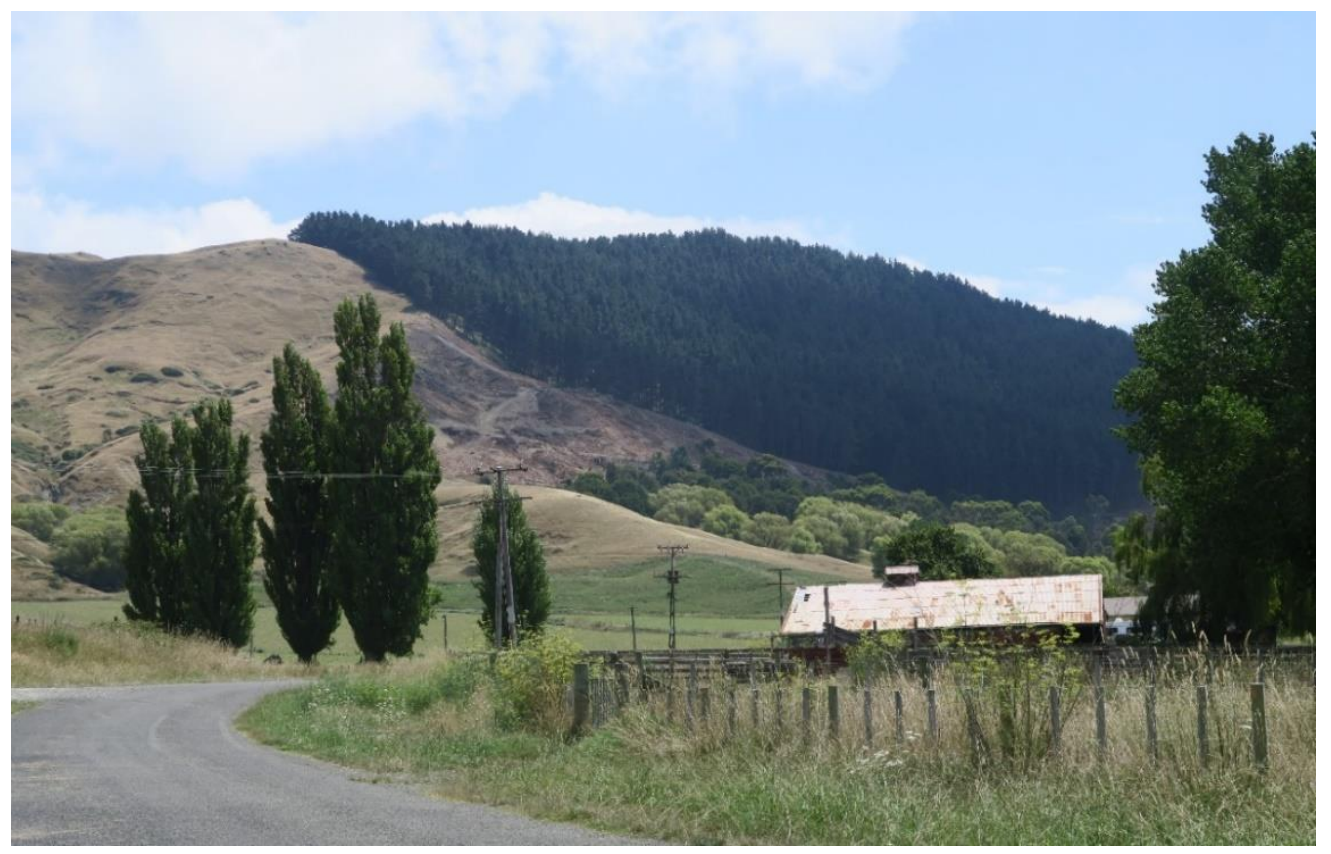

Figure 1.5: Forestry blocks are a factor in the Waimarama economy

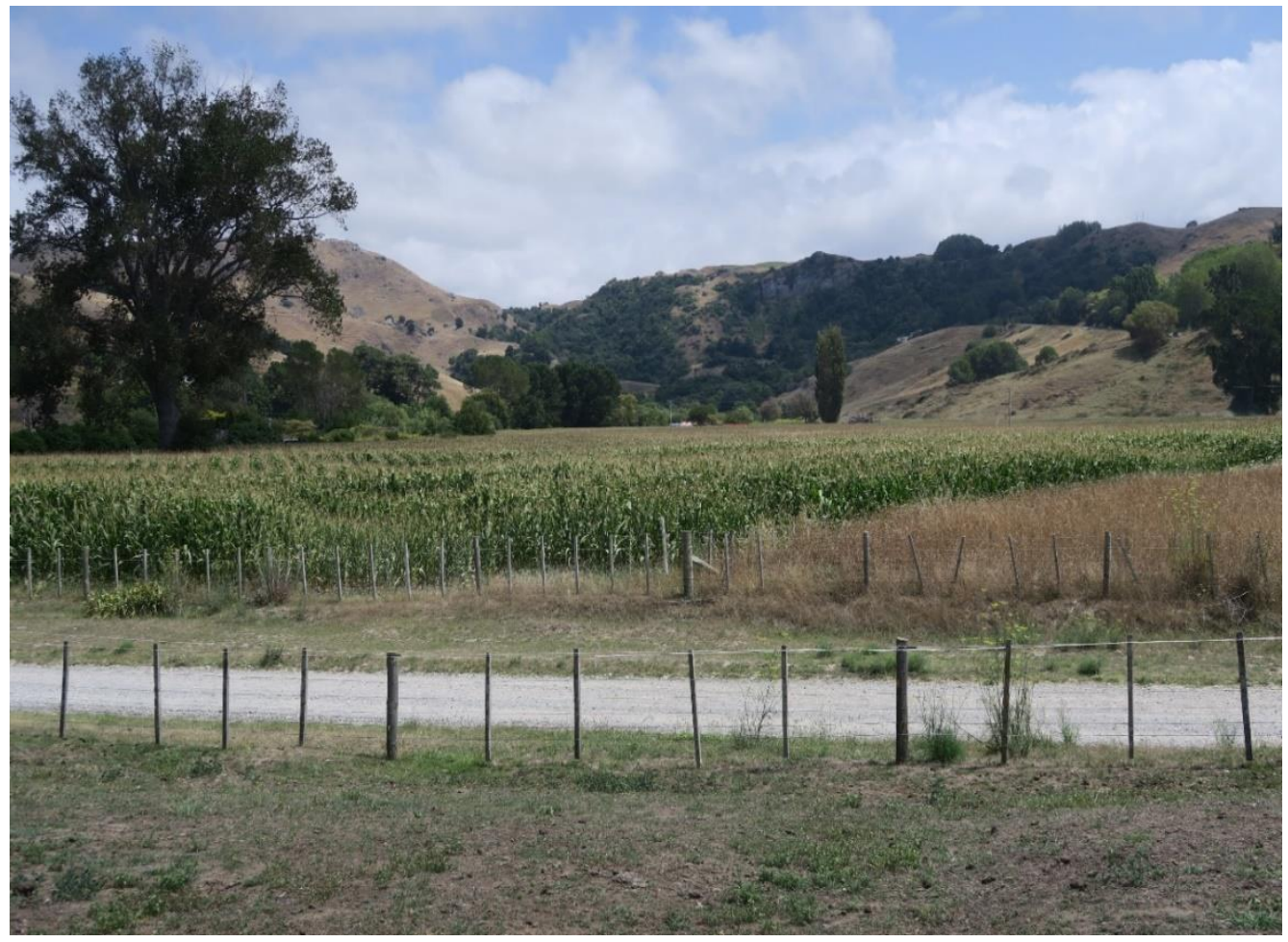

Figure 1.6: Waimarama agriculture 


\subsection{Aims and Objectives}

Study aim Waimarama Landslides

There are many reasons why landslides occur in New Zealand, including; high precipitation and weak regolith structure, volcanism, earthquake and tectonic uplift. The aim for this study is to understand and evaluate the cause of hillslope failure following an extreme weather event at the seaside village of Waimarama, Hawke's Bay, North Island, New Zealand and the effect it had on the community through the physical loss of buildings and land and the economic loss of redevelopment and income.

The focus will be on why slope failure occurred at this site with a view towards understanding future hazards for the community. Are there mitigating factors available to reduce further regolith loss and what contributing factors other than precipitation and steep hillslopes can be considered as a catalyst for slope failure?

Also, this work aims to gain an understanding if the reaction of a community to an extreme event and the help available from local and regional authorities. Although news reports and TV cover the event, once the weather clears the general public soon forget what happened as other newsworthy events take their place. Public perception is short-term, while the real tragedies are left to the locals to deal with.

Objectives of this study

Why do hillslopes collapse? What is the threshold of soil to precipitation? To find those answers for Waimarama, the physical structure of the regolith, the position of the landslides to their location on the hillslope, and the prevailing weather conditions were analysed. Soil/regolith weakness, slope angle, gravity, aspect and curvature are some reasons why hillslopes collapse, and these vary from location to location. These factors were examined at Waimarama by field observations, soil sampling and laboratory testing.

The second part of this study questions how humans are affected by and react to weather disasters. To test their reactions and responses, to perception/risk/mitigation, a survey questionnaire seeking generic answers without financial or economic \$ figures was undertaken. Cold calling on local farms and residences was the option taken to include a cross-section of permanent and/or holiday residents. This approach was to obtain background knowledge of losses - economic, financial, mitigation and recovery. 


\subsection{Literature Review}

\section{Landslides}

Landslides are the movement of regolith (soil, rock, boulders; anything that is not bedrock) downslope. The Varnes (1978) classification of landslides describes the various systems and types of landslides that develop when hillslopes collapse. The environment and parent rock type are the important components when describing landslides (Hungr et al., 2013), (Table 1).

\begin{tabular}{|c|c|c|c|}
\hline Movement type & Rock & Debris & Earth \\
\hline Fall & 1. Rock fall & 2. Debris fall & 3. Earth fall \\
\hline Topple & 4. Rock topple & 5. Debris topple & 6. Earth topple \\
\hline Rotational sliding & 7. Rock slump & 8. Debris slump & 9. Earth slump \\
\hline Translational sliding & 10. Block slide & 11. Debris slide & 12. Earth slide \\
\hline Lateral spreading & 13. Rock spread & - & 14. Earth spread \\
\hline \multirow[t]{6}{*}{ Flow } & 15. Rock creep & 16. Talus flow & 21. dry sand flow \\
\hline & & 17. Debris flow & 22. Wet sand flow \\
\hline & & 18. Debris avalanche & 23. Quick clay flow \\
\hline & & 19. Solifluction & 24. Earth flow \\
\hline & & 20. Soil creep & 25. Rapid earth flow \\
\hline & & & 26. Loess flow \\
\hline Complex & 27. Rock slide-debris avalanche & 28. Cambering, valley bulging & 29. Earth slump-earth flow \\
\hline
\end{tabular}

\section{New Zealand Human Occupation}

New Zealand has a history of shallow and deep landslides from pre-European times during occupation by the first Polynesian immigrants until the eventual settlement of European immigrants. In New Zealand's early occupation 700-800 years ago the first population cleared land for settlements and cultivation near rivers, coasts and plains, but their influence on land and vegetation cover was generally localised (Glade, 2003).

During European migration from the early 1840s to the present, land clearing and clear felling of native forests became widespread, substantially altering the landscape (Glade, 2003). Deforested regions were turned into agricultural and pastoral land, while continued anthropogenic influence included expanding urban centres, widespread milling of native forests, and cultivation of exotic forestry species. However, little attention was paid to landslide impacts on the natural environment (Geertsema et al., 2009; Schuster and Highland, 2007). 
Annually, during periods of continuous precipitation or heavy rainstorm events, regolith is lost downslope, into streams and rivers and eventually discharged into the ocean ("regolith" describes all sediment that is not bedrock). According to a sediment model by Hicks et al. (2011), the sediment discharge yield for the North Island is $118 \mathrm{Mt} / \mathrm{y}$ and the South Island discharge is 91 Mt/y (Hicks et al., 2011).

The land this sediment originated from was once protected by pristine forest cover and vegetation. When trees were removed for habitation and agriculture, the root systems previously supporting hillslope stability decayed, leading to loss of cohesion and allowing hillslope problems to accelerate (Glade, 1998).

The introduction of sheep and beef to these cleared hillslopes for global and local consumption, has contributed to slope failure in many regions of the world (Blaschke et al., 1992). Heavy animals in large numbers compact the soil, cut the covering vegetation and break open the topsoil, which allows increased water access, thereby weakening soil tension and accelerating slope failure (Blaschke et al., 1992).

The loss of regolith through shallow landslides at Waimarama, has been shown to involve slope failure and re-deposition at slope base ("colluvial footslope", see Figure 4.10 p 66); (Brooks et al., 2002). An important feature of this process is a dependence on intense precipitation over an extended period, or a short term extreme weather event that saturates the soil to the point of collapse. Over time as the regolith is stripped upslope, slope threshold failure changes to allow the landscape to stabilise (Brooks et al., 2002). Due to varying storm intensity, slope failure, and regolith stripping can be triggered by altered hydrological and geotechnical conditions (Brooks et al., 2002).

According to shallow regolith landslides are the most frequent and widespread problem in New Zealand. Regolith materials consisting of tephra and loess that cover many parts of the central to lower North Island, mixed with parent rock regolith, are represented in the clusters of rainstormtriggered landslides. They consist of numerous 'debris' and 'soil' slides which are seldom larger than 2-3 metres deep, and generally transport material over the ground surface by flowage for considerable distances. The New Zealand Land Resources Inventory records these landslide types as having affected 27 percent of New Zealand land area (Eyles, 1983). Crozier et al. (1992) further state that these types of shallow regolith landslides are seldom found on slopes less than 20 degrees and more commonly on slopes between 25-30 degrees. On average, two or three of these major episodes occur somewhere in the country each year (Crozier et al., 1992). 
When it comes to identifying geomorphic processes (Crozier, 2010), rather than formative processes, slope processes (mass movement and landsliding in particular) are generally treated equivalent to fluvial glacial, coastal, aeolian, and periglacial processes. This implies that while landsliding is recognised as an important process that works on hillslope processes and mountain geomorphology it is not considered a formative process in its own right. Crozier (2010) argues, that land sliding can have a significant control on landform development making it is a formative process. Formative processes include, fluvial, glacial, coastal and karst, which can dictate the character of the terrain over extensive areas. Crozier (2010) asks why landsliding is not considered to be a formative process, since it is a major contributor to the processes that change the shape of hillslopes and river channels (Figure 1.7).

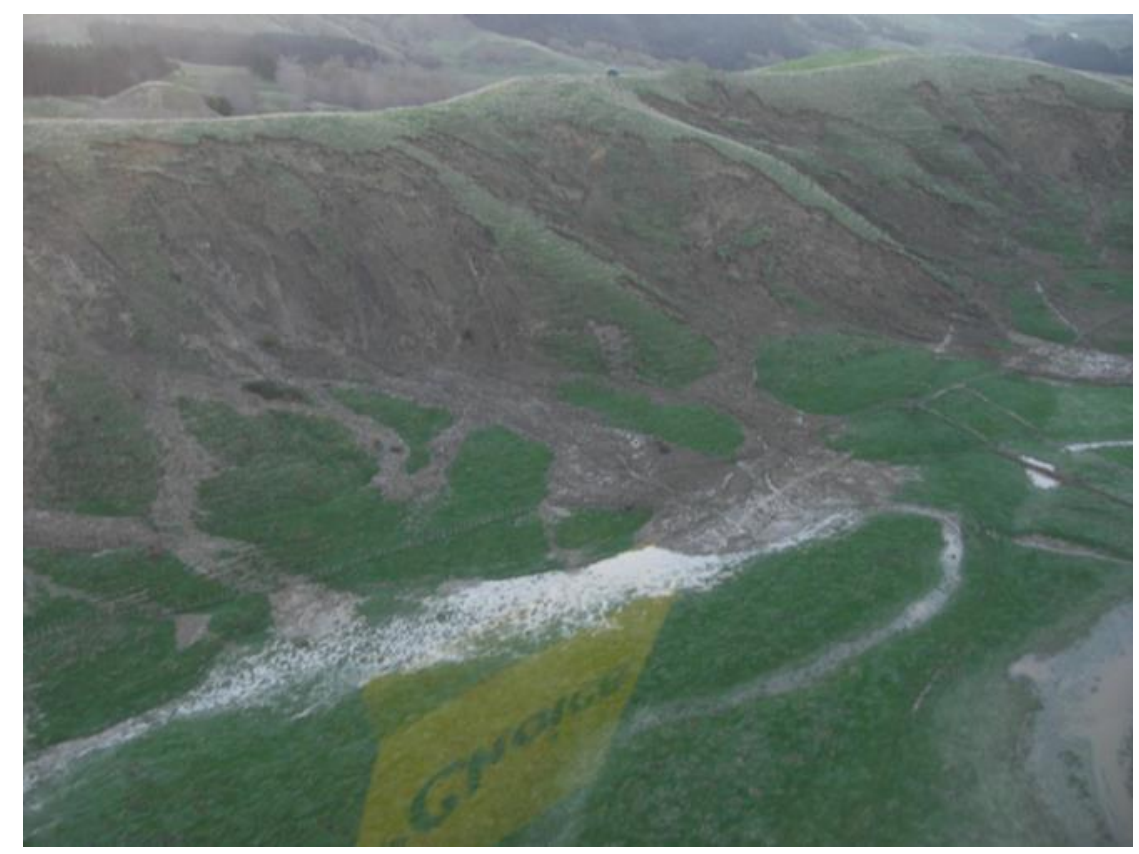

Figure 1.7: Ariel view of McNeur farm landslides, Te Apiti Road after storm 2011 Photo K. McNeur

In summary, landslide geomorphology characterises the recurring relationship between dominating landslide activity, and the associated processes of land form, in time and space. There are three diagnostic criteria that can be used at the reconnaissance level, to indicate the existence of landslide geomorphology systems, and these are described as follows:

\section{Extent of a landslide signature in the terrain}

There is no defined proportion of land surface that must be occupied by landslide features in order to meet this criteria (Crozier, 2010). The relationship between the extent of land-sliding and the influence of geomorphic processes can vary with the landslide types involved. In defining 
New Zealand landslide systems, a landslide signature over at least $20 \%$ of the terrain has been used as a tentative working criterion (Crozier, 2010).

\section{Temporal persistence of landslide features}

Brunsden and Thornes (1979) argue that the relaxation time of terrain with respect to magnitudefrequent character of landsliding (transient form ratio) can indicate whether landslides are a formative process or merely a perturbation in a system dominated by other processes (Crozier, 2010). Brunsden and Thornes (1979) and Crozier (2010) suggest that where there is insufficient information on relaxation times, the age of existing landslide morphological features can provide some indication of temporal persistence. From frequency magnitude analysis combined with extinctions and appearances of landslide features in British Columbia over time, Guthrie and Evans (2007) showed that the persistence equation is a function of landslide area; indicating, as an example, that debris slides/flows of $1000 \mathrm{~m}^{2}$ in area would endure for 25 years while a rock slide of $2.7 \mathrm{~km}^{2}$ in area would remain for 8000 years (Crozier, 2010; Guthrie and Evans, 2007).

\section{Degree and effectiveness of fluvial coupling}

The term of degree and effectiveness of fluvial coupling recognises the landslide signature through the residence time of landslide deposits, the sediment delivery ratio, and/or the dominance of load supply. The effectiveness concept used here relates to overall effectiveness (system effectiveness) of fluvial coupling. As such, these terms are not only for work done, but also include work that contributes to removal of mass from the system and therefore their effectiveness in overall landscape denudation and evolution. It is also argued, that effectiveness in these terms is not simply a product of frequency and magnitude of landsliding, but also of the degree of coupling and sediment delivery ratio to the fluvial system (Crozier, 2010).

On the basis of the previous criteria listed, Crozier (2010) suggests that there are six landslide geomorphologic systems identified and operating in New Zealand. These are:

1. Alpine: the term alpine (mountains) and hill country are defined topographically based on relative relief, mass and altitude (Cotton, 1968), (refer Cotton, 1968, p. 737). Between them, they cover about $70 \%$ of New Zealand land area, with hill country accounting for $40 \%$. Hill country in New Zealand is generally less than $1000 \mathrm{~m}$ in altitude with slopes commonly between $20^{\circ}$ and $30^{\circ}$. The summit of alpine terrain is above the forest limit and in the South Island, is commonly glaciated. 
2. A stratigraphically controlled landslide geomorphology system occurs mainly in weak Tertiary sedimentary rocks, but is not exclusive to them, occurring also in some of the volcanic regions of the country. Undeformed soft rock hill country is located behind (west of) the frontal ridge on the Australian plate or, on continental material of the Pacific plate, away from the direct influence of a plate boundary. This system is best represented in the Western North Island tectonic province.

3. Tectonically deformed soft rock hill country has strata dipping at greater than $10^{\circ}$ with some formations strongly folded and crushed. These rocks form part of the accretionary prism associated with the compressional boundary between the Pacific and Australian plate, and occur within the axial tectonic belt.

4. Undeformed soft rock is located behind (west of) the frontal ridge on the Australian plate or on continental material of the Pacific plate boundary. This system is best represented in the 'Western North Islands' tectonic province.

5. Edge forms or slopes are extensive linear zones of relatively steep slope angle. Some may have a near vertical free face and are generally (but not exclusively) structurally controlled. Edge slopes may be tableland escarpments, terrace risers, contemporary or relict coastal cliffs, submarine slopes or fault and faulting scarps.

6. Destabilised regolith hill country consists of hill country where the regolith and associated soils are undergoing extensive and rapid landslide erosion. These conditions are found in 'Down land and easy hill country' and the 'Rough hill country' Page et al. (2000). The soils in this system have been destabilised by the anthropogenic removal of the natural vegetation cover (Page et al., 2000) and are subject to frequent and extensive multiple-occurrence regional landslide events (Crozier, 2005b; Crozier, 2010).

No-one envisaged that, given the extent of influence of human activity on vegetation changes (Glade, 2003), after forest clear-felling, the exposed land would collapse under certain climatic conditions. Rain and gravity are the primary movers of soil, and when the protection of the forest cover is removed, the surface becomes exposed to more direct rainfall and saturation takes less time to filter through the soil which in turn causes landscape instability (Glade, 2003).

\section{Criteria for dealing with destabilised hill country}

The features of Waimarama following the extreme event, show all the processes from a tectonic setting, including the following for destabilised hill country. 
- Tectonic setting: hill country in all tectonic provinces

- Low-medium relief; uplift <2mm/year

- Regolith of permeable loess, ash or residual soil, $<2 \mathrm{~mm}$ thick overlying less permeable bedrock

- Shapes micro-relief (slope irregularity, footslopes, depositional valley smoothing)

- Episodic

- Landslide persistence 50-100 years (Thomas and Trustrum, 1984)

- Coupling sediment delivery ratio <51\% (Page et al., 1994), occurrence coupling 17\% (Schneider, 2002), predominantly wash load (Crozier, 2010).

Destabilised hill country and the occurrence of multiple shallow landslides is not restricted to New Zealand. Brunetti et al. (2010) refers to a 60 year period in Italy from 1950-2009, which endured 16 harmful events per annum and involved 6,349 casualties. This large number of harmful events indicates there is considerable risk to the Italian population through landslides and debris flows (Brunetti et al., 2010). The province of Reggio Emilia, northern Italy, was also affected by intense rainfall triggering dozens of landslides (Montrasio et al., 2011). Other countries that suffer intense rainfall events causing landslides are British Isles (Bromhead and Ibsen, 2007); parts of Uttarakland State, India (Martha et al., 2014); and Panay Island, Philippines flooding in June 2008 (Catane et al., 2012; Zieher et al., 2016).

Many New Zealand landslides are also of the destabilised variety. For example, a major rainstorm event occurred in the Southern Hawke's Bay and Wairarapa during a seven week period from end July 1977. The severity of flooding and mass movement resulted in the region being declared a disaster area (Crozier et al., 1980). Hawley and King (1978), reported that the mass movement occurred in at least five distinct episodes, involving mostly debris flows and a reduced number of debris slides (Crozier et al., 1980; Varnes, 1978).

An early report by King and Blakemore (1977) indicated an apparent pattern in the distribution of landslips in the Wairarapa hill country (Crozier et al., 1980). The pattern occurrence was closely related to the slope aspect and position on the hillslope, showing that the concentration of slips was located on the upper parts of northerly facing slopes (Crozier et al., 1980). An area of $1350 \mathrm{~km}^{2}$ was used as the study area and recorded that the preference for northerly aspects was evident in each of the distributions of slips drawn separately from upper, central and lower sections of the hillslopes which yielded a mean density of 0.98 slips/ha. The field measurements for one catchment showed 4.78 slips/ha and a mean surface lowering of $69 \mathrm{~mm}$. In comparison to other recorded events the degree of erosion was severe (Crozier et al., 1980; Lambert et al., 1984). 
The conclusions drawn after analysing the research data from penetration tests indicated that the bedrock surface was much stronger than the regolith. The reduction in regolith depth from previous erosion allowed the vegetation roots to bind the soil close to the bedrock surface (Crozier et al., 1980). Crozier et al (1980) states that a further conclusion to be drawn from the relationship between undisturbed surface and the 1977 slipping frequency is that these episodes were unusual in that slips favoured slopes which had experienced less movement in the past (Crozier et al., 1980).

Due to the unusual climatic conditions during the 7 week period of 1977, the prolonged period of precipitation was enough to saturate previously undisturbed regolith causing multiple landslides on all slope aspects. Research as noted by Crozier et al. (1980) indicated that the northerly aspects were considered to reach this condition less frequently due to the greater availability of weak, undisturbed regolith that was sufficient in most cases to account for the higher incidence of slipping (Crozier et al., 1980).

In 1985 a New Zealand Erosion Classification Inventory of Landslides was produced by Eyles (1985) that remains in use (Figure 1.8).

\begin{tabular}{|lcc|}
\hline Erosion Type & Symbol & Symbol \\
\hline Surficial Erosion & & \\
\hline Sheet & $\mathrm{Sh}$ & $\mathrm{Sh}$ \\
\hline Wind & $\mathrm{W}$ & $\mathrm{W}$ \\
\hline Scree & $\mathrm{Sc}$ & $\mathrm{Sc}$ \\
\hline Mass Movement Erosion & & \\
\hline Soil slip & $\mathrm{sSl}$ & $\mathrm{Ss}$ \\
\hline Earth slip & $\mathrm{eSl}$ & $\mathrm{eS}$ \\
\hline Slump & $\mathrm{Su}$ & $\mathrm{Su}$ \\
\hline Debris avalanche & $\mathrm{daF}$ & $\mathrm{dF}$ \\
\hline Earthflow & $\mathrm{eF}$ & $\mathrm{eF}$ \\
\hline Mudflow & $\mathrm{mF}$ & $\mathrm{mF}$ \\
\hline Fluvial Erosion & & \\
\hline Rill & $\mathrm{R}$ & $\mathrm{R}$ \\
\hline Gully & $\mathrm{G}$ & $\mathrm{G}$ \\
\hline Tunnel gully & $\mathrm{T}$ & $\mathrm{T}$ \\
\hline Streambank & $\mathrm{Sb}$ & $\mathrm{Sb}$ \\
\hline Deposition & $\mathrm{D}$ & $\mathrm{D}$ \\
\hline
\end{tabular}

Figure 1.8: New Zealand land erosion chart (Eyles, 1985)

1. According to Eyles (1985), types of surficial erosion include sheet, wind and scree. Sheet erosion is caused by a combination of raindrop impacts dislodging fine soil particles that are moved short distances, and overland flow that transports them greater distances. Soil particles dislodged by needle ice formations, are a process common to many high country areas where water and wind are the modes of transport and deposition. 
Wind erosion is the detachment and transportation of soil particles due to wind. Wind erosion results from an airstream passing over a surface with sufficient force to overcome gravity and friction of soil particles (sand to clay-sized).

Scree is a depositional process of coarse angular rock debris mantling slopes. Scree, as referred to in the New Zealand Land Resource Inventory (NZLRI), corresponds to rock falls and rock slides as referred to in (Varnes, 1978), falls and talus creep referred to by (Hutchinson, 1968) and talus rock, glacier and block slides of (Eyles, 1985; White, 1981).

2. Mass movement erosion according to Eyles (1985) includes soil slip erosion, which is the rapid sliding or flowing movement of soil and subsoil that exposes a slip surface approximately parallel to and less than one metre below an original surface (modified from (Campbell, 1951). Soil slip includes some debris slides, debris avalanches and debris flows described by Varnes (1978) and detritus or debris slides and mudflows described by Hutchinson (1968) and Eyles (1985). Most soil slips develop during periods when regolith saturation from high intensity rainstorms or prolonged bouts of wet periods occur.

Earth slip erosion is a rapid sliding (or flowing) movement of the subsoil that exposes a generally concave slip surface, which extends more than a metre below the original surface (Campbell, 1951). The process of failure by soil saturation is the same as soil slip.

Slump erosion is the downward slipping of a mass of rock or unconsolidated material of any size moving as a unit, or several subsidiary units, usually with a backward rotation, on a more or less horizontal axis parallel to the slope from where it descends (Campbell, 1951). These slumps are most common in tertiary and unconsolidated sediments in both North and South Islands (Eyles, 1985).

3. Debris avalanche (refers to Earthflow and Mudflow) - Earthflow erosion of soil and underlying regolith, normally characterised by the retention of a surface cover, broken by tension cracks and smaller secondary movements. Earth flows do not usually result in separate scar and debris features (Eyles, 1985).

Mudflow erosion is a very rapid flow of predominantly fine-grained materials that have a high water content, and often recurring in the same channels (Campbell, 1951). This term also corresponds to mudflows as described by Hutchinson (1968) and Varnes (1978). 
4. Fluvial erosion - rill erosion is the close spacing of channels resulting from uneven removal of surface soil. Running water concentrated into streamlets with sufficient discharge and velocity generates the cutting power (Bates and Jackson, 1980; Eyles, 1985). Rills are most common on cultivated slopes where they incise to the base of the cultivated layer. The potential for rilling increases with increasing slope angle.

Gully erosion is the removal of soil or soft rock material by water, forming distinct narrow channels which are, larger and deeper than rills and usually only carry water during and immediately after rain (Bates and Jackson, 1980; Eyles, 1985).

Tunnel gully erosion is a compound erosion form initiated by the subsurface concentration and flow of water, which results in scouring, and the formation of narrow conduits, tunnels and pipes (Lynn and Eyles, 1984). Tunnel gullies form in the regolith where subsurface water becomes concentrated above a relatively impervious layer (Eyles, 1985).

According to Benda and Dunne (1987) debris flows provide important transport links between hillslope and stream channels, and are a significant factor in drainage-basin sediment budgets (Schuster and Highland, 2007). In addition, debris flows influence the spatial and temporal distributions of sediment in stream channels. This is because they deposit sediment in channels or become the deposit themselves, providing a source for enhanced transport of sediment further downstream (Benda, 1990; Schuster and Highland, 2007).

With the increase in sediment delivery to streams and rivers the aggradation of water-ways can cause flooding of pasture and agricultural land downstream. In a summary of landslide impacts on streams Schuster and Highland (2007) and Geertseema et al., (2009) commented that the main types of landslides to have this impact are debris flows that may fill or erode a stream channel. Debris flows are an important link with sediment transport between hillslopes and alluvial channels, and an important factor in drainage-basin sediment budgets (Butler, 2001 as cited in Geertsema et al., 2009).

It is important to note that while the dominant landslide type at Waimarama was translational there were a number of debris flows that reached the colluvial footslope where they are still visible today.

A number of mechanisms can be attributed to slope failure. One of these is heavy or prolonged precipitation, which can permeate through soft regolith and saturate the bedded layers below 
which then can lose tension with the bedrock base and succumb to gravity. The angle of slope and regolith lithology can determine the type of failure that takes place. Tectonic uplift determines the angle of slope, and causes weakness in the bedrock structure, while seismic activity acts on weak bedrock and regolith that is susceptible to lack of consistency. These activities can also determine the type of slope failure. Ice and solar energy are two other components of mechanical slope failure: ice can invade and expand stress fractures and joints in fractured rock and tension cracks in slope regolith, while solar energy reduces the moisture content in soil and clay beds causing surface rupture due to shrinkage, these two mechanisms then allow water to invade and create a situation for slope failure. Precipitation, weak regolith, slope angle and impervious bedrock were four primary factors for multiple landslides in Waimarama, Hawke's Bay.

Farming in New Zealand developed from early beginnings of forest milling and land clearing. Government farm subsidies supported wealth and high livestock numbers. Farmers were forced to reorganise their activities when subsidies were cancelled, during a Labour government restructuring of the New Zealand economy in 1981-1984. A number of government departments that were available for river control, land development, and forestry were redesigned and funding disestablished. Land began to revert back to scrubland, and lack of maintenance allowed many hillslopes to develop multiple landslides during lengthy periods of precipitation and cyclonic weather events (Author experience and observations). Economic lessons have been learned but they have not been able to reduce erosion on hillslopes.

Hill country is defined by the New Zealand Land Resource Inventory (NZLRI) as all Class V, VI, VII, VIII land. Grade D slopes and above (i.e. slopes $>15^{\circ}$ ) and below an altitude of $1000 \mathrm{~m}$ above sea level (Environment, 2008). Under this definition, 37\% (10 million hectares) of New Zealand's total land area is classified as hill country, with the majority (6.3 million hectares) located in the North Island (Basher et al., 2008).

Of an estimated 2,688,000ha of land classified as potentially highly erodible in the North Island, 840,000 ha or $31 \%$ was at severe erosion risk as recorded in 2012 (Environment, 2012). This equated to an estimated 192 million tonnes of eroded soil entering North and South Island rivers annually. Of the 840,000 ha exposed to landslide activity, $61 \%$ (515,000ha) had a high risk of landslides (Environment, 2012).

Several regions are exposed to severe risk of erosion and contribute to high sediment deposition in rivers. These include the Manawatu-Wanganui, which is the largest area in the North Island with 255,000 ha of highly erodible land, which releases $13 \mathrm{Mt} / \mathrm{yr}$ sediment into waterways. The 
Gisborne, Hawke's Bay and Northland regions each have 100,000ha of highly erodible land and contribute sediment into waterways at an annual rate of $40 \mathrm{Mt} / \mathrm{y}$ from Gisborne, $15 \mathrm{mt} / \mathrm{y}$ Northland. The total statistic for Gisborne, West Coast and Northland regions where each has contributed to an estimated yield of more than 1000t/ $\mathrm{km}^{2}$ annually (Environment, 2012). The total estimated sediment yield for the Hawke's Bay region waterways was $9.299 \mathrm{t} / \mathrm{km}^{2} \mathrm{yr}$ and the average soil erosion was 656t/ $\mathrm{km}^{2}$ in 2012 (Environment, 2012).

Dymond et al. (2006) notes the high rate of soil erosion in the North Island as due mostly to historical clearance of forest for agriculture, whereas in the South Island, erosion is due mostly to natural and climate processes of high precipitation and steep mountain slopes. Gullying and earthflow erosion takes place on all slopes irrespective of steepness, however, the land is only considered at risk if woody vegetation has been removed or if the land is devoid of vegetation. Shallow landslide erosion (approximately $1 \mathrm{~m}$ depth) is a sudden failure of soil slopes during intense rainfall (Dymond et al., 2006; Research, 2012) . Gully erosion is caused by soil erosion that develops at gully heads and expands upslope over decadal time scales, whereas earthflow erosion is a slow downslope movement of wet soil slopes towards waterways at approximately 1m/yr (Dymond et al., 2006).

New Zealand lies across the deformation zone between two converging tectonic plates, King (2000); Jiao et al. (2017). There have been many studies concerning hillslope failure brought about by forest and vegetation clearing by early settlers from Polynesia, (Glade, 2003; Sidle et al., 1985; Young and Saunders, 1986) and later the surge in migration from Europe and Asia. Brown (1983) considered the most common landslide types according to Varnes's (1975) classification as flows and slides. He described the role of domesticated animals as the main cause of the deterioration of protective vegetation. This included burning tussock in the high country to create new growth which contributed to widespread debris sliding (Brown, 1983). However, Mosley (1980) and Whitehouse (1978) amassed photographic and sediment source evidence disputing the assertion that all this sliding was caused by human and animal interference, especially in Canterbury in the South Island (Brown, 1983). As much of the North Island was clothed in luxuriant forest when the first European settlers arrived, the direct effect of their attitude towards the indigenous forest was very draconian (Brown, 1983).

According to Mather (1980), many people regarded landsliding as a natural phenomenon unrelated to human use of the land, and there was scepticism regarding the publicity given to anthropogenic interpretations of the slip-scarred landscape. The Royal Commission Report of 
1949, on the sheep farming industry in New Zealand recognised that much of the information on the country's soil erosion had been misleading propaganda (Brown, 1983; Mather, 1980).

During the 20th century Brown (1983) recorded the proliferation of technological adjustments to slope failures that required the installation of mechanical structures and/or the application of chemical techniques such as restraining structures, slope excavation and slope regrading that form preventative or corrective measures. Many of these measures required engineering expertise which is generally used in urban areas and along lines of transportation (Brown, 1983).

Rogers and Selby (1980), contended that a principle cause of landsliding in New Zealand is the development of pore water pressure in the soil. They indicated that piezometric heights can be greatly reduced by soil drainage, however they conceded that in pastoral areas extensive drains would be uneconomic (Brown, 1983). In contrast, Van Kraayenoord (1976) described the use of biological control, which involves the use of vegetation and offers a less expensive way to help slope stabilisation. It was also suggested by Van Kraayenoord (1976) that vegetative control of slope instability in New Zealand could be achieved through adjustments in land use, which also entailed modification to management practices (Brown, 1983; Van Kraayenoord, 1976). In theory, according to Sorensen et al. (1975), there is a need for several social adjustments including prediction insurance, disaster preparedness and emergency evacuation, relief and rehabilitation and land-use management (Brown, 1983).

In 1941 the Soil Conservation and Rivers Control Council (SCRCC) was established to promote slope stability on pastoral hill country through miscellaneous agricultural, silvicultural and associated practices (Brown, 1983; Brown, 1991). In 1949 the first large-scale aerial trial of seed sowing and fertiliser topdressing took place (Brown, 1991; McCaskill, 1973). During the 1980's fixed wing aircraft were gradually replaced by helicopters. Another principle method of promoting slope stability was tree planting to prevent reactivation of rapid mass movements. The SCRCC promoted the spaced planting of exotic tree species (Brown, 1991). Many pastoralists created woodlots which covered several hectares. These woodlots, were invariably Pinus radiata at densities of 1500 stems a hectare. These woodlots if pruned and trimmed, were millable after 25 years and provided a valuable income source (Brown, 1991). Recently (2014) a 100 hectare woodlot of 28yr pinus radiata sold for $\$ 800,000.00$ (personal communication with owner).

Another government-sponsored soil-conservation authority followed the SCRCC in 1967, under a new name of the National Water and Soil Conservation Authority (NWASCA). The Water and Soil Directorate of the Ministry of Works and Development, was another authority that provided administrative, technical and research services Brown (1991). Important research was 
undertaken by its Soil Conservation Centre on vegetation stabilisation of slopes, storm-damage assessment and mapping of landslide severity (Brown, 1991).

There were twelve catchment authorities in the North Island who were instrumental in promoting and implementing landslide control on agricultural land. They administered NWASCAapproved schemes, funded through governmental grants and through direct charges to landholdings that drew the most benefit from the work (Brown, 1991). At the level of individual holdings, the instructional vehicle for soil conservation is the Farm Plan. This is typically a fiveyear renewable programme of scheduled soil-erosion control, integrated with modified farm management to sustain agricultural production and increase land protection. These plans prescribe remedial revegetation and engineering measures for landslide reduction. The Farm Plan system was introduced in 1956. From 1970 to 1985 there was a cumulative national total of more than 4500 plans, two-thirds in the North Island (Brown, 1991; Miller, 1986). Forty percent of the plans were prepared by the three catchment authorities of the East Cape, Hawke's Bay and Wairarapa. The plans were assessments of farm and hill country land that were required to be controlled and managed to avoid long term erosion, management and precipitation runoff.

An even more potent system than farm plans, was the coordination of all soil conservation measures in a drainage basin through a catchment control scheme. The first scheme was for the Whareama Basin in the Wairarapa in 1957. The Puhokio and Wainongoro Catchment and Control Scheme, was introduced by the Hawke's Bay Catchment Board, in 1982. The scheme was to manage flooding and sediment runoff, and shared responsibilities with local farmers and the Board. (Peploe, et al. 1982). By 1970 there were 24 schemes nationally and by 1985 the schemes had increased five-fold. Most of these schemes were in the North Island and required a large financial commitment by central government for subsidies on conservation works, and administrative grants to catchment authorities (Brown, 1991).

Several government agencies complemented the work of the NWASCA, the Water and Soil Directorate and catchment authorities. The Ministry of Agriculture and Fisheries played a useful role in improving hill country farming and had significant landslide reduction results. Through its constituent New Zealand Soil Bureau, the Department of Scientific and Industrial Research furnished information on susceptibility of slope materials to failure. In 1986 the Forest Service was closed, but prior to that it had made important contributions by promoting woodlot establishments on unstable, or otherwise marginal farmland (Brown, 1991; Le Heron and Roche, 1985). 
In 1984, when the urban-based Labour Party won the election, institutional support for landslide control on farmland changed dramatically. The Party's monetarist economic policies resulted in widespread deregulation of the national economy. All subsidies for forestry and most of those for agriculture were either abolished or severely reduced (Brown, 1991; Moran, 1989). Following this shift in economics policy the Labour Government implemented a user-pays policy for provision of services as part of a strategy to reduce public expenditure. Since those funding cutbacks, agricultural research has been severely affected (Brown, 1991; Kirton, 1989). When the National Party was returned to government in 1990 they retained the policy of stringent control on public spending (Brown, 1991).

When the Forest Service was abolished, its research was continued by the Ministry of Forestry, where emphasis shifted from a balance between protection and production to the development and management of commercial forests (Brown, 1991). Since the elimination of the Forest Service and the NWASCA there has been no government department or agency responsible for promoting and safeguarding principal conservation forests. Regional councils now oversee the establishment and management of farm woodlots (Brooks et al., 1995; Brown, 1991).

Thompson and Luckman (1993) investigated the performance of biological erosion control measures applied to support pastoral land use in soft rock hill country. Evidence has shown, that in many areas, forestry can greatly reduce erosion and promote a social need for land uses which match the skills and inclinations of landowners (O'Loughlin, 1984; Sidle et al., 1985; Thompson and Luckman, 1993; Ziemer, 1981). To improve the knowledge of the impacts of trees on slope stability, Thompson and Luckman (1993) began an investigation of the performance of biological erosion control on 278 sites of gully and earthflow erosion. These sites were situated in Gisborne, East Cape. This region is susceptible to weak erodible soil and rock materials, tectonically active terrain, and seasonal cyclonic storms where this combination produces severe erosion on pastoral land (Eyles, 1983). The field work began in 1989-1991 after tropical cyclone Bola in March, 1988, (Thompson and Luckman, 1993).

Cyclone Bola produced torrential precipitation of $>500 \mathrm{~mm}$ over two days and covered 11,500 $\mathrm{km}^{2}$. The mean annual rainfall is $1600-1800 \mathrm{~mm}$ for a large part of the area and is known to be as low as $1000 \mathrm{~mm}$. Damage and loss of land was estimated at $\$ 26,000$ per hill country farm (Brown, 1991; Singleton et al., 1988b; Thompson and Luckman, 1993).

The introduction of exotic forestry and hillslope plantings for erosion control has been widely accepted as a control measure on many Hawke's Bay farms, and these can be observed whilst driving inland between Havelock North and Waimarama. 
Gray and Leiser (1982) and Sidle et al. (1985) discussed the use of vegetation control along with Van Kraayenoord and Hathaway (1986) who describes poplar willow species used in New Zealand. These poplars included Populus alba, P. deltoids, P. nigra 'Italica', Italian deltoids $\mathrm{x}$ nigra hybrids ( $P . \mathrm{x}$ euramericana) of which I-78, I-214 and I-455 were most widely used, American balsam and black poplar hybrids and the Dutch 'Flevo' poplar. Willows include Salix matsudana, S. matsudana x alba (hybrid tree willows), S. babylonica (weeping willow), $S$. fragilis (crack willow) and S. alba var. vitellina (golden willow), (Thompson and Luckman, 1993).

With Pinus radiata forestry, rainfall interception rates reach up to 35\% (Sidle et al., 1985) which leads to reduced streamflow and therefore reduced channel scour through forest transpiration and hillslope stability. Forest litter provides a second tier of interception, and a measure of protection against rain-splash erosion and scour from overland flow. Networks of tree roots, regardless of species planted, increase rigidity of the regolith, and reduce cracking that may lead to increased gullying. A direct effect on sub-soil moisture regimes can be controlled by tree transpiration, whereas pasture transpiration has primarily indirect (therefore potentially lower) effect on subsoil moisture. As most moisture is extracted directly from surficial soils, subsoil moisture levels may be significantly altered by rainfall interception (Thompson and Luckman, 1993).

Biological treatments are feasible, subject to economic evaluation and mobility in New Zealand to exploit revenue-earning potential (timber, biomass for pulp and energy) of poplar and willow tree species. The appeal of treatments has been reduced since central government support for erosion control has been curtailed (Thompson and Luckman, 1993). Although poplars and willows are both quick-growing and have extensive root systems, particularly in the case of willows, which have a tolerance to moist ground conditions, these trees are deciduous and leafless for long periods, particularly when regolith movements are most likely. Therefore, it cannot be assumed that their impact is solely through mechanical reinforcing effects of their roots. High transpiring trees have the potential to cause increases in density, strength and rigidity within the vicinity of roots in heavy clay soils, suggesting that hydrological effects can extend beyond the growing period (Thompson and Luckman, 1993).

According to Thompson and Luckman (1993) there are some uncertainties regarding minimum space planting configurations in silvio-pastoral systems. This uncertainty is important if factors such as relative values of tree crops, and pastoral production, dictate significant pastoral components to land use (wider average tree spacing). It is also necessary to adapt a minimum 
planting strategy, and clearly important to ensure that trees are correctly chosen and targeted to the specific landforms and processes (Thompson and Luckman, 1993).

Preston and Crozier (1999) suggest that the continued stability of regolith slopes can be attributed to the action of mechanical cohesion derived from the root networks of pasture grasses. The mechanical cohesion provided by a turf mat membrane is a significant component of slope resistance. These values are consistent with previous reports for root strength cohesion covering similar situations (Preston and Crozier, 1999).

Rosser and Ross (2011) reported that the sustainability of pastoral agriculture on steeper slopes in soft-rock hill country, is increasingly under threat from progressive reduction of pasture production from cumulative erosion. There are significant differences in underlying geology in Taranaki where harder sandstone is dominant, siltstone in Wairarapa and mudstone in East Cape. Depth of landsliding and soil development appears to proceed at a quicker rate in Taranaki hill country compared with the Wairarapa, due most likely to a higher rainfall. The mean annual rainfall for the North Island west coast New Plymouth is 1250-1500mm; Mount Egmont, 400010,000mm; central plateau (Taupo Volcanic Zone), 1500-4000mm; Wanganui-Manawatu, 7501250 and Hawke's Bay, Waimarama and Wairarapa 750-1500mm (NIWA, 2003). Smale et al. (1997) attributed the substantially faster rate of soil development on slip scars re-colonised by scrub at East Cape, to the rapid weathering of the underlying bedrock mudstone through desiccation, frittering and headwall collapse of the highly pedal mudstone (Rosser and Ross, 2011).

A severe storm event on June 19-20, 2015, over a period of 48 hours, caused extensive landsliding in the hill country of Taranaki, Wanganui, Rangitikei and Manawatu districts. Government estimates of the economic impact of the storm have recently been revised up to \$275M Horizons Regional Council (2004). Rainfall for the event was between 150mm and $250 \mathrm{~mm}$. The area affected was widespread; from Waitara/Urenui in the north, to Levin in the south and Woodville in the east, for a total area of $8900 \mathrm{~km}^{2}$. The return storm period is between 10 and 50 years (Page et al., 2015)

Moir et al. (2000) identified soil moisture, climate and soil fertility as three major factors influencing annual pasture production. In a modelling exercise Moir et al. (2000) used field trial data from Wairarapa hill country farms (Whareama, Gladstone, Mauriceville), excluding previously eroded sites. The data of (Rosser and Ross, 2011) suggests that erosion, through to loss of soil (particularly top-soil), directly affects the soil moisture-holding capacity through reduced topsoil and sub-soil thickness, which includes organic matter content that affects the soil 
nutrient status. Soil erosion is considered an important factor influencing annual pasture production in the hill country of New Zealand (Rosser and Ross, 2011).

In their conclusion, Rosser and Ross (2011) concur with Lambert et al. (1984) that pasture dry matter production on landslide scars in the Wairarapa recovered to about $80 \%$ of uneroded levels after 66 years, and was unlikely to exceed further recovery past $80 \%$. Rosser and Ross's research found no additional improvement in production occurred after a further 25 years of recovery on Te Whanga's (Gladstone) oldest 1941 and 1961 scars. Maximum pasture recovery occurred within about 20 years, however beyond that there was no evidence of further recovery Their results (Rosser and Ross, 2011) were in support of conclusions by other researchers (Lambert et al., 1984; Sparling et al., 2003; Trustrum and De Rose, 1988). The implication from this and previous research, shows that the sustainability of pastoral agriculture on steeper east coast hill country, which is underlain by poorly consolidated parent materials, will be increasingly under threat from progressive reduction of pasture production through cumulative erosion (Rosser and Ross, 2011).

Further trials of revegetation on landslips and hillslopes were conducted by Phillips et al. (2014) with the use of poplar and willow plantings, Schwarz et al. (2016) used two root data-sets of Veronese poplar (Populus deltoides x nigra) to calibrate a root distribution model. Their study showed that root distribution data are important inputs for quantifying root reinforcement at the hillslope scale.

New Zealand has not been slow to recognise the importance of research onto stabilising unstable hillslopes. The quality of bedrock, weak regolith and steep slopes are the areas where natural vegetation and revegetation programmes must take place. Unfortunately government and local councils no longer have the financial ability to continue supporting many regions landslide problems. 


\section{Chapter 2: Anthropogenic Influence on Landscape}

\section{1: Land Mitigation and Assessment}

Globally, very few countries escape regolith loss through landslides be it by avalanche, earthquake, precipitation, or tectonic uplift. Every country has a similar story of deforestation, removal of vegetation, and replacement by roading, industry and residential communities. There are many instances where loss of life is involved with landslides. Financial and economic loss is also very high. Each country deals with landslide devastation in their own way (Galve et al., 2015)

Italy is regarded as the country that has the worst landslide record in Europe and exceeded only by China, Japan and countries of Central and South America (Trezzini et al., 2013) globally. Because of the landslide problem, large amounts of mitigation work is carried out there. What follows is an introduction to a few case studies, highlighting human impact and response.

In northern Italy, 2011, along the coasts of Cinque Terre, eastern Liguria, a rainfall-triggered debris flood (Hungr et al., 2001) killed 3 people and left economic losses of 130M Euros. A large volume of the sediment carried by the debris flood came from 364 shallow landslides generated in the Vernazza catchment (Galve et al., 2015).

The Vernazza catchment $\left(5.8 \mathrm{~km}^{2}\right)$ belongs to a National Park and is recognised as a "World Heritage Site" by UNESCO. This is where land management strategies should recognise all issues related to natural hazards and include their complex interaction with environmental, cultural and socio-economic aspects (Galve et al., 2015).

The most common anthropogenic modification of natural slopes worldwide is the construction of terraces on hillsides. The terrace is a popular agricultural landform used in mountainous regions to raise crop output, control runoff and reduce erosion (Galve et al., 2015; Rackham and Moody, 1992; Terranova, 1989). Over the centuries the people of Liguria have modified the landscape by building terraces on more than $20 \%$ of the territory, creating a suitable terrain for farming. Since the 1960s the terraces have suffered extensive abandonment causing changes to land use and increasing landslide activity (Canuti et al., 2004; Galve et al., 2015; Plieninger et al., 2006). Galve et al. (2015) developed a susceptibility model that was used to produce a series of scenarios. The model provided information regarding landslide conditioning factors that could be modified to reduce shallow landslide processes and risk. The simulations showed the effects 
of their alternatives for landslide risk management: 1 restoration of the abandoned terraces; 2 reforestation of the terraces; 3 application of local structural measures over unstable hillsides and 4 do nothing (Galve et al., 2015).

Terrace restoration is very likely to attract public and private funding. This intervention could promote socio-economic activities, favouring the return of new generations to agricultural activities. Terrace reconstruction is very expensive, and the lack of skilled workers able to reconstruct dry stone walls is a problem to be recognised (Galve et al., 2015).

Reforestation is a cheap and easy solution to reduce landslide processes, but leads to loss of the cultural heritage of the terraced landscape and its biodiversity, and impacts on socio-economic development (Antrop, 2003; Galve et al., 2015; Terranova, 1984; Terranova et al., 2006). Avoiding any intervention on the current slope dynamics, even if the cheapest option, could result in increased risk and loss of the terraced landscape heritage. This susceptibility model was used to quantitatively assess land planning measures that may reduce landslide frequency and related risk (Galve et al., 2015).

Trezzini et al. (2013) consider that an increase in damages is likely to follow continuous urban sprawl. They collected data showing damages caused by events over the last 60 years and compared them to cost of prevention, demonstrating that preventative activities cost less than repairing the damage. Their research also found that there was no national body responsible for a systematic data collection related to natural disasters and the estimated costs of the damages. Total expenditure was also an uncertain quantity related to prevention activities due to different funding sources (Trezzini et al., 2013).

The lack of landslide and flood risk culture led to a fatalistic attitude towards natural disasters that could be predicted and prevented. However, mitigating the effects of disasters, requires knowledge of the phenomena involved and the scenarios that can be produced, as well as the things that can be done at all levels to manage risk (Trezzini et al., 2013).

Trezzini et al. (2013) maintain that many countries that have adopted insurance systems, have at the same time adopted rules for sharing costs of insurance protection between the public and private sectors. These insurance systems are dependent on the risk class of the area and where the establishment is located. The amount of requests for repair of damage caused by adverse weather during the period October, 2008 - June 2009 in Italy reached 4.6B Euros The maximum annual government funding for preventative interventions in the last 20 years reached about $400 \mathrm{M}$ Euros (1/3 of the expenditure for repair of the damage), about $1 / 8$ of the damage caused by events (Trezzini et al., 2013). 
Aaheim et al. (2010) refer to a message from the IPCC fourth assessment report (Parry et al., 2007), Climate Change 2007 Working Group II that states "The main challenge in developing adaption strategies to climate change relates to an enhanced risk of natural hazards" (Aaheim et al., 2010; Willbanks et al., 2007). An assessment of the likelihood of hazards and how it is affected by climate change is basic to the development of adaption strategies. Adaption strategies should take into account, how people respond in hazard situations (Aaheim et al., 2010). Slovic (1987) records that different people perceive risks differently, and therefore tend to disagree with the experts. Perception and action depend on cultural aspects, which are emphasised by Aaheim et al. (2010) and Douglas (1990).

Areas subject to earthquakes have fixed building standards, flood-prone areas are regulated according to flood frequency in many countries, and areas at risk of landslide development may be regulated according to the return period of landslides. In Norway, it is prohibited to develop properties within zones with a return period of less than a 1000 years for landslides. Aaheim et al. (2010) consider assessments are helpful for two reasons. First, decision making criteria helps define what information is required and enable evaluation of the quality of available information, including identification of non-available information. Second, pieces of information can be attached to decision making, and can be helpful to understanding how decision makers with different objectives interpret information differently (Aaheim et al., 2010).

Aaheim et al. (2010) believe that risk assessment should include information about the probability of landslides, asset at risk, and a damage profile in case of a landslide and extra costs related to such an event. Decisions based on expected costs or lost welfare provide the best and most consistent reference to other socio-economic decisions by enforcing a general evaluation of how much risk a community should tolerate (Aaheim et al., 2010). This includes mitigation of landslides as noted by Norris et al. (2008) and Stokes et al. (2014).

\section{Vegetation and eco-engineering}

Norris et al. (2008) and Stokes et al. (2014) explain that to mechanically stabilize a slope against shallow landslides, plant roots must cross the shear surface of a landslide that could be $2 \mathrm{~m}$ below the soil surface (Norris et al., 2008). The thick roots act like soil nails on slopes reinforcing soil in the same manner as steel rods reinforce cement. Thin and fine roots act in tension during slope failure and if they have crossed the slip surface they reinforce soil by adding cohesion (Stokes et al., 2009; Stokes et al., 2014). Vegetation contributes to soil surface protection, water infiltration, strength and fertility as well as to the enhancement of biological activity within the soil. 
Using vegetation in ecological rehabilitation and restoration projects promotes the recovery of ecosystem structures and functions which add to general ecological infrastructure. However, vegetation has the potential to destabilise slopes when high winds fell trees that can act as levers, leading to their breaking or uprooting with consequences for slope mechanical integrity (Mitchell, 2013).

Stokes, et al. (2014) describes eco-engineering as a long-term ecological and economic strategy, to manage a site with regard to natural or man-made hazards and bio-engineering is defined as a technology that uses engineering practices in conjunction with integrated-ecological principles to assess, design, construction and maintenance of living vegetation systems and to rapidly repair damage caused by erosion and failures (Norris et al., 2008; Stokes et al., 2010). Both of these fields lie within the discipline of "ecological-engineering", defined as the design of sustainable eco-systems, that integrate human society with the natural environment for the benefit of both (Mitsch and Jorgensen, 2004). The ecological mitigation of hillslope instability combines science and practice at the intersection of civil/geotechnical engineering, geomorphology, soil science, hydrology, silviculture, plant science, landscape design and ecological restoration (Stokes et al., 2014).

To identify key issues of concern to researchers and practitioners, Stokes et al. (2014) organised a round table discussion on the use of vegetation to improve slope stability at the Third International Conference on Soil Bio and Eco-Engineering held in Vancouver, Canada, during 23-27 July 2012, Stokes et al. (2014). Prior to the round table, delegates were asked to write their responses to these three questions.

1: What do practitioners need from science?

2: What are some of the key knowledge gaps?

3: What ideas do you have for future collaborative research projects between practitioners and researchers?

The questions posed to the roundtable were discussed by many scientists/researchers who identified ten key issues that were central in mitigating land loss through hillslope regolith failure.

The following is a summary of the issues that attendees at the roundtable acknowledged were relevant for morphological mitigation. 


\section{Evaluating how small scale, soil fixation can have large scale consequences}

Biophysical effects

Slope instability and erosion control can be mitigated at different scales. Soil structure and aggregate stability (the percent of stable aggregates after immersion in water) (Le Bissonnais, 1996) can be enhanced rapidly by introducing vegetation (Fattet et al., 2011; Gyssels et al., 2005; Jastrow et al., 1998; Stokes et al., 2014). In certain soils, herbaceous vegetation is more efficient than trees in improving aggregate stability due to a greater density of fine roots and associated fungal hyphae, both of which enmesh soil particles (Fattet et al., 2011; Gyssels et al., 2005; Stokes et al., 2014)

Physio-chemical effects

Within certain soils a positive relationship between aggregate stability and shear strength has been demonstrated (Fattet et al., 2011; Frei et al., 2003), however the mechanism for this relationship is not entirely understood. It is hypothesized that shear strength within a soil matrix results from the resistance to movement at interparticle contacts, physical bonds formed across the contact areas and chemical bonds (Craig, 2004; Stokes et al., 2014).

\section{Understanding the effects of vegetation on slope hydrology}

Soil hydrology is one of the main drivers of shallow landslides. While precipitation events are often linked to triggering landslides, it is changes in pore water pressure that cause a slope to fail (Stokes et al., 2014; Toll et al., 2011).

Variations in soil moisture due to vegetation

Vegetation is capable of removing large quantities of water from the soil, but how this translates to soil cohesion and whether this effect persists through season, soil types and depth is unknown for many varieties of vegetation and climate. How vegetation affects variations in soil moisture across depth is an important question for soil bio- and eco-engineers (Stokes et al., 2014).

\section{Understanding the role of vegetation in reducing debris flow activities}

Soil erosion and slope failure, if left unchecked, can increase in width, length and depth, while material can accumulate into zones that have the potential to mobilise as debris flows.

Avoiding recurrent debris flows

Debris flows are an extremely complex phenomena, and the use of vegetation to prevent or reduce a flow will only be a partial solution. Jacob and Hungr (2005) suggest that vegetation can stabilise debris in channels prior to a flow event occurring, but once a small scale flow takes 
place rapid engineering stabilisation has to be undertaken to prevent more failures occurring, particularly if infrastructure exists downslope (Stokes et al., 2014).

\section{Understanding the impact of trees on the stability of dikes (Levees)}

Loading effects

Dikes are a natural embankment or artificial fill slope at the edge of watercourses, and are similar in several ways to riverbanks or artificial slopes associated with infrastructure. Problems associated with vegetation and dike stability are specific to dikes due to the hydrological loading to which they are subjected. They offer favourable conditions for tree growth with vegetation providing abundant ecological and social services. Trees and woody vegetation may improve dike stability but there are risks which may compromise their stability including increased infiltration and seepage associated with live or dead roots, and an increase in burrowing animal numbers and potential for root-system pull out during floods or windstorms, (Corcoran et al., 2011; Stokes et al., 2014; Zanetti, 2010).

Internal erosion

Zanetti (2010) examined growth and architecture of more than 100 root systems of common tree species in France. The structure of tree roots depended on the species, age and type of materials constituting the dike and the location of the tree on the dike. Results showed that the construction of tree root systems and root decomposition significantly influenced the rate of subsurface erosion, or piping in the dike (Stokes et al., 2014).

\section{Modelling the mechanical stability of vegetated slopes}

Modelling in different dimensions

There are several commercial and freely available tools for calculating slope stability, and they are often not able to predict accurately the likelihood of a landslide within a given landscape. One of the biggest challenges in model development is to appropriately take account of the temporal and spatial heterogeneity of soil properties, root and water distribution along a slope.

\section{Alternative models}

Safety (FOS). Many prevailing models consider FOS as a global "slope scale" indicator and One of the most common outputs of numerical simulations of slope failure is the Factor of thereby compute only one FOS value to represent the average stability of a whole slope. This approach can be appropriate for relatively small slopes under a full cover of homogenous varieties of vegetation (Mickovski and van Beek, 2009; Stokes et al., 2014), but the use of a global FOS will probably mask the details of small-scale effects of vegetation on slope stability. Future modellers 
should define alternative safety indicators to give greater accuracy to slope stability as a function of time and space (Stokes et al., 2014).

\section{Identifying the most appropriate plant types}

Limitations in using traditional species

There are several plant genre that are often preferred by soil bio-engineers carrying out slope restoration in different locations around the world. The species preferred have significant properties that permit rapid stabilisation of unstable or failed slopes. The most popular tree/shrub species are poplar (Populus sp.) and willow (Salix sp.). These species populate extremely well from vegetative cuttings or 'live poles', if placed immediately in contact with moist soil (McIvor et al., 2014; Stokes et al., 2014; Wilkinson, 1999). Willow species are also used for a range of functions in riparian areas including streambank protection and nutrient sediment management (Kuzovkina and Volk, 2009; Stokes et al., 2014).

Criteria and challenges in the selection of alternative species

To screen for the most appropriate plant, or variety of plants, assessment of their biophysical and ecological functions are required (growth rate, cost of establishment, survival rate, colonisation requirements, life forms, longevity and successional dynamics). Their characteristics are particularly important when choosing whether to install trees, shrubs or herbaceous species. Grasses and ground cover species can reduce superficial erosion and propagation of soil cracks, which avoids the creation of preferential flow pathways along fissures that can lead to mass failure. Deeper-rooted woody perennials will improve mechanical reinforcement of soil at depth (Stokes et al., 2014).

Dynamic evolution of vegetation

Individual species can be used for mitigating hillslope instability and rendering land use sustainable, to restore full ecosystem function. The replacement of pioneer plants by successional communities is highly desirable. Pioneer shrub and tree species are often short-lived and unable to reproduce in their own shade and possibly only enhance stability over a short period of time (Stokes et al., 2014).

\section{Using inert engineering structures and live plant material: efficacy over time} Hard and soft engineering structures

Hard engineering structures such as gabions, retention walls, anchors and check dams, provide immediate solutions for slope and (gully) stability, while soft engineering structures like brush layers or fascines, can be constructed with timber (wood) or live plant cuttings (Gray and Sotir, 
1996; Stokes et al., 2014), however they take longer to stabilise soils. Soft structures are suitable where unstable slope problems are anticipated and live plant material is likely to have time to develop, but may lack sufficient strength. (Stokes et al., 2014).

Monitoring longevity and efficacy over time

The lifetime of hard engineering structures used for stabilising slopes or conserving soil, is approximately 50-100 years with regard to optimal quality, however, this time frame can be highly variable for soft engineering structures that use non-living plant material (crib-walls and slope grids), (Böll et al., 2009; Stokes et al., 2014). The longevity of inert soft engineering structures depend on species used and biological activity of local degrading organisms (Lacasse and Vanier, 1999). Any data on longevity of structures is only valid for similar conditions. The durability of timber structural elements is dependent on air temperature, humidity and soil moisture variability (Lacasse and Vanier, 1999; Stokes et al., 2014).

\section{Improving engineering in harsh environments}

Climate

A significant influence on plant development and function is climate. Some of the world's harshest conditions for plant growth occur in high altitude environments, with acute fluctuations in temperatures and precipitation (Körner, 2003; Stokes et al., 2014). Areas of little precipitation often support reduced vegetation cover. Hence, large areas of exposed bare soil may result in increased vulnerability to erosion (Stokes et al., 2014).

\section{Topography}

The topography of an extreme environment can determine the success of planting and restoration programmes. Bochet et al. (2009) investigated topographic thresholds (slope angle and aspect) for plant colonisation on semi-arid eroded slopes in Spain, where they observed that the slope angle threshold for plant colonisation decreased from north-facing slopes $\left(63^{\circ}\right)$ to south-facing slopes $\left(41^{\circ}\right)$. Site-dependent studies are a useful method to determine topographic thresholds for plant colonisation in hilly areas (Hales et al., 2009; Stokes et al., 2014).

Substrate

Soils on slopes can be in a disturbed state, due to engineering activities, previous erosion or current erosion processes. Topographic thresholds are important for colonisation, and root/soil interactions and play a critical role in plant establishment and success (Stokes et al., 2014). 
Keystone and native species

Hillslopes where climate or substrate conditions are not conducive to plant survival mortality can be high on introduced species. Use of native keystone species is a recommended solution for planting on slopes in such environments. Keystone species are defined as having a disproportionately large effect on the local environment, relative to their abundance (Paine, 1995; Stokes et al., 2014).

Restoration actions

Effective long-term slope stability and erosion control can be achieved by ecosystem recovery which includes re-establishment of community and ecosystem properties. Complexity, selforganisation and resilience reduce the need for human maintenance over time. Beyond plants, community components include soil organisms, dispensers, pollinators and herbivores. Restoration actions in stressful or extreme environments depend on specific goals driven by a specific set of site conditions that range from adding mulch, plant microbes or fertilisers (Stokes et al., 2014; Walker and Shiels, 2013).

\section{Assessing how vegetation on slopes provide ecosystem services}

Ecosystem services are benefits from functioning ecosystems to the overall environment, including products and services that humans receive from natural, regulated or otherwise perturbed ecosystems (Costanza et al., 1997; Stokes et al., 2014), (MEA 2005).

\section{Water provisioning}

Artificial or natural revegetation of a slope may have several benefits additional to slope stabilisation. Hydrological effects include reduction of sediment and nutrient loads of runoff and enhancement of water quality for downstream users (drinking water, hydropower and reduced peak flows), thereby providing improved flood control (Postel and Thompson, 2005; Stokes et al., 2014).

\section{Carbon sequestration}

The revegetation of slopes could have a positive benefit for climate mitigation with the sequestration of excess carbon. Vegetated land surfaces hold more carbon within their soil biomass than do sparsely vegetated surfaces or areas where vegetation is absent (Post and Kwon, 2000; Stokes et al., 2014). 


\section{Diversity effects}

Restored hillslopes with natural regeneration may increase the diversity of native flora and fauna in the area (Cavaille et al., 2013). A higher biodiversity can enhance overall ecosystem functions including nutrient cycling and resilience to the disturbances of drought and hurricanes (Loreau et al., 2001). Forests may also serve as habitats or migration corridors for species that may bring economic benefits, such as pollination of crops or wildlife eco-tourism and other recreational activities (Kremen et al., 2007; Stokes et al., 2014).

Improving the widespread adaption of eco- and bio-engineering

Civil and geotechnical engineers have several concerns about the use of soft engineering techniques. First, soil bio-engineering is often viewed as simply the stabilisation of superficial layers, with limited effectiveness to the depth permeated with roots. Although this is correct with regard to the effects of live vegetation, reinforcing effects deeper in the soil are possible through the addition of inert but natural materials (Gray and Sotir, 1996). Another perceived shortcoming is the low durability of system/strategy, yet Stokes et al. (2014) argue that the durability over time is comparable to that of civil engineering structures.

Cost analysis

A concern about the implementation of soil biology and eco-engineering is the high cost. An appropriate approach for cost analysis is to employ whole life cycle costing (WLCC), which is the systematic consideration of all relevant costs and revenues associated with the acquisition and ownership of an asset such as the stabilised slope (Boussabaine and Kirkham, 2004; Stokes et al., 2014). Costs to be taken into account include initial capital and procurement costs, and opportunity and future costs. Only options which meet the performance requirements for the stabilised slope should be considered - with a preference for those with lower costs over that period (Stokes et al., 2014).

\section{Benefits}

Civil engineering structures including dams, walls, retention basins and other engineered solutions such as terra forming and drainage manipulation are very useful tools for soil loss and erosion control, but they also have drawbacks. These approaches have large carbon footprints, are expensive and sometimes dangerous to construct, disrupt local and regional ecological processes, and need ongoing maintenance and eventually require repair or replacement (Stokes et al., 2014). 
Awareness

Confidence in soft engineering structures and vegetation cover should increase if awareness was at a high level, and funding agencies or clients requested such solutions. For example, in Hong Kong, where steep slopes and monsoon rains and tropical cyclones have caused thousands of landslides around infrastructure (Choi and Cheung, 2013), geotechnical engineers work with landscape architects and botanists to produce mechanically safe, vegetated slopes. Over 60,000 man-made slopes are referenced in a database open to the public (http://hkss.cedd.gov.hk). It is for professionals and students to access and update the database, and with public desire for green slopes ensures that vegetation is planted, monitored and maintained (Stokes et al., 2014).

Practitioners provide opportunity for researchers to access work sites, make experienced observations and collect useful data. Researchers gain insights that may not be evident in smaller scale research projects, and the practitioner is likely to involve the researcher in the planning process. A researcher can add value to projects through a beneficial understanding of ecological processes and time scales. The rate of technology transfer is likely to increase because both researcher and practitioner are involved with the process (Stokes et al., 2014).

It is obvious from the efforts of Stokes et al. (2014) that geomorphologists and geologists have a very real concern for the environment, particularly hillslope failure, extreme precipitation events, earthquake and tectonic uplift.

The discussion and results that have emerged from the Stokes et al. (2014) round table has covered many areas that are pertinent to New Zealand's landslide problems. This work has important concepts that can be utilised, and identifies mitigation options for hillslope stability that can be optimised in certain conditions.

Well-planned mitigation is required to stabilise New Zealand hillslopes, protect against extreme events and protect the economy that is produced on the hillslopes from animal and agricultural farming. 


\section{2: Modelling Landslides}

Why do we model landslides? Models are designed for many purposes, one of which is to understand how to mitigate the effects of landslides, understand hillslope behaviour and define the drivers of slope failure.

There are many forms of scientific models used for measuring, weighing or assessing the vulnerability of soil on hillslopes and the aftermath of severe events. Some of these models are designed for a specific purpose, such as hazard management, and are used to interpret local, regional and nationwide landslide issues. They promote the safety of communities, flood mitigation, and preparation for evacuation, emergency and medical services.

There are numerous methods for measuring and modelling landslides; some of these are multipurpose whereas others are for individual tasks. Aleotti and Chowdhury (1999) say the achievement of any objective has been enhanced by the introduction of Geographic Information System (GIS). It is very important that the first step in any assessment concerning a study area is the collection and assessment of all available information and data, while the accuracy of the collection and storage of the information is also acknowledged by Amanti et al. (1996); Carrara (1982); Chowdhury and Flentje (1998a); Cruden and Brown (1992); (Aleotti and Chowdhury, 1999).

Leroi (1996) and Aleotti and Chowdhury (1999), maintain there are two fundamental rules that must be followed when creating a database. These are: a) that the information has to be homogeneous, and that it must have the same work-scale and the same geographic projection system and; b) the database should be organised into monothematic layers, each one containing homogeneous data (Aleotti and Chowdhury, 1999). The selection of an approach to be used for a project is often based on economic concerns (cost/benefit analysis or political convenience) depending on the technical nature of the problem (Aleotti and Chowdhury, 1999).

Although the discussion by Aleotti and Chowdhury (1999) suggest using certain criteria for research, this study was developed along similar lines which included, selection of type of approach to research, cost benefit analysis (self-funded), collection of soil samples, and field observation. The use of GIS as an analysis tool and laboratory analysis of homogenous soil samples were backed up by GPS positioning. 


\section{Using GIS}

The detection of large, potentially unstable rock masses according to Jaboyedoff et al. (2005) remains a challenge because the potential instabilities are not detected due to unusual rockfall activities. Due to the increased availability of digital elevation models (DEM) it is now possible to investigate these large rockfalls (Jaboyedoff et al., 2005).

For many years potential rockfall was assessed by using rock mass type rating systems (Mazzoccola and Hudson, 1996; Romana, 1993). The new tendency correlates these assessments with Geographical Information Systems (GIS) (Jaboyedoff et al., 2004b; Jakob and Hungr, 2005; Rouiller et al., 1998; Wagner et al., 1988). Some attempts to assess large landslide hazards have used simple mechanical modelling (Miller, 1995) and more recently, geomorphic analysis (Jaboyedoff et al., 2004b; Jaboyedoff et al., 2004a; Jakob and Hungr, 2005).

According to Sassa et al. (2009) GIS/remote sensing is the second most frequently recognised method (19\% of study methods) of modern technologies used for landslide hazard mapping analysis. Reliability of results from GIS/remote sensing are greatly increased when supported by inclusion of other methods i.e. field investigation; experiment and monitoring, pin-point location.

GIS/remote sensing is able to cover wide areas. Nadim et al. (2006) and Sato et al. (2007) dealt globally and with the area damaged by an Mw7.6 earthquake at 8.50am, local time on October 8, 2005 in northern Pakistan. GIS/remote sensing risk maps provide risk assessment and management tools. Colombo et al. (2005) introduced an example by using web-GIS services to public regional authorities.

It is suggested by Sassa et al. (2009) that "theoretical/analytical/numerical study" forms $18 \%$ of methods. Single methods or combinations of theoretical, analytical or numerical studies have been used in many papers to analyse phenomena and solve intricate problems. While experiment forms $16 \%$ of study methods including laboratory and in situ geotechnical testing, physical model tests, field experiments, and physical exploration that are commonly used by researchers and engineers studying landslide events (Sassa et al., 2009).

Hazard assessment slope screening tools

Two slope instability screening tools were developed in Washington State, NW USA, for use in forest practice planning and permit granting by the Washington Department of Natural Resources (WDNR), which was formed to manage forest practice regulation and management of state forest trust lands. These tools are SLPSTAB (Vaugeois, 2000) and HAZONE 
(Resources, 2010). These screening tools are used by WDNR during forest practices application processes to flag potentially unstable slopes where harvesting of timber, or road building and related activities have been proposed (Whittaker and McShane, 2012).

SLPSTAB is GIS-based and used for screening inherent landform characteristics that covers nearly all of 488 watersheds of western Washington (Vaugeois and Shaw, 2000; Whittaker and McShane, 2012). SLPSTAB was derived from two deterministic, physically-based models SMORPH (Shaw and Johnson, 1995) and SHALSTAB (Montgomery and Dietrich, 1994). Whittaker and McShane (2012) believe that topographic relief (hillslope gradient) and form (slope curvature) are the principle driving factors that promote shallow landslides (Vaugeois and Shaw, 2000). SLPSTAB utilizes slope geometry derived from $10 \mathrm{~m}$ digital elevation models (DEMs) and climatic data establishing frequency of critical rainfall (Montgomery et al., 1998) in a given area that would cause a slope to destabilise. (Vaugeois, 2000; Whittaker and McShane, 2012).

HAZONE (Resources, 2010) is a screening tool developed by using an inferential approach. The predictive capability of HAZONE relies on past information as a prediction for future hazard potential. This approach is consistent with standard geomorphic analysis of an area. HAZONE hazard ratings rely on a semi-quantitative assessment method that uses slope stability data from previously existing watershed analysis. This screening tool utilised aerial photographs; topographic, geologic and hydrologic maps; 10m LiDAR (Light Detection and Ranging) DEM; and field observations (Whittaker and McShane, 2012).

Tree root systems

According to Schwarz et al. (2016), methods to quantify root reinforcement have been developed over the past 35 years. The most significant advance has been the introduction of the fibre bundle model concept by (Pollen and Simon, 2005) which applies a stress-stop loading approach to consider the progressive failure of roots with various root diameters. This was further extended in the 'Root Bundle Model' (Schwarz et al., 2013; Schwarz et al., 2016).

The Root Bundle Model described by Schwarz et al. (2016) uses a strain-step loading approach to calculate the force-displacement behaviour of each single-root of a bundle while considering the progressive failure of the roots as a function of displacement. This model also uses a Weibull survival function that describes the range of probability that a single root fails before or after the fitted value of maximum estimated tensile force based on its diameter class. This function considers the mechanical variability of root strength due to root material properties, root geometry and soil mechanical conditions (Schwarz et al., 2016). 
The comparison of data from two different datasets by Schwarz et al. (2016) provides a rare opportunity to discuss the effects of environmental conditions and measuring methods on the results of root distribution.

Process-based models

These models (Brunetti et al., 2013) rely on the understanding - and schematisation - of the physical laws controlling instability, and attempt to extend spatially the simplified stability models that have been widely adopted in geotechnical engineering. While stability conditions can be evaluated by means of a static model, local equilibrium forces follow a predefined slip surface. Most commonly, the slip surface is assumed to be planar at a fixed depth, and parallel to the topographic surface. Values for pore water pressure are assumed, or obtained by adopting rainfall infiltration models, coupled to surface and sub-surface runoff models (Brunetti et al., 2013).

According to Brunetti et al. (2013) the main problem with process-based models is the difficulty to obtain reliable and accurate information that is necessary to construct and calibrate distributed models. A particularly severe problem occurs where the models are applied to large areas (Brunetti et al., 2013).

\section{GPS Tracking}

GPS is becoming extensively used for field work to pinpoint specific landslides that have been used for measuring, and for soil sampling when a multiple event has occurred and may need to be identified at a later date.

GPS is also used for tracking large landslides that appear stable, but require positioning to monitor and record evidence of movement, and to help mitigate continued movement. Uhlemann et al. (2016) used GPS markers in five parallel lines with nine markers in each. The initial positions were surveyed using real-time kinematic GPS equipment that is able to provide centimetre accuracy enabling a time-series of landslide movements (Uhlemann et al., 2016).

For the first time in their knowledge, Uhlemann et al. (2016) introduced and compared conventional techniques such as GPS, inclinometer and tilt meter with recently emerging deformation monitoring techniques which include, acoustic emission (AE) monitoring using active waveguides (AEWG) and Shape Acceleration Array (SAA) on an active landslide providing long-term (2009-2014) measurements. The research of Uhlemann et al. (2016) highlights the relative performance of these techniques which focus on different movement periods and provides detailed, integrated interpretations of movement, environmental, and 
geotechnical data (Uhlemann et al., 2016). No one system proved a best performer, but a collection of well-balanced monitoring devices delivered the information required for the behaviour of a slope in greater detail.

\section{Measuring and monitoring devices}

Weather Stations

Weather stations can measure maximum and minimum temperatures, precipitation, wind direction and speed, humidity and barometric pressures. They should be an integral part of equipment in all regions with minor stations installed to record temperature and precipitation.

These are extremely important items for researchers who require additional information on a local environment. It is with concern that NIWA (National Institute of Water and Atmospheric Research) and MetService (Meteorological Service of New Zealand) have removed or made redundant many of the remote outlying weather stations that make back calculations difficult and hinder forecasting.

Piezometers

Piezometers were installed by Uhlemann et al. (2016) in boreholes at $2.85 \mathrm{~m}$ and $2.8 \mathrm{~m}$ close to predicted shear surfaces. As the active zones of the piezometers were in close proximity to the shear zone $(<0.35 \mathrm{~m})$, the measured pore water pressures were considered indicative for the conditions of the shear surface (Uhlemann et al., 2016). However, Uhlemann et al. (2016) acknowledged that there are significant constraints on many such projects due to financial restraints. Their study provided examples of various techniques and instruments used on a landslide over an extended period. The level of information attained from using a combination of instruments showed that a well-balanced choice of monitoring equipment delivers information that can be used to understand triggering mechanisms and deformation behaviour of slope instability in significant detail (Uhlemann et al., 2016).

\section{Drones}

New technology that is becoming increasingly useful is the hand-controlled drone. This machine has a wide variety of uses and is capable of saving hours of field work observations. With a camera attached, it is capable of recording areas where multiple landslides occur, alleviating the necessity of lengthy trekking in field work, and using photography to help with counting and measuring landslides at a finer temporal and spatial scale than airborne or satellite imagery.

The use of new technology has advanced the study of slope stability and failure, to locate and identify areas of slope weakness beyond normal field observations. Geological features and 
regolith lithology that were once difficult to identify are now available, allowing collection of important structural information for analysing and adding to database collections where scientists have access to research information that has similarities to their study projects. 


\title{
Chapter 3: Area Geology, Soils and Location
}

\section{1: Tectonics and Geology}

\author{
A history of the East Coast construction
}

The Australian plate is subducting below the overriding Pacific Plate on the western side of the South Island, while on the eastern side of the North Island the Pacific plate is subducting below the Australian Plate (Jiao et al., 2014; Pohlen, 1971).

The New Zealand landmass exists, due to the involvement of continental lithosphere in convergent plate boundary interactions (Kamp, 1992). Onshore New Zealand is only a finite part of a larger landmass of the sub-continent. Most is submerged and is underlain by a thin continental crust, with particularly thin crust beneath basins such as the New Caledonia Basin, Bounty Trough and Great South Basin (Kamp, 1992; Mortimer, 2004a). Most of these features have been oriented NW-SE due to inherited rifting events in the mid-Cretaceous. The modern Australia-Pacific plate boundary cuts at $90^{\circ}$ (NE-SW) across the older structures (Kamp, 1992).

According to Lee et al. (2011), the basement rocks of Hawke's Bay area comprise terranes of the Eastern Province of New Zealand. These fragmented arc-trench complexes of deposited deep water marine sediments were derived from the erosion of a continental hinterland with an active volcanic belt (Bradshaw, 1993; Lee et al., 2011).

By using thermochronology, Jiao, et al. (2014) were able to study the basement rocks of the central North Island, and to record thermal and exhumation histories related to two subduction cycles since the late Jurassic. The basement rocks of the North Island were formed by deposition and accretion onto the eastern Gondwana margin in the Mesozoic. These rocks are now placed at the leading edge of the upper plate of the modern Hikurangi subduction margin, with respect to the westward subducting Pacific Plate (Jiao et al., 2014a). The central North Island basement rock has been modified and deformed during two major subduction events, one starting in the late Mesozoic, and the other initiating in the late Oligocene (Jiao et al., 2014a; King, 2000; Mortimer, 2004b) separated by a long period associated with drift from the eastern margin of Gondwana (Jiao et al., 2014b).

Studies by Litchfield and Berryman (2006) and Pulford and Stern (2004)revealed variations in the uplift and exhumation rates with distance inland from the modern Hikurangi Trough in the North Island. In the east, closer to the subduction zone stratigraphic mapping of Neogene paleo 
shorelines, mudstone porosity analysis suggests a mean rock uplift rate in the fore arc of up to $1 \mathrm{~mm} / \mathrm{yr}$ over the last 5Myr (Jiao et al., 2014a; Litchfield and Berryman, 2006). According to Kerr and Bishop (1971), the Hawke's Bay region is structurally composed of a basement of greywacke (sandstone) and argillite (mudstone), covered with a thick blanket of younger sedimentary rocks. Erosion has produced the present landscape by fluvially eroding out small and large valleys and depositing the material as river flats, coastal plains and alluvium filled depressions where the process of fluvial action continues (Kerr and Bishop, 1971; King, 2000; Mortimer, 2004a; Pettinga, 1982).

In the South Island, continent-continent convergence across the Alpine Fault has dominated the scene with major tectonic uplift (Kamp, 1992). The late Cretaceous-early Cenozoic cover rock, as a consequence, has been largely removed, and the landforms have developed from the indurated basement rocks. However, the ocean-continent convergence in the North Island has more commonly developed from marine sedimentary basins and these have been inverted, therefore, Cretaceous-Cenozoic rock sequences (including volcanic rocks) subsequently cover most of the North Island (Kamp, 1992). The uplift of the crust in the northern and central North Island originated from high heat flows and thermal elevation, but is driven by tectonic thickening in the south east of the North Island due to compressional tectonics associated with plate convergence (Kamp, 1992).

Dominant soils of the east coast of the North Island have developed from sedimentary rocks brought to New Zealand and tectonically uplifted from the converging Australian and Pacific plates (Pohlen and Congdon, 1971). During the subduction process, accretionary wedges of oceanic crust and overlying sediment are scraped from the descending Pacific Plate and these form the marine sediment hills of the east coast (Pohlen and Congdon, 1971). During prolonged periods of precipitation or cyclonic storms these hillslopes become saturated and unstable, making them prone to multiple landslides (Crozier, 2005b; Crozier et al., 1980; Pohlen, 1971). Such instability is exacerbated by seismic activity.

The geology of the East Coast of Hawke's Bay consists of a soft bedrock of tertiary sedimentary rock, which consists of siltstones and sandstones with bands of limestone and conglomerates.

Steep high relief slopes are a result of rapid tectonic uplift during the Pleistocene to present and fluvial dissection (Haywick, et al. 1991). The parent material of the soil consists largely of allochthonous volcanic tephra, tephric loess, with small amounts of residual soil, formed as a weak regolith mantle, averaging approximately $1-2 \mathrm{~m}$ depth. The regolith is highly permeable, compared to the impermeable bedrock. 
This geological landscape is constantly uplifted by the effects of the converging Pacific plate subducting beneath the Australian plate. These two merging plates have provided the topography and lithology that comprise Waimarama and the surrounding area.

\section{Stratigraphy}

Pettinga (1982) shows seven phases using the New Zealand Series Geological time scale as against the global Geological, Tertiary and Quaternary sedimentation table phases: (Figure 3.1).

\begin{tabular}{|c|c|c|}
\hline NZ Series & & Phases \\
\hline $\begin{array}{l}\text { Upper Wanganui } \\
\text { Hawera } \\
\text { (Pleistocene-Holocene) }\end{array}$ & 7. & $\begin{array}{l}\text { Shallow marine and } \\
\text { non-marine (Gravels), } \\
\text { lake beds }\end{array}$ \\
\hline $\begin{array}{l}\text { Lower Wanganui } \\
\text { (Pliocene) }\end{array}$ & 6. & $\begin{array}{l}\text { Limestones; } \\
\text { Sandstones }\end{array}$ \\
\hline $\begin{array}{l}\text { Landon-Taranaki } \\
\text { (Oligocene) }\end{array}$ & 5. & $\begin{array}{l}\text { Mass-flow Deposits } \\
\text { (turbidites; Debris } \\
\text { Flows); Massive } \\
\text { Mudstones and } \\
\text { Sandstones; } \\
\text { Tuffaceous Beds }\end{array}$ \\
\hline $\begin{array}{l}\text { Arnold } \\
\text { (Upper Eocene) }\end{array}$ & 4. & $\begin{array}{l}\text { Bentonic Marls; } \\
\text { Calcareous Mudstones }\end{array}$ \\
\hline $\begin{array}{l}\text { Dannevirke } \\
\text { (Paleocene-Lower } \\
\text { Eocene) }\end{array}$ & 3. & $\begin{array}{l}\text { Alternating Bentonic } \\
\text { Mudstones and } \\
\text { Sandstones }\end{array}$ \\
\hline $\begin{array}{l}\text { Mata - Dannevirke } \\
\text { (Upper Cretaceous } \\
\text { Lowermost Tertiary) }\end{array}$ & 2. & $\begin{array}{l}\text { Argillites, Glauconitic } \\
\text { Flysch, Carbonaceous } \\
\text { Mudstones, Shales }\end{array}$ \\
\hline $\begin{array}{l}\text { Raukamara-Mata } \\
\text { (Upper Cretaceous) }\end{array}$ & 1. & Carbonaceous Flysch \\
\hline
\end{tabular}

Figure 3.1: Adapted from Pettinga 1982 (NZ J of Geol and Geo, 1982, Vol. 25, P152

Using a simplified sequence as mapped by Pettinga (1982) and produced by Peploe et al. (1982), the following sections describe the main formation groups located within the Puhokio catchment.

\section{Upper Cretaceous - Lower Tertiary}

Diverse lithologies are found within this sequence with the oldest formation, the Waimarama (Glenburn) Formation containing carbonaceous sandstones, overlain by the Whangai Formation, comprised of well-indurated, poorly bedded, siliceous mudstone. Outcrops, typically show weathered yellow jarosite; thin bedded mudstone and glauconitic sandstone, concretionary 
sandstone beds and chert lenses in coastal areas at Waimarama and Blackhead Point, with small outcrops in Puhokio Valley usually over shadowed by bentonite (Pettinga, 1980).

\section{Middle Tertiary}

These sediments are mudstones and very fine sandstone that are often seen as alternating sequences. There are two formations: the Makara Formation which sits conformably above the Puhokio Formation and crops out in an extensive band within the Puhokio and Te Apiti Valleys (Pettinga, 1980). The best exposure of the Puhokio Formation is found at the south end of Waimarama Beach. The geology of the region is consistent with much of the east coast south of Cape Kidnappers, with marine sediments of the Puhokio Formation consisting of glauconitic sandstone and mudstone, overlain by green-blue mudstone and alternating sandstone and mudstone (flysch). Foraminifera indicate an Oligocene to middle Miocene age (Pettinga, 1980).

A further two small outcrops of the Puhokio Formation are recorded on the coast south of Waimarama, and are important to the structural and tectonic history of Southern Hawkes Bay (see part iii), (Pettinga, 1980). The lithology of the Puhokio Formation according to Pettinga (1980) is characterised by a calcareous dark greenish grey to greyish-blue, to greenish grey coloured mudstone, which has a high clay content and is perceptibly finer grained than the overlaying mudstones of the Makara Formation stratigraphy, where alternating sandstonemudstone sequences occur (Pettinga, 1980). The sandstones are calcareous and glauconitic while tuffaceous beds near the top of the formation are present at the Hawea Stream locality, in the Puhokio Valley, and are excellent stratigraphic marker horizons (Pettinga, 1980) (Figure 3.2) shows the New Zealand Plate Boundary.

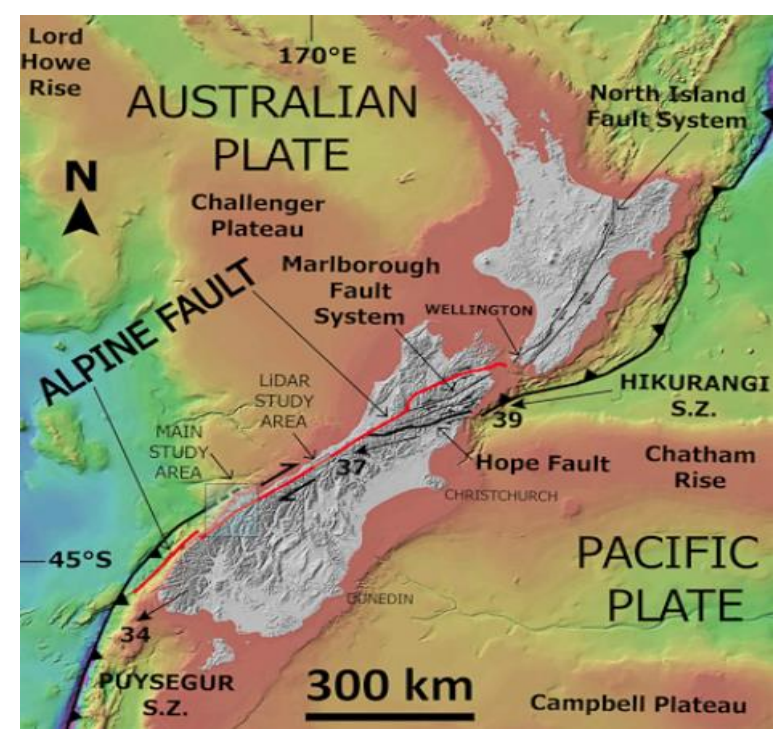

Figure 3.2: New Zealand Plate Boundary with Hikurangi Trough opposite East Coast NZ (Bath, N. - Research Image 


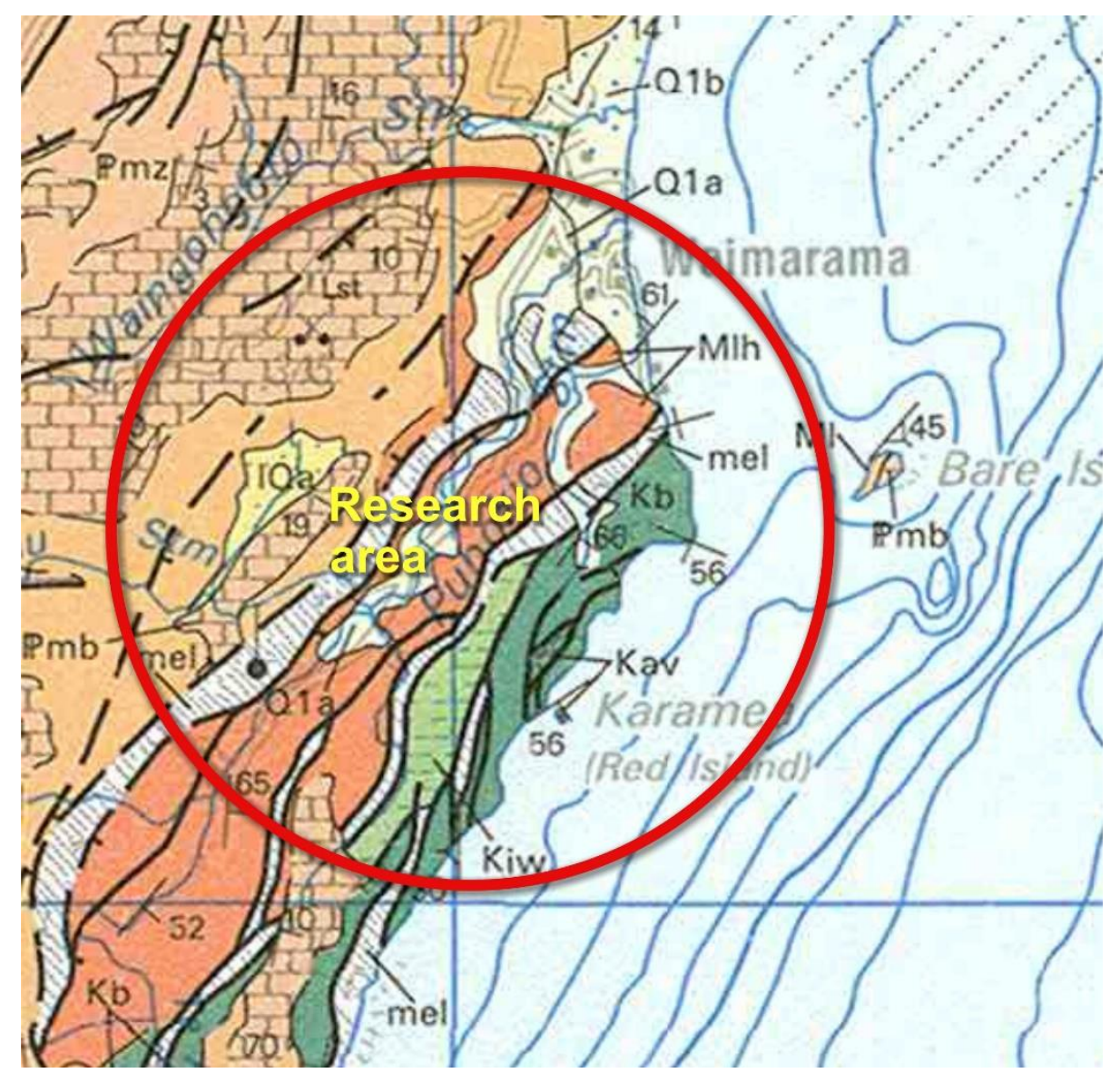

Figure 3.3: Q Map of lithology and structures in the Waimarama region (from Lee et al. 2011)

Lithology Definitions from Q Map (Figure 3.3)

Mlh - Puhokio Formation (early Miocene)

Mel - Mélange blocks of Glenburn Formation, Tinui and Mangatu group lithologies

Kav - Glenburn Formation (mid Cretaceous)

$\mathrm{Kb}$ - Glenburn Formation (mid Cretaceous)

Kiw - Whangai and Waipawa Formations (late Cretaceous - early Paleocene)

Plmb - Kairakau Limestone (early Pliocene)

Q1a - Estuarine and alluvial deposits, unconsolidated 
Structure and Geomorphology:

There are four distinct land-form units within the Puhokio-Wairongoro Catchment these are the Makara, Puhokio, Weber and Raratu Formations. The relict limestone western plateau forms an almost complete flat lying sequence on the western margin of the catchment. From early Pliocene there is the Kairakau Limestone, yellow-grey barnacle rich cross-bedded sandy limestone (Lee et al., 2011). This lithology forms a dominant ridge unit to the west of the catchment, and includes a number of outcrops in the valleys to the east. Numerous limestone outcrops within the catchment were originally at the same level as the plateau, but were moved to their present location along a low angle shear plane (Pettinga, 1982). The Kaiwhakapiripiri Ridge, and the rejuvenated steepland below the Makara Formation, are predominantly undeformed and exhibit normal shallow erosion forms, including Pa Hill (Peploe et al., 1982 ).

Active areas of rejuvenated visible erosion are due to the change in base-level of the sea and river terraces over Holocene geological times (Litchfield and Berryman, 2006). Native forest clear felling has accelerated the erosion cycle (Peploe et al., 1982 ). Land forming the main valley system is referred to as rolling earth flow as described by Peploe et al. (1982), and consists of all the land between the limestone ridges exhibiting mass flow (earth flow landforms). This zone is composed mainly of Puhokio Formation that has been deformed by multiple low angle thrust faults which have created a series of westward dipping sandwich like blocks. Areas between these faults are likely to have "crush or mélange zones" (Pettinga, 1982). Other areas where high angle normal faulting has occurred have not produced the same degree of crushing (Peploe et al., 1982 ). The eroding coastal hill country was originally the submarine basement on which the Puhokio and Makara Formations were deposited, however, continued thrust faulting during deposition resulted in formation of the mélange zones. Bentonite intrusion from the MacIntosh (Wanstead) Formation often lubricated these zones. The presence of bentonite does not necessarily initiate earthflow erosion (Peploe et al., 1982 ; Pettinga, 1982).

\section{Soils of Hawke's Bay}

Age

Erosion and sediment deposition during the Pleistocene Ice Ages onto oldest land surfaces of Puhokio and Makara Formations as described by Pohlen and Congdon (1971) as very old are the upper Whaingaroan, Clifenden and Lillburnian New Zealand stages dating from 34.3-12.7 My as noted by Pettinga (1982). If normal erosion is allowed for, with additions of wind-blown loess and volcanic ash, the development of soils in the Hawke's Bay has continued for over half a million to one million years on remnants of these land surfaces, while the oldest soils have been 
modified to a greater or lesser degree by normal erosion, and additions of loess and ash. These weatherable minerals form a reserve supply of plant nutrients (Pohlen and Congdon, 1971).

Soils of the region fall into three classes:

1. Zonal soils that are formed on ordinary siliceous rocks and have properties determined largely by climate and vegetation;

2. Intrazonal soils have distinctive properties contributed by particular kinds of parent rock, including limestone or volcanic ash, or to salinity or high ground water;

3. Azonal soils are formed from fresh sediments or, on steep unstable slopes that are too young to have strongly developed profiles (Pohlen and Congdon, 1971).

\section{Zonal Soils}

Yellow-grey earths

The yellow-grey earths are the zonal soils of the sub humid seasonally dry, lowland basins between Napier and Waipukurau. They have medium to high natural fertility but, have a low available content of phosphorus. Their compact subsoils impede percolation during wet spells, and in many places form hard pans. Drainage has been improved in some places with mole drains (Pohlen and Congdon, 1971).

\section{Intrazonal soils}

Yellow-brown sands

The yellow-brown sands are formed from coastal wind-blown sands and, stabilised in part by vegetation, have little or no profile development. They have loose subsoils and are susceptible to drought except where ground water approaches the surface, and have low to medium natural fertility (Pohlen and Congdon, 1971).

\section{Azonal soils}

\section{Alluvium and Gley Recent Soils}

Recent soils from alluvium and the gley recent soils are formed on flats and flood plains where river sediments have recently been deposited. Where accumulation of sediments has recently been rapid, the soils have scarcely any differentiated topsoil, but where it has been slow, they have a thick dark granular top soil. If the soils are well-drained or moderately well-drained, they are classified mostly as recent soils from alluvium; where they are poorly-drained and their subsoils are gleyed, they are classed as gley recent soils. Except where they are stony or shallow, 
the soils have high natural fertility and rank among the most productive soils for crop or pasture (Pohlen and Congdon, 1971). This is the setting for many North Island landslips. Abnormally high localised precipitation onto hill country farmland grass cover, with an impervious bedrock of marine sediment, a thin layer of organic soil on top, unable to retain water past saturation level, eventually collapsing, causing multiple shallow landslides (Brooks et al., 2002; Crozier et al., 1992).

Soil descriptions as described by Peploe et al. (1982) within the Puhokio Catchment taken from (Soil Bureau Bulletin 94).

\section{Hastings silt loam/Twyford silt loam}

Both these soils are highly fertile, formed in deep deposits of river silts, although the Twyford soils are subject to flooding and their productive potential is reduced. Due to the flooding and deposition risk, the Twyford soils have little or no profile development and consist of a deep grey-brown silt loam, loam or sandy loam. Drainage can be fairly rapid, with most of the Twyford soils found in lower rainfall areas (Peploe et al., 1982 ). Hastings soils are similar but have a greater degree of profile development and have more organic matter in the topsoil with a more compacted subsoil, which can result in poor drainage. When stocked in wet conditions pugging will occur on undrained soils (Peploe et al., 1982 ).

\section{Maraetotara sandy loam and light silt}

These soils are formed from limestone and calcareous sandstone, found on the plateau land on rolling to strongly rolling topography. High rainfall and internal drainage is rapid despite compacted subsoils. Distinguished by their fluffy consistency, the danger of wind blow when cultivated may be high (Peploe et al., 1982 ).

\section{Kidnapper silt loam}

This is a soil associated with the Makara Mudstone, and is located on steep slopes mainly on lower levels of the plateau escarpment, where soil depth may be shallow. It has a heavy texture with high natural fertility. A feature of this soil is its ability to shallow slip (Peploe et al., 1982 ).

\section{Te Apiti clay}

This soil is formed on Puhokio Mudstone on moderately steep slopes. It has a high clay content that allows the soil to retain a high moisture capacity while remaining saturated for 2-3 months of the year. This soil cracks under dry conditions and is susceptible to erosion during high precipitation events. Gully erosion can be activated in stream sections (Peploe et al., 1982 ). 


\section{Wanstead clay loam}

This is a very heavy soil with a high bentonitic clay content that has expansion and contraction properties dependant on the soil moisture content. This soil is associated with the geological instability at Waimarama as it is generally located within the crush zones. Severe erosion from soil in the form of gullying, soil creep, earth flow and slumping can be expected. The horizon profile usually consists of $13 \mathrm{~cm}$ dark grey clay loam over $13 \mathrm{~cm}$ of silty clay over a very compact clay of dark grey-blue colour (Peploe et al., 1982 ).

\section{Waimarama sandy loam}

This is a soil formed on Waimarama sandstone and confined to a coastal strip extending south from Waimarama Township to Karamea (Red Island). It is mapped on moderately steep slopes with erosion showing as slips and tunnel gullies. The soil is located within the catchment in low rainfall areas. The effect on the sandy topsoil through rapid drying during summer results in poor pasture species dominated by Sporobolus africanus (ratstail grass) (Peploe et al., 1982 ).

Vegetation cover is an important factor influencing the occurrence and movement of rainfall triggered landslides, and changes to vegetation cover often results in modified landslide behaviour (Glade, 2003). Blaschke et al. (2000) emphasise that, the loss of agricultural land that is listed sometimes among the impacts of a particular mass movement episode, is often treated as a loss of infrastructure rather than a loss of production capacity (Figure 3.4). 


\section{Estimated long-term soil erosion, 2012}
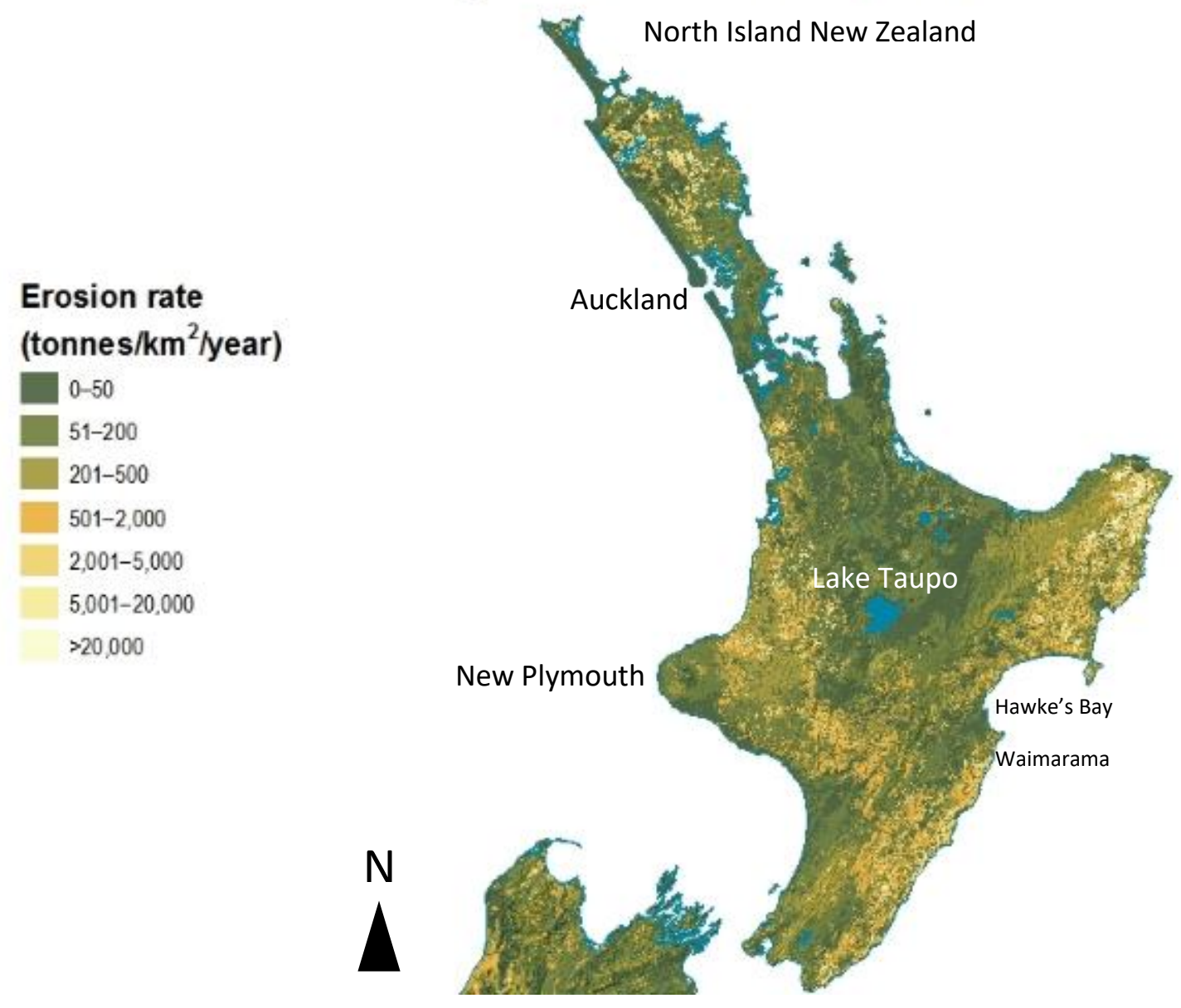

Figure 3.4: North Island erosion loss map. (Landcare Research)

Mass movement erosion is often regarded as a natural process and appears to have been misjudged by productivity researchers who had assumed that all erosion occurring on agricultural land was anthropogenic (Lal and Stewart, 1990). Most forms of erosion, either fluvial, aeolian or mass movement, do occur naturally as well as the result from human activity (Young and Saunders, 1986). Loss of productivity due to mass movement is commonly more extreme at the affected site, than that due to surface erosion, as the event can often remove the entire soil profile at once, while surface erosion can take many years to remove an equivalent depth (Blaschke et al., 2000).

Sources of mass movement-derived sediment in downstream agricultural districts, include natural landslides on steep slopes, failures caused by runoff from roads, or leakage from ditches, failure of artificial embankments on terraced slopes, and collapse of hillsides where they have been undercut to increase cultivable area of footslope terraces (Blaschke et al., 2000; Diemont 
et al., 1991). Emphasis on mass movement as a hazard has led to an emphasis on the off-site impacts, as opposed to land productivity impacts that are largely on-site.

There is a fundamental difference between surface and mass movement erosion from a land productivity perspective. Surface erosion rates are increased (relative to natural rates) due to inappropriate agricultural management, including excessive cultivation, overgrazing or repeated burning of vegetation. In contrast, the rate of mass movement is not necessarily responsive to changes within an existing agricultural management regime (more careful cultivation). It can increase or decrease with change from one type of agricultural regime to another i.e. a shift from cultivation to cash cropping (increase) and livestock grazing to a mix of livestock grazing and agro-forestry (decrease). Minimization of mass movement impacts on land production can be achieved by changing strategies, whereas, changes to land husbandry techniques can be applied to control surface erosion (Blaschke et al., 2000)

Within the central North Island there is an active volcanic zone referred to as the TVZ (Taupo Volcanic Zone). There is approximately $150-200 \mathrm{~km}$ between Taupo and the East Coast where large deposits of volcanic ash (tephra) have been deposited along that seaboard due to the prevailing north-west wind. There have been a number of large volcanic eruptions in the past. The most recent from Mt Ruapehu in 25-9-2007, left a powdering of ash in some areas of the East Coast (personal observation and communication with farmer I C Brickell). 


\section{2: Puhokio Valley}

There is a variation in the spelling of Puhokio and Pouhokio. This thesis uses "Puhokio" as per the use in Pettinga (1982) and as used by the residents in Te Apiti Road.

The Puhokio Valley lies in a north-south direction with mixed farming both sides of the main Puhokio Stream. The true right is less steeply inclined than the true left where, in the past, large landslides have re-contoured the land into steep grassy slopes, with numerous slip scars and minimal vegetation. There are small pine and mixed plantations, some used for landholding ability with native forest removed and replaced by grassland

Records from (local farmer) K McNeur rain gauge showed precipitation during January 21, 22, 23 and 24, 2011, totalled 232mm, March 11, 3.6mm; March 22, 54mm; March 23, 48mm; on April 4, 19mm and then on 26, 27 April, 750>mm fell in just over 48 hours, at some stages reaching $120 \mathrm{~mm}$ an hour (personal communication with $\mathrm{McNeur}$ ). The rain started at approximately 5.30pm, 26 April with the storm intensifying later that evening. Although antecedent moisture retention is unknown, it is likely that pre-storm moisture was retained in the soil and may have contributed to regolith saturation quicker than normal from an average January-May precipitation of 400-450mm (Figure 3.5). Regolith depth showed a consistent $80 \mathrm{~cm}$ to1m, as measured during on site surveys, and was able to absorb rainfall over the normal annual average of $784.8 \mathrm{~mm}$ per annum consistently over a 30 year period, from 1981 to 2010, as recorded by (NIWA, 2017), (Figure 3.6).

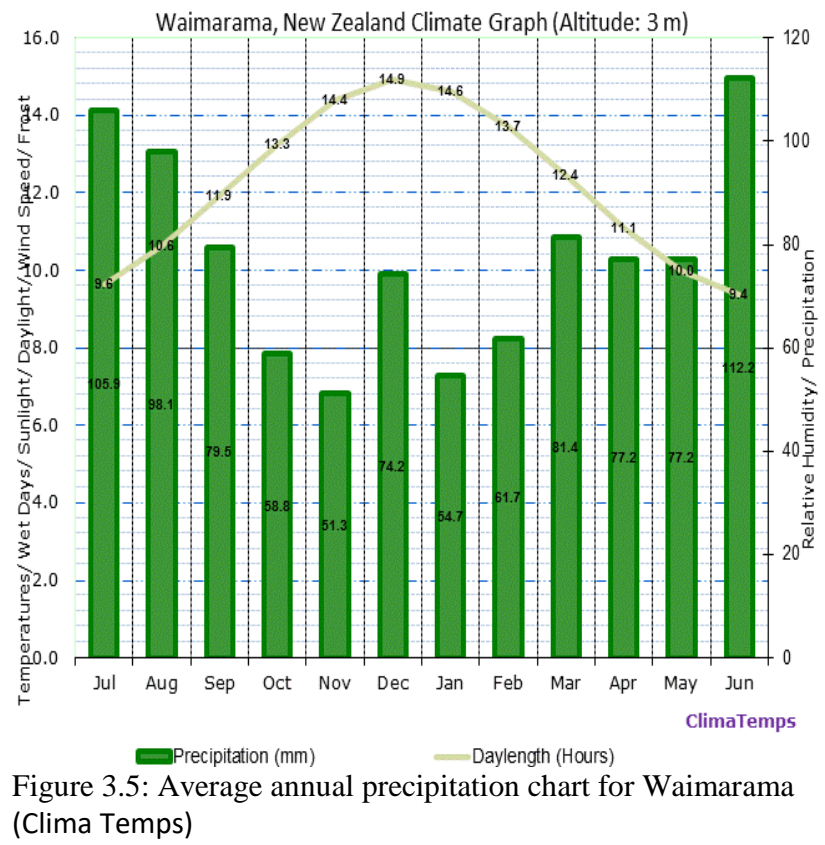




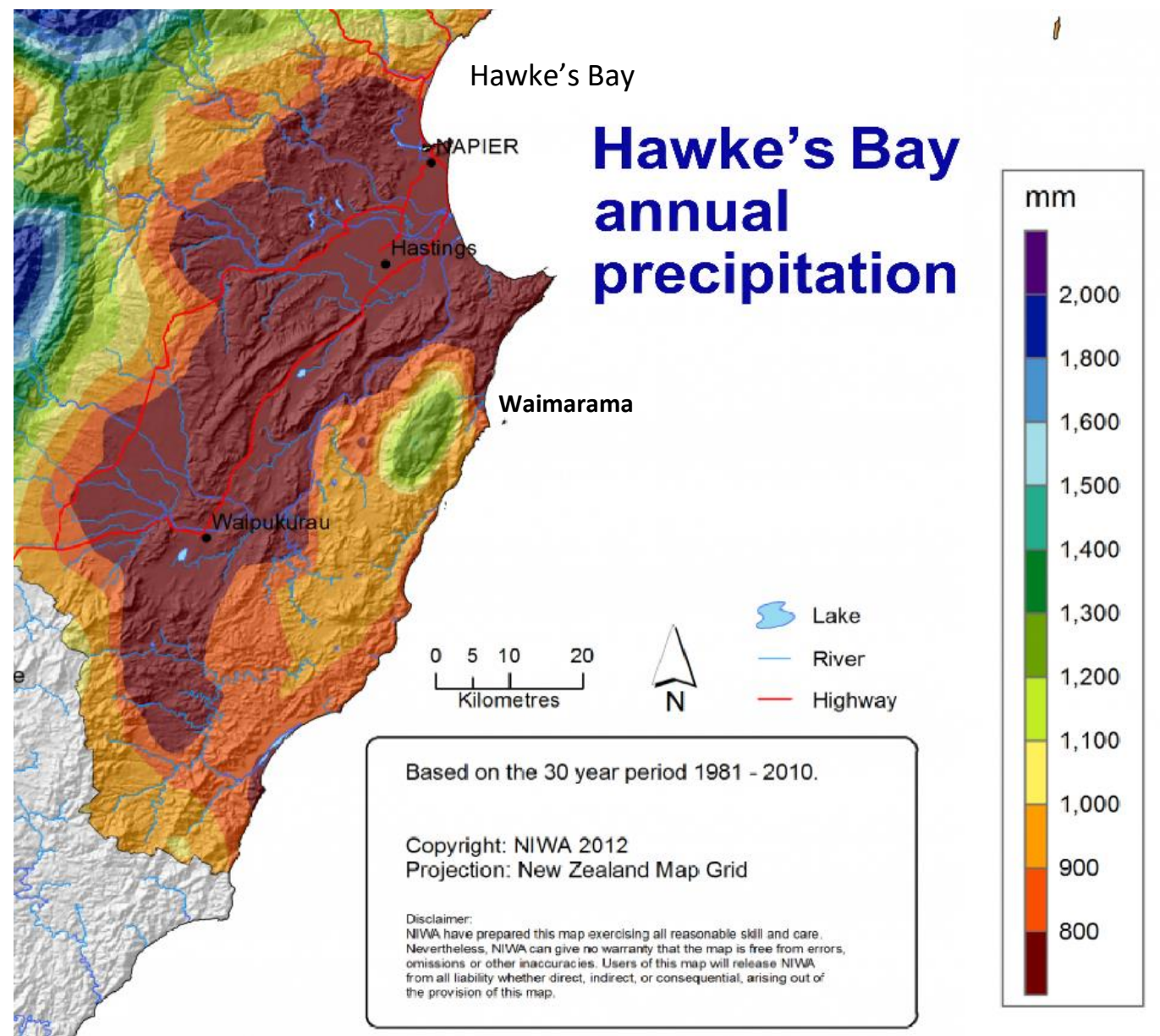

Figure 3.6: NIWA 2012 precipitation chart based on rainfall of between $800-1300 \mathrm{~mm}$ average for precipitation for Waimarama, Hawke's Bay (Chappell, P. R.(2013)

On April 26-27, 2011 the landscape was subjected to a severe weather event that caused widespread flooding in the Hawkes Bay region and massive terrestrial loss in the coastal areas of Ocean Beach, north of Waimarama and Kairakau in the south. Over 650-800mm of rain were recorded in the Puhokio Valley by local farmer (McNeur, 2011), covering 36-48 hours. At $10.28 \mathrm{pm}$ on the night of 26 April, 2011 during the height of the downpour a Mw4.5 earthquake situated $40 \mathrm{~km}$ southeast of Waipukurau, Latitude $40.14^{\circ} \mathrm{S}$, longitude $176.98^{\circ} \mathrm{E}$ at a focal depth of $40 \mathrm{~km}$ (reference No. 3503071/G. GeoNet) was recorded. It was felt over a wide area of the Hawkes Bay. The following morning many slips were observed and it is highly likely they resulted from a combination of saturated hillslopes and the earthquake. These were mostly shallow translational slides with some very steep washouts (Figure 3.7) There are no records of previous events of this magnitude in recent memory and only infrequent evidence of old overgrown slips (Pettinga, 1980). 


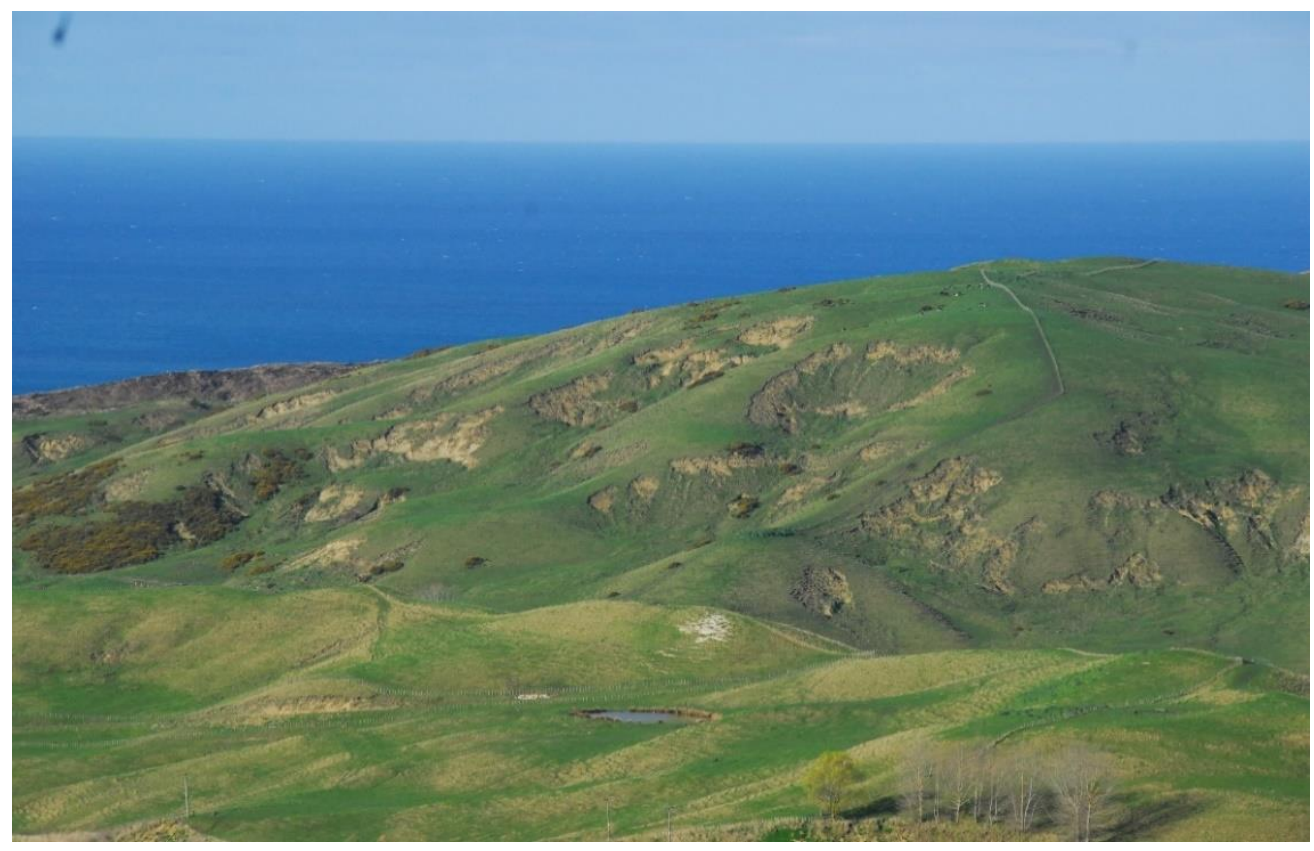

Figure 3.7: Multiple landslides on coastal grassland pastures Waimarama

\section{Valley Area}

The Puhokio valley runs to the south of the main road into Waimarama. It is a small catchment surrounded by rolling hills and steep slopes along the coast on the eastern freeboard and higher hills of the Kaiwhakapiripiri Range to the west. The Puhokio Stream splits the valley where mixed beef and sheep farming dominates land production. Small production pine plantations are used for slope stability and income benefits at maturity. There are several farms that form a small community within the valley where this study had permission and access to three farms, bordering both sides of the valley. Remnant patches of original forest remain on the higher slopes and steep gulleys.

Puhokio Valley is approximately $23 \mathrm{~km}^{2}$ and the study area within that is approximately $11 \mathrm{~km}^{2}$. The three farms (of McNeur, McKay and Chesterman) have reliable access tracks where a quad bike ( 4 wheel drive farm bike) proved a valuable tool for travel between sample plots for equipment and heavy soil sample transport (Figure 3.8). 


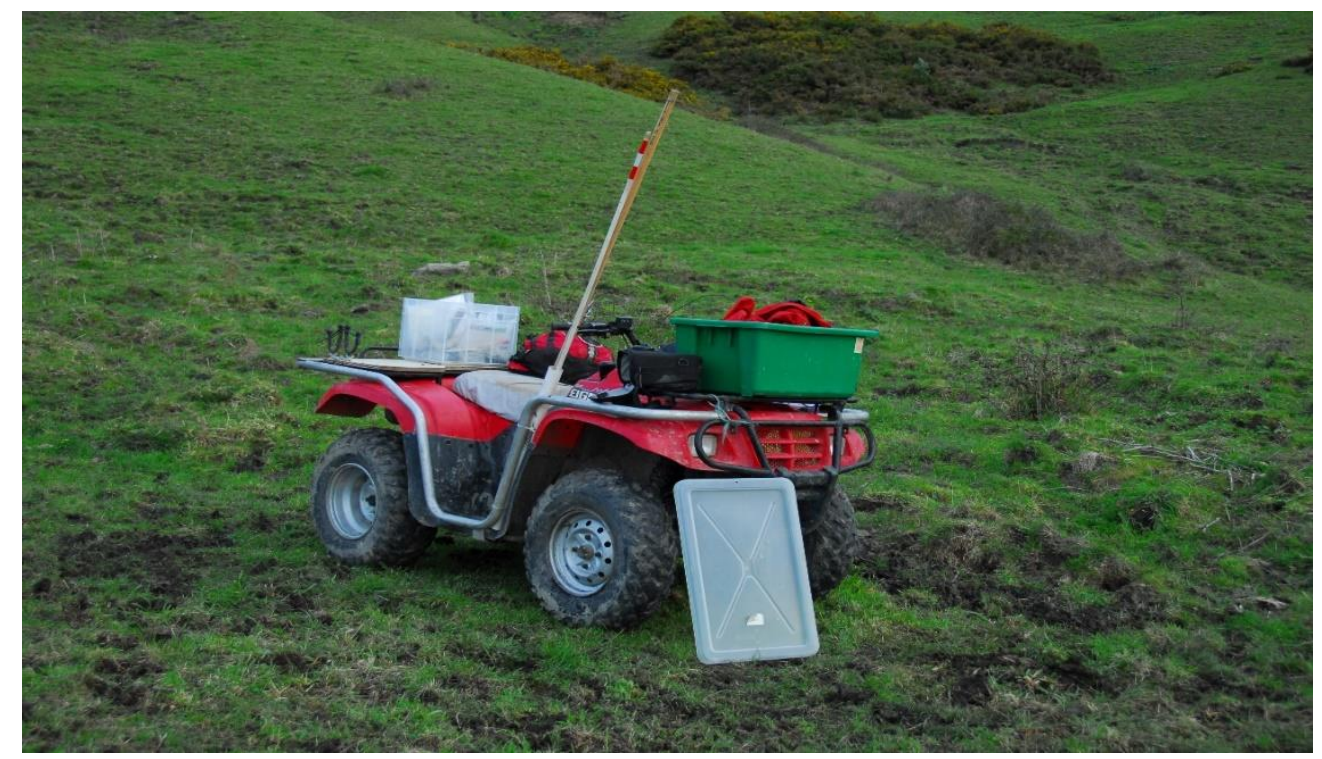

Figure 3.8: Author-owned Quad bike transport with associated survey equipment on McNeur farm

Episodic rainstorm-triggered landslide events are often associated with tropical cyclones and are a frequent phenomena in Hawke's Bay. These may affect tens to hundreds of square kilometres at a time. They typically involve hundreds of shallow, rapid earth slips, as in the April 2011 event at Waimarama. When surveyed on site, these landslides showed a similar regolith rupture profile and exposed bedrock surface, as described by Brooks et al. (1995), (Figure 3.9).

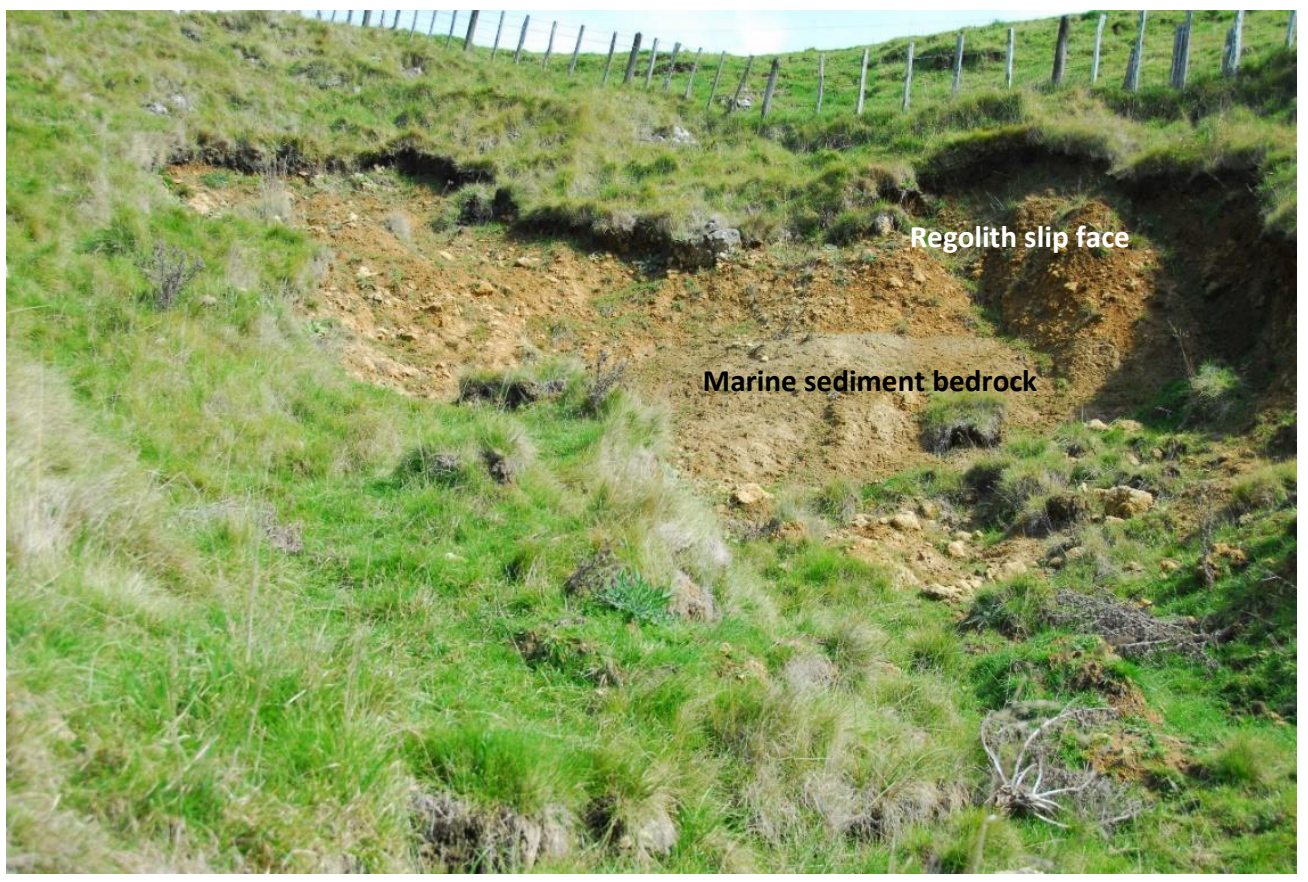

Figure 3.9: Bedrock stripped of regolith below ridgeline on McNeur farm, Waimarama 


\section{Chapter 4: Methods and Results}

\section{1: Field work}

A total of 54 numbered slips in 8 locations (Figure 4.1) were randomly selected covering steep to rolling slopes and separated some distance from each other to determine if changing slope and lithology sequences had any influence on landslip morphology.

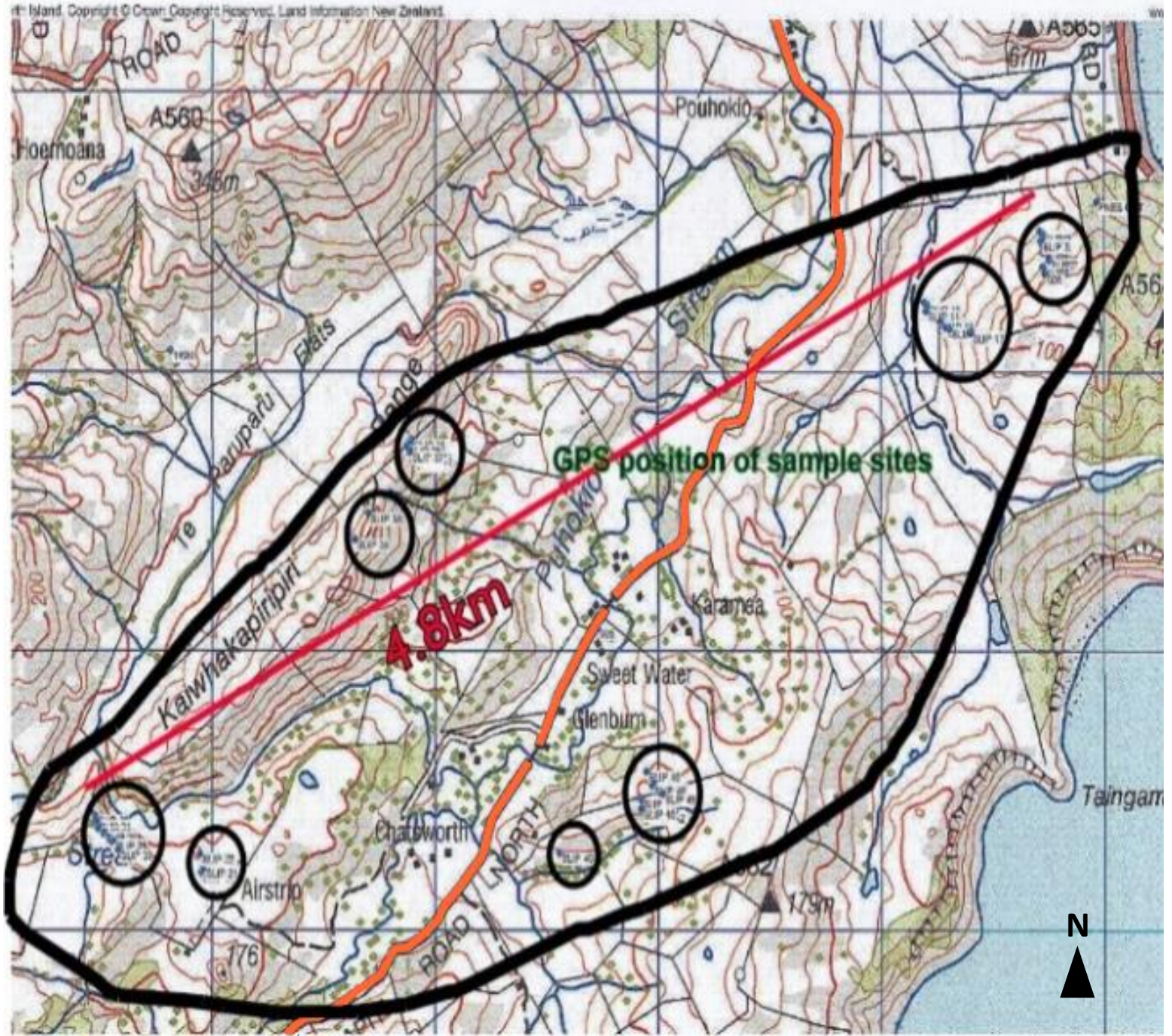

Figure 4.1: 54 sample plots enclosed in ovals inside research border.Te Apiti Road runs south west-north east, orange line. Locations are shown in Fig. 4.2

The first slip samples 1-39 were collected from 1-9-13 to 4-9-13. Second sample collection 40-49, on 248-14 to 25-8-14. Final sample collection 50-54 was 13-11-16 (see Figure 4.2, page 67). 
GPS locations were taken of all measured slips (Figure 4.2).

\begin{tabular}{|c|c|c|c|c|c|c|c|c|c|c|c|}
\hline \multirow[t]{2}{*}{ Slip/Date } & \multirow[t]{2}{*}{ Compss Brng } & \multirow[t]{2}{*}{ GPS } & \multicolumn{2}{|c|}{ Slip wdth $\mathrm{m}$ Length $\mathrm{m}$} & \multirow[t]{2}{*}{ Depth m } & \multirow[t]{2}{*}{ Slope Angle ${ }^{0}$} & \multirow[t]{2}{*}{ Slip Angle ${ }^{\circ}$} & \multirow{2}{*}{$\begin{array}{l}\text { Height } \\
\text { a.s.l. m }\end{array}$} & \multirow{2}{*}{$\begin{array}{l}\text { 19mm Soil } \\
\text { Shear 1st }\end{array}$} & \multirow{2}{*}{$\begin{array}{l}19 \mathrm{~mm} \text { Soil } \\
\text { Shear 2nd }\end{array}$} & \multirow[t]{2}{*}{ TOTAL LOSS ${ }^{3} \mathrm{~m}$} \\
\hline & & & & & & & & & & & \\
\hline $1-25-8-12$ & $146 \mathrm{SE}$ & E2851656/N6145159 & 8.8 & 13.5 & 1 & 26 & 40 & 45 & 66 & 74.5 & 118.8 \\
\hline $2-25-8-12$ & & E2851670/N6145153 & 14.5 & 11 & 1 & 26 & 30 & 52 & 84 & 79 & 159.5 \\
\hline $3-25-8-12$ & & E2851667/N6145130 & 5.3 & 7.8 & 0.8 & 17 & 32 & 59 & 54.5 & 59.5 & 33.1 \\
\hline $4-25-8-12$ & & E2851667/N6145130 & 7.6 & 16 & 1.2 & 20 & 28 & 59 & 72 & 57 & 145.9 \\
\hline $5-25-8-12$ & & E2851672/N6145105 & 14.8 & 20 & 1.6 & 20 & 28 & 57 & 41 & 62 & 473.6 \\
\hline $6-25-8-12$ & & E2851674/N6145083 & 13.6 & 17 & 1.8 & 25 & 28 & 66 & 64 & 48 & 416.2 \\
\hline $7-25-8-12$ & & E2851696/N6145061 & 18.7 & 28 & 1 & 20 & 25 & 84 & 62.5 & 72 & 523.6 \\
\hline $8-25-8-12$ & & E2851671/N6145032 & 14.9 & 45 & 1.7 & 23 & 29 & 85 & 56.5 & 56 & 1139.9 \\
\hline $9-26-8-12$ & $94 \mathrm{~S}$ & E2851138/N6144 & 19.4 & 10 & 1.3 & 26 & 34 & 53 & 56 & 38 & 252.2 \\
\hline $10-26-8-12$ & & E2851151/N6144897 & 8.9 & 12 & 1.1 & 25 & 28 & 20 & 60 & 56 & 117.5 \\
\hline $11-26-8-12$ & & E2851149/N6144879 & 14.3 & 11 & 1 & 19.5 & 29 & 19 & 52 & 55 & 157.3 \\
\hline $12-26-8-12$ & & E2851168/N6144865 & 4.9 & 5 & 1.1 & 19.5 & 25 & 27 & 48 & 64 & 27 \\
\hline $13-26-8-12$ & & E2851212/N6144837 & 23.3 & 25 & 1.4 & 20 & 30 & 31 & 60 & 51 & 815.5 \\
\hline $14-26-8-12$ & & E2851236/N6144817 & 10.1 & 20 & 1.4 & 23 & 25 & 37 & 52 & 64 & 282.8 \\
\hline $15-26-8-12$ & & E2851252/N6144815 & 10.8 & 30 & 1.7 & 16 & 25 & 44 & 52 & 56.5 & 550.8 \\
\hline $16-26-8-12$ & $262 \mathrm{~W}$ & E2851349/N6144806 & 13.4 & 33 & 1.65 & 20 & 26 & 71 & 54 & 66.5 & 729.6 \\
\hline $17-26-8-12$ & & E2851347/N6144798 & 11.5 & 45 & 2.6 & 23 & 40 & 59 & 43 & 35 & 1345.5 \\
\hline $18-27-8-12$ & $236 \mathrm{SW}$ & E2847924/N6142842 & 24.6 & 25 & 3 & 28 & 50 & 147 & 76 & 74 & 1845 \\
\hline $19-27-8-12$ & & E2847913/N6142854 & 9.2 & 11 & 1.7 & 21 & 36 & 127 & 60 & 48 & 172 \\
\hline $20-27-8-12$ & & E2847901/N6142865 & 10.2 & 17 & 1.9 & 19 & 39 & 111 & 68 & 68 & 329.5 \\
\hline $21-27-8-12$ & & E2847916/N6142882 & 10.2 & 7 & 1.1 & 26 & 48 & 121 & 76.5 & 72 & 78.5 \\
\hline $22-27-8-12$ & & E2847897/N6142934 & 8.4 & 8 & 1.3 & 31 & 54 & 121 & 69 & 55 & 87.4 \\
\hline $23-27-8-12$ & $96 \mathrm{NE}$ & E2847430/N6143069 & 9.9 & 7.3 & 1 & 35 & 46 & 129 & 60 & 68 & 72.3 \\
\hline $24-27-8-12$ & $40 \mathrm{NE}$ & E2847435/N6143046 & 17.7 & 26.5 & 1.5 & 23 & 30 & 127 & 45 & 45 & 703.6 \\
\hline $25-27-8-12$ & $130 \mathrm{SE}$ & E2847440/N6143025 & 6.5 & 5 & 1.1 & 31 & 30 & 135 & 46 & 57 & 35.8 \\
\hline $26-27-8-12$ & 354 NW & E2847466/N6143007 & 13.8 & 24 & 2.2 & 34 & 50 & 148 & 47 & 47 & 728.6 \\
\hline $27-27-8-12$ & 23NE & E2847490/N6142985 & 11.7 & 14 & 1.4 & 30 & 38 & 155 & 40 & 46 & 229.3 \\
\hline $28-27-8-12$ & & E2847499/N6142981 & 4.3 & 4.3 & 1.2 & 25 & 53 & 153 & 62 & 55 & 22.2 \\
\hline $29-27-8-12$ & & E2847509/N6142979 & 15.9 & 18.7 & 1.8 & 20 & 36 & 144 & 51 & 61 & 535.2 \\
\hline $30-27-8-12$ & $26 \mathrm{NE}$ & E2847536/N6142944 & 16.7 & 15 & 1.3 & 27 & 34 & 145 & 52 & 43 & 325.7 \\
\hline $31-28-8-12$ & $20 \mathrm{NE}$ & E2848861/N6144341 & 6 & 15 & 1 & 27 & 32 & 132 & 45 & 57 & 90 \\
\hline $32-28-8-12$ & & E2848872/N6144353 & 6.8 & 14.5 & 1.1 & 27 & 39 & 146 & 29 & 21 & 108.5 \\
\hline $33-28-8-12$ & & E2848856/N6144363 & 12.5 & 11 & 0.7 & 29 & 35 & 147 & 33 & 47 & 96.3 \\
\hline $34-28-8-12$ & & E2848849/N6144382 & 12.3 & 10 & 1.3 & 13 & 44 & 143 & 76 & 44 & 159.9 \\
\hline $35-28-8-12$ & & E2848842/N6144411 & 15.9 & 12.8 & 1.3 & 38 & 36 & 147 & 58 & 58.5 & 264.6 \\
\hline $36-28-8-12$ & & E2848820/N6144392 & 9.5 & 16.3 & 1.3 & 45 & 45 & 150 & 50 & 45 & 201.3 \\
\hline $37-28-8-12$ & & E2848833/N6144370 & 7.8 & 7 & 0.9 & 38 & 38 & 172 & 38 & 46 & 49.1 \\
\hline $38-4-9-13$ & W & E1938699/N5582492 & 22.6 & 17 & 0.65 & 26 & 35 & 212 & 7.2 & 9 & 249.7 \\
\hline $39-4-9-13$ & & E1938634/N5582417 & 12.5 & 15 & 0.8 & 22 & 34 & 203 & 118 & 100 & 150 \\
\hline $40-24-8-14$ & 140SE & E1939555/N5581279 & 16.5 & 22.7 & 2 & 28 & 35 & 70 & 9.8 & 8.4 & 749.1 \\
\hline $41-24-8-14$ & 144SE & E1675074/N5332397 & 21 & 30 & 3.3 & 28 & 48 & 75 & 9.4 & 10.4 & 2079 \\
\hline $42-24-8-14$ & & E1939966/N5581422 & 20 & 65 & 2.8 & 34 & 36 & 79 & 4.4 & & 3640 \\
\hline $43-24-8-14$ & & E1939939/N5581450 & 10.4 & 12 & 2.6 & 29 & 42 & 88 & 11.4 & 8.7 & 324.5 \\
\hline $44-24-8-14$ & 150SE & E1939921/N5581470 & 7.7 & 10 & 0.9 & 25 & 35 & 90 & 8.6 & 12.8 & 69.3 \\
\hline $45-24-8-14$ & & E1939925/N5581435 & 5 & 24 & 1.8 & 28 & 35 & 71 & 9.2 & 12.3 & 216 \\
\hline $46-25-8-14$ & & E1939947/N5581569 & 27.5 & 6.2 & 0.7 & 27 & 32 & 106 & 10.8 & 15 & 119.4 \\
\hline $47-25-8-14$ & 263SW & E1939981/N5581523 & 17 & 25 & 1.8 & 21 & 35 & 124 & 10.8 & 12.8 & 765 \\
\hline $48-25-8-14$ & $283 \mathrm{~W}$ & E1939970/N5581516 & 10 & 22 & 0.8 & 19 & 28 & 120 & 14 & 15.2 & 176 \\
\hline $49-25-8-14$ & 194SW & E1940016/N5581489 & 24 & 14 & 1.4 & 15 & 28 & 124 & 13.4 & 9.2 & 470.4 \\
\hline $50-13-11-16$ & $324 \mathrm{~W}$ & E1938466/N5582251 & 11 & 11 & 1.2 & 26 & 32 & 182 & 40 & 49 & 145.2 \\
\hline $51-13-11-16$ & & E1938338/N5582164 & 4.5 & 7.3 & 0.9 & 32 & 38 & 174 & 47 & 68 & 29.6 \\
\hline $52-13-11-16$ & $345 \mathrm{~W}$ & E1938358/N5582130 & 16 & 19 & 0.7 & 30 & 44 & 184 & 52 & 48 & 212.8 \\
\hline 53-13-11-16 & $344 W$ & E1938316/N5582137 & 16.7 & 21 & 0.9 & 35 & 39 & 174 & 79 & 81 & 315.6 \\
\hline \multirow[t]{2}{*}{$54-13-11-16$} & 287WN & E1938326/N5582? & 10 & 7 & 1.1 & 37 & 43 & 186 & 76 & 95 & 77 \\
\hline & & & & & & & & & & Total & \\
\hline & & & & & & & & & & & \\
\hline
\end{tabular}

Figure 4.2: GPS locations and on site information of 54 landslides

The organic A horizon on most measured slips showed a maximum thickness of $10 \mathrm{~cm}$ and in a few cases $8 \mathrm{~cm}$, and although the cohesive binding of the grass root system was sufficient to hold a greater area of the hillslopes together, it was the saturation and weaker cohesion that eventually caused collapse. The east coast from Gisborne south to the Wairarapa is known for its ability to slip and there are documented records by Brooks et al. (2002); Crozier et al. (1980); Lambert et al. (1984) discussing those events (Figure 4.3). 


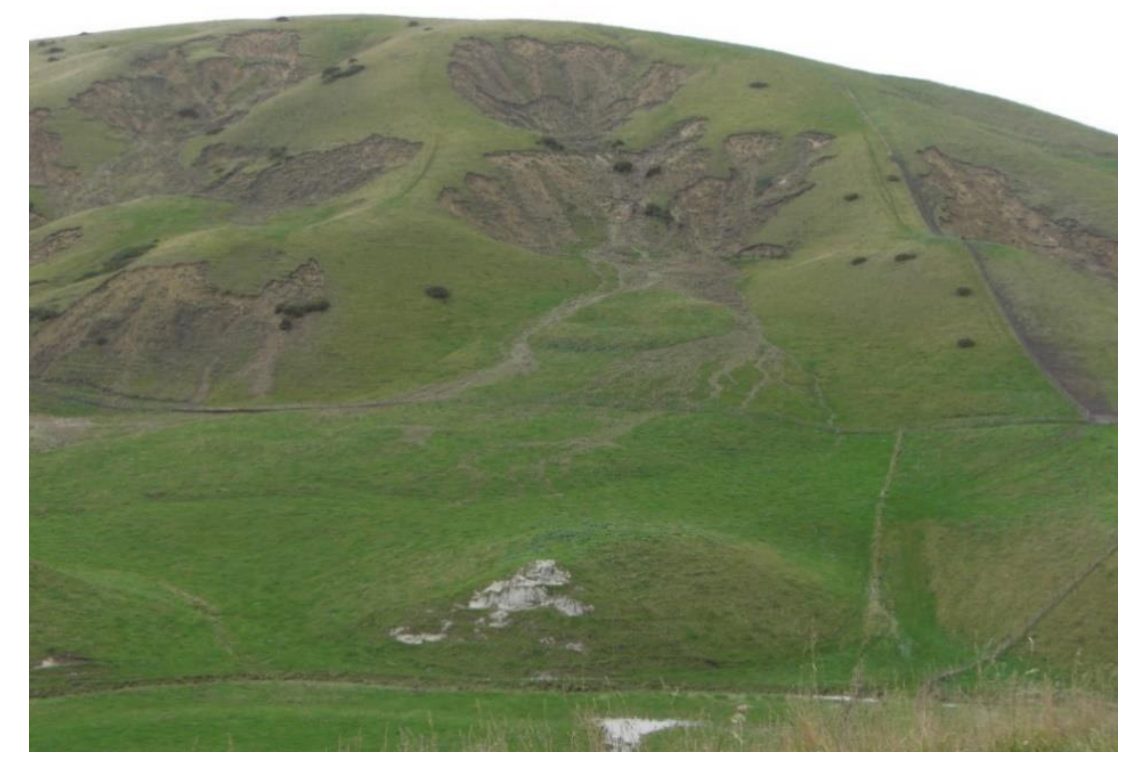

Figure 4.3: Landslides after the storm. McNeur photo

All slips were measured for length, width and depth. The slip measurements were taken with a $100 \mathrm{~m}$ cord with $5 \mathrm{~m}$ red and $10 \mathrm{~m}$ blue markings. At the head scarp on most slips the regolith depth measured 80-100 cm, while above many of the slips soil stress fractures were observed. To measure length, a peg was attached at slip top with cord attached and unravelled for tossing to the slip base, if a measurement came between the two markers, an expanding tape completed the measurement (Figure 4.4). Sediment runout was not recorded. The same process was used for width, and the height was taken from a taut cord across the deepest point and a sectioned $1.8 \mathrm{~m}$ dowel and expanding tape to record depth. A laser light tool was later used to record a more accurate width and depth.

Two or three core samples were collected from every slip; from the top of slip head scarp, organic, and lower horizons were exposed down to bedrock to be used for laboratory analysis. GPS position was taken, and slope and slip angles were measured using an Abney level attached to the $1.8 \mathrm{~m}$ x $25 \mathrm{~mm}$ diameter dowel (Figure 4.5). The core samples were removed using stainless steel core tubes $9.6 \mathrm{~cm} \times 5 \mathrm{~cm}$ Internal diameter $(\mathrm{Id})=188.5 \mathrm{~cm}^{3}$, these were hammered into the respective exposed horizons (Figure 4.6). All material was emptied into clear plastic lock tight bags, dated and numbered by slip, and horizon beds, $\mathrm{A}=$ top, $\mathrm{B}=$ centre and $\mathrm{C}=$ bottom. $\mathrm{A}$ day to day field diary was kept to record all details. 


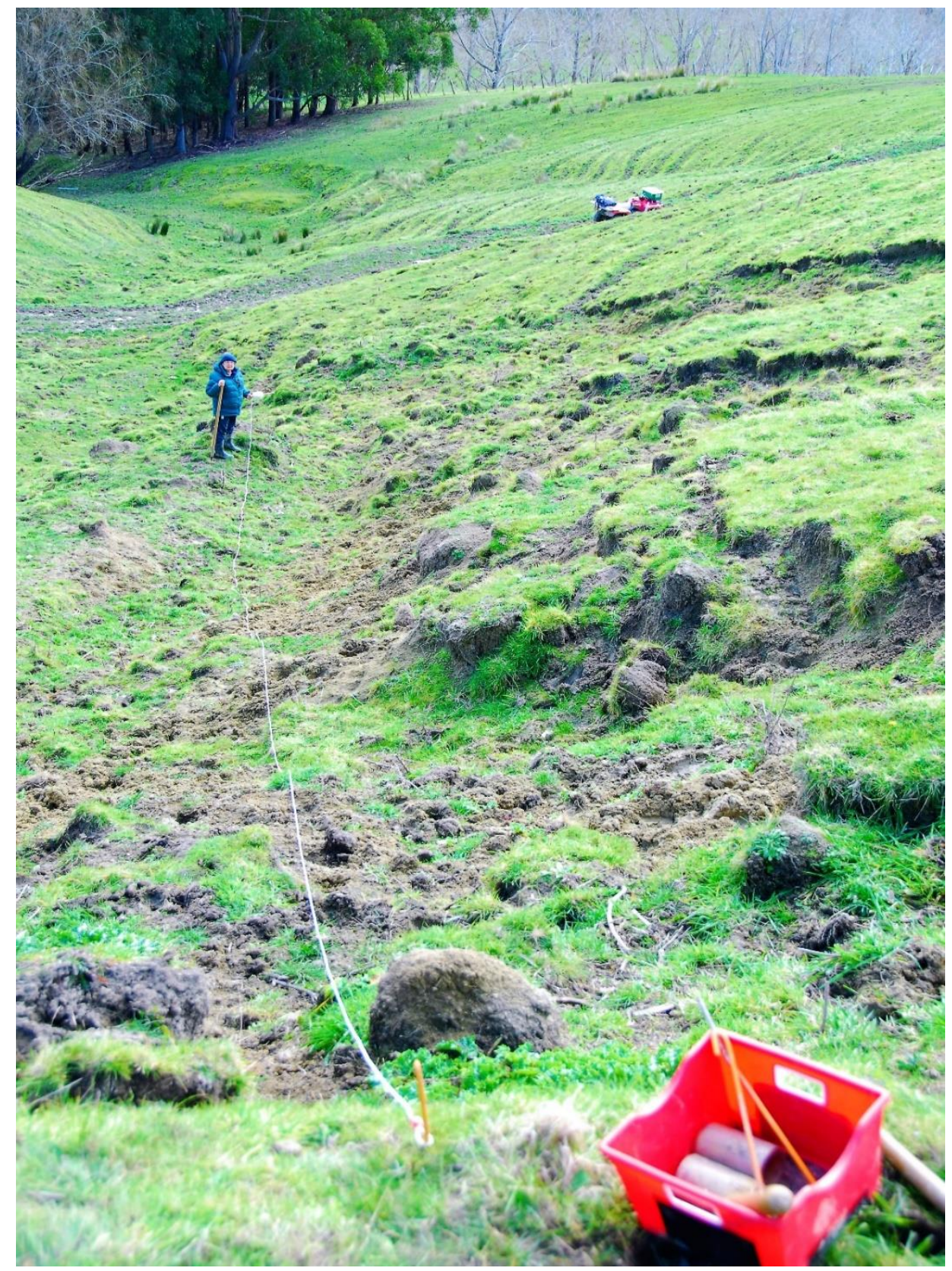

Figure 4.4: Rope and peg slip length measuring on McKay farm adjacent to McNeur farm 


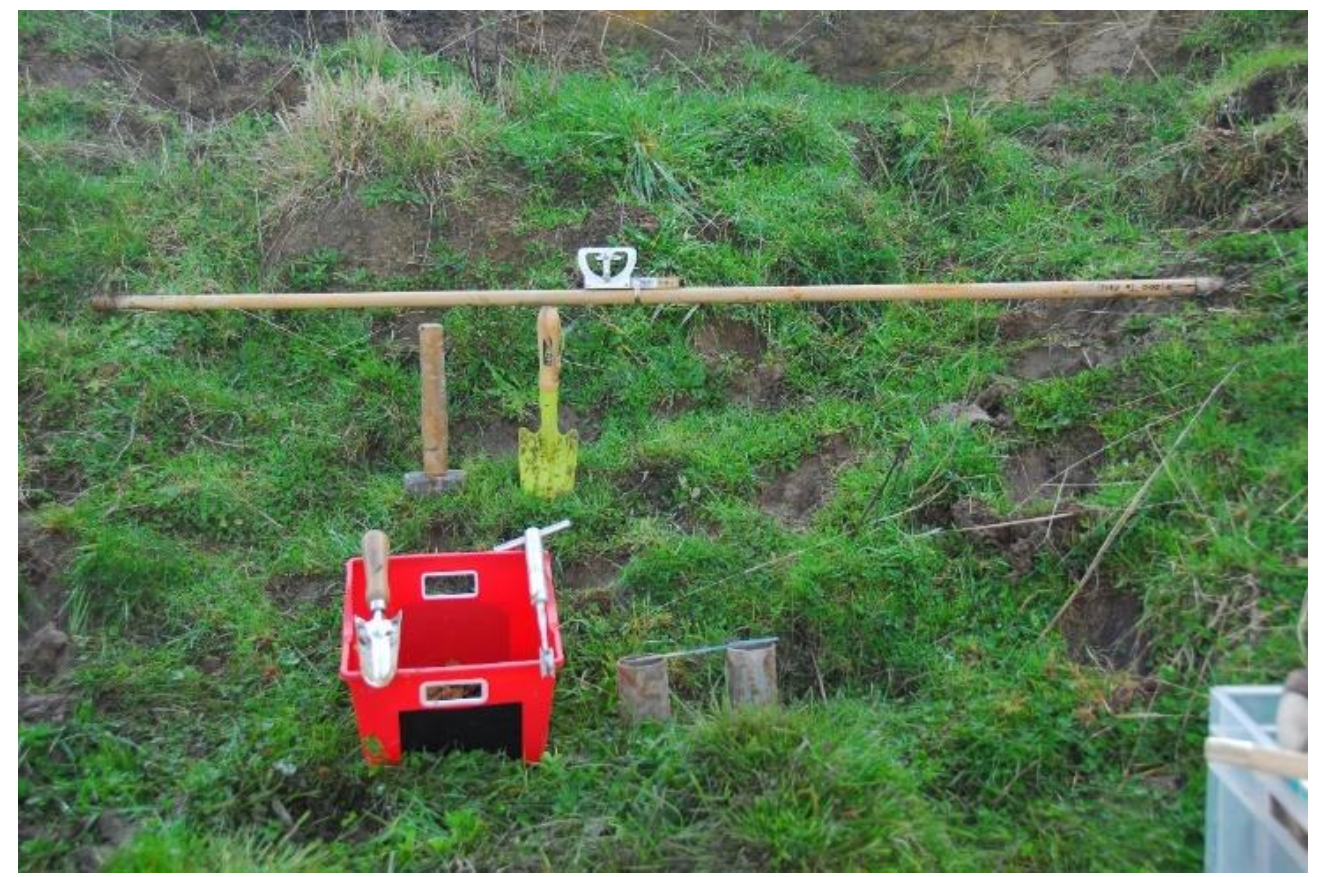

Figure 4.5: Tools used for obtaining regolith samples; Abney level on measuring rod, trowels, hammer, soil box, stainless steel cores, scraper, and soil sheer tester.

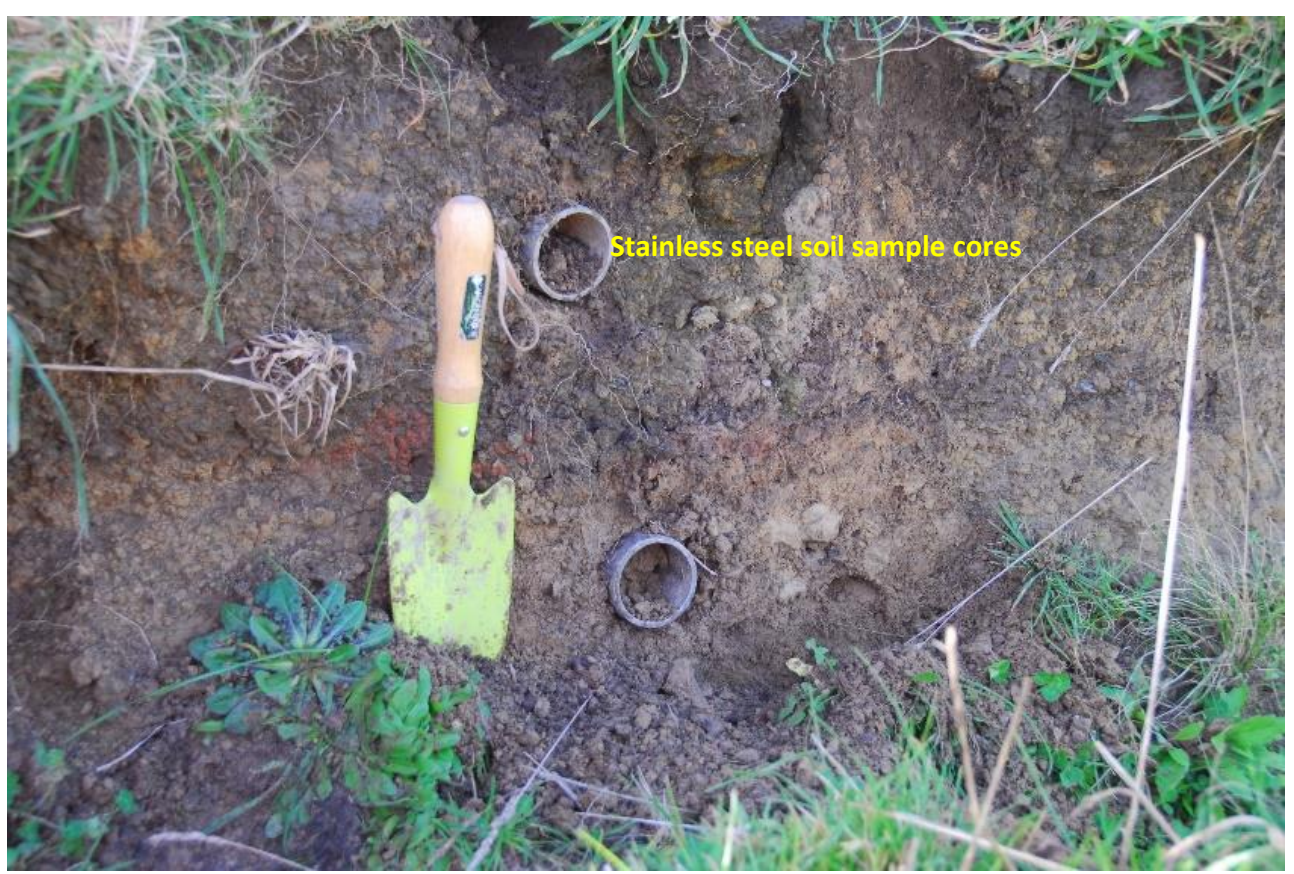

Figure 4.6: Collecting regolith samples with stainless steel cores 
(Figures 4.7 and 4.8) show the relative depths of slip face where samples were removed from regolith horizons. Measured units on ruler are $10 \mathrm{~cm}$ up to top $1 \mathrm{~m}$.

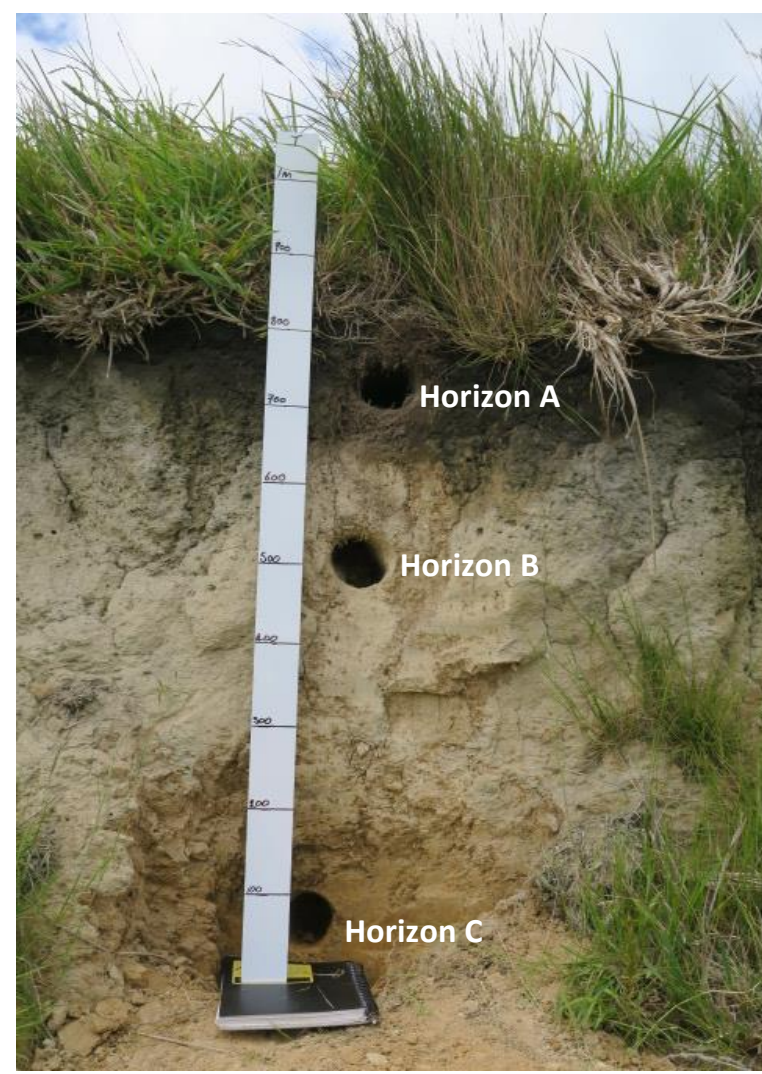

Figure 4.7: Slip head scarp measuring, $8 \mathrm{~cm}$ to grass line

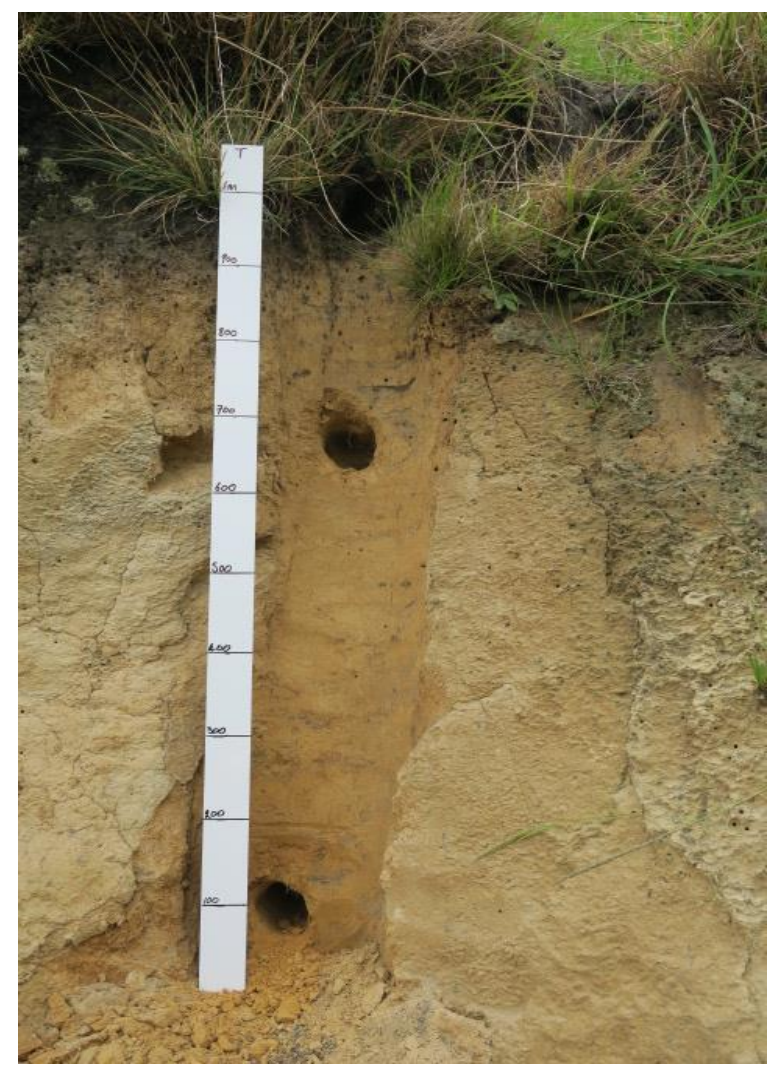

Figure 4.8: $1 \mathrm{~m}$ to grass line. Note levels of horizons 
(Figure 4.9) shows the locations of numbered slips in relation to each group with GPS flags, Figure 4.1 page 66 shows the area that these groups were taken from.

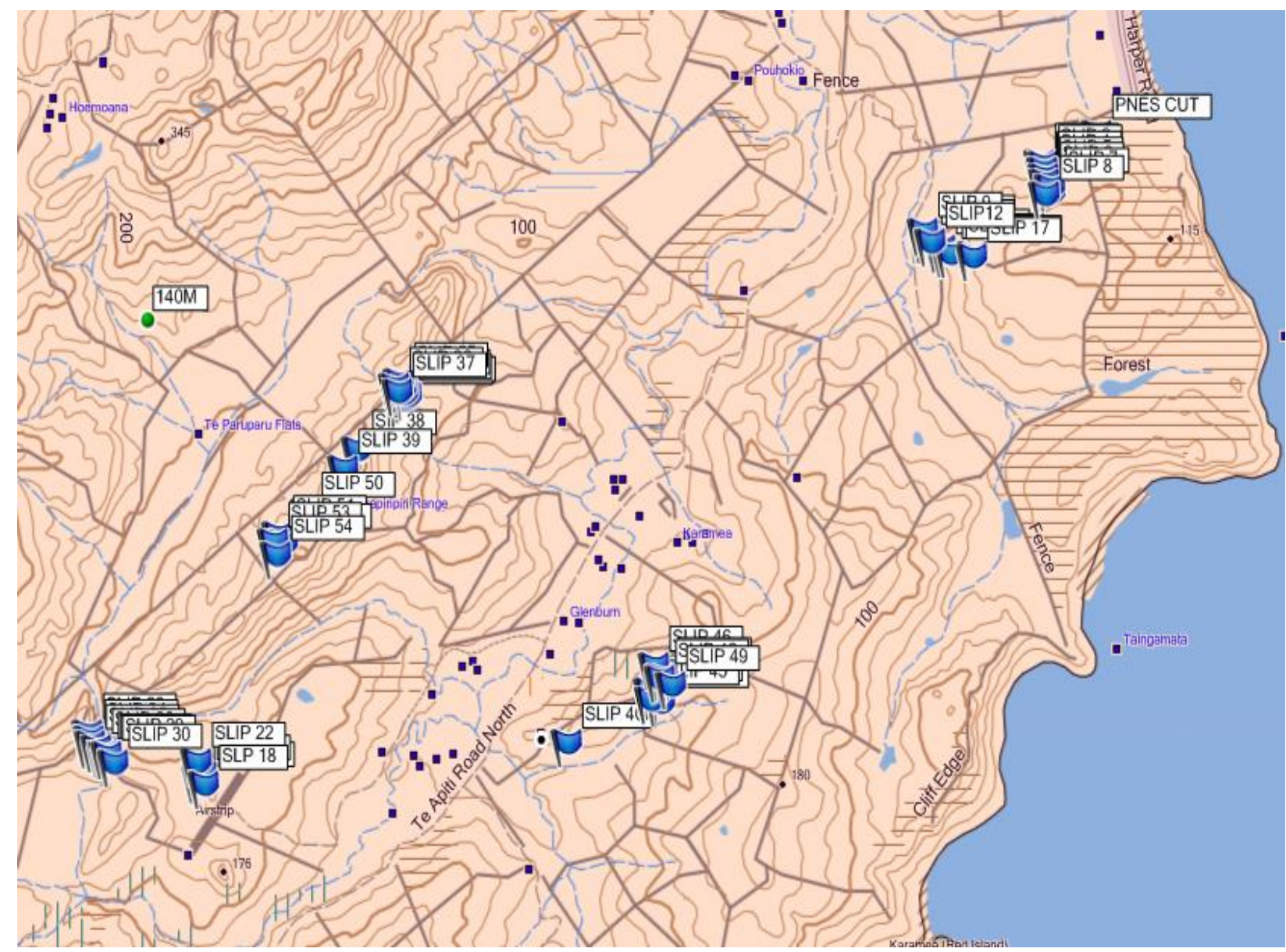

Figure 4.9: Clusters of fixed GPS slip sites in relation to Te Apiti Road North, Waimarama

Clusters of between 5-8 slips were chosen from each slope or ridge, using the nine unit landsurface model (Figure 4.8) (Dalrymple et al., 1968). Twenty-five slips were recorded within the $26-35^{\circ}$ transportational midslope, four on the fall face at $37-45^{\circ}$ and 25 at the colluvial footslope ranging from $13-25^{\circ}$. (Figure 4.10 ). 


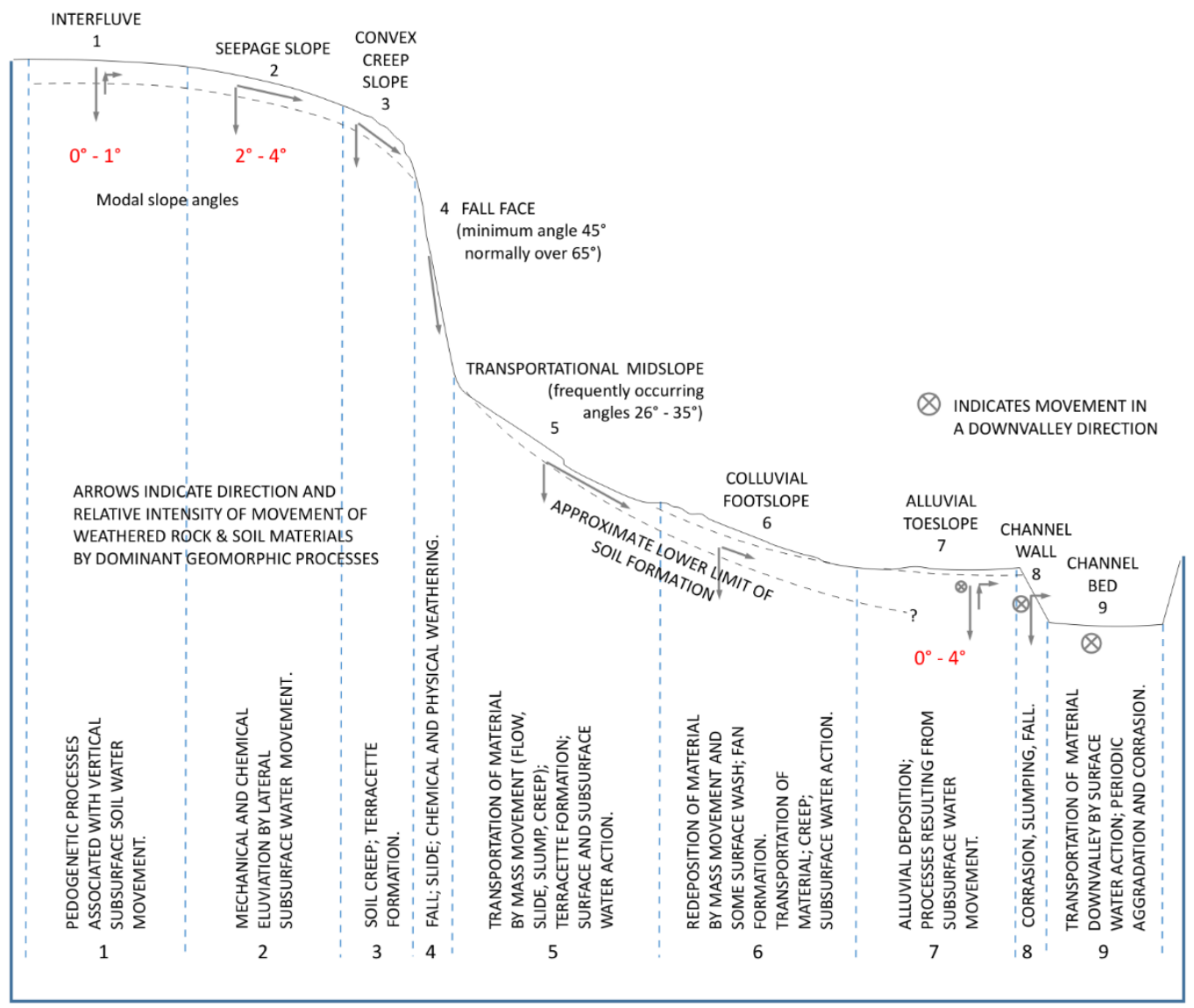

Figure 4.10: The hypothetical nine-unit land surface model. (After Dalrymple et al. 1968)

While on site the day after the Kaikoura earthquake of 14/11/16, at a location which the day before had been a relatively flat paddock, a dome of approximately $1.5 \mathrm{~m}$ height and approximately $15 \mathrm{~m}$ diameter, had been uplifted during the night (Figure 4.11). A large fissure had opened up running across the dome top from side to side with smaller fissures starred out from the main one (Figure 4.12). One side of the dome had subsided $50 \mathrm{~cm}$, while the fissure had a measured depth of $1.5 \mathrm{~m}$, and below, a further depth was unable to be recorded (Figure 4.13). 


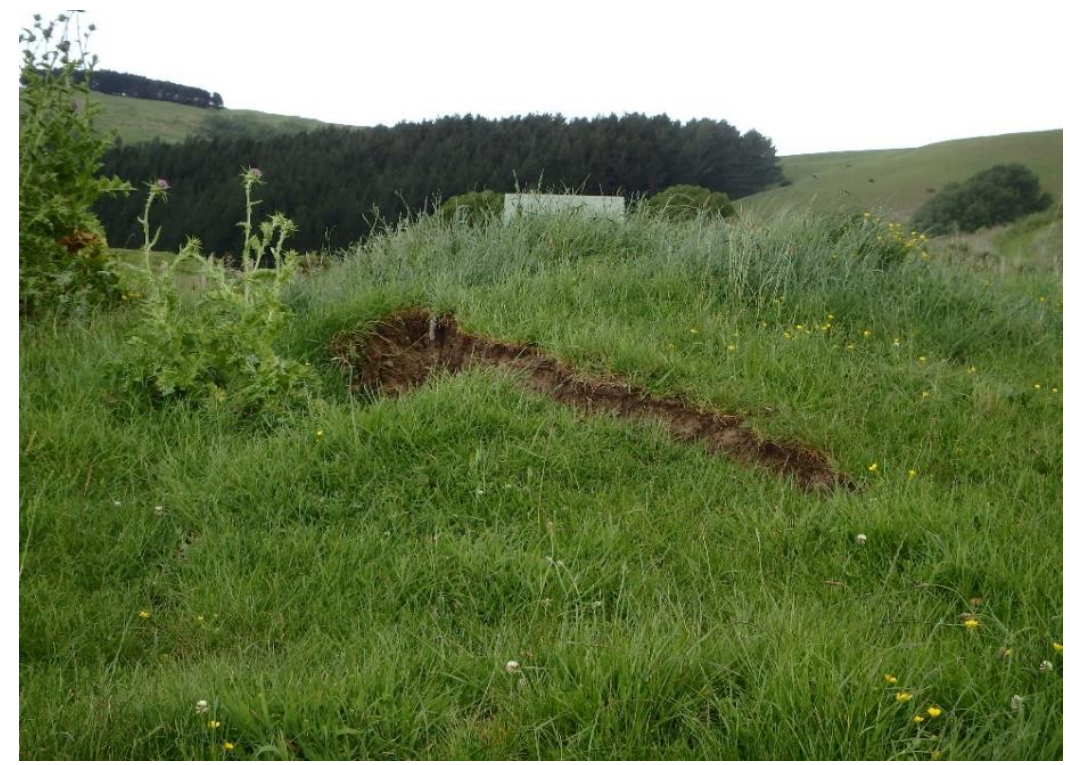

Figure 4.11: This dome appeared after Kaikoura Mw7.8 earthquake 14-11-16

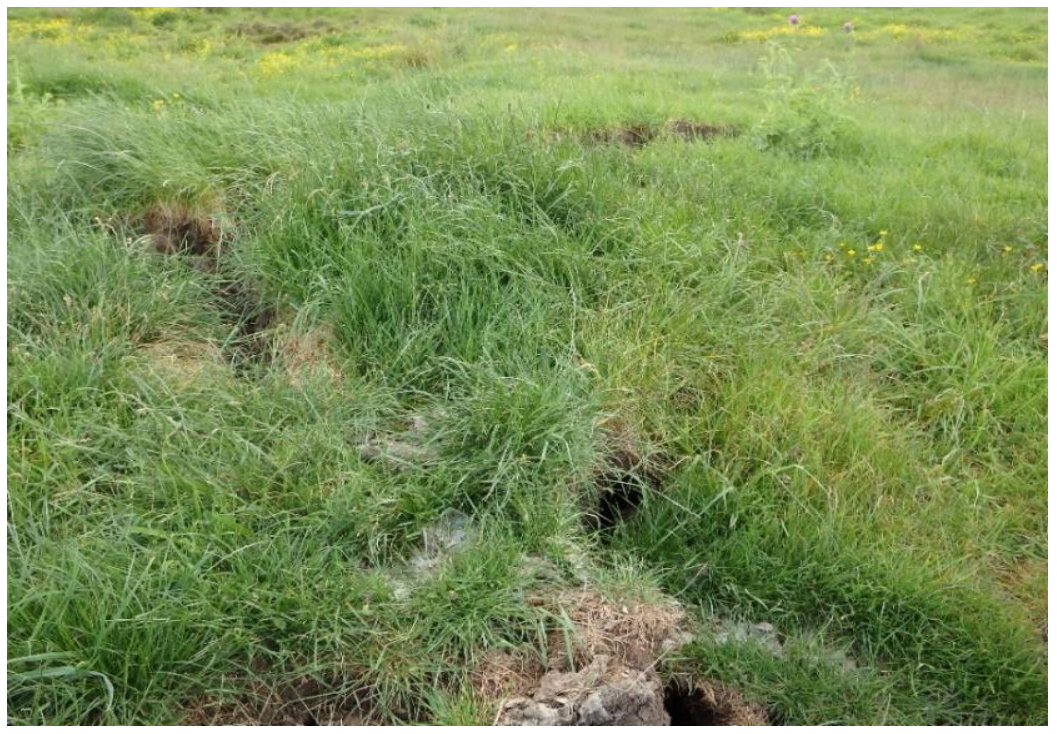

Figure 4.12: Large fissure appeared after Kaikoura earthquake November 14, 2016. Photo K McNeur

The width of the fissure was $60 \mathrm{~cm}$ at its widest and approximately $50 \mathrm{~m}$ long. Small bentonite mud volcanoes were also associated with the Kaikoura earthquake. Farm manager K McNeur reported that these mud volcanoes showed activity after earthquake tremors (Figure 4.14) and as recorded by Pettinga, (1982, p180-181). These small units have a tendency to activate after earthquakes. 


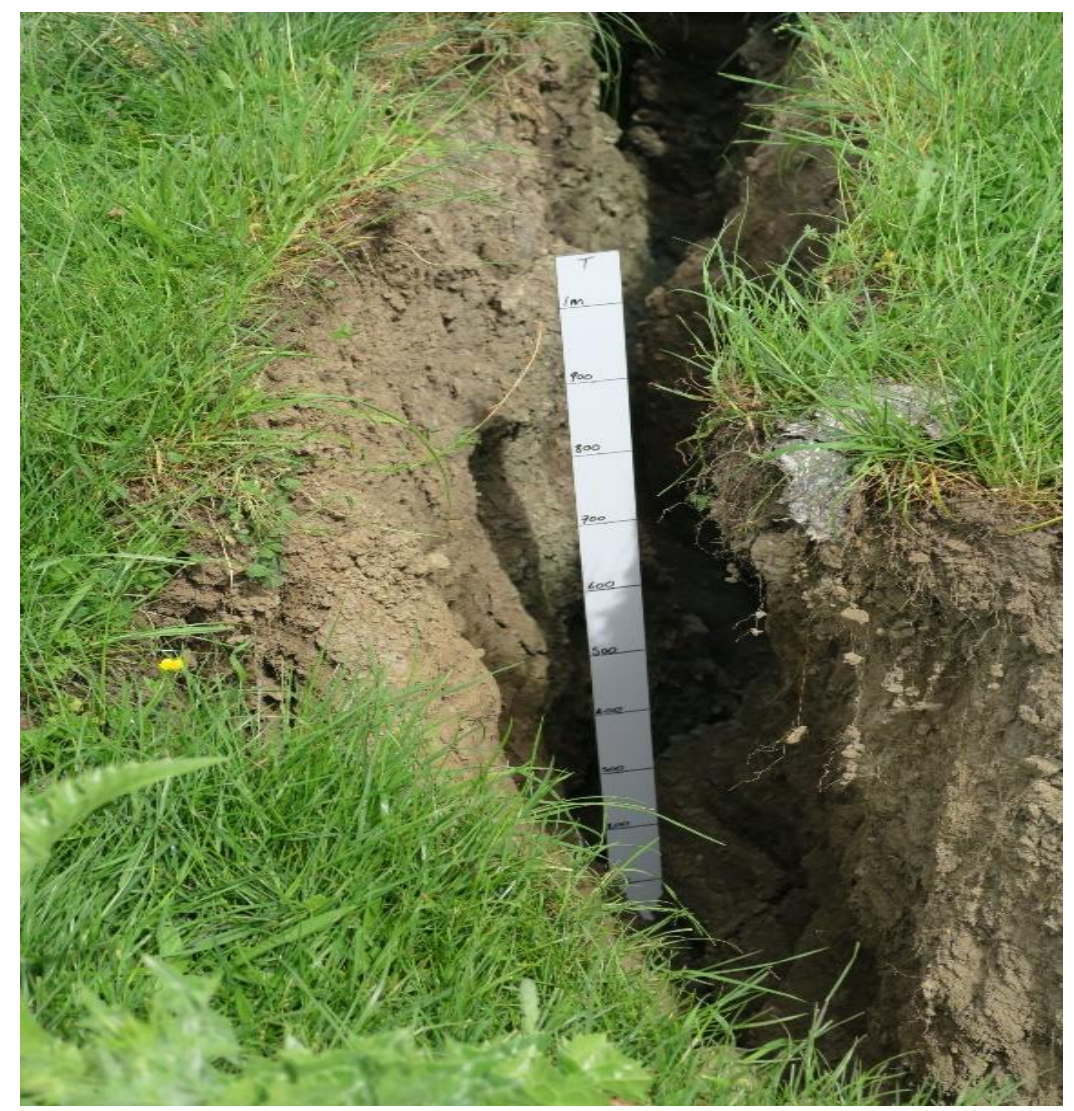

Figure 4.13: Depth over 1m in earthquake fissure

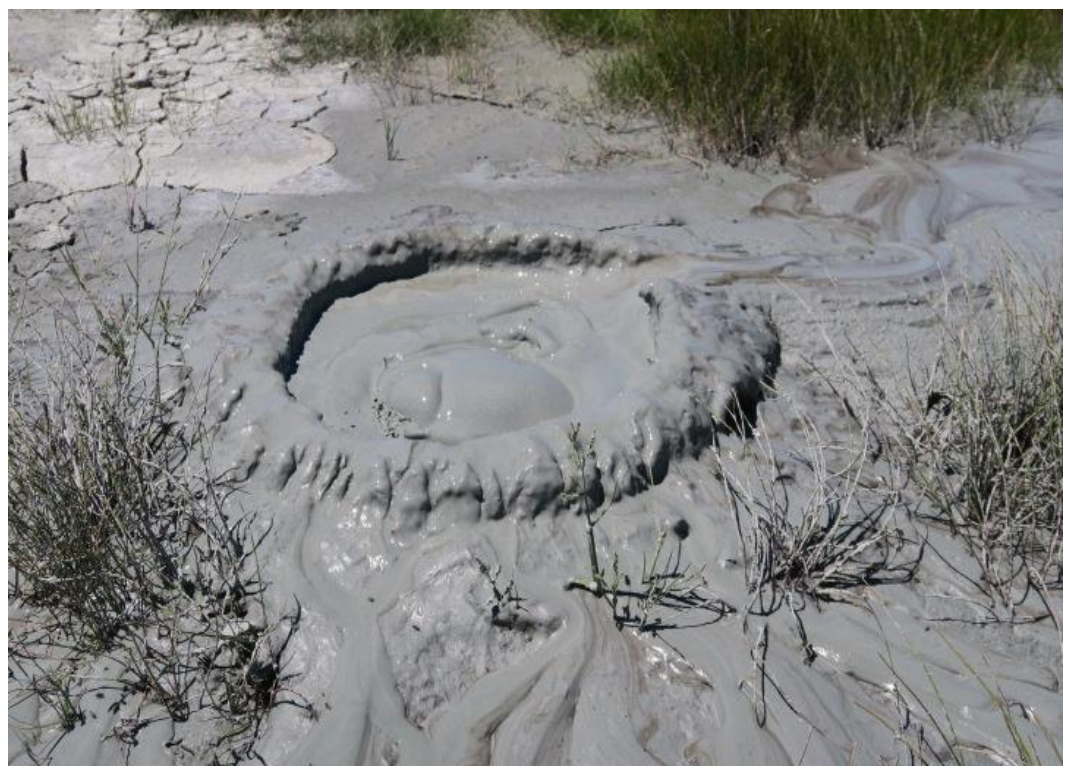

Figure 4.14: This small erupting bentonite mud volcano appeared in a paddock after the November 14, 2016, 7.8 Kaikoura earthquake on the Puhokio study farm. 


\section{2: Laboratory Analysis:}

The first visual investigative visit took place in November 2011, and working field trips began on $24-28 / 8 / 2012 ; 1-9 / 4 / 2013 ; 24-25 / 8 / 2014 ; 13-17 / 11 / 2016 ; 27 / 1 / 18$. There were also days taken up interviewing residents with the questionnaire.

\section{Soil and water lab VUW}

A total of 54 sample plots were inspected. An average of three samples were taken per slip, with an average weight per bag of 350-400g. Soil from each bag was removed for various experiments. It was necessary to remove all organic and other non-soil matter from each of the sample horizons as they could impede the descent of the penetrometer weight thereby giving a false reading.

Utensils used for this task were potato mashers, mortar and pestle, and sieves. Once broken down weighed samples were removed for each of three main experiments. Altogether, over 3500 individual measurements were made.

The three geotechnical elements of this research are Plastic Limit, Liquid Limit and Plasticity. Plastic limit is the minimum water content that a soil can be deformed without rupture, and below which soils no longer behave as plastic materials. Liquid limit is the water content above which the soil behaves as a viscous liquid (no measureable strength). The Plasticity index is the range of water content when a soil is in a plastic state (liquid limit minus plastic limit). Cohesion reaches a maximum slightly above the plastic limit (Baver et al., 1972). Cohesionless soils essentially have zero plasticity indices. A thickening of water forms a film around individual particles of cohesive soils, while the moisture content within the plastic range, results in reducing shear resistance. It has been shown by Rogers and Selby (1980) that the cohesion component of two landslide soils (clay and silty clay textures) decreased $18 \%$ and $70 \%$ respectively following saturation (Sidle and Ochai, 2006).

Liquid Limit Determination (Cone penetrometer); Plastic Limit Determination; Soil Moisture Density

A cone penetrometer to determine specific gravity, plastic limit determination, and soil moisture density were selected to analyse if there was any consistency between the soil moisture content from each of the measured slips (54) and to determine if there was any change of soil moisture between the eight selected sites. Although all sites were measured for length, width, depth and GPS location, not all slips had soil samples collected. The reasoning was that if the slips were 
within a few metres $(10-15 \mathrm{~m})$ of each other and in the same aspect it was very likely that the soil would be of the same lithology. Where the soil horizons were indistinct only the top two horizons were sampled, A and B. A water spray was used to identify some horizons by colouration and texture change. At slip 34 there were two recorded organic levels (Figure 4.15) which indicated a past history of slope movement.

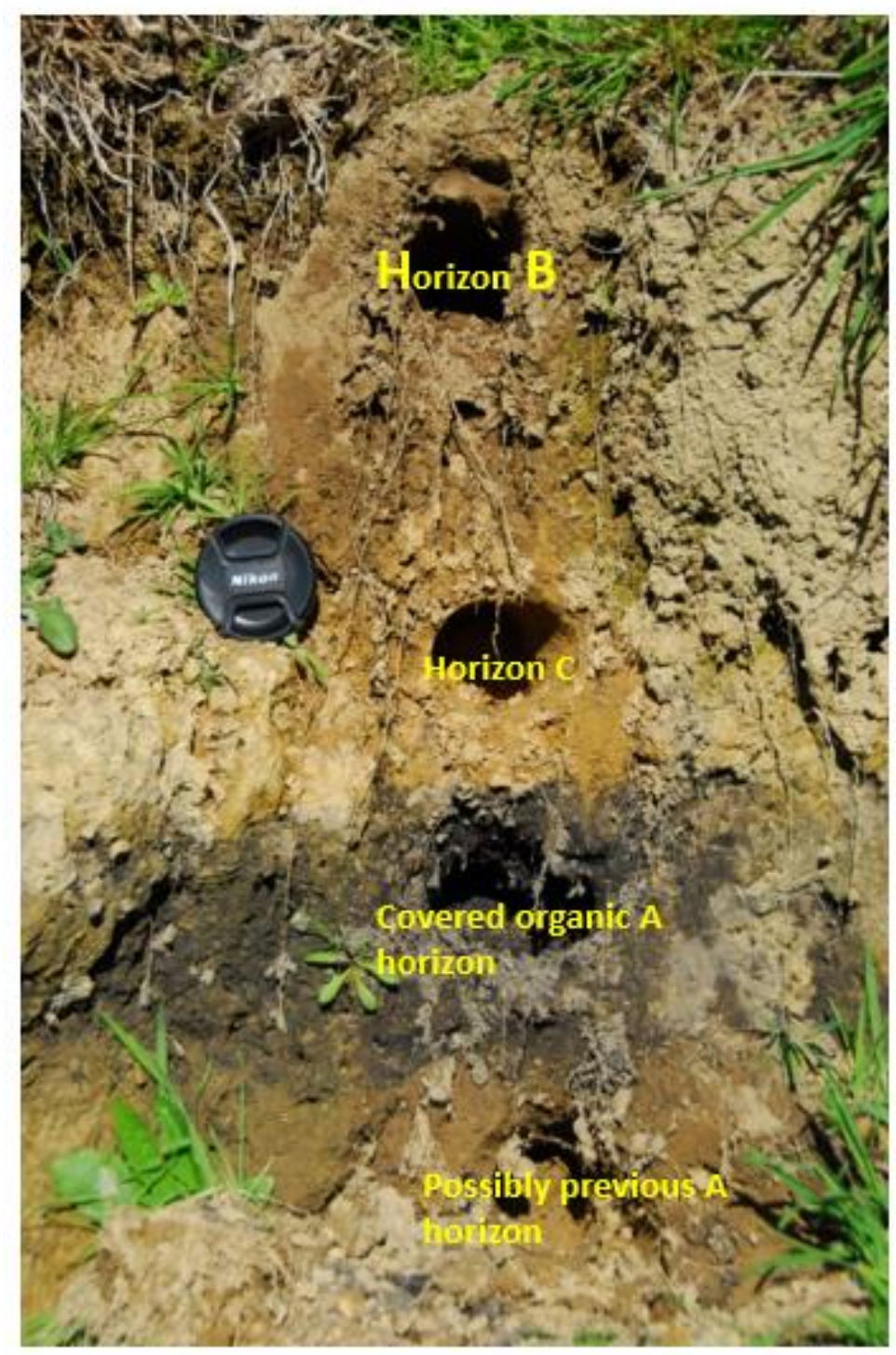

Figure 4.15: Slip shows a result of an older landslide by a buried organic layer below two distinct horizons

The marine bedrock of mudstone/siltstone at the base of each slip head scarp after exposure and weathering showed excessive friability (Figure 4.16 and Figure 4.17) that may eventually continue downslope. As all landslides showed a similar pattern of collapse, it was decided to test for soil moisture content. The test results may be able to show the precipitation level that was required to cause loss of cohesion before regolith failure. 


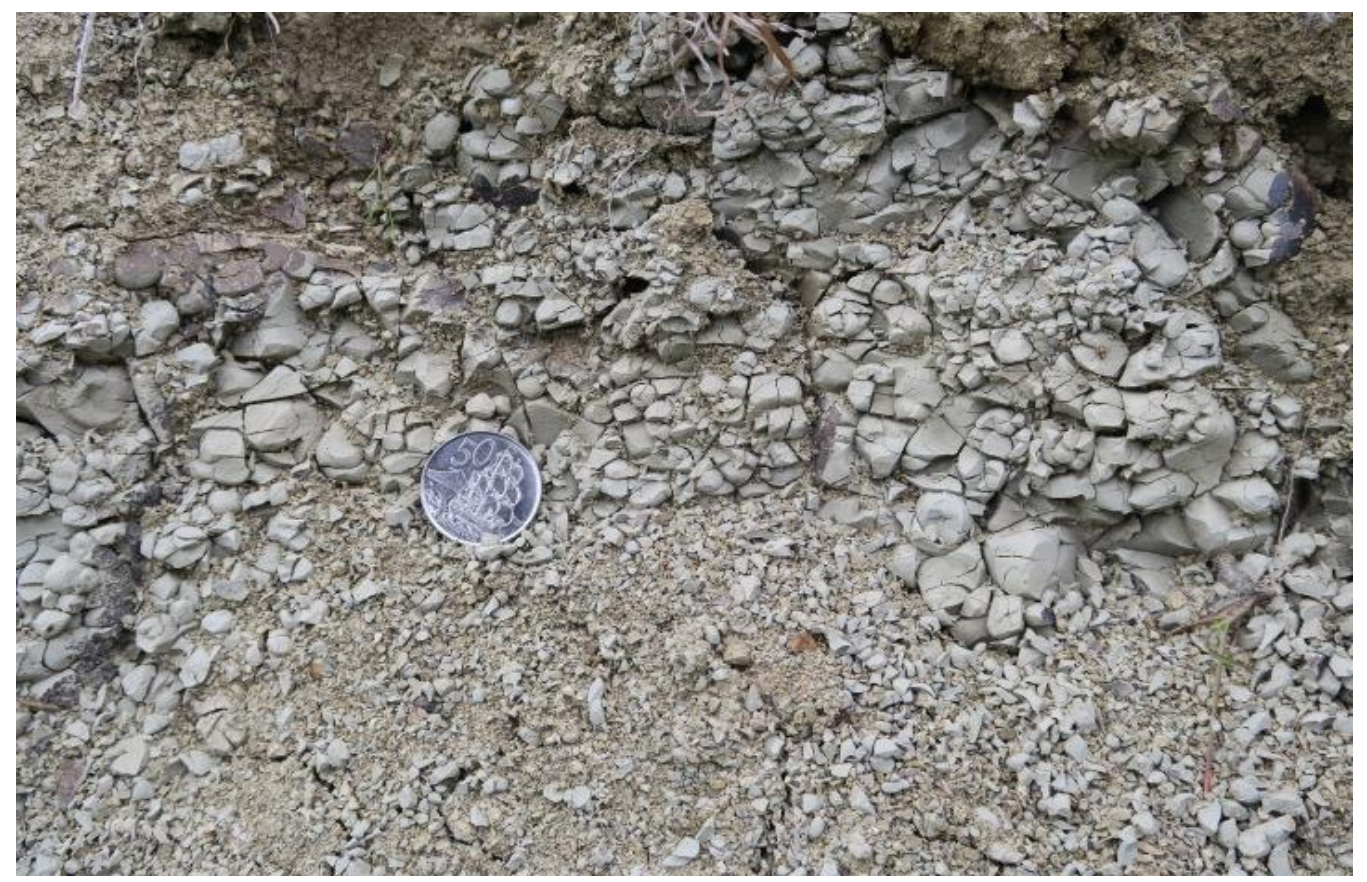

Figure 4.16: Weathering breakdown of marine bedrock

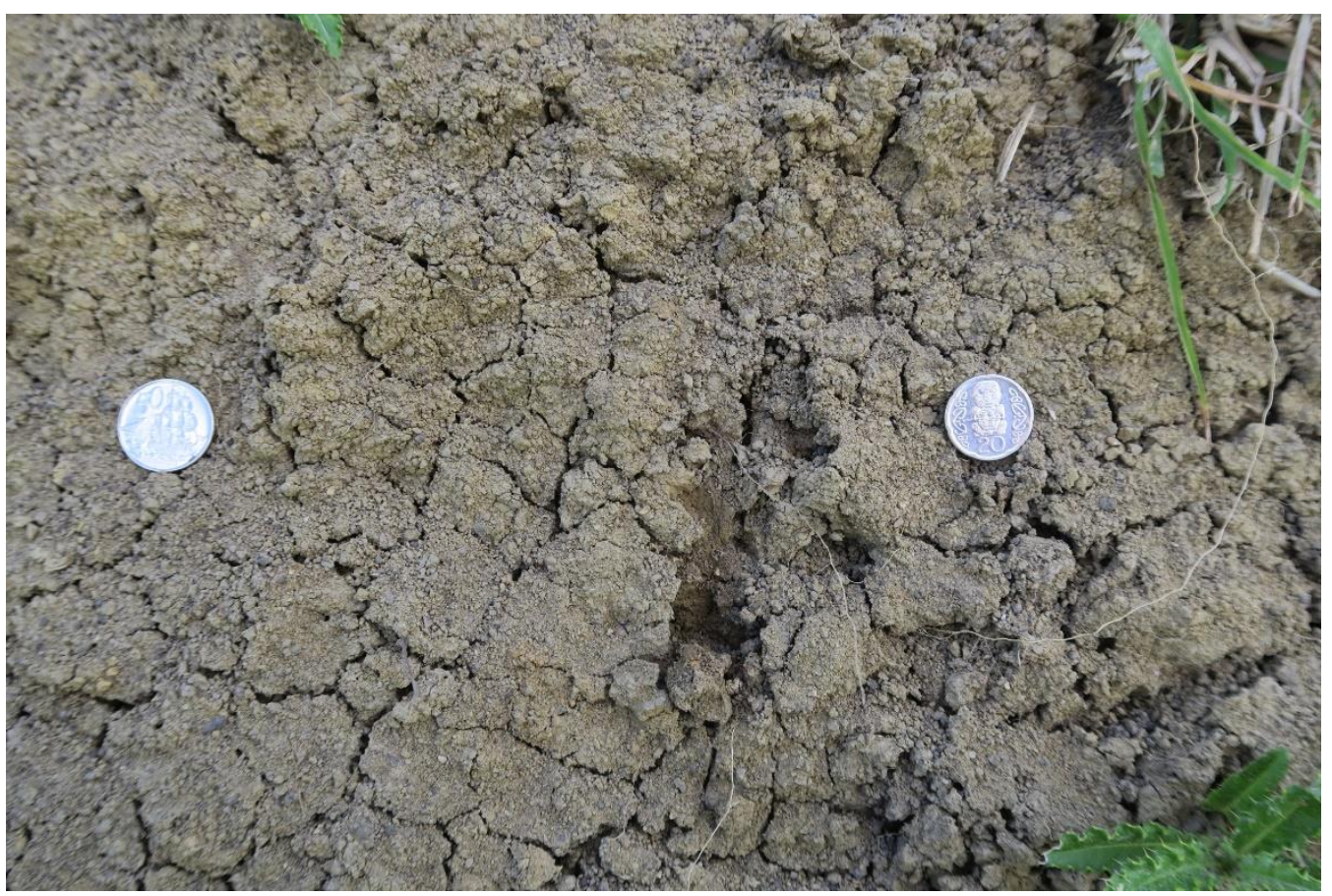

Figure 4.17 Fine friable regolith 


\section{Cone Penetrometer tests: NZ Standards NZS 4402:1986 Test 2.5}

This laboratory research used a newly acquired cone penetrometer, manufactured by Controls S.r.l.; made in Italy, model number 22-T0029/AD, semi-automatic digital liquid limit penetrometer with micrometric vertical adjustment. $230 \mathrm{~V}, 50-60 \mathrm{~Hz}, 1 \mathrm{~F}$. Electronically timed at 5 seconds for cone penetration drop (Figure 4.18).

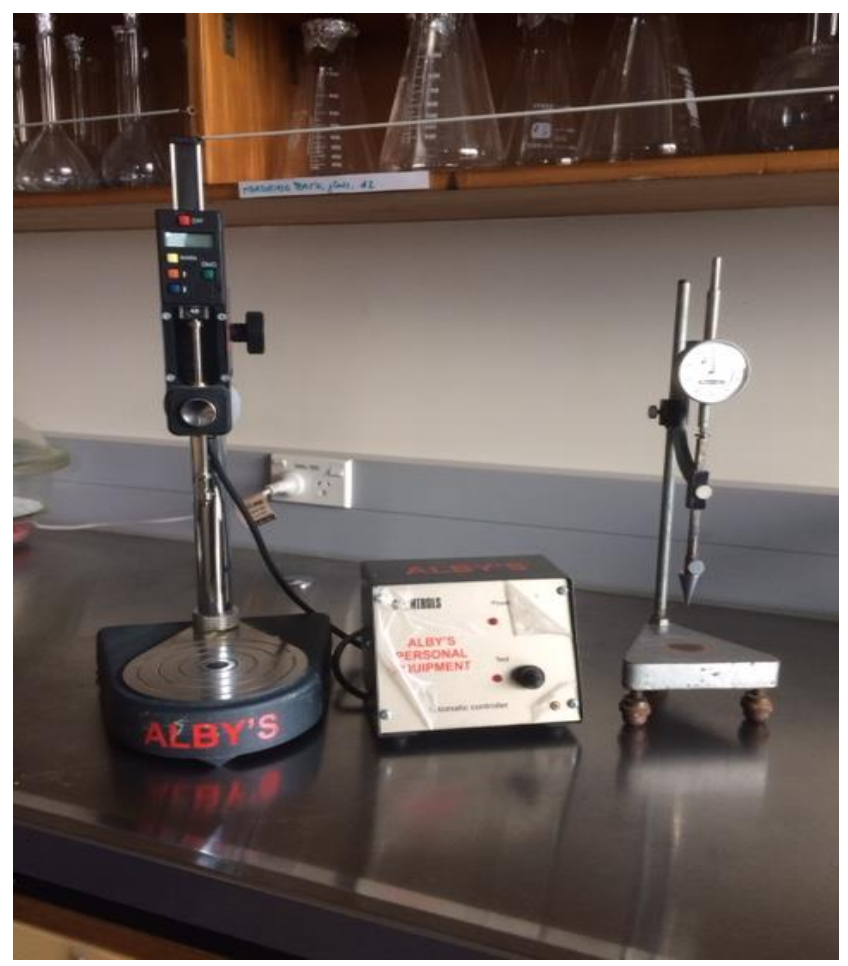

Figure 4.18: New cone penetrometer (left) alongside practice penetrometer (right)

The first part of this CP test is to mix approximately $250-300 \mathrm{~g}$ of soil with distilled water into smooth soft paste. The sample is then left overnight to allow moisture content to equilibrate through the sample.

Slip one, organic (A) and (B) horizons

Four tests were run for each of the horizon samples with approximately 2-3 hours between each test and up to 12 hours between the first and last test. The time lapse was to allow moisture to evaporate in order to record contrasting readings and to determine soil moisture retention. From each of four readings when a combination of 2 or 3, 5 second timed drops of the penetrometer cone records $0.5 \mathrm{~mm}$ or less an approximate $10 \mathrm{~g}$ soil sample is removed, and placed in a glass pre-weighed beaker, the total weight is recorded as wet matter. The beaker is placed in an oven at $105^{\circ}$ for 24 hours, cooled in a desiccator then reweighed to record the dry weight - the final calculation is the amount of moisture removed from the $10 \mathrm{~g}$ sample. 
As this test was taken four times from each original sample there was only enough lab apparatus to trial three complete slip units at a time. Three units per slip x $3 \times 4$ samples $=36$ samples over 24 hours, at the same time as obtaining further information from these samples from plastic limit determination and soil moisture density (Figure 4.19) sample result.

Liquid limit is determined from the plot of the relationship between water content.

Water content $\%$ is calculated as $=100 *((\mathrm{~m} 2-\mathrm{m} 3) /(\mathrm{m} 3-\mathrm{m} 1))$

Where:

$\mathrm{m} 1=$ container $(\mathrm{g})$

$\mathrm{m} 2=$ container and wet soil $(\mathrm{g})$

$\mathrm{m} 3=$ container and dry soil $(\mathrm{g})$

$\mathrm{m} 2-\mathrm{m} 3=$ mass of water $(\mathrm{g})$

$\mathrm{m} 3-\mathrm{m} 1=$ mass of dry soil $(\mathrm{g})$

The liquid limit is determined from extrapolation or interpolation and is the \% water content corresponding to a penetration depth of $20 \mathrm{~mm}$

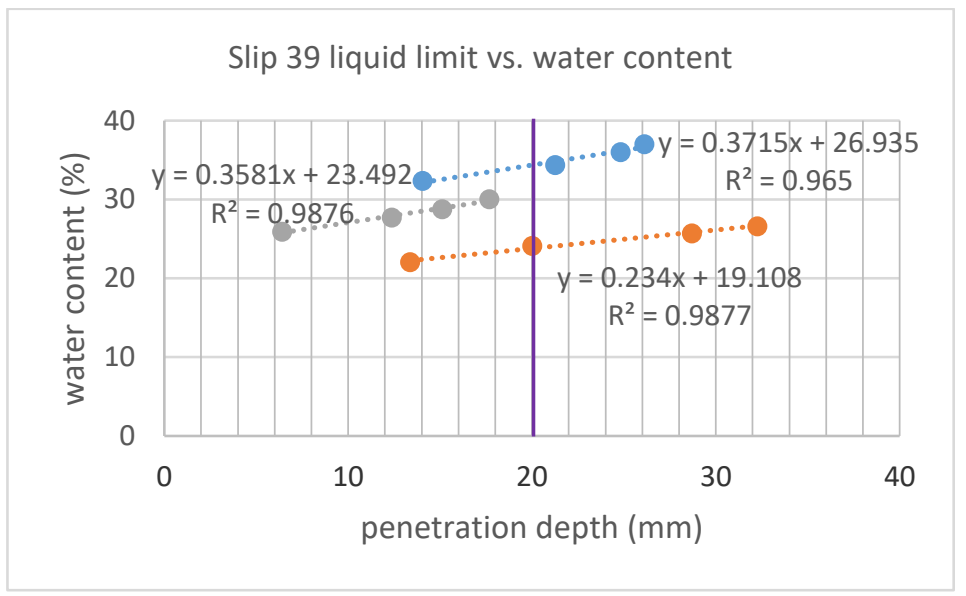

Figure 4.19: Liquid limit determination sample

\section{Plastic Limit Determination: NZ Standards NZS 4402:1986 Test 2.3}

This test covered every slip in each of the 8 locations marked on map 4.1 page 67 . A $30 \mathrm{~g}$ (approx.) sample is crushed to fine grains, the organic material is removed by tweezer, and small amounts of water added till the soil is easily moulded between hands forming a ball until signs of slight cracks appear, the sample is then split into half. Each half is again reduced to four separate samples. Each sample is rolled out on a flat surface forming a worm or spaghetti strand 
to approximately $3 \mathrm{~mm}$ diameter, then rolled back into a ball and repeated until the unit crumbles (Figure 4.20).

When the soil has crumbled it is placed in a pre-weighed beaker until the first half of 4 samples has been completed, a lid placed over the beaker reduces evaporation prior to weighing. Weight of beaker and moist soil is recorded then left on tray until all samples have been finished for that session, and placed in oven for 24 hours at $105^{\circ}$. Dry weight is measured following cooling.

The water content at the plastic limit is calculated as $=100 *((\mathrm{~m} 2-\mathrm{m} 3) /(\mathrm{m} 3-\mathrm{m} 1))$

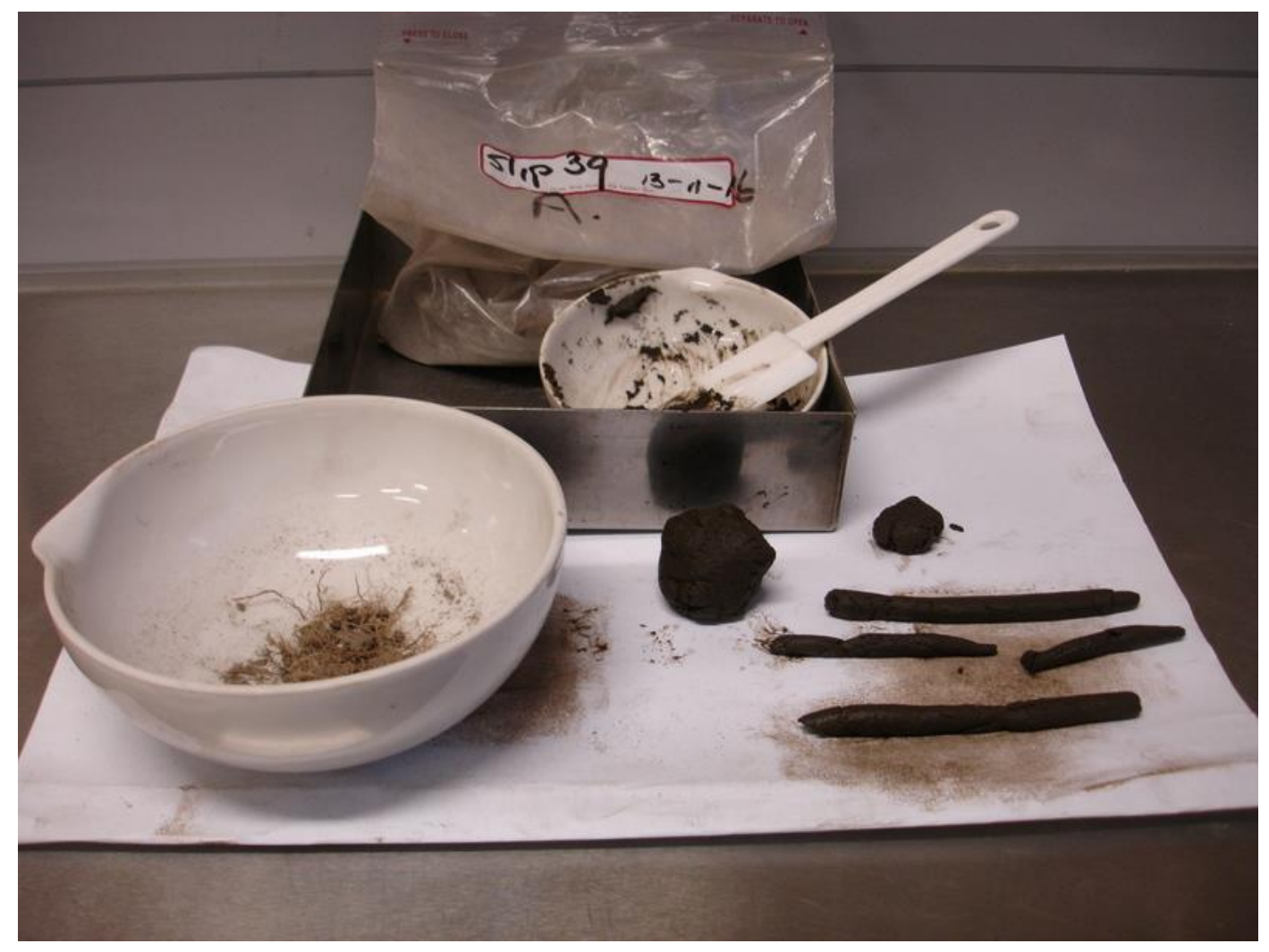

Figure 4.20: Plastic Limit with organics removed, 30g soil in two halves, one half rolled out, one half to do

\section{Soil Moisture Density: NZ Standards NZS 4402: 1986 Tests 2.1 and 5.1.3}

From the mixed soil samples retained after Penetrometer testing the moist soil is placed in a core tube. For this experiment 6 cores were manufactured from stainless steel tube. They were machined to the same length; $6 \mathrm{~cm} \times 3.1 \mathrm{~cm} \mathrm{Id},=45.29 \mathrm{~cm}^{3}$. Each core is identified with the slip and soil unit number, placed upright on a steel tray - weighed wet, oven dried for 24 hours, cooled then weighed dry. The core sample is removed, from the core tube and tray cleaned then re-weighed empty, leaving the final moisture content to be entered for analysis (Figure 4.21). 
The results from this experiment were used to define the soil moisture water percent content only. Although the soil was broken down with distilled water it is the same sample texture as used in the liquid limit and penetrometer tests. Bulk density was not calculated for this experiment.

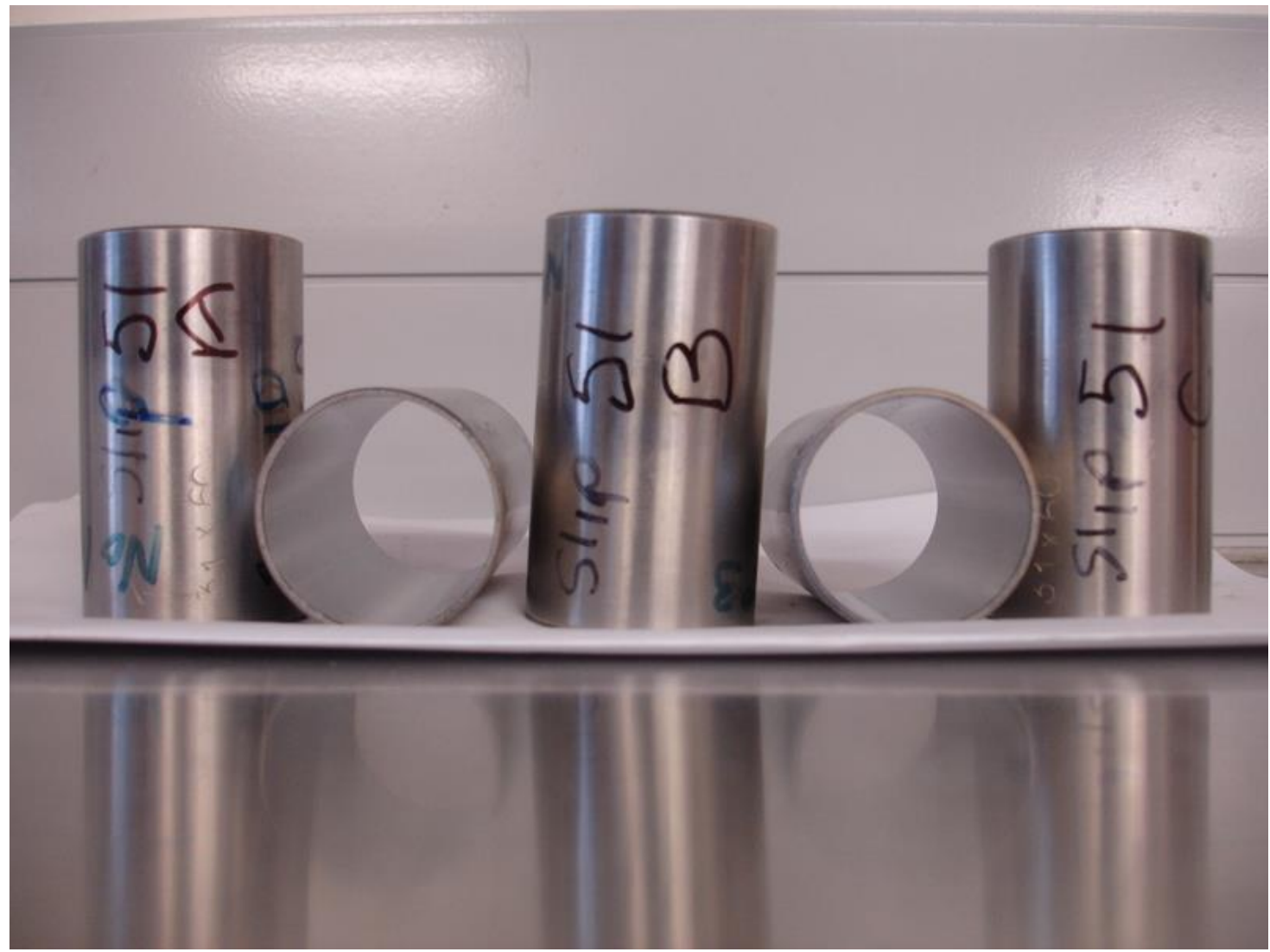

Figure 4.21: Core tubes used for soil moisture density. 


\section{Chapter 5: Results -}

\section{Physical attributes of Waimarama Landslides}

\section{1: Slip characteristics:}

To expand the number of studied slips, all definable slip outlines were traced in Google Earth imagery within the study area. A boundary line was extended beyond the area of measured slips (Google Earth), to include a greater number of unmeasured slips for comparison with those site measured. The intention was to provide a wider digital view of aspect, slope, elevation and curvature of the slips within the Waimarama Valley. These slip units were then used as a base for preparing a Google Earth map location of all slips and then converted to a shapefile, which included slips visible pre-storm event on 22/2/07, figure 5.1. Polygons were drawn around these slips with identification coloured flags numbered, slip 1-28; research slips measured on site were numbered m1-m54, (measured) and polygon slips drawn after April 2011 storm were numbered um1-um570 (unmeasured) on Google Earth images from 24-11-2012 and 13-11-2016. A total of 653 slips were measured.

The unmeasured (um) post-storm polygon slip areas were calculated in ArcGIS and compared with ground measured slips to ensure compatibility with the ground measurements. Figure 5.1 shows an aerial Google Earth view of total research area with pre-storm slips and (Figure 5.2) shows post storm and all marked slip sites. 


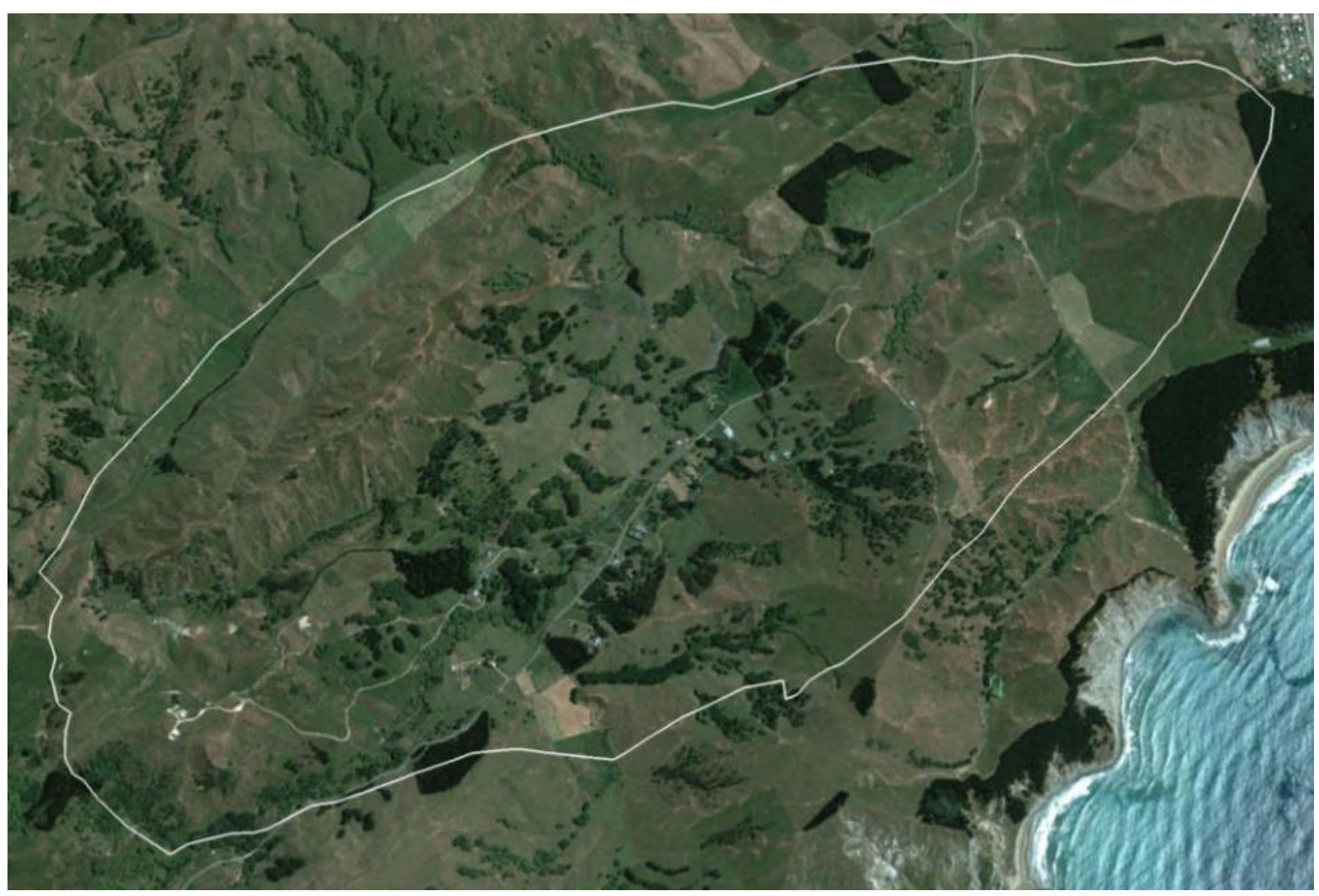

Figure 5.1: Pre storm Google Earth 13-1-2010 


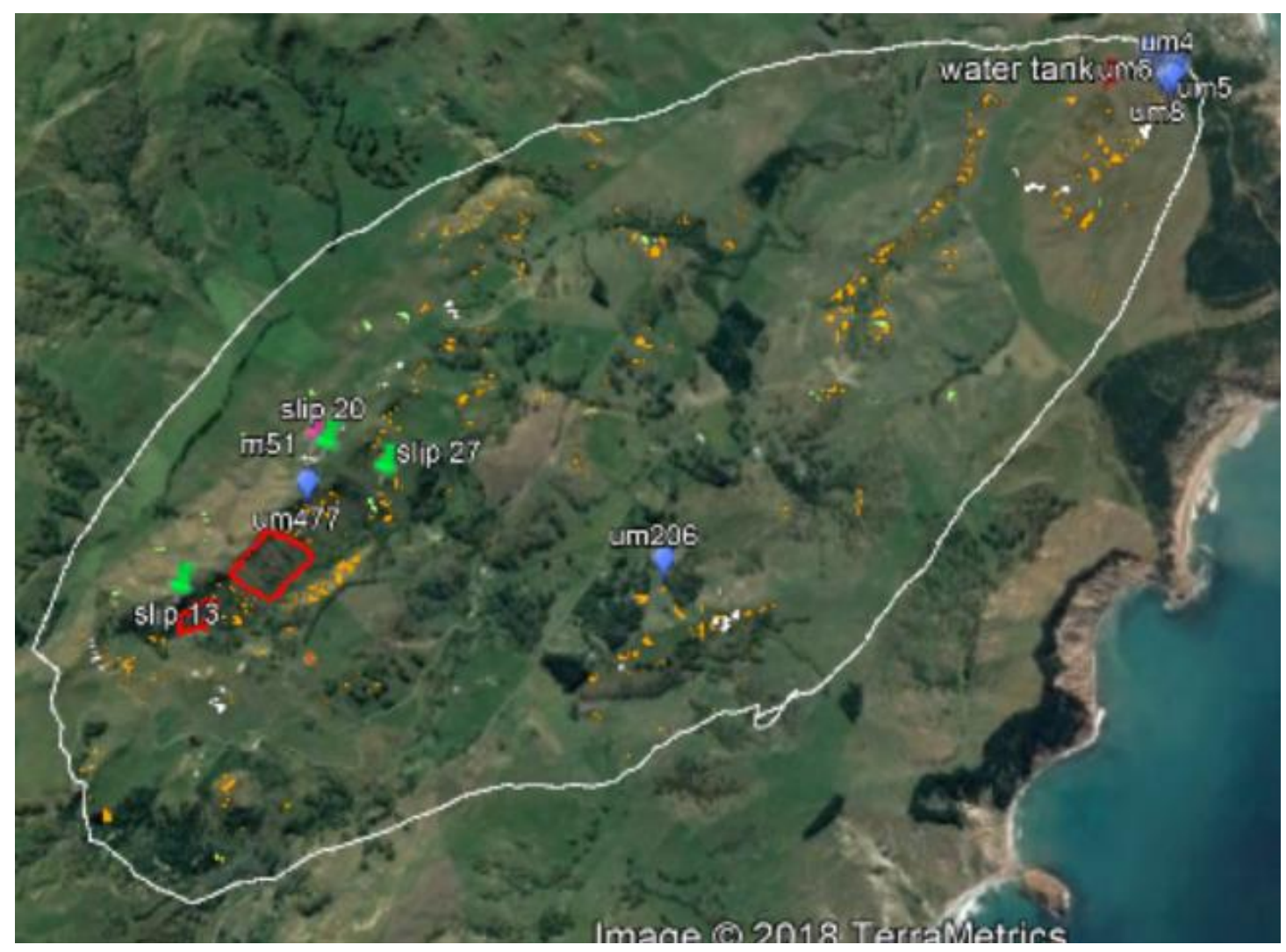

Figure 5.2: Slip sites drawn with a polygon coloured yellow. Post storm Google Earth 24-11-12 and 13-11-16

Table 2 shows comparisons between the on-site field measurements and Google Earth polygon measurements. Although they are similar, there are also quite significant differences between the two measurement methods. These anomalies are likely due to the difference between the techniques used for each measurement. With the field measuring process, the results were arrived at by measuring the longest vertical length and the widest horizontal width, without a circumference measurement of the slip, while the Google Earth measurements were taken from a polygon drawn around each slip and then measured for length and width and circumference. Both these options require a skilful set up by the operator and providing that measurements are recorded accurately for both operations a close relationship should result. In this case, a discrepancy of an average of $18.5 \mathrm{~m}^{2}$, with the Google Earth polygon indicated a larger measurement. 
Table 2 Comparisons for field measurements and GIS measurements

\begin{tabular}{|c|c|c|c|c|c|c|c|}
\hline \multicolumn{3}{|c|}{ Slips Measured } & \multicolumn{4}{|c|}{ Slips Measured } & \multirow{3}{*}{$\begin{array}{r}\text { SQM } \\
\text { actual } \\
\text { difference }\end{array}$} \\
\hline & \multirow{2}{*}{$\begin{array}{l}\text { On site } \\
\text { Length }\end{array}$} & \multirow[b]{2}{*}{ Width } & \multirow{2}{*}{$\begin{array}{c}\text { on site } \\
\text { slips area }\end{array}$} & \multicolumn{2}{|c|}{ Google Earth } & \multirow{2}{*}{$\begin{array}{l}\text { Google } \\
\text { slip area }\end{array}$} & \\
\hline & & & & Length & Width & & \\
\hline 1 & 13.5 & 8.8 & 118.8 & 13.56 & 8.7 & 117.972 & 0.828 \\
\hline 2 & 11 & 14.5 & 159.5 & 12.22 & 12.39 & 151.4058 & 8.0942 \\
\hline 3 & 7.8 & 5.3 & 41.34 & 8.41 & 6.15 & 51.7215 & -10.3815 \\
\hline 4 & 16 & 7.6 & 121.6 & 12.68 & 6.71 & 85.0828 & 36.5172 \\
\hline 5 & 20 & 14.8 & 296 & 23.32 & 15 & 349.8 & -53.8 \\
\hline 6 & 17 & 13.6 & 231.2 & 19.76 & 11.96 & 236.3296 & -5.1296 \\
\hline 7 & 28 & 18.7 & 523.6 & 25.38 & 18.68 & 474.0984 & 49.5016 \\
\hline 8 & 45 & 14.9 & 670.5 & 48.37 & 15.23 & 736.6751 & -66.1751 \\
\hline 9 & 10 & 19.4 & 194 & 11.57 & 21.68 & 250.8376 & -56.8376 \\
\hline 10 & 12 & 8.9 & 106.8 & 11.13 & 9.12 & 101.5056 & 5.2944 \\
\hline 11 & 11 & 14.3 & 157.3 & 12.7 & 15.45 & 196.215 & -38.915 \\
\hline 12 & 5 & 4.9 & 24.5 & 5.82 & 3.82 & 22.2324 & 2.2676 \\
\hline 13 & 25 & 23.3 & 582.5 & 22.01 & 22.81 & 502.0481 & 80.4519 \\
\hline 14 & 20 & 10.1 & 202 & 18.9 & 8.75 & 165.375 & 36.625 \\
\hline 15 & 30 & 10.8 & 324 & 24.73 & 12.3 & 304.179 & 19.821 \\
\hline 16 & 33 & 13.4 & 442.2 & 29.57 & 14.19 & 419.5983 & 22.6017 \\
\hline 17 & 45 & 11.5 & 517.5 & 45.19 & 11.28 & 509.7432 & 7.7568 \\
\hline 18 & 25 & 25.6 & 640 & 25.27 & 22.82 & 576.6614 & 63.3386 \\
\hline 19 & 11 & 9.2 & 101.2 & 8.99 & 10.54 & 94.7546 & 6.4454 \\
\hline 20 & 17 & 10.2 & 173.4 & 17.79 & 10.59 & 188.3961 & -14.9961 \\
\hline 21 & 7 & 10.2 & 71.4 & 7.18 & 10.18 & 73.0924 & -1.6924 \\
\hline 22 & 8 & 8.4 & 67.2 & 11.88 & 8.55 & 101.574 & -34.374 \\
\hline 23 & 7.3 & 9.9 & 72.27 & 8.86 & 8.96 & 79.3856 & -7.1156 \\
\hline 24 & 17.7 & 26.5 & 469.05 & 8.39 & 10.96 & 91.9544 & 377.0956 \\
\hline 25 & 5 & 6.5 & 32.5 & 8.7 & 5.04 & 43.848 & -11.348 \\
\hline 26 & 24 & 13.8 & 331.2 & 23.05 & 12.5 & 288.125 & 43.075 \\
\hline 27 & 14 & 11.7 & 163.8 & 10.09 & 11.89 & 119.9701 & 43.8299 \\
\hline 28 & 4.3 & 4.3 & 18.49 & 5.83 & 3.45 & 20.1135 & -1.6235 \\
\hline 29 & 18.7 & 15.9 & 297.33 & 17.15 & 15.83 & 271.4845 & 25.8455 \\
\hline 30 & 15 & 16.7 & 250.5 & 14.69 & 15.36 & 225.6384 & 24.8616 \\
\hline 31 & 15 & 6 & 90 & 13.28 & 5.9 & 78.352 & 11.648 \\
\hline 32 & 14.5 & 6.8 & 98.6 & 12.96 & 6.42 & 83.2032 & 15.3968 \\
\hline 33 & 11 & 12.5 & 137.5 & 12.26 & 11.57 & 141.8482 & -4.3482 \\
\hline 34 & 10 & 12.3 & 123 & 6.19 & 7.97 & 49.3343 & 73.6657 \\
\hline 35 & 12.8 & 15.9 & 203.52 & 12.21 & 10.38 & 126.7398 & 76.7802 \\
\hline 36 & 16.3 & 9.5 & 154.85 & 11.16 & 8.24 & 91.9584 & 62.8916 \\
\hline 37 & 7 & 7.8 & 54.6 & 6.36 & 4.78 & 30.4008 & 24.1992 \\
\hline 38 & 17 & 22.6 & 384.2 & 17.57 & 23.52 & 413.2464 & -29.0464 \\
\hline 39 & 15 & 12.5 & 187.5 & 14.97 & 12.05 & 180.3885 & 7.1115 \\
\hline 40 & 22.7 & 16.5 & 374.55 & 22.17 & 15.64 & 346.7388 & 27.8112 \\
\hline 42 & 65 & 20 & 1300 & 57.49 & 19.89 & 1143.4761 & 156.5239 \\
\hline 43 & 12 & 10.4 & 124.8 & 12 & 7.74 & 92.88 & 31.92 \\
\hline 44 & 10 & 7.7 & 77 & 9.33 & 7.3 & 68.109 & 8.891 \\
\hline
\end{tabular}

$\mathbf{8 6} \mid \mathrm{P}$ a g e 


\begin{tabular}{|rrrrrrrr|}
\hline 45 & 24 & 5 & 120 & 15.12 & 7.57 & 114.4584 & 5.5416 \\
\hline 46 & 6.2 & 27.5 & 170.5 & 5.25 & 28.24 & 148.26 & 22.24 \\
\hline 47 & 25 & 17 & 425 & 25.24 & 19.12 & 482.5888 & -57.5888 \\
\hline 48 & 22 & 10 & 220 & 23.52 & 10.37 & 243.9024 & -23.9024 \\
\hline 49 & 14 & 24 & 336 & 12.5 & 29.69 & 371.125 & -35.125 \\
\hline 50 & 11 & 11 & 121 & 10.9 & 10.07 & 109.763 & 11.237 \\
\hline 51 & 7.3 & 4.5 & 32.85 & 6.47 & 3.26 & 21.0922 & 11.7578 \\
\hline 52 & 19 & 16 & 304 & 19.04 & 15.57 & 296.4528 & 7.5472 \\
\hline 53 & 21 & 16.7 & 350.7 & 19.59 & 15.94 & 312.2646 & 38.4354 \\
\hline 54 & 7 & 10 & 70 & 8.38 & 9.85 & 82.543 & -12.543 \\
\hline & & & & & & & Average 18.5 \\
\hline
\end{tabular}

A Digital Elevation Model (DEM) was downloaded from LINZ and downsized to $1 \mathrm{~m}^{2}$ pixels to allow zonal statistics on the smallest slips. However the (um) slips were likely to be more accurate from Google Earth as they were measured by circumference of polygon and then length and width, while the field slips were hand tape measured for length and width. The digital dataset was used to extract the topographic characteristics of the slips and the total study area.

\section{Elevation}

The study used the Otago $15 \mathrm{~m}$ DEM (LINZ), which was down-sampled to a resolution of $1 \mathrm{~m}^{2}$ in order to allow spatial analysis with the smallest slips. This does not improve the precision or accuracy of the DEM but is necessary for spatial analysis. The interpretation from the results shows that at an elevation between $60 \mathrm{~m}$ and $180 \mathrm{~m}$ a.s.1. (above sea level), 64.4 percent of land area showed the highest slope failure of 66.4 percent. At 20-40m elevation, 22.8 percent of land area had only 7 percent of landslide activity and at 200-340m elevation covering 12.8 percent of land area there was a combined total of 26.3 percent of slope failure (Figure 5.3).

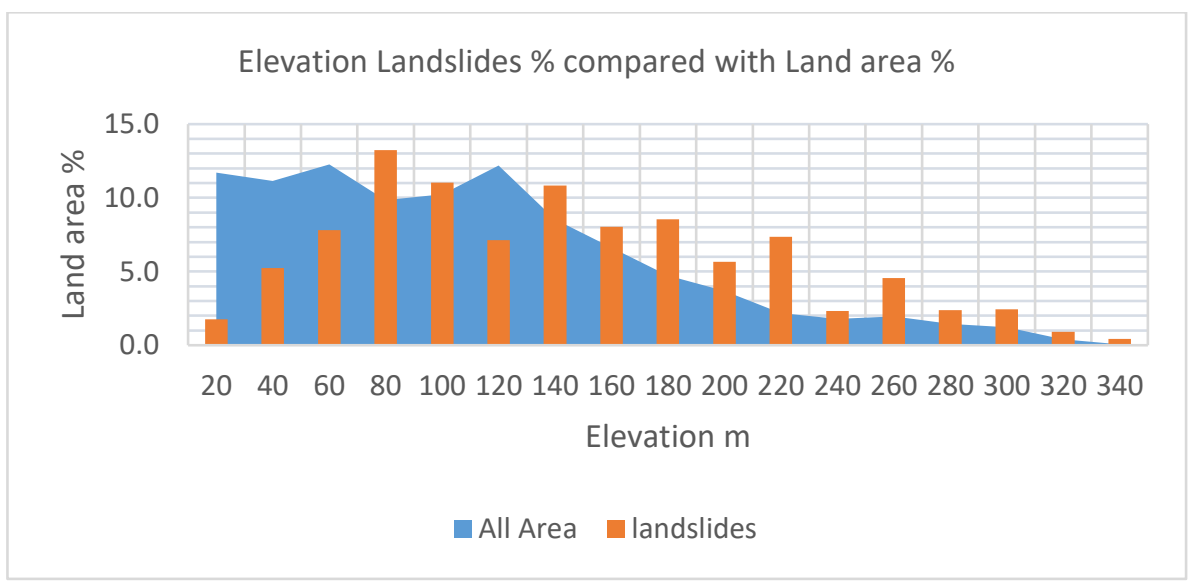

Figure 5.3: Results from elevation of landslides and land area 
Elevation area compared to percent of landslide area

The lower elevations of $20-40^{\circ}$ show a low number of landslides, $7 \%$ in $22.8 \%$ of land area. From $60-180^{\circ}$ the proportion of area at $65.4 \%$ has the highest number of slips at $66.4 \%$. Above $180^{\circ}$ elevation there is a significantly higher percentage of slips $26.3 \%$ to land area of $12.8 \%$, which shows a disproportionate number of slips at the highest elevation a.s.l.

\section{Aspect}

When the direction of slope failure is considered on compass points there is a dramatic increase between east $90^{\circ}$ and south east $135^{\circ}$ that 18.4 percent of land cover had 20.9 percent of regolith loss. On the western slopes at west $270^{\circ}$ to north west $315^{\circ}$ had regolith loss of 20.8 percent to 11.4 percent of land area. North west $315^{\circ}$ to north $360^{\circ}$ had a similar percentage of regolith failure of 20.7 percent for 14.1 percent of land area (Figure 5.4).

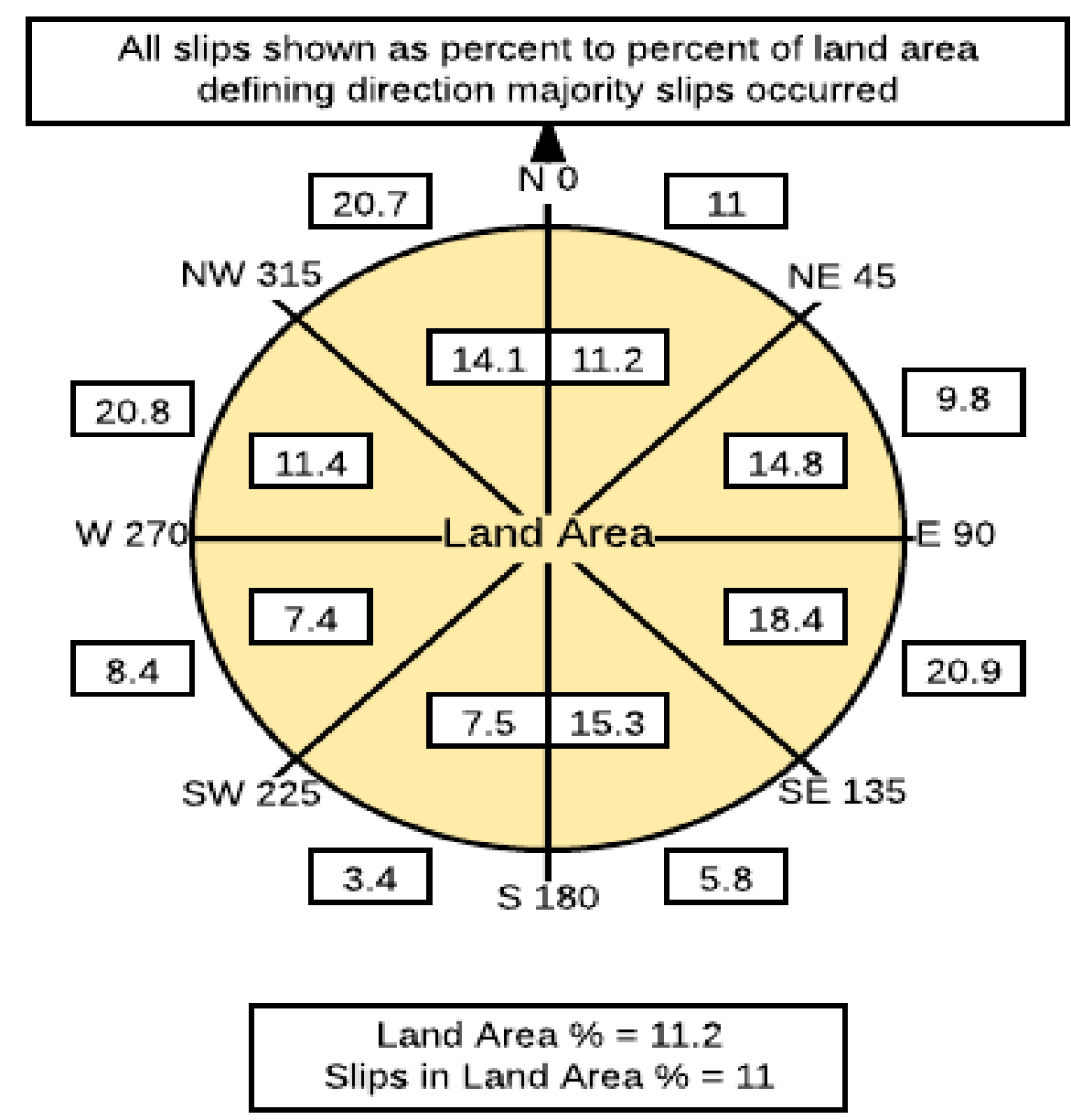

Figure 5.4: Land area percent vs slip area percent 
Between these three bearings a total of 62.4 percent of slope failure occurred on 43.9 percent of land area. The most likely reason for this is that the Waimarama valley trends $\sim$ NE-SW, where the valley sides dip towards the NW and SE, and, the steepest slopes in the valley are found at these orientations. In addition, the regional strike is $\sim$ NE-SW, which could enhance sliding along NW and SE dipping rocks. The least affected land areas 56.2 percent only had 38.4 percent of slope failure. Figure 5.5 shows the structural geology of the Waimarama region and Figure 5.6 shows the elevation and landslide area.

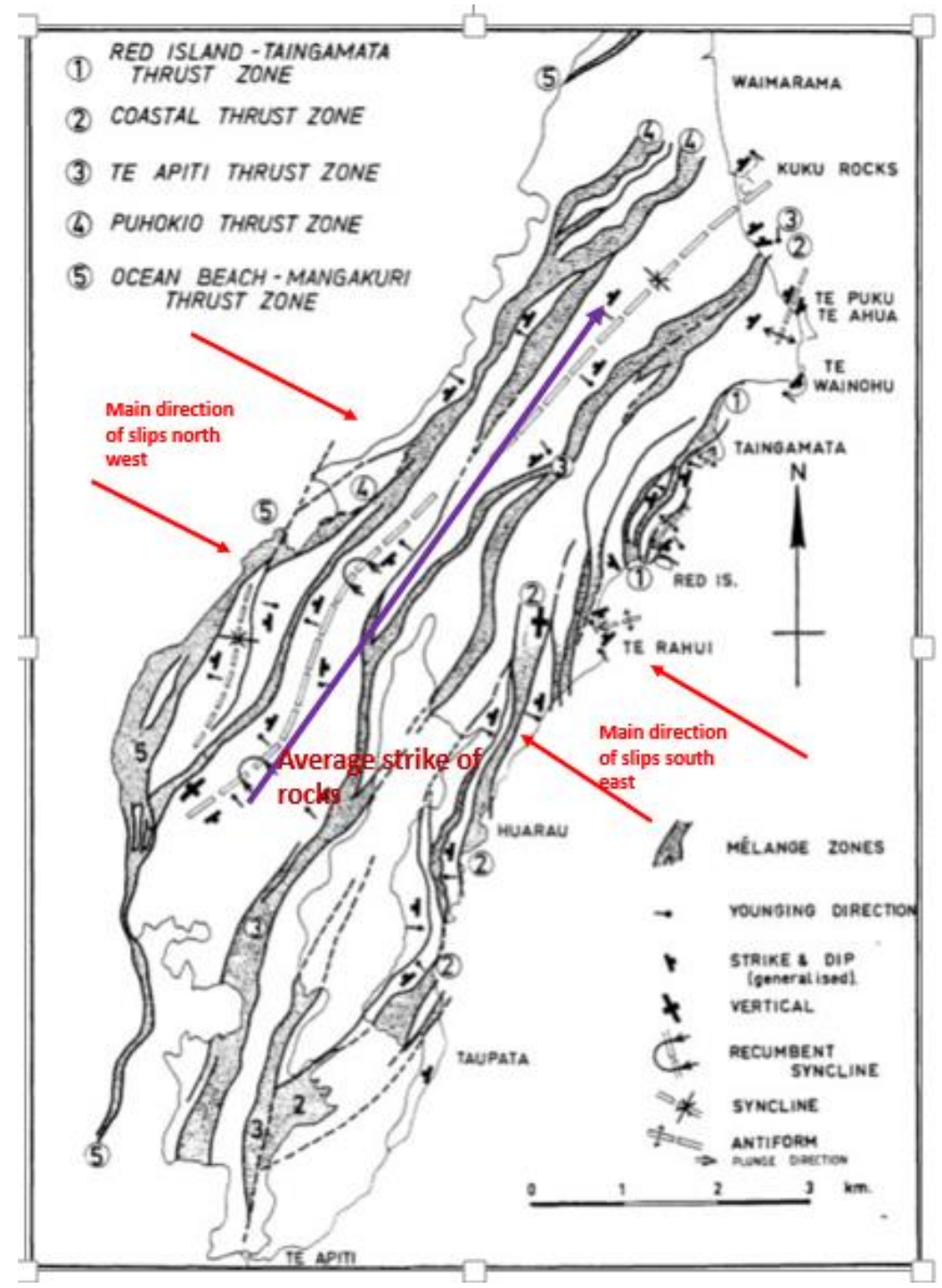

Figure 5.5: Structural-tectonic map of the Waimarama-Mangakuri Coastal High from Waimarama to Te Apiti. Pettinga 1980

The prevalence of NW and SE facing slips is due to a combination of structural control and topographic form (i.e. Valley orientation and dip direction). 


\section{Hill-slope angle}

The highest percentage of slope failure occurred between $15^{\circ}$ and $25^{\circ}$ where 40.9 percent of land area recorded 74.7 percent of landslides, with $25^{\circ}$ showing 6.5 percent of land area had a record of 23.4 percent of all landslides. The lower slopes between $5^{\circ}$ and $10^{\circ}$ had an area of 55.5 percent only recorded 12.7 percent of landslides. Between thirty degrees and $40^{\circ}$, with land area of 3.5 percent had slope failure of 12.6 percent (Figure 5.6).

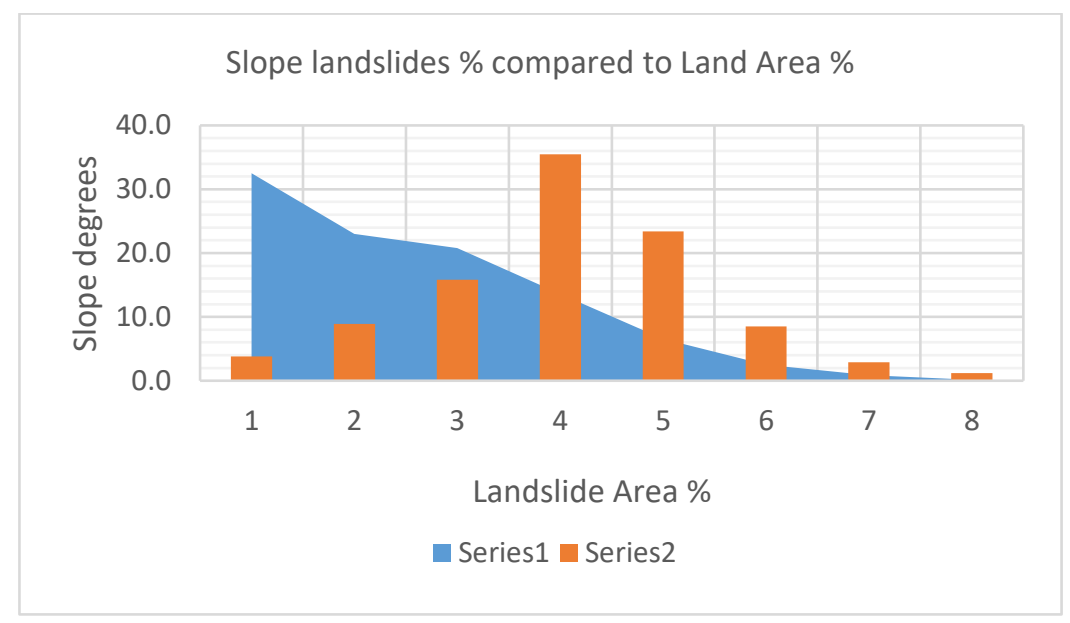

Figure 5.6: Results of slope and land area

These results including those of elevation and aspect, strongly agree with previous research, showing that most elevation and slope failures occur within a set criteria of $15^{\circ}$ to $25^{\circ}$ slope, at elevations between mid-slope and top of slope while aspect shows a dominant east, south east and west, north west situation which is due to the tectonic plate uplift of the hillslopes (Brooks et al., 2002; Chen et al., 2016; Crozier et al., 1980; De Rose, 2013; Dymond et al., 2006). 
Slope and slip angles show variable degrees and how they relate to each other (Figure 5.7).

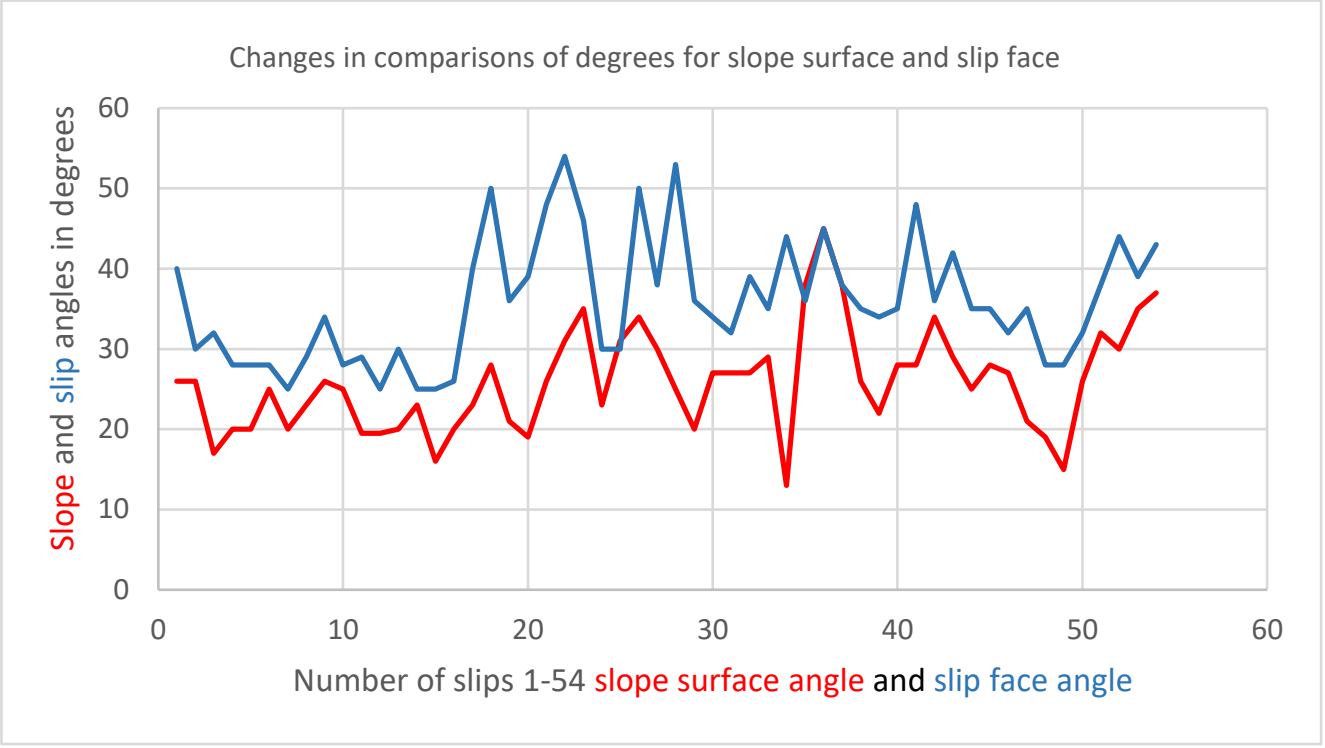

Figure 5.7: Chart showing comparisons of slope and slip angles. See Fig. 4.2, p. 67 for all measured slips 


\section{Laboratory results:}

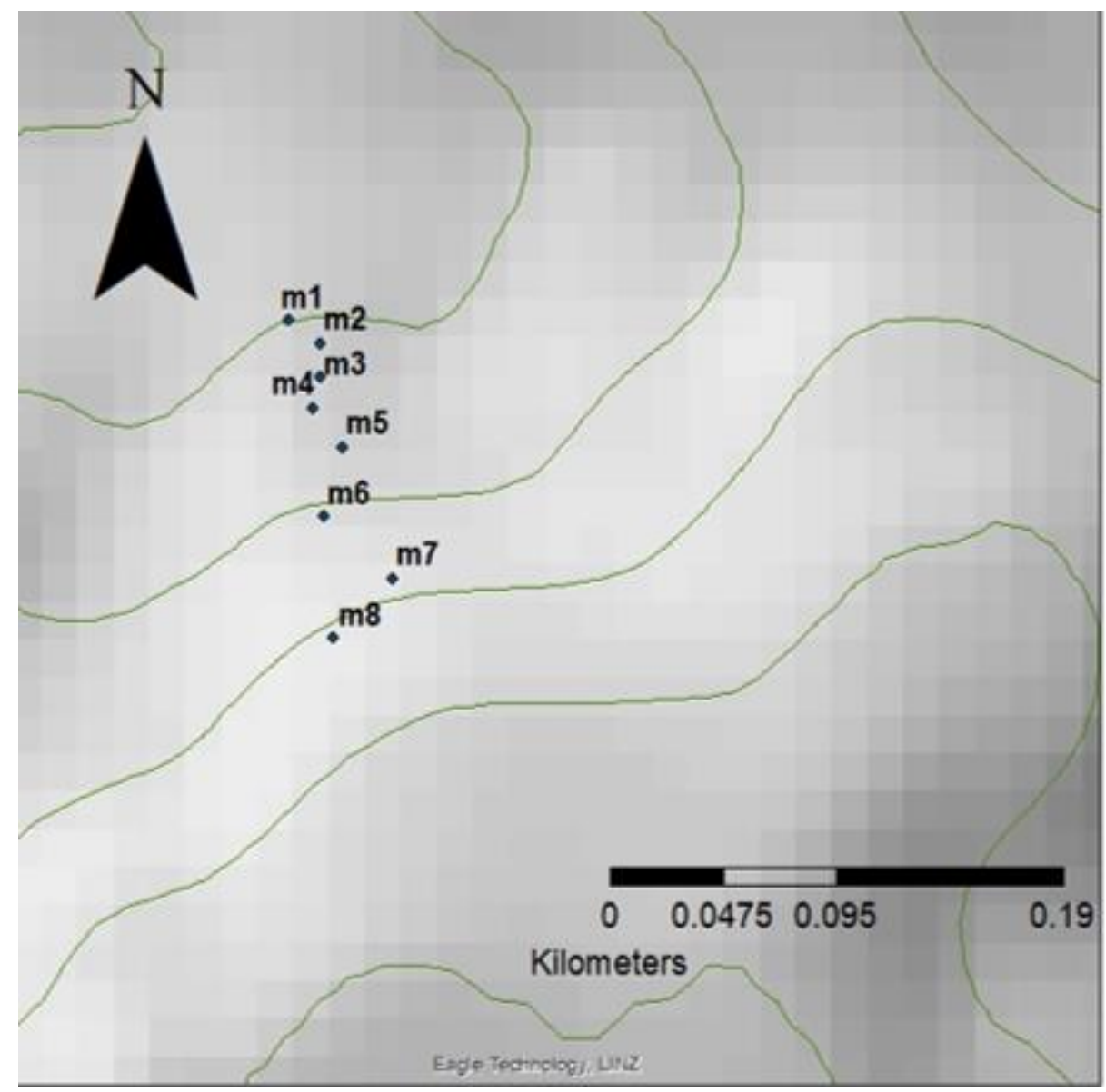

Figure 5.8: Hillslope indication of slips 1-8. Slip 1 at $45 \mathrm{~m}$ a.s.1.; 8 at $85 \mathrm{~m}$ a.s.1. Contours at 20m

Note: Colours on tables: Blue $=\mathrm{A}$ horizon; Red $=\mathrm{B}$ horizon; Green $=\mathrm{C}$ horizon; Purple $=\mathrm{D}$ horizon

A The plastic limit of the A horizon for slips 1-7 is at water content of between $38 \%$ and $29 \%$ while the B horizons shows a plastic limit of $36 \%$ to $28.8 \%$. The $\mathrm{C}$ horizon was only measured at slip 6 and shows 29\%. These results show there is a tendency for the A and B horizons to reach a saturation level at or above $29 \%$ water content while the $\mathrm{C}$ horizon is lower, at least for the one measured slip.

B Specific gravity of the soil in slips 1-8 follow a similar pattern to plastic limit where the A horizon tends to show higher values, except for slips 3 and 7 where the specific gravity (Sg) of horizon B is higher. Slip $6 \mathrm{C}$ horizon has a higher specific gravity than the B horizon at 1.48 $\mathrm{g} / \mathrm{cm}^{3}$. The A horizons range from a high of $1.63 \mathrm{~g} / \mathrm{cm}^{3}$ at slip 4 to a low of $1.51 \mathrm{~g} / \mathrm{cm}^{3}$ at slip 7 , while the B horizons range from a high at slip 3 of $1.65 \mathrm{~g} / \mathrm{cm}^{3}$ to a low of $1.44 \mathrm{~g} / \mathrm{cm}^{3}$ at slip 6 . The two $\mathrm{C}$ horizons register $1.48 \mathrm{~g} / \mathrm{cm}^{3}$ at slip 6 and $1.38 \mathrm{~g} / \mathrm{cm}^{3}$ for slip 8 . The total range for all slips $1-8$ is $1.65 \mathrm{~g} / \mathrm{cm}^{3}-1.38 \mathrm{~g} / \mathrm{cm}^{3}$. 
C Liquid limit water content is variable with the A horizon showing a high of $74 \%$ for slip 2 then an even spread from $65.9 \%$ to a low of $57.6 \%$ for slip 7 . The B horizon trends to be higher from $77 \%$ for slip 3 to a low of $59.8 \%$ for slip 8, while both $\mathrm{C}$ horizons of slips 6 and 8 record the same at $57.6 \%$. The trend for horizon $\mathrm{C}$ within the three results indicates less tolerance towards excess water content.
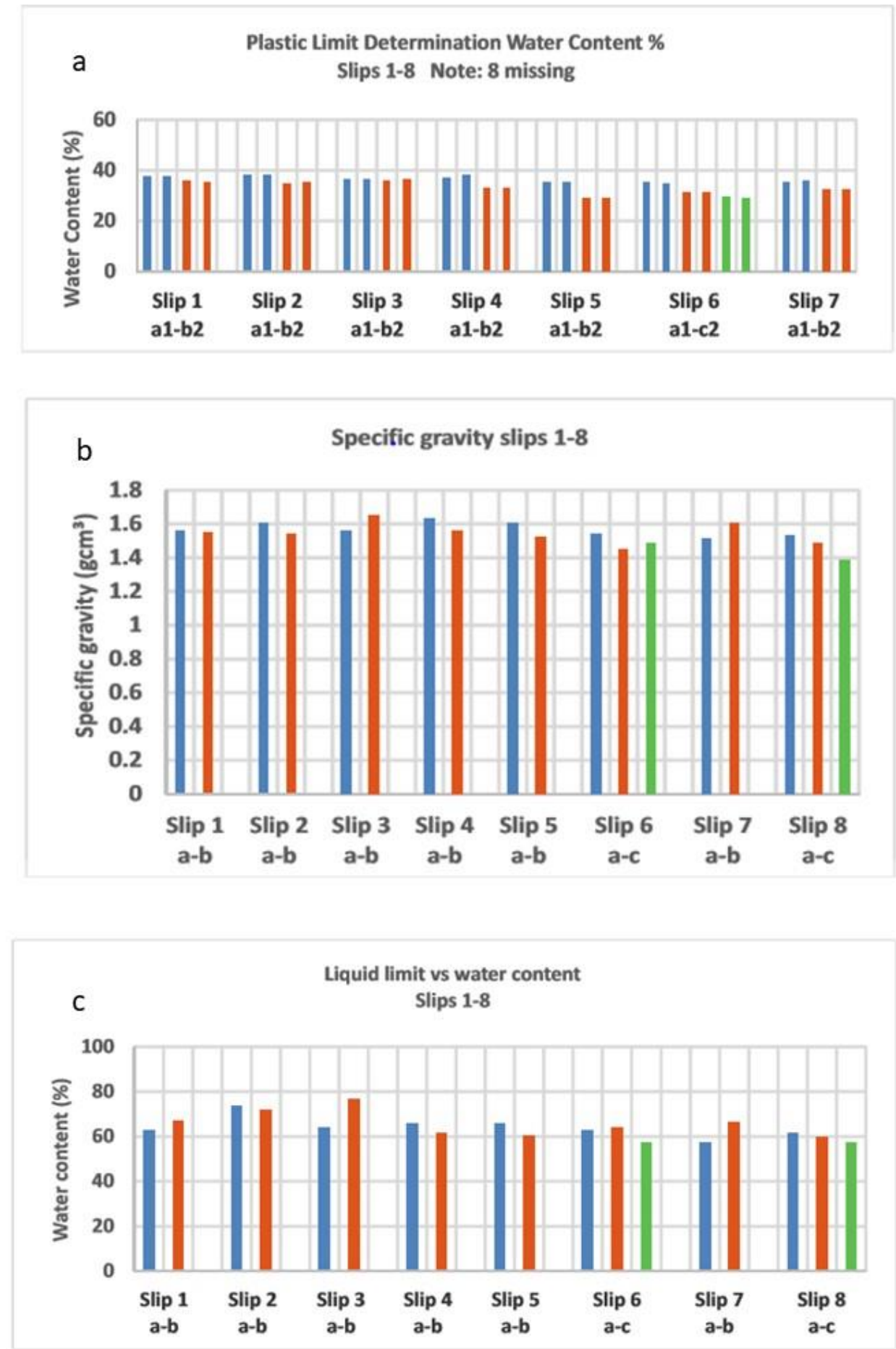

Figure 5.9: Plastic limit, specific gravity and liquid limit, laboratory results on page above 


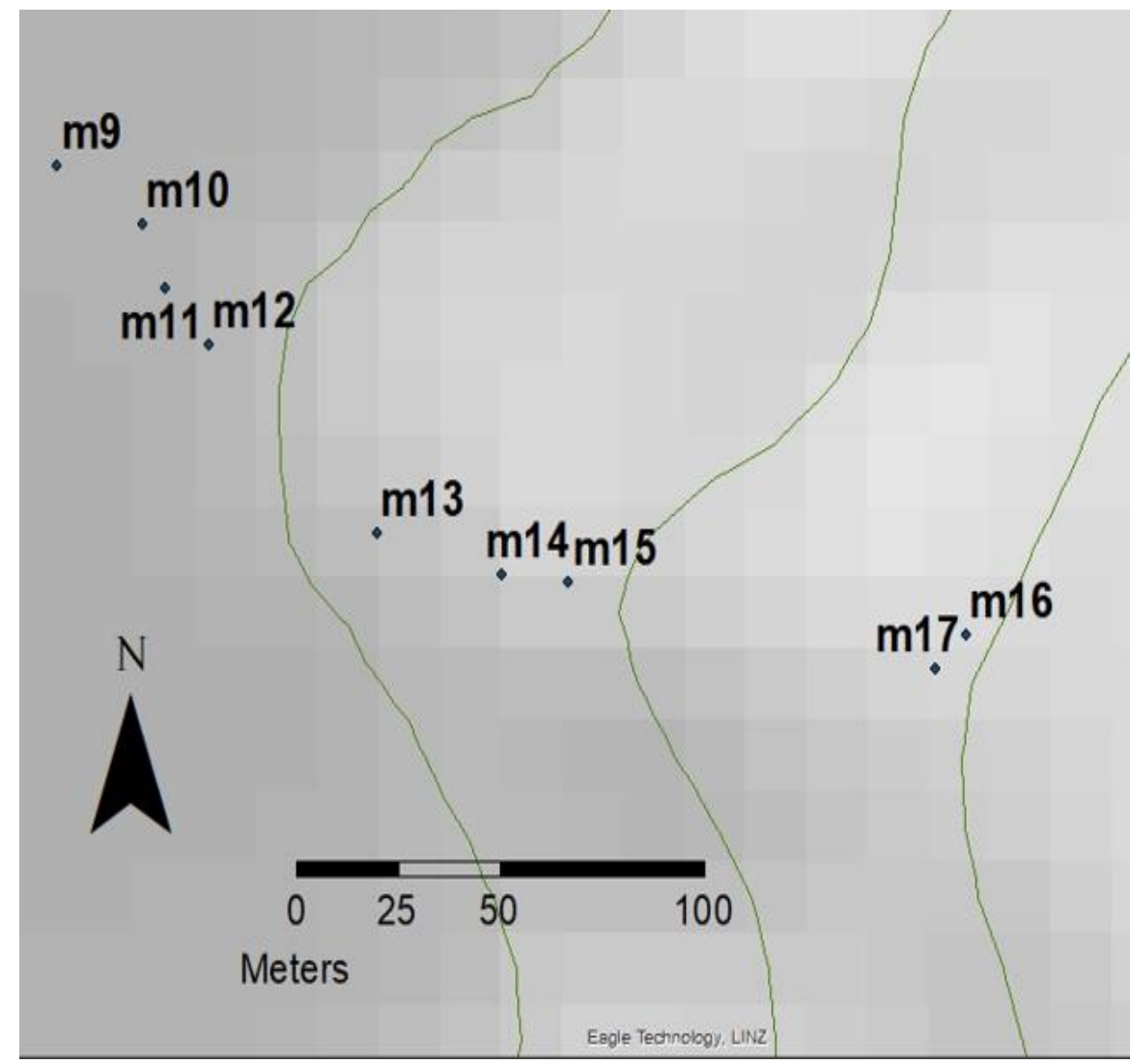

Figure 5.10: Hillslope indication of slips 9-12. Slip 9 at 53m a.s.1. and 12 at $27 \mathrm{~m}$ a.s.1. Contours $20 \mathrm{~m}$

A The plastic limit of the A horizons for slips $9-12$ show a water content high of $46 \%$ and a low of $33 \%$. The B horizon shows a plastic limit higher than the A horizons. The B horizon high is $51 \%$ and low is $33 \%$ water content. The C horizon plastic limit high is $43 \%$ and low is $33 \%$. These results show the $\mathrm{B}$ and $\mathrm{C}$ horizons have a tendency towards a higher water content than horizon A.

B The specific gravity of the soil in slips 9-12 show the B and C horizons have a higher specific gravity value than the A horizon. The A horizon has a high of $1.62 \mathrm{~g} / \mathrm{cm}^{3}$ and low of $1.51 \mathrm{~g} / \mathrm{cm}^{3}$. The B horizon shows a high of $1.70 \mathrm{~g} / \mathrm{cm}^{3}$ and low of $1.52 \mathrm{~g} / \mathrm{cm}^{3}$. The $\mathrm{C}$ horizon has a high of $1.63 \mathrm{~g} / \mathrm{cm}^{3}$ and low of $1.57 \mathrm{~g} / \mathrm{cm}^{3}$. The total range for all slips $9-12$ is $1.70 \mathrm{~g} / \mathrm{cm}^{3}-1.51 \mathrm{~g} / \mathrm{cm}^{3}$.

C The liquid limit water content in slip 12 of the A horizon shows a high of $70.1 \%$ and low of 65.1. The B horizon, slip 12 high of $73.4 \%$ and low of $65.9 \%$. The $\mathrm{C}$ horizon shows a high of $81.3 \%$ for slip 9 and $68.4 \%$ for slip 10 . The $\mathrm{C}$ horizon in this group of slips has a higher water content than the $\mathrm{A}$ and $\mathrm{B}$ horizons. 
a Plastic Limit Determination Water Content \% Slips 9-12 Note: 11 missing

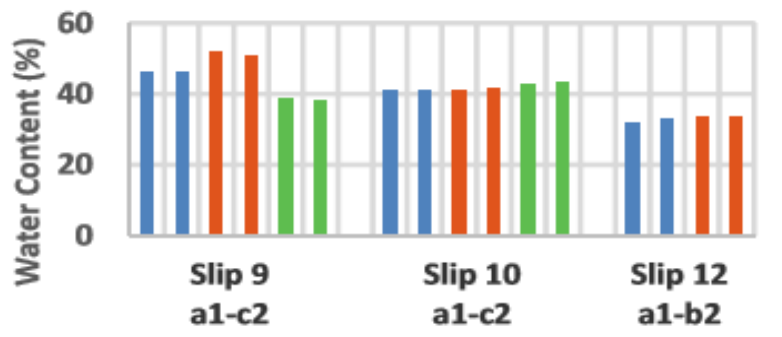

b Specific gravity slips 9-12 Note: slip 11 missing
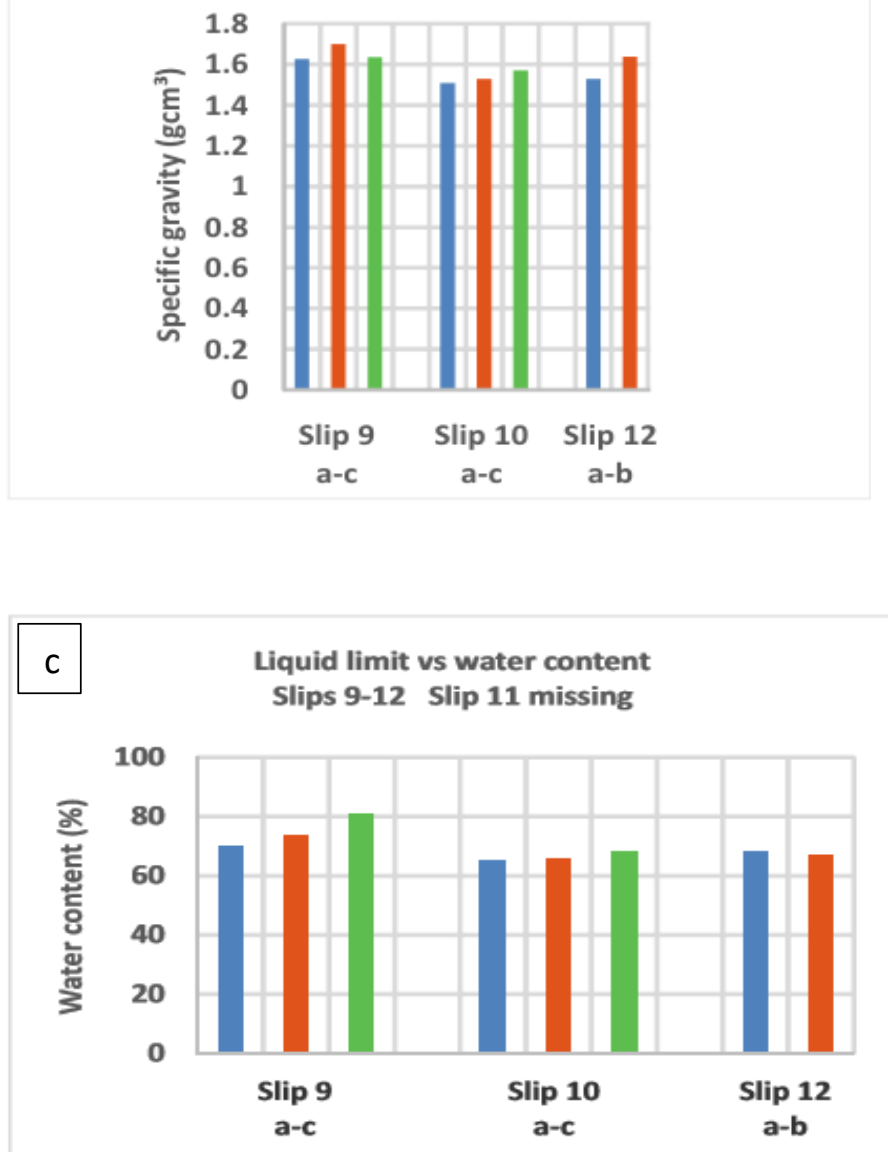

Figure 5.11: Plastic limit, specific gravity and liquid limit, laboratory results on page above 


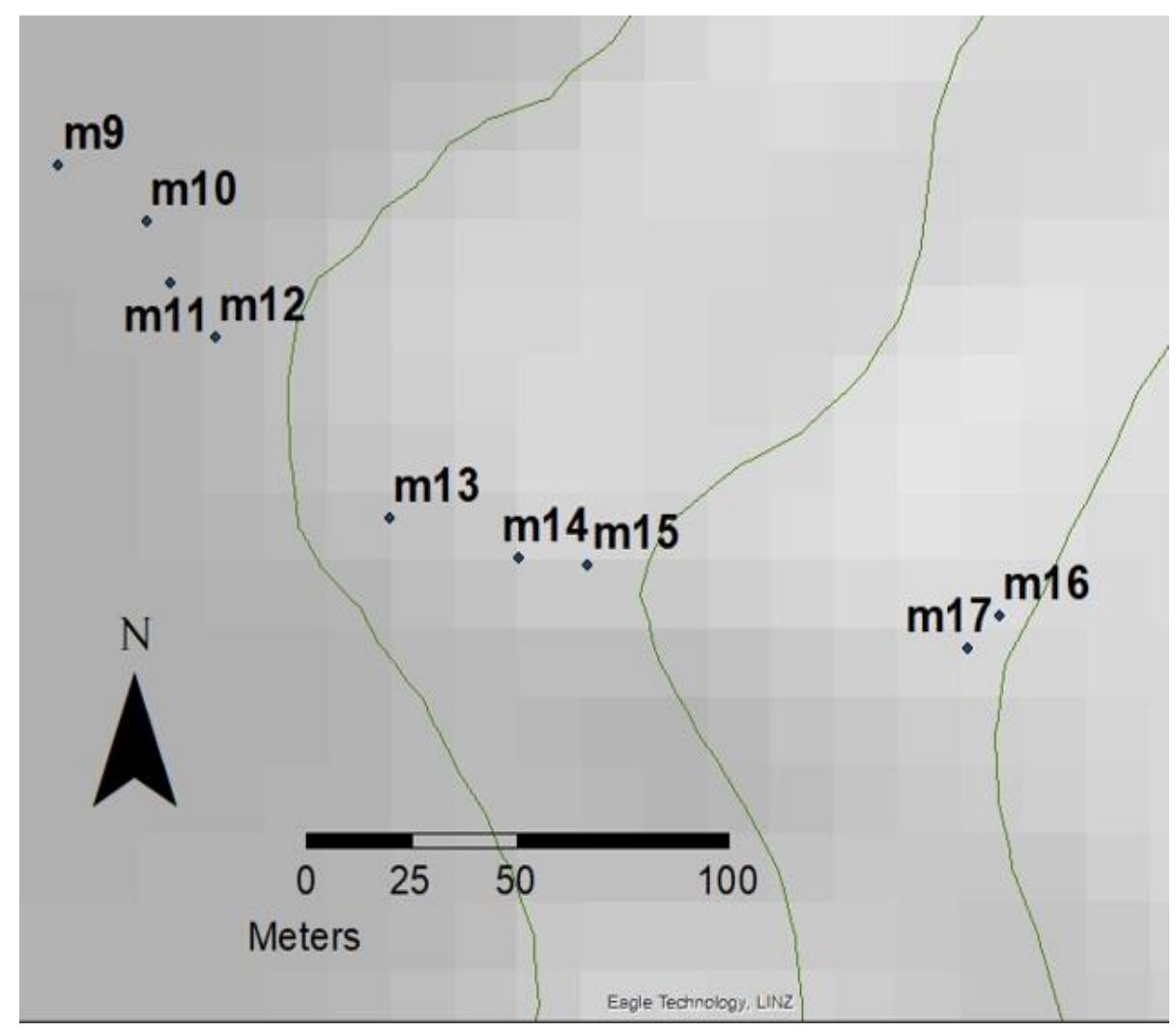

Figure 5.12: Hillslope indication of slips13-17. Slip 13 at 31m a.s.1; slip 17 at 59m a.s.l. Contours $20 \mathrm{~m}$

A The plastic limit of the A horizon for slips 13-17 show a water content range of $45.8 \%$ $27.4 \%$. The B horizon has a lower water content of 37.4\% - 23.3\%. Slip 13C shows a high plastic limit of $41 \%$ and a low of $34.4 \%$. These results show the A horizon reached saturation level at $45.8 \%$ water content while the $\mathrm{B}$ and $\mathrm{C}$ horizons were in a saturation range of $41 \%-23.3 \%$.

B Specific gravity of soil in slips 13-17 show the A horizon has a high value of specific gravity of $1.58 \mathrm{~g} / \mathrm{cm}^{3}$ and $1.41 \mathrm{~g} / \mathrm{cm}^{3}$. The B horizons of slips 15 and 16 have values of $1.69 \mathrm{~g} / \mathrm{cm}^{3}$ and $1.54 \mathrm{~g} / \mathrm{cm}^{3}$. The $\mathrm{C}$ horizons highest values are $1.58 \mathrm{~g} / \mathrm{cm}^{3}$ for slip 13 and $1.52 \mathrm{~g} / \mathrm{cm}^{3}$ for slip 16 . The specific gravity of the $\mathrm{B}$ and $\mathrm{C}$ horizons have higher values than the A horizon while the total range for all slips is $1.69 \mathrm{~g} / \mathrm{cm}^{3}-1.35 \mathrm{~g} / \mathrm{cm}^{3}$.

C There are no values for this group of slips as the original data became contaminated from an input mistake. Two uncontaminated slips 15 and 17 are not compared with other slips in their group to accurately record any trend. 

Slips 13-17 Note: 14 missing

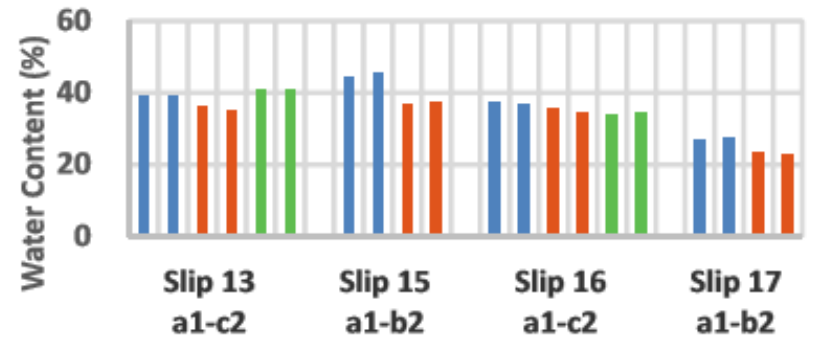

b Specific gravity slips 13-17 Note: slip 14 missing

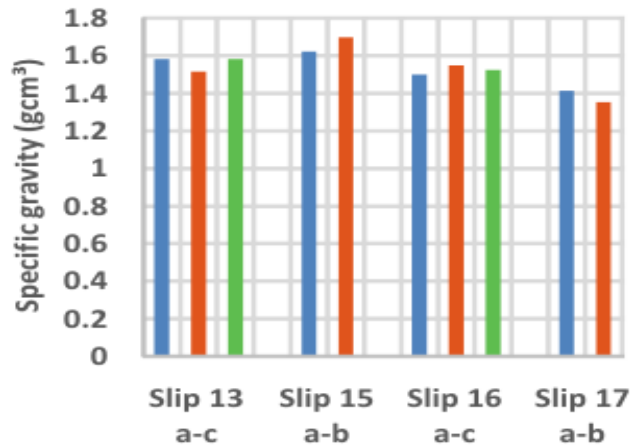

C Liquid limit vs water content Slips 13-17 note slips 13 \& 16 wrong trends 14 missing

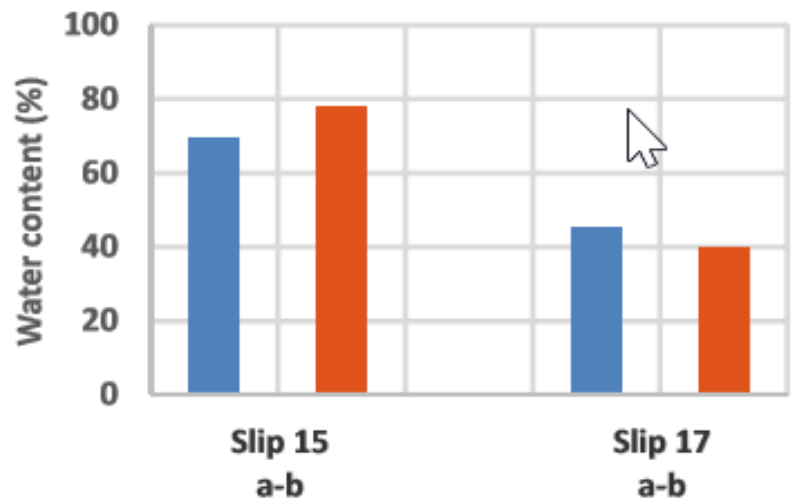

Figure 5.13: Plastic limit, specific gravity and liquid limit, laboratory results on page above 


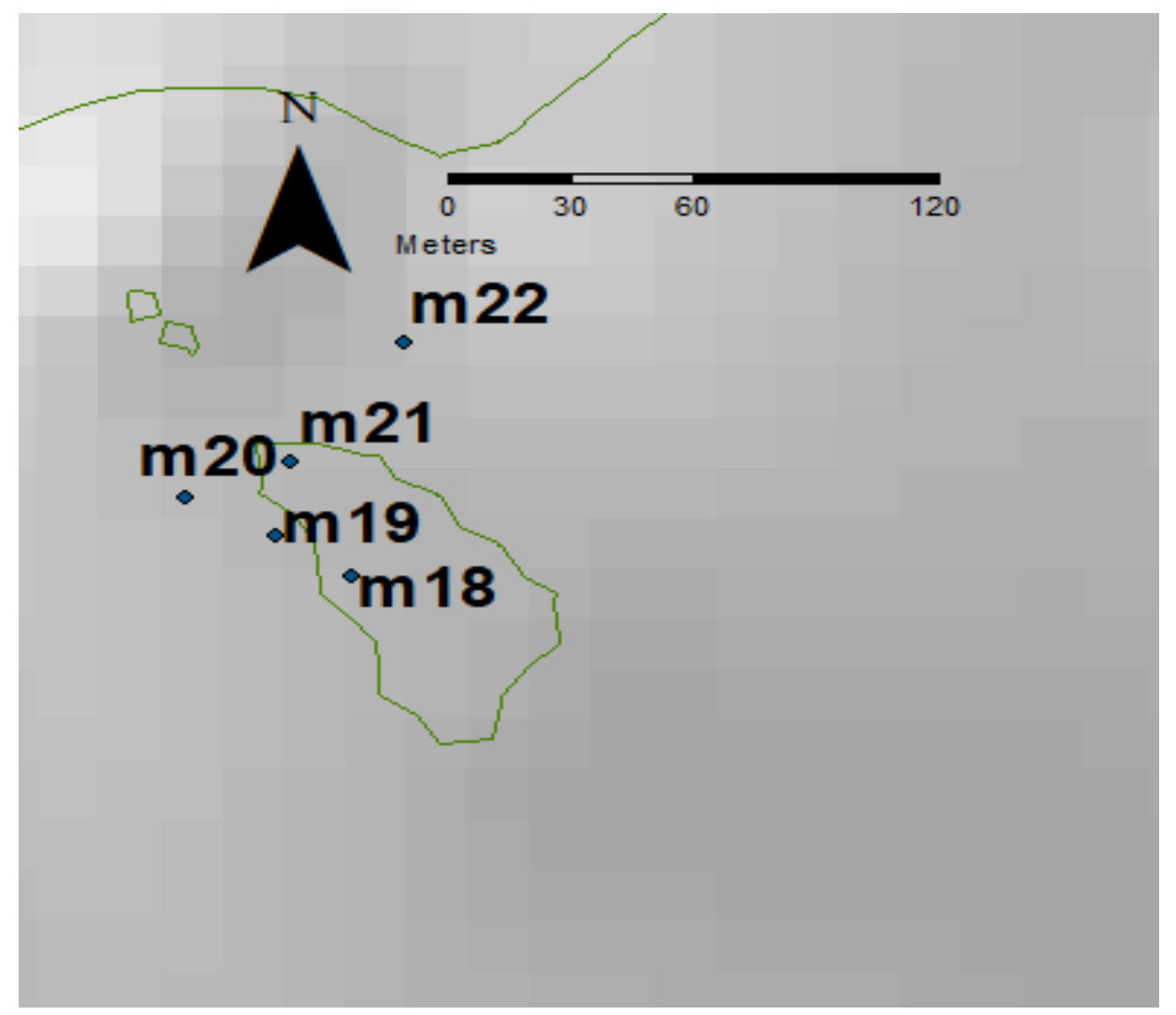

Figure 5.14: Hillslope indication of slips 18 -22; slip 18 at $147 \mathrm{~m}$ a.s.l; slip 22 at 69m a.s.l. Contours $20 \mathrm{~m}$

These three slip samples A, B, and C show a distinct trend with the A horizon displaying a higher water content $\%$ than the $\mathrm{B}$ and $\mathrm{C}$ horizons.

A Plastic limit of the A horizon has a high of $45.7 \%$ and a low value of $35.9 \%$. The B horizon shows a plastic limit of $38.5 \%$ and a low of $28.5 \%$. The $\mathrm{C}$ horizon values for water content are $36.4 \%$ high and low of $26.7 \%$. These results show the A and B horizons have a tendency to reach saturation level at or above $35 \%$ water content, while the $\mathrm{C}$ horizon has a lower water content tolerance.

B The specific gravity of the soil in slips 20-22 have similar trends to plastic limit. Slip 18, C horizon has a high value of $1.56 \mathrm{~g} / \mathrm{cm}^{3}$. The A horizons show values of $1.57 \mathrm{~g} / \mathrm{cm}^{3}$ to $1.40 \mathrm{~g} / \mathrm{cm}^{3}$. The trend for the B horizons specific gravity are $1.51 \mathrm{~g} / \mathrm{cm}^{3}-1.37 \mathrm{~g} / \mathrm{cm}^{3}$. The $\mathrm{C}$ horizon values are from $1.56 \mathrm{~g} / \mathrm{cm}^{3}$ to $1.38 \mathrm{~g} / \mathrm{cm}^{3}$. The range of specific gravity values for slips 18-20-21-22 are $1.57 \mathrm{~g} / \mathrm{cm}^{3}-1.37 \mathrm{~g} / \mathrm{cm}^{3}$.

C Liquid limit water content for A horizon slip 21 has a high $62.8 \%$ and slip 22 with a low of $39.4 \%$. Slip 20 has $57.9 \%$ and slip 18 values are 50.5\%. The B horizons have a range of values from $69.9 \%$ for slip 20 and $39.1 \%$ for slip 22 . The water content range for the $\mathrm{C}$ horizon is $60 \%$ 5and low of $39.5 \%$. The D horizon is a covered A horizon from a previous slip, $49.5 \%$. These 
results show a variety of values with some horizons having a lower water content than $\mathrm{C}$ horizons, this trend shows slips 20 and 22 have a higher tolerance towards excess water.

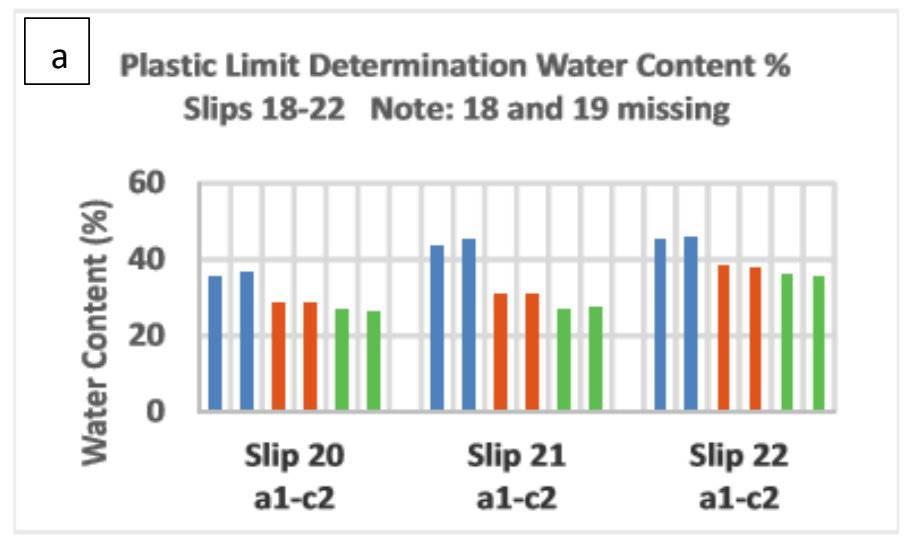

b Specific gravity slips 18-22 Note: slip 19 missing
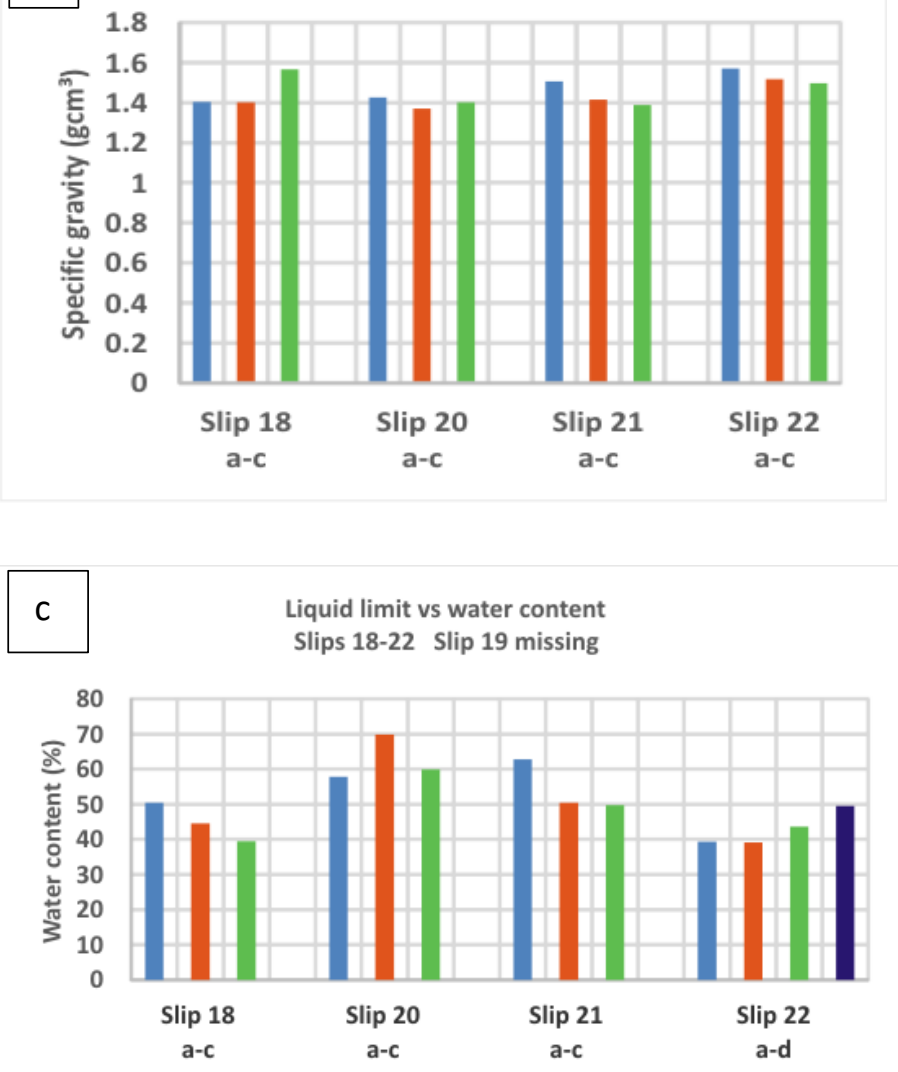

Figure 5.15: Plastic limit, specific gravity and liquid limit, laboratory results on page above 


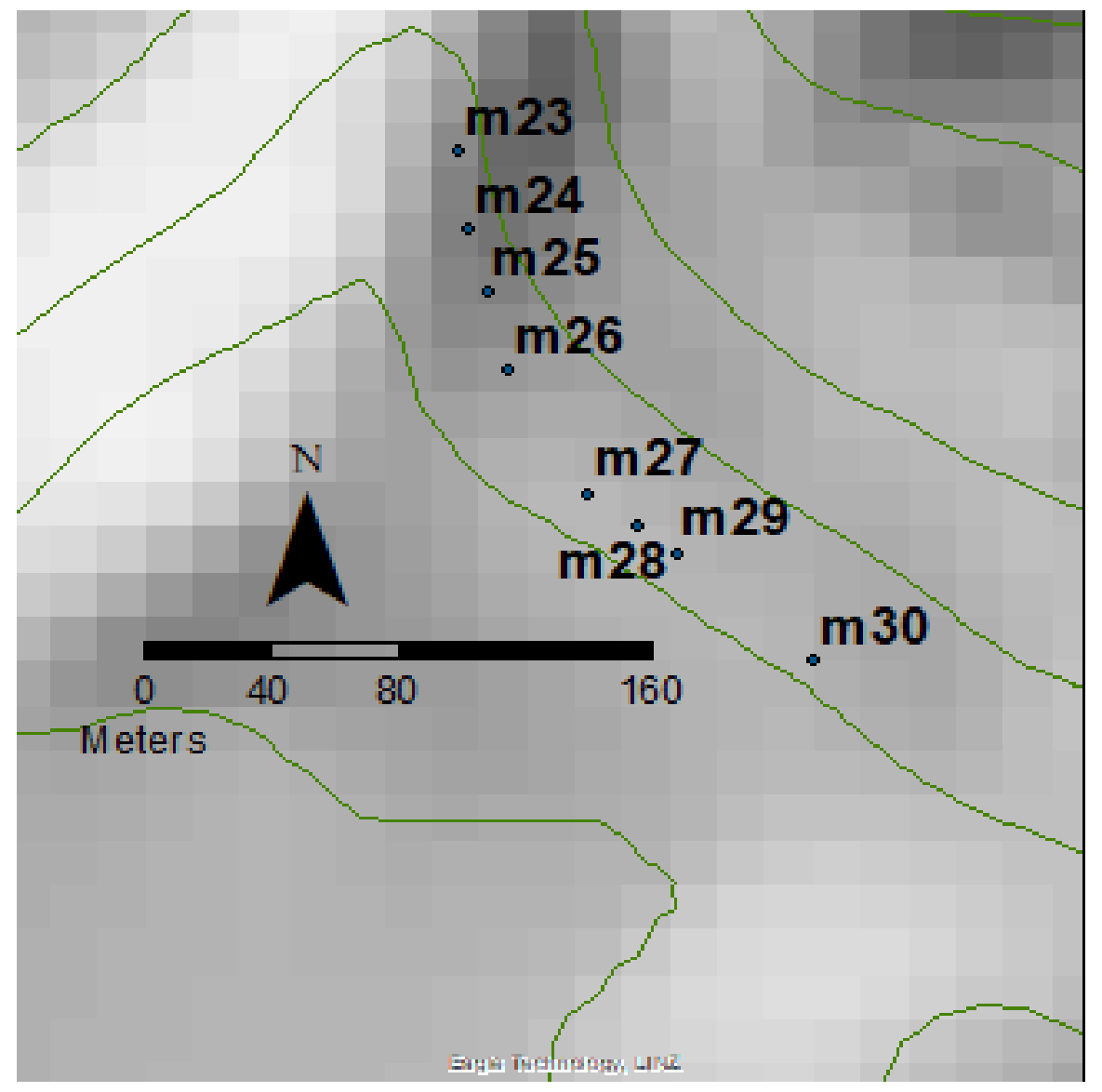

Figure 5.16: Hillslope positions of slips 23-30: Slip 23 at 129m a.s.1; slip 30 at 145m a.s.1. Contour 20m

A The plastic limit of the A horizon on slips $23,24,26,28$, and 30 indicate a high water content percent of $34.8 \%$ to $23.9 \%$. The B horizon has values from $24.3 \%$ to $17.6 \%$. The C horizon has a high percent of water content at $25.8 \%$ and low of $18.6 \%$. This indicates the $\mathrm{C}$ horizon could reach saturation levels at about $18.6 \%$. The BB horizon (should read D horizon) at slip 26D shows a high of $19.6 \%$. The A and B horizons show a trend that saturation levels could be above $25.8 \%$ while the $18.6 \%$ shows the saturation level for horizon C.

B Specific gravity of the soil in slips $23,24,26,28$, and 30 follow a similar trend to plastic limit where the A horizon has a high of $1.45 \mathrm{~g} / \mathrm{cm}^{3}$ and a low value of $1.42 \mathrm{~g} / \mathrm{cm}^{3}$. The B horizon has a high of $1.36 \mathrm{~g} / \mathrm{cm}^{3}$ and low of $1.19 \mathrm{~g} / \mathrm{cm}^{3}$. The $\mathrm{C}$ horizon has two values, slip 26 with 1.34 $\mathrm{g} / \mathrm{cm}^{3}$ and slip 24 is $1.23 \mathrm{~g} / \mathrm{cm}^{3}$. The total range of values for slips 23, 24, 26, and 28 are 1.45 $\mathrm{g} / \mathrm{cm}^{3}-1.19 \mathrm{~g} / \mathrm{cm}^{3}$. The $\mathrm{C}$ horizon has a high of $1.34 \mathrm{~g} / \mathrm{cm}^{3}$ where the D horizon below is 1.22 $\mathrm{g} / \mathrm{cm}^{3}$. 
C Liquid limit water content has a pattern that follows plastic limit and specific gravity. Slip 23 A horizon has a high water content of $52 \%$ and the low value is $40.9 \%$. The value for B horizon high is $46.2 \%$ and low of $23.6 \%$. The $\mathrm{C}$ horizon water content high is $48.4 \%$ and low of $27.5 \%$. The BB (D horizon) water content high $30.4 \%$ and low of $23.4 \%$. The B and C horizon trend indicates a less tolerance towards lower water content than the A horizon.

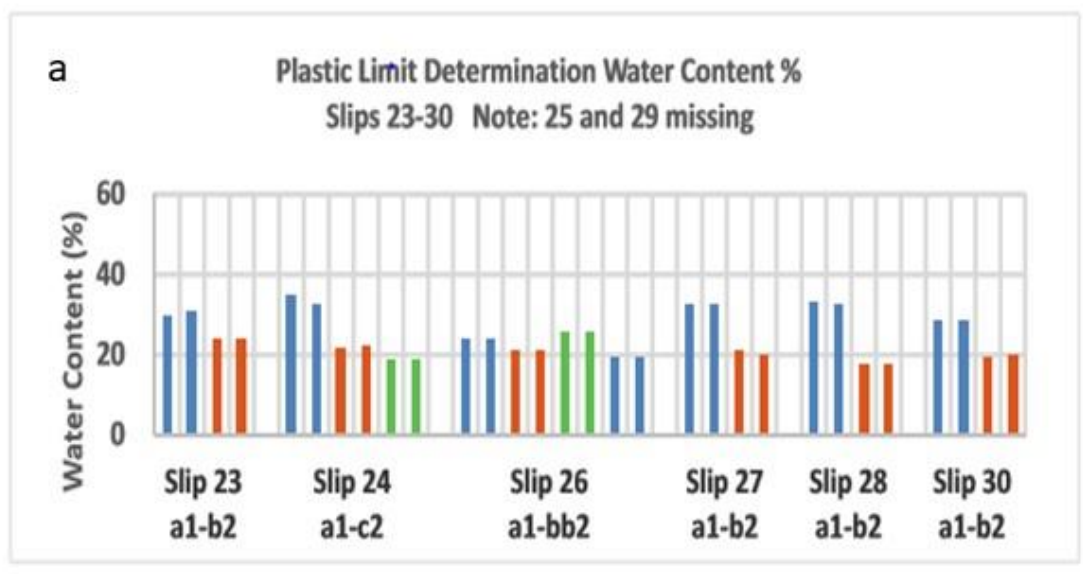

b Specific gravity slips 23-30 Note: slips 25 and 29 missing
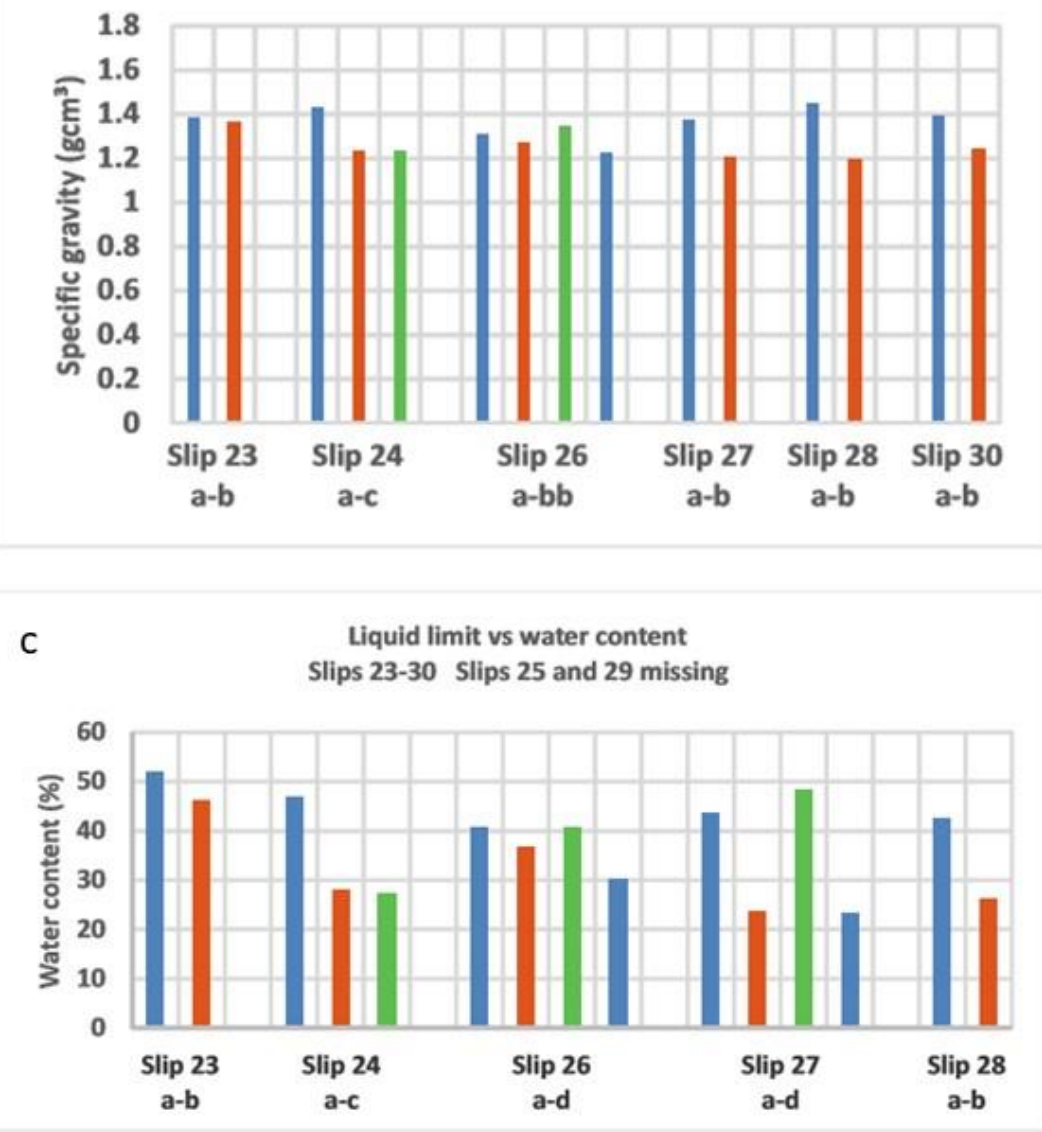

Figure 5.17: Plastic limit, specific gravity and liquid limit, laboratory results 


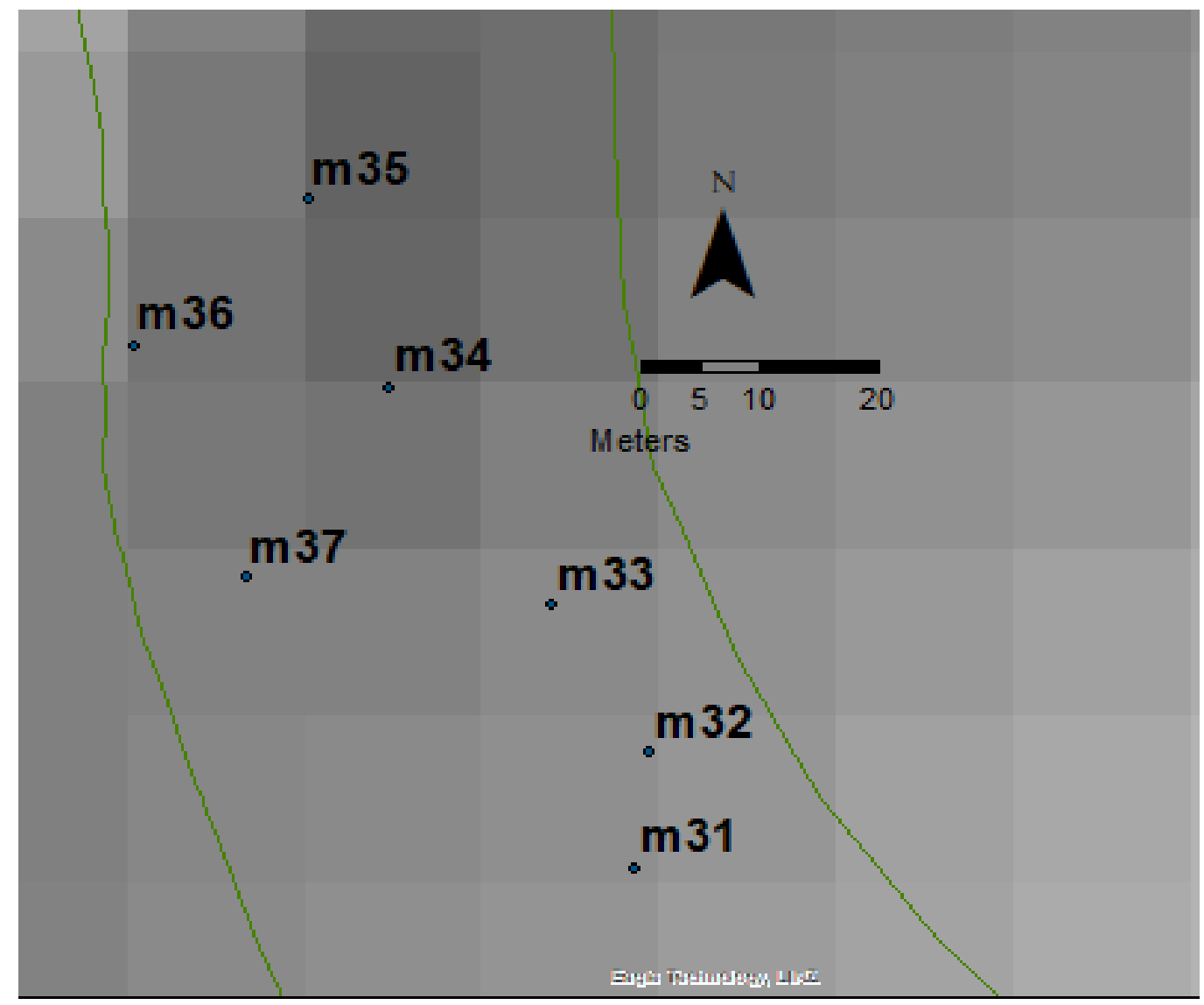

Figure 5.18: Slips 31 to 35: Slip 31 at $132 \mathrm{~m}$ a.s.l. and slip 35 at $172 \mathrm{~m}$ a.s.l. Contours $20 \mathrm{~m}$

A The plastic limit of the A horizon for slips 31-35 have a high water content of between $38.8 \%$ and $22.4 \%$, while the B horizon shows a plastic limit of $28.4 \%$ and low of $17.9 \%$. The C horizon has a water content range of $28.7 \%$ to $16.1 \%$. These results show a tendency for the A and $\mathrm{B}$ horizons to reach a saturation level above $25 \%$ while the $\mathrm{C}$ horizon is lower at $16 \%$ water content.

B The specific gravity of the soils in slips $31,33-34$, and 35 follow a similar pattern to plastic limit, where the A horizon has a high of $1.4 \mathrm{~g} / \mathrm{cm}^{3}$ and low value of $1.38 \mathrm{~g} / \mathrm{cm}^{3}$. The specific gravity for the $\mathrm{B}$ horizon has an even range of $1.35 \mathrm{~g} / \mathrm{cm}^{3}$ to $1.25 \mathrm{~g} / \mathrm{cm}^{3}$. The $\mathrm{C}$ horizon has a high of $1.44 \mathrm{~g} / \mathrm{cm}^{3}$ to a low of $1.24 \mathrm{~g} / \mathrm{cm}^{3}$. The total range for all slips $31-35$ is $1.44 \mathrm{~g} / \mathrm{cm}^{3}-1.24$ $\mathrm{g} / \mathrm{cm}^{3}$.

C Liquid limit water content for the A horizon has a high value of $88.5 \%$ and a low of $27.2 \%$. Slip 35 has $49.4 \%$. The B horizon has a high water content of $38.9 \%$, and a low of $28.1 \%$. The $\mathrm{C}$ horizon has a high water content of $45.5 \%$ and low of $26.5 \%$. These show liquid limit higher than B horizon. The trend for B and C horizons indicate they will saturate at or above $30 \%$ water content. 
a

Plastic Limit Determination Water Content \% Slips 31-37 Note: 32,36 and 37 missing

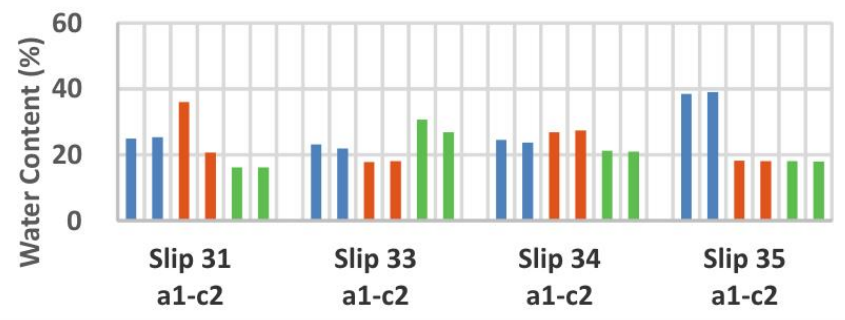

b

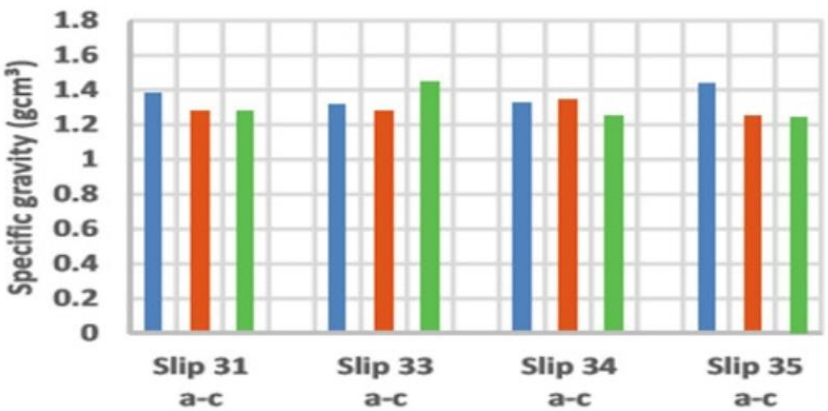

C

Liquid limit vs water content

Slips 31-37 Slips 32, 34, 36 and 37 missing

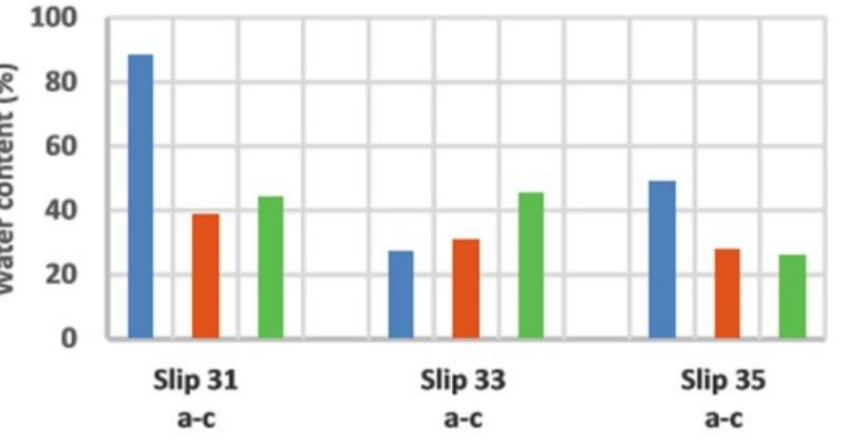

Figure 5.19: Plastic limit, specific gravity and liquid limit, laboratory results 


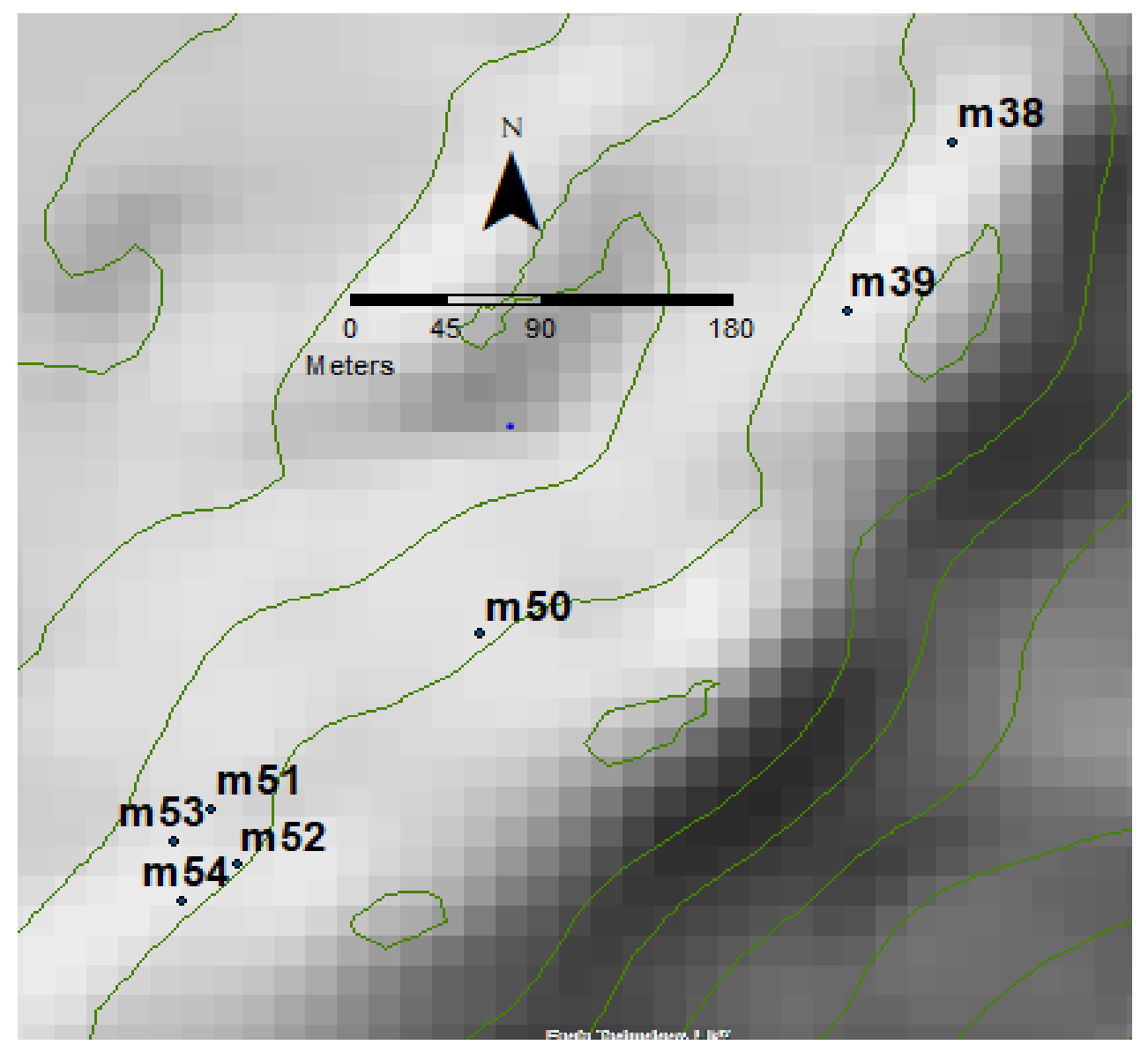

Figure 5.20: Slips 38-39 and 50-54: Slip 38 at 212m a.s.1. and slip 54 at $186 \mathrm{~m}$ a.s.1. Contours 20m

Note: Slips 38 and 39 were measured on 4/9/13 and 50-54 were measured on 13/11/16. The time lapse was due to a damaged track that restricted access. Once the track was repaired the 50-54 slips were measured. All slips face west and in a line along the same ridge face.

A The plastic limit for slips 38-39 and 50-54 has an even range of results with the A horizon water content in a range of $39.4 \%$ to $22.8 \%$. The $\mathrm{B}$ horizon has a water content trend from $19.1 \%$ to $17.1 \%$. The $\mathrm{C}$ horizon plastic limit has a range from $21.7 \%$ to $17.9 \%$. Results from these horizons indicate a trend where all slips show a water content from 39.4\%-17.1\%. The tendency for all slips in this group indicate they could reach saturation level at or about $20 \%$.

B The specific gravity of these soils indicate a similar trend as for plastic limit. The A horizon shows higher values for all slips in a range from $1.36 \mathrm{~g} / \mathrm{cm}^{3}$ to $1.21 \mathrm{~g} / \mathrm{cm}^{3}$. The B horizon values are $1.22 \mathrm{~g} / \mathrm{cm}^{3}$ and $1.16 \mathrm{~g} / \mathrm{cm}$. C horizon trend is showing higher than the B horizons with values of $1.25 \mathrm{~g} / \mathrm{cm}^{3}$ and low of $1.19 \mathrm{~g} / \mathrm{cm}^{3}$. The total range for all slips is $1.36 \mathrm{~g} / \mathrm{cm}^{3}-1.16 \mathrm{~g} / \mathrm{cm}^{3}$. 
C Liquid limit water content follows the same trend as specific gravity with the A horizon high of $40.2 \%$ and low of $30.1 \%$. The B horizon shows a high of $23.8 \%$ and low of $18.8 \%$. The $\mathrm{C}$ horizon liquid limit high is $30.7 \%$ and low of $22.4 \%$. The trend from these results show horizon B has less tolerance to excess water content.
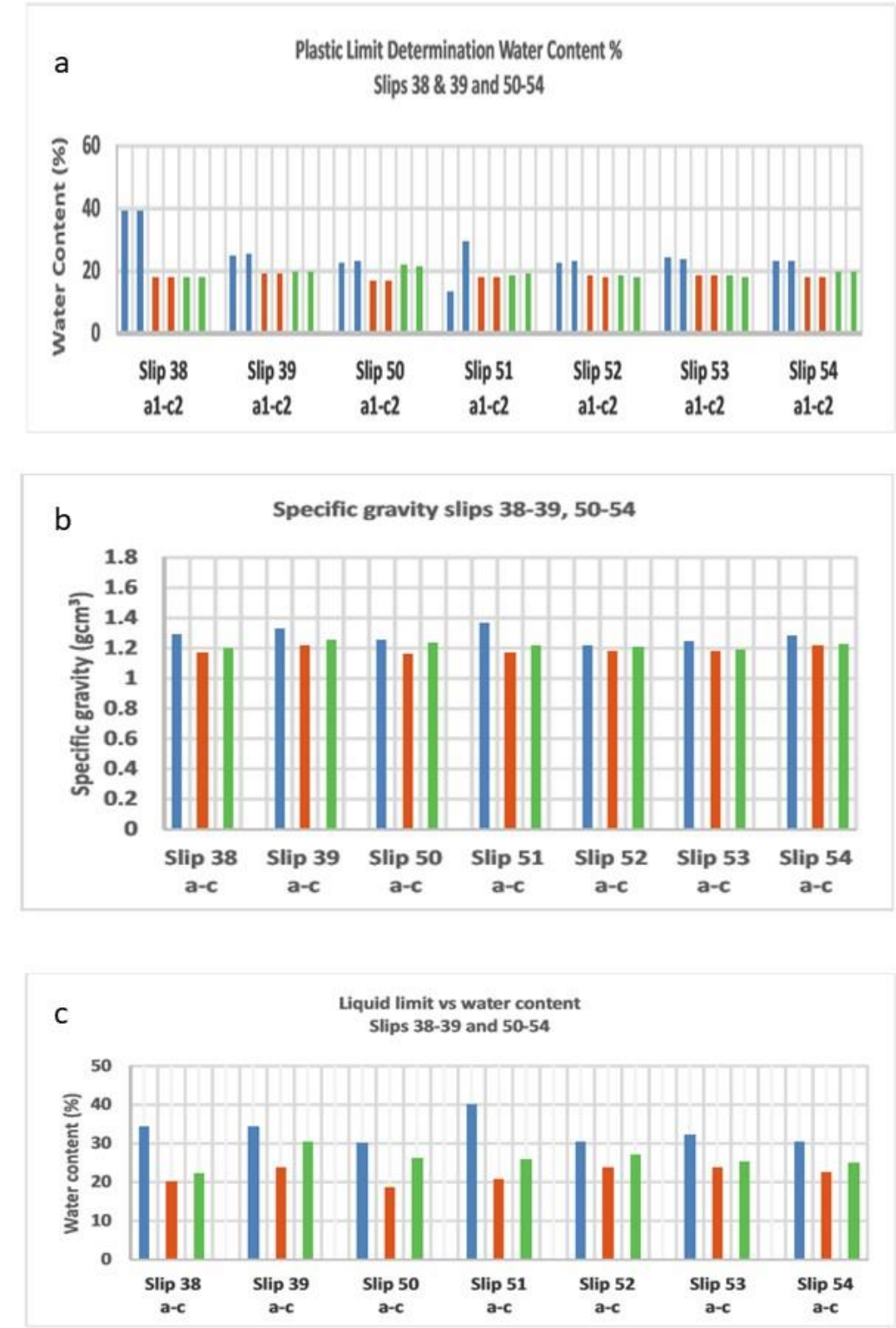

Figure 5.21: Plastic limit, specific gravity and liquid limit, laboratory results 


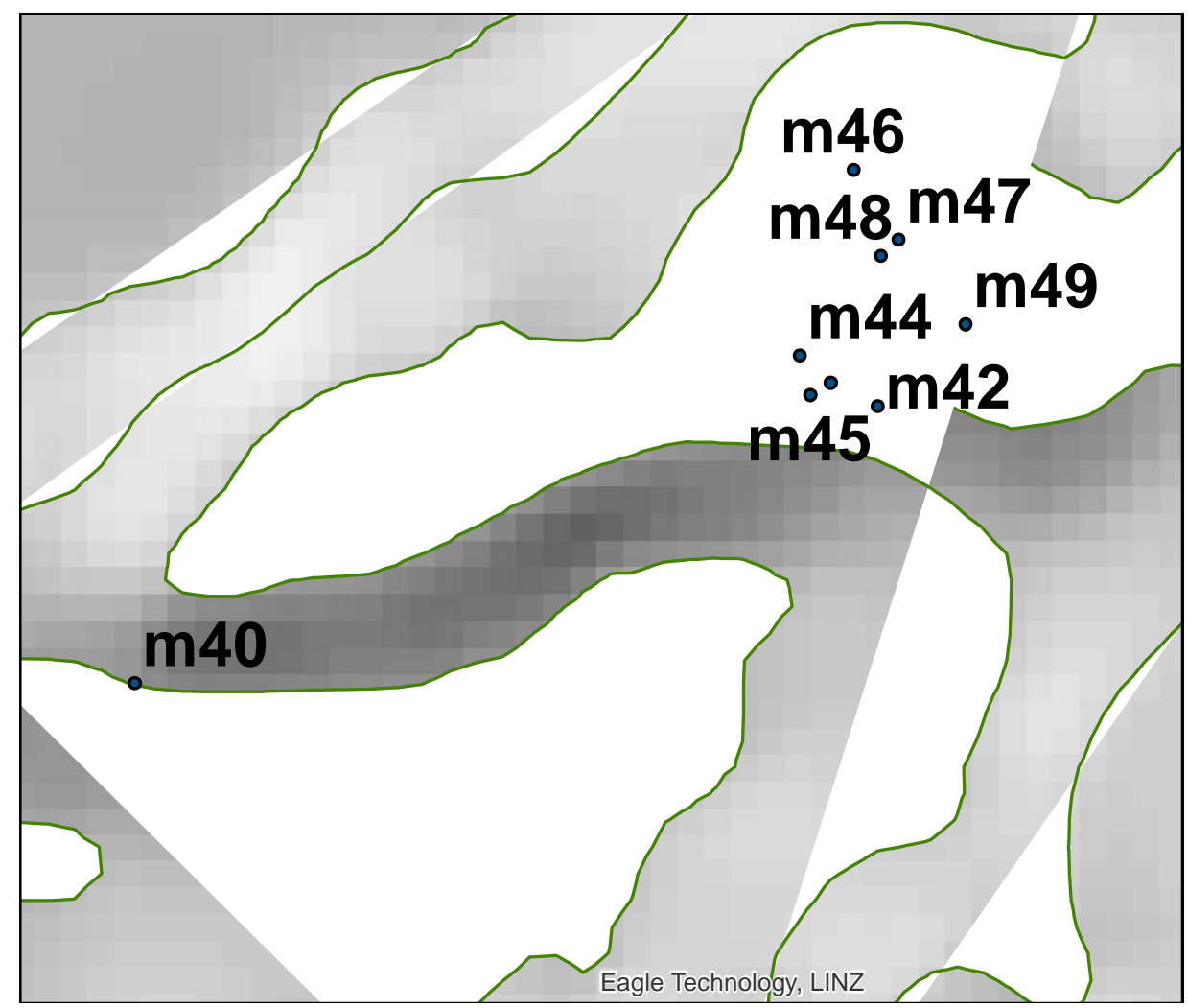

Figure 5.22: Slips 40-45: Slip 40 at 70m a.s.1. and slip 45 at $71 \mathrm{~m}$ a.s.1. Contours $20 \mathrm{~m}$

A The plastic limit for slips 40-45 for the A horizon shows a water range of $43 \%$ and $35 \%$, while the B horizon shows a plastic limit of $42 \%$ and $33.2 \%$. The $\mathrm{C}$ horizon plastic limit shows $41.5 \%$ and $32.6 \%$. The D horizon water content is $33.3 \%$. These results show a tendency for all horizons to reach saturation levels at or above $32 \%$ water content.

B The specific gravity of the soils in slips $40-45$ show changes in values. The A horizon has a high of $1.74 \mathrm{~g} / \mathrm{cm}^{3}$ and a low of $1.62 \mathrm{gcm}^{3}$. The $\mathrm{B}$ horizon has a high of $1.8 \mathrm{~g} / \mathrm{cm}^{3}$ and a low of $1.57 \mathrm{~g} / \mathrm{cm}^{3}$. Values for the $\mathrm{C}$ horizon are high $1.69 \mathrm{~g} / \mathrm{cm}^{3}$ and low of $1.49 \mathrm{~g} / \mathrm{cm}^{3}$. The D horizon is $1.59 \mathrm{~g} / \mathrm{cm}^{3}$. The range of all slips is $1.8 \mathrm{~g} / \mathrm{cm}^{3}-1.49 \mathrm{~g} / \mathrm{cm}^{3}$.

C Liquid limit water content is similar to the specific gravity with the A horizon showing a high of $78.3 \%$ and low of $70.8 \%$. The B horizon has a high value of $85.7 \%$ and low of $75.8 \%$. The $\mathrm{C}$ horizon values are $83.7 \%$ and $53.5 \%$. The $\mathrm{D}$ horizon, at slip 45 is $62.7 \%$. The trend from these results indicate a similar tolerance to higher levels of water content above $50 \%$ for all horizons. 


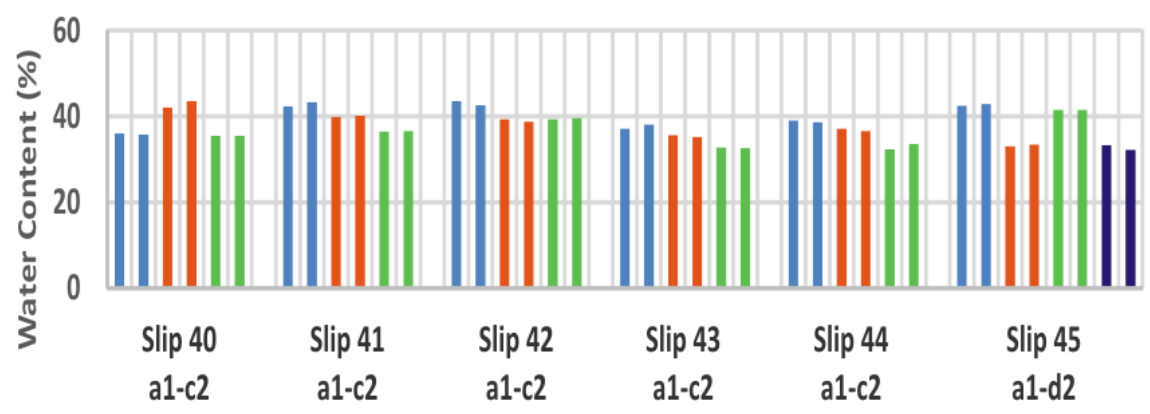

b

Specific gravity slips $\mathbf{4 0 - 4 5}$

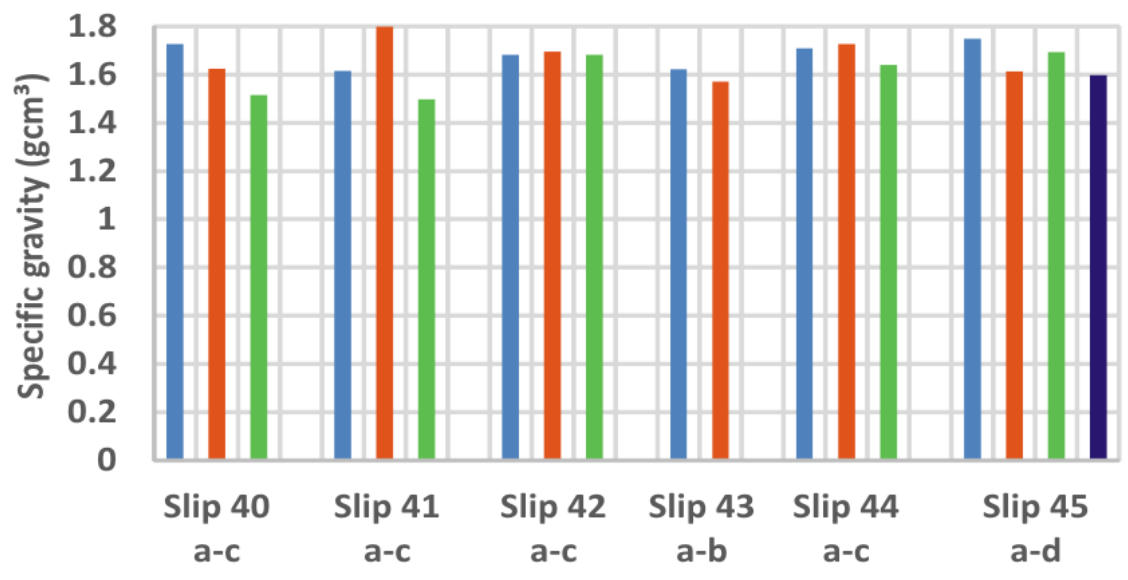

C Liquid limit vs water content Slips 40-45

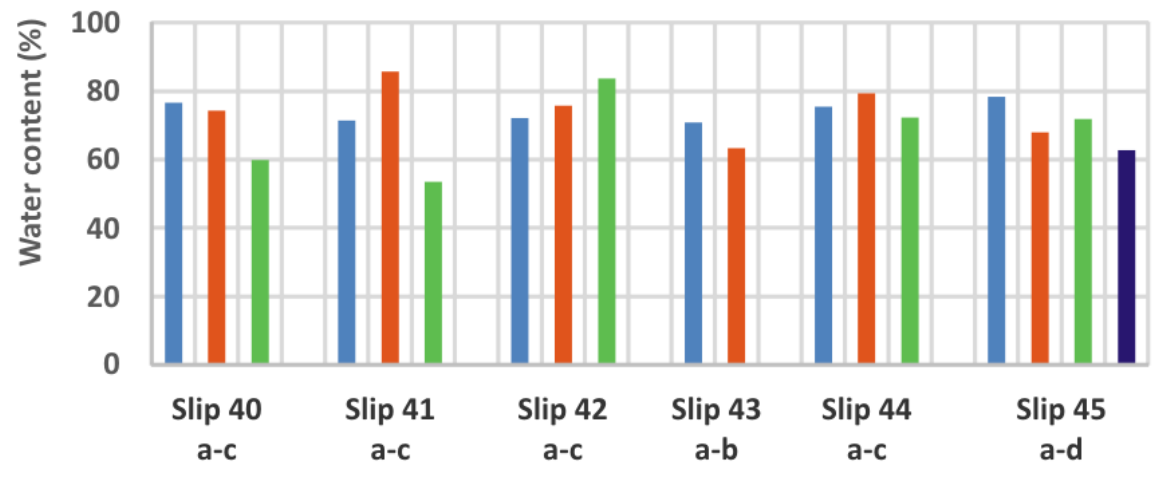

Figure 5.23: Plastic limit, specific gravity and liquid limit, laboratory results 


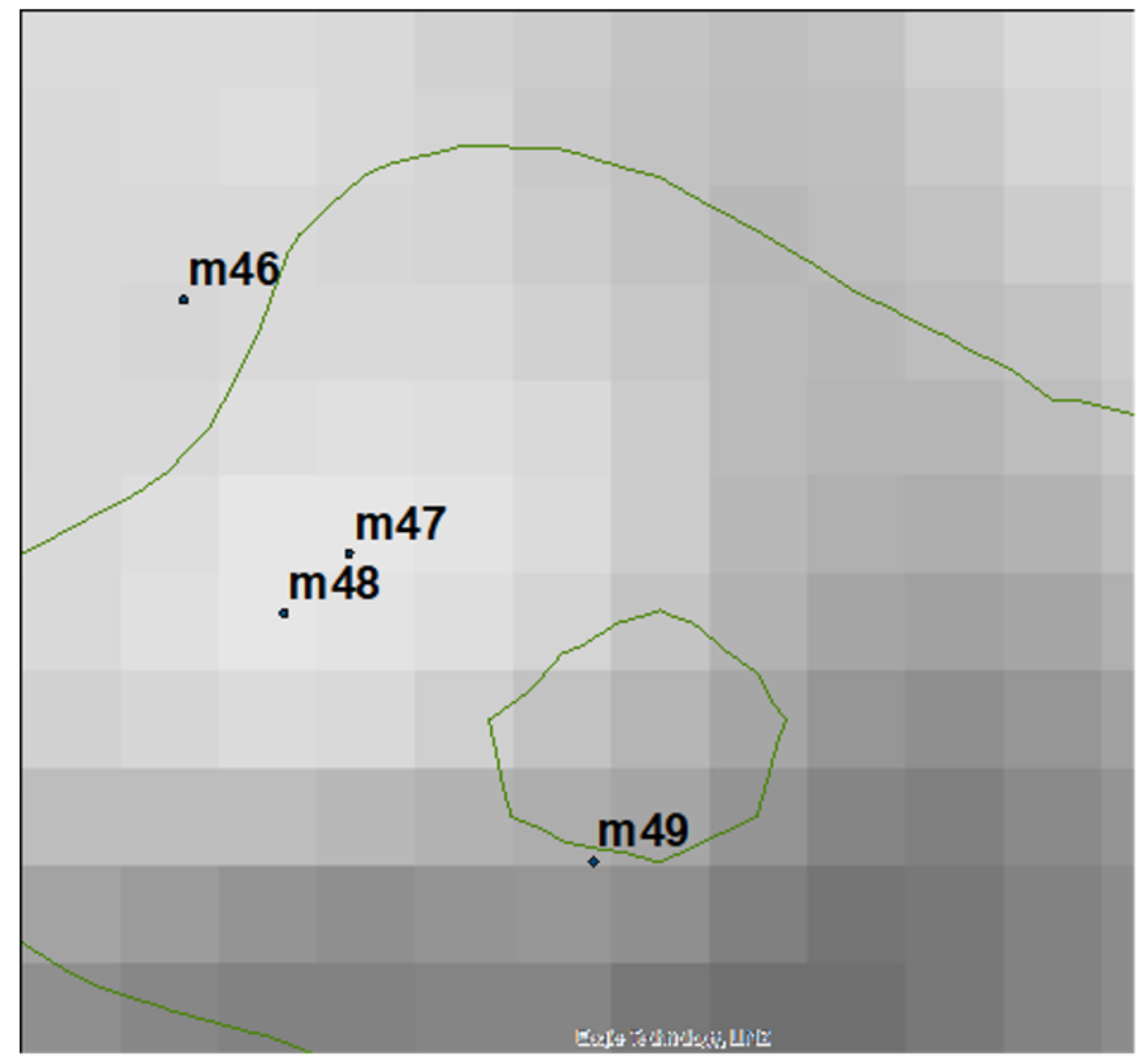

Figure 5.24: Slips 46-49: Slip 46 at 106m a.s.l. and slip 49 at $124 \mathrm{~m}$ a.s.l. Contours $20 \mathrm{~m}$

A The plastic limit of the A horizon for slips 46-49 have a water content between $48.4 \%$ and $39.8 \%$ while the $\mathrm{B}$ horizon shows a plastic limit of $41.4 \%$ and $38.9 \%$. The $\mathrm{C}$ horizon shows a plastic limit between $39.4 \%$ and $38.2 \%$. The water content results for the $\mathrm{B}$ and $\mathrm{C}$ horizons indicate that saturation levels could be $35 \%$ or above.

B The specific gravity of the soil in slips $46-49$ have an even range with the B and C horizons trending higher than the A horizon. The A horizon high is $1.71 \mathrm{~g} / \mathrm{cm}^{3}$ and a low of $1.63 \mathrm{~g} / \mathrm{cm}^{3}$. The $\mathrm{B}$ horizon has a high of $1.74 \mathrm{~g} / \mathrm{cm}^{3}$ and low of $1.57 \mathrm{~g} / \mathrm{cm}^{3}$. The $\mathrm{C}$ horizon high is $1.72 \mathrm{~g} / \mathrm{cm}^{3}$ and a low of $1.62 \mathrm{~g} / \mathrm{cm}^{3}$. The total range for all slips $46-49$ is $1.74 \mathrm{~g} / \mathrm{cm}^{3}-1.57 \mathrm{~g} / \mathrm{cm}^{3}$.

C Liquid limit water content is similar to specific gravity where $\mathrm{B}$ and $\mathrm{C}$ horizons show a higher level of water content than horizon A. Horizon A has a high of $74.4 \%$ and low of $67.1 \%$. 
The B horizon trend is higher at $76.4 \%$ and low of $63 \%$.with slips 46,47 and 48 indicating a higher result than horizon $\mathrm{A}$. The $\mathrm{C}$ horizon slips 46,47 and 48 also show a liquid limit at a higher level than A horizon. The $\mathrm{C}$ horizon high is $85.2 \%$ and low of $69.6 \%$. The trend within these three results show that all horizons could have a high tolerance towards excess water content.

a Plastic Limit Determination Water Content \% Slips 46-49
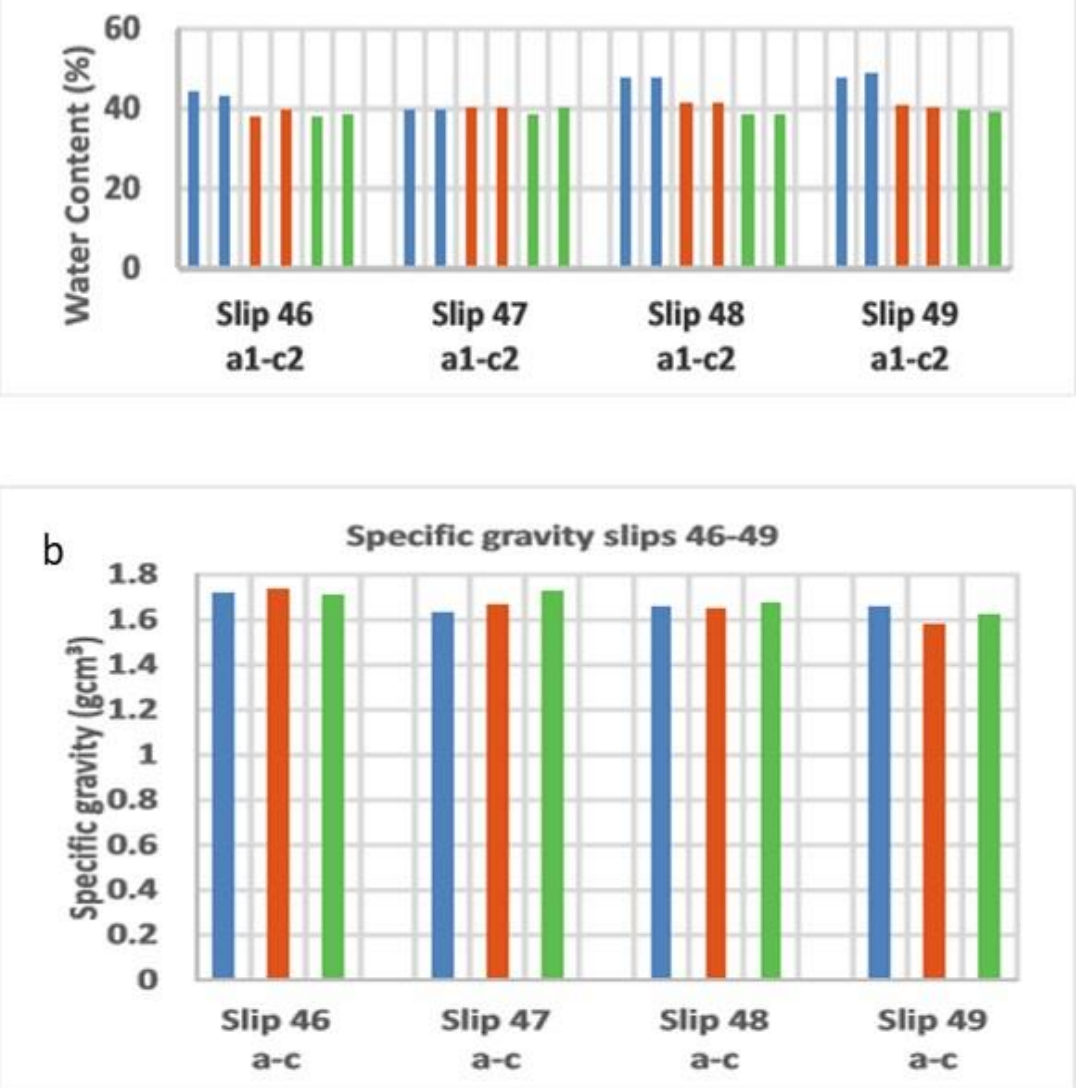

C Liquid limit vs water content Slips 46-49

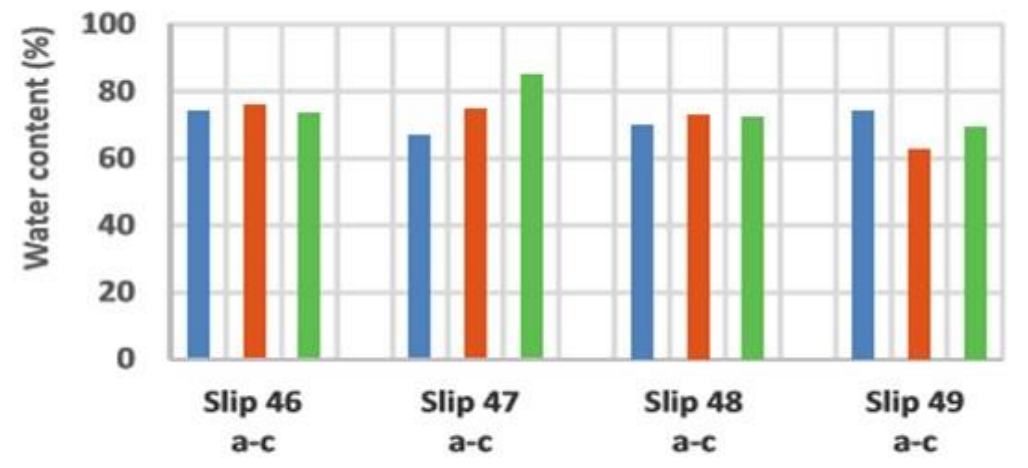

Figure 5.25: Plastic limit, specific gravity and liquid limit, laboratory results 
Laboratory results show some interesting comparisons between the slip groups.

Plastic limit indicates the average water content of all horizons at $36 \%$. However there is a significant trend showing that the A horizon in all groups has the highest plastic limit with the B and $\mathrm{C}$ horizons showing varying results. The group of landslides 9-12 have the most consistent analysis results when compared to the other landslide groups. For the $\mathrm{B}$ and $\mathrm{C}$ horizons, specific gravity and liquid limit show a reaction to loss of stability. The organic horizon A has a consistently high saturation level, while the B horizon is more stable than $\mathrm{C}$, which indicates a lower water content $\%$ and is more likely to lose stability and develop as a landslide.

There are quite a few variations in all groups through specific gravity and liquid limit, however the dominant result shows the A horizon to be consistently more stable than the lower B and C horizons. There is a mixture of results between the $\mathrm{B}$ and $\mathrm{C}$ horizons with neither having a distinctly different liquid limit.

These results indicate that some landslide locations were able to support a higher saturation level while other locations were more susceptible to lower saturation levels.

The higher saturation levels in the plastic limit of the A horizons could be attributed to vegetation cover and the organic thickness of $8 \mathrm{~cm}$ to $10 \mathrm{~cm}$ that allowed quicker drainage. The lower horizons with variations of permeability could be attributed to a combination and composition of the regolith, and it was noticeable when adding small amounts of calgon to soil samples in group 31-37 for analysing, that they became saturated very quickly due to fineness of the regolith grain. The slips in this group had a fine limestone mixture in all horizons. Variations in regolith lithology would be a considerable factor in the saturation and drainage levels within the different groups.

The level of accuracy for these lab results depends on a rigid control of mixing, weighing, drying and reweighing, plus timing. Some inaccuracies may have occurred in the field or in the laboratory. The anomalies only appeared when charts were prepared from the laboratory notes. These results have been rechecked with some minor corrections due to wrong interpretation inputs and in general are accurate to best lab practice (Table 3 ). 


\begin{tabular}{|c|c|c|c|c|c|c|c|}
\hline \multirow[b]{3}{*}{ Slip Nos } & \multirow{2}{*}{\multicolumn{2}{|c|}{$\begin{array}{l}\text { Plastic } \\
\text { Limit \% }\end{array}$}} & \multirow{2}{*}{\multicolumn{2}{|c|}{$\begin{array}{r}\text { Specific } \\
\text { Gravity } \\
\text { g/cm }\end{array}$}} & \multicolumn{3}{|c|}{ Liquid } \\
\hline & & & & & \multicolumn{3}{|c|}{ Limit \% } \\
\hline & Horizon & High & Low & High & Low & High & Low \\
\hline \multirow[t]{3}{*}{1 to 8} & A & 38 & 29 & 1.63 & 1.51 & 74 & 57.6 \\
\hline & B & 36 & 28.8 & 1.65 & 1.44 & 77 & 59.8 \\
\hline & C & 29 & - & 1.48 & 1.38 & 57.6 & 57.6 \\
\hline \multirow[t]{3}{*}{9 to 12} & A & 46 & 33 & 1.62 & 1.51 & 70.1 & 65.1 \\
\hline & B & 51 & 33 & 1.7 & 1.52 & 73.4 & 65.9 \\
\hline & $\mathrm{C}$ & 43 & 33 & 1.63 & 1.57 & 81.3 & 68.4 \\
\hline \multirow[t]{3}{*}{13 to 17} & A & 45.8 & 27.4 & 1.58 & 1.41 & - & - \\
\hline & B & 37.4 & 23.3 & 1.69 & 1.54 & - & - \\
\hline & $\mathrm{C}$ & 41 & 34.4 & 1.58 & 1.52 & - & - \\
\hline \multirow[t]{3}{*}{18 to 22} & $A$ & 45.7 & 35.9 & 1.57 & 1.4 & 62.8 & 39.4 \\
\hline & B & 38.5 & 28.5 & 1.51 & 1.37 & 69.9 & 39.1 \\
\hline & $C$ & 36.4 & 26.7 & 1.49 & 1.37 & 60 & 39.5 \\
\hline \multirow[t]{4}{*}{23 to 30} & A & 34.8 & 23.9 & 1.45 & 1.42 & 52 & 40.9 \\
\hline & B & 24.3 & 17.6 & 1.36 & 1.19 & 46.2 & 23.6 \\
\hline & C & 25.8 & 18.6 & 1.34 & 1.23 & 48.4 & 27.5 \\
\hline & D & 30.4 & 23.4 & 1.22 & - & 30.4 & 23.4 \\
\hline \multirow[t]{3}{*}{31 to 35} & A & 38.8 & 22.4 & 1.4 & 1.38 & 88.5 & 27.2 \\
\hline & $\mathrm{B}$ & 28.4 & 17.9 & 1.35 & 1.25 & 38.9 & 28.1 \\
\hline & $\mathrm{C}$ & 28.7 & 16.1 & 1.44 & 1.24 & 45.5 & 26.5 \\
\hline $38-39$ & A & 39.4 & 22.8 & 1.36 & 1.21 & 40.2 & 30.1 \\
\hline \multirow[t]{2}{*}{$50-54$} & B & 19.1 & 17.1 & 1.22 & 1.16 & 23.8 & 18.8 \\
\hline & C & 21.7 & 17.9 & 1.25 & 1.19 & 30.7 & 22.4 \\
\hline \multirow[t]{4}{*}{40 to 45} & A & 43 & 35 & 1.74 & 1.62 & 78.3 & 70.8 \\
\hline & B & 42 & 33 & 1.8 & 1.57 & 85.7 & 75.8 \\
\hline & C & 41.5 & 32.6 & 1.69 & 1.49 & 83.7 & 53.5 \\
\hline & $D$ & 32.8 & - & 1.59 & & 62.7 & 33.3 \\
\hline \multirow[t]{4}{*}{46 to 49} & A & 48.4 & 39.8 & 1.71 & 1.63 & 74.4 & 67.1 \\
\hline & B & 41.4 & 38.9 & 1.74 & 1.57 & 76.4 & 63 \\
\hline & $C$ & 39.4 & 38.2 & 1.72 & 1.62 & 85.2 & 69.6 \\
\hline & & $=$ & $=$ & $=$ & $=$ & $=$ & $=$ \\
\hline \multirow[t]{2}{*}{ Averages } & & 36.81724138 & 27.71111111 & 1.534827586 & 1.418888889 & 62.19615385 & 45.92307692 \\
\hline & & 36.82 & 25.8 & 1.53 & 1.42 & 55.8 & 41.2 \\
\hline
\end{tabular}




\section{Discussion}

The results from this study have shown that field work, sample collection and laboratory analysis are essential in determining the dynamics and interaction of an extreme weather event and hillslope failure. The April 2011 storm was perhaps the most destructive event in the small coastal villages' history, especially in living memory.

Although serious flooding of the Puhokio stream disrupted village life for a period of a few days, the damage and soil loss on the surrounding hillslopes introduced an economic loss that will last for years.

The precipitation for the valley annually averages $900-1200 \mathrm{~mm}$. Rain gauges from residents and NIWA recorded precipitation between $650-800 \mathrm{~mm}$ in approximately 48 hours. This was almost the entire years supply in that time. While searching for further local weather and precipitation records, either from NIWA or the MetService online, it was found that many of the local weather stations were obsolete or closed. Up-to-date weather records were only available from city stations. Although these provide an annual precipitation summary the local outlying areas have been discontinued, which leaves only the rain gauges kept by local inhabitants.

The east coast of the North Island has a history of hillslope failure due to large magnitudes of precipitation. Events at Waimarama, Wairarapa, Manawatu-Wanganui and Tutira (Brooks et al., 2004; Brown, 1991; De Rose, 2013; Dymond et al., 2006; Hennrich and Crozier, 2004; Preston and Crozier, 1999; Thompson and Luckman, 1993) were due mainly to the region's proximity to the convergent tectonic plate boundary and the mixture of poorly lithified marine based sediments that have difficulty in absorbing water. Hurricane Bola had a very high rainfall, recorded at $725 \mathrm{~mm}$ in $82 \mathrm{hrs}$, with a recurrence in excess of 100 years. To add to this, at Waimarama an earthquake happened around the time soil saturation would have been reaching its peak. Whether the earthquake precipitated hillslope failure or not, the resulting mass of regolith movement downslope left landslide scars over a wide area.

In the weeks prior to the storm there had been an above average rainfall that may have contributed to a quicker than normal saturation level due to antecedent ground moisture. It has been noted in previous research that antecedent moisture can be an important condition for slope failure (Crozier, 2005b). 
To determine if the regolith was in fact a weak structure, soil samples were collected from 54 landslide interfaces, on hillslopes from the three farms mentioned within the Puhokio Valley. The landslides used for sampling were in groups separated from each other. Samples were collected from the exposed head scarp and taken in each identifiable horizon.

Laboratory analysis of these samples suggest, that the sample closest to the marine bedrock i.e. some slips showed a tendency to reach saturation early in some cases, but overall, all horizons were capable of weakness under saturation extremes. There were observed stress fractures at the head of most slips which indicated a weight factor with stretching of the soil surface where gravity may eventually take over. All farms have sheep and beef cattle that contribute to surface compaction. The compaction can decrease porosity/permeability, but might also promote water moving into fractures, providing a source for water penetration to the impermeable layer of bedrock.

It was observed from Google Earth photos taken years pre-event that very few open landslide scars are visible, however, there are scattered overgrown areas that suggest intermittent landsliding has occurred. The low number of slides, and their relatively 'healed' state suggest that the 2011 event is rare.

Currently, as noted by Marden and Rowan (2015), the standard response following a significant storm is to undertake a post-storm damage assessment, where most assessments are produced as reports for clients or internal file notes and are rarely made public. These assessments are generally of a cursory nature and non-quantitative of the extent and type of slope failure. These reports may include an assessment of possible causative factors such as geology, maturity of vegetation, slope angle and storm-related factors of rainfall intensity amount, and duration of the storm (Marden and Rowan, 2015). Marden and Rowan (2015) suggest that similar studies should be undertaken across greater coverage of physiographic and climatic regions to provide more transparent information on the relationship between factors that contribute to landslide occurrence. To be of value, the information collected should be standardised, quantitative and in a format that is easy to analyse and interpret so results can be compared (Marden and Rowan, 2015). The questionnaire for this research had already been formatted in 2012 prior to the printing of (Marden and Rowan, 2015).

Many landslide scars are still visible today, seven years post-storm. There has been some aerial resowing, but generally the landslide scars have been left to revegetate independently of human support. Animals have been allowed to graze on the slips that in some cases show signs of compaction and breakdown of the siltstone/mudstone into friable components. The fracturing of 
the bedrock shows the fragility of the land, and should another extreme event occur there is every possibility that any new or remnant regolith will move downslope. A possible solution would be to remove all stock for a period, grade the land where possible, over sow with grasses (Blaschke et al., 2000) and retire the land till grass cover recolonises the slip scars.

According to Trustrum and De Rose (1988) who carried out a chronosequence on landslide scars and formation rate of soil replacement, soil depth increased with landslide age. Mean soil depth increased from $5 \mathrm{~cm}$ on 15 year old scars to $20 \mathrm{~cm}$ on 82 year old scars. These measured soil depths were attributed to rafted soil, colluvium, bedrock weathering and animal movement which helps revegetation of the slip surface (Trustrum and De Rose, 1988).

Using the NIWA return period calculation chart for this density of precipitation over a 48 hour time frame for Waimarama, the indications are that it may be at least a once in a $100 \mathrm{yr}$ event. Although, calculations show a significantly longer period, of up to a thousand years (Figure 5.26). Note: This value should be treated with caution as it is the result of extrapolation.

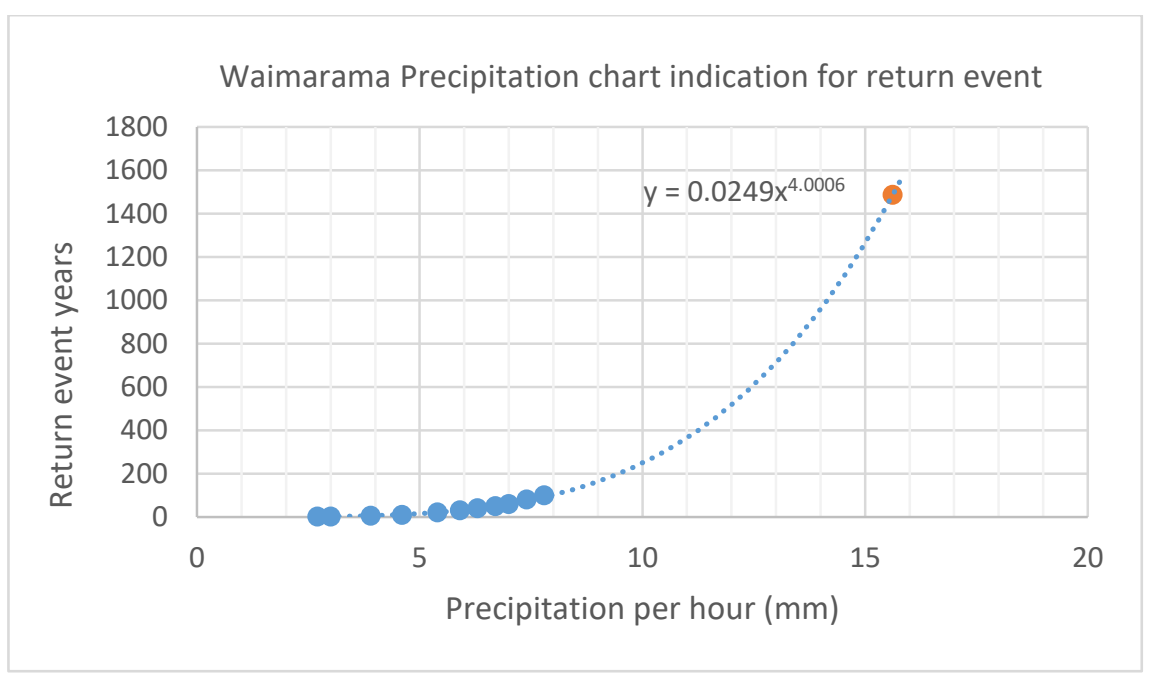

Figure 5.26: NIWA calculation for return period of extreme event precipitation

The total sediment volume from the 54 measured slips yielded $23,212 \mathrm{~m}^{3}$, the largest slip produced $3,640 \mathrm{~m}^{3}$ and the smallest $27 \mathrm{~m}^{3}$. These measured slips, were compared with Google Earth results from aerial images. Results from this combination provided similar results to those of (Crozier et al., 1980) which supported the view that the lithology of the soil, location of the slip to the configuration of the hillslope, and aspect, were the most likely areas to fail in some future event. 


\section{Developments in the use of Atterberg limits}

Atterberg (Bain, 1971) recognized five distinct stages in the development of a clay-water system from a maximum cohesive condition at low water content to a fluid slip at high water content (Bauer, 1960). Two of these, now called plastic limit and liquid limit, have long been accepted by civil engineers as important criteria for characterizing finely-divided cohesive soils, and standard procedures have been drawn up for their determination (British Standards Institution: B.S. 1377: 1967). The liquid limit is taken as the water content of the soil at which it will just begin to flow when jarred in a specific manner. The plastic limit is the minimum water content at which the soil can just be rolled by hand into threads $3 \mathrm{~mm}$ thick without crumbling. Both are expressed as a percentage by weight of the oven-dried soil. At moisture contents between the two limits the soil is in a plastic state, so that the mathematical difference between the two values, known as the plasticity index, is a measure of the range of moisture content over which the soil behaves plastically (Bain, 1971) (Figure 5.27).

\section{Atterberg limits of clays}

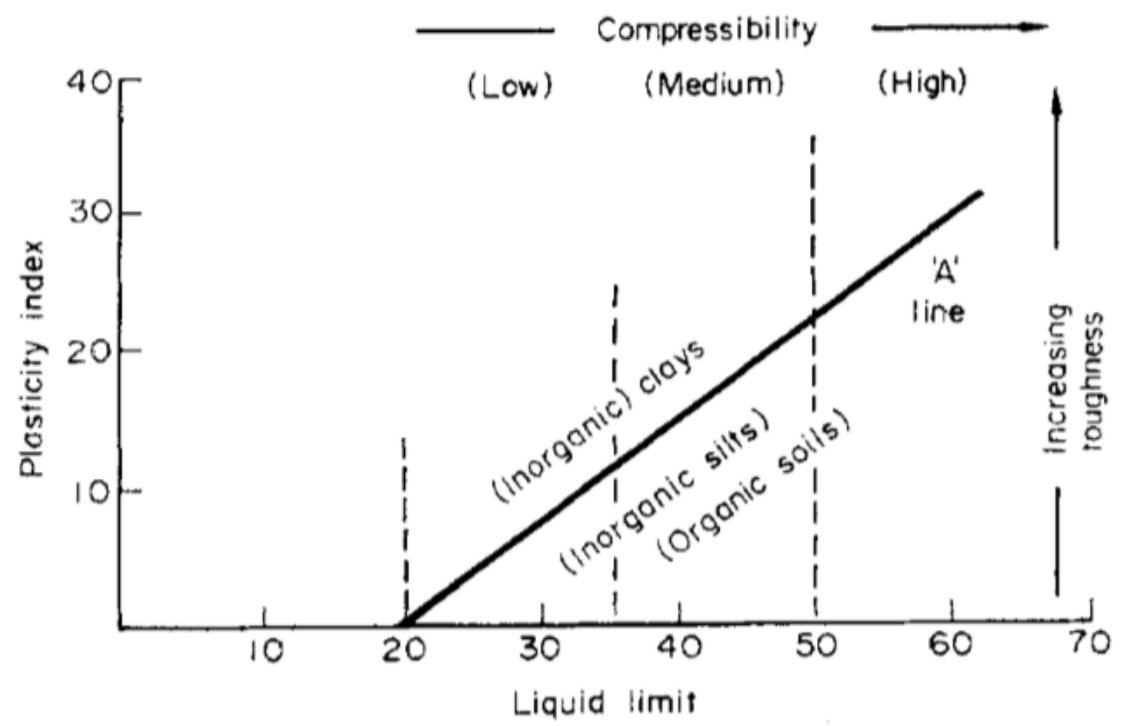

Figure 5.27: Plasticity chart for classification of cohesive soils (after A. Casagrande)

Field observations, soil sampling and laboratory testing are the most reliable way to obtain an accurate picture of the geomorphological structure and lithology of soils in the localised area of research.

Figure 5.28: Shows the Plastic Limit results of the 54 slips tested, those below the trendline are the most likely to fail through saturation. Slips can be referred to Table 3 on page 111. 


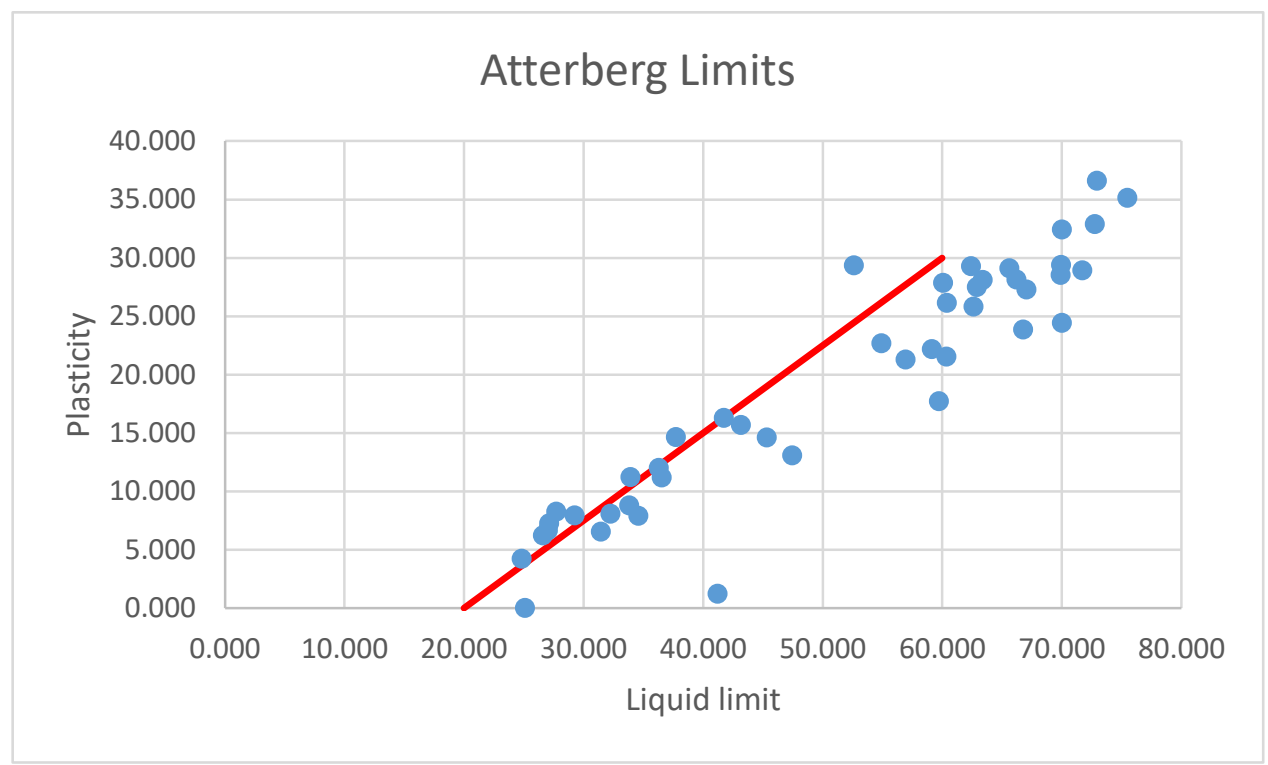

Figure 5.28: Slips shown below trendline indicate slips most likely to fail

It is important that any research undertaken in an area that has been seriously affected by extreme weather be carried out at the earliest opportunity - weeks instead of months. The reason is, that if the total slip runout sediment at landslide base is to be calculated, the best opportunity is when the sediment has settled. A longer delay may have the opposite effect as the sediment could be thinned out and transported further down slope by following precipitation or animal disturbance. As the first field research began in August 2012, it was 16 months post event and significant annual rainfall and animal disturbance had already taken place. As such, it was not possible to measure the sediment runout. Although slip runouts were not measured, regolith was still visible, showing there had been deposition. This material was stable until a force stronger than gravity occurred in the form of heavy precipitation or wind volume. The finer particles had already spread further down slope, showing up in graded lenses with the finest furthest from the slip toe. The assumption from this observation is that precipitation or aeolian forces had already been at work and the regolith will eventually reach the toe slope and river over time. 


\section{Chapter 6: Community perceptions and response to the}

\section{Waimarama Landslides}

This research included two separate studies; empirical examination of landslide loss attributed to the storm; and a questionnaire exploring the effects of this event on the local community. The Standing Committee of the Human Ethics Committee of Victoria University of Wellington oversaw the writing and approval of the questionnaire, number 19476. See Appendix for copy of questionnaire.

Residents were asked yes/no questions of an impersonal nature to gather and record information that may help communities and, local, regional and government agencies to understand what mitigating initiatives communities can expect when major events occur.

The questionnaire aimed to gauge whether small communities came together when abnormal events created hazards that threatened life, property and animals. This information should be collected as soon after the event as possible, but not during restorative recovery, because unhelpful information and anger towards outside help could dominate responses (Smith et al., 2011).

The questionnaire comprised three sheets of questions and a one sheet consent form asking participants to permit use of the information collated with that of other individuals for the purpose of this thesis. No person other than the author or supervisor(s) are privy to this information. However, item six on the consent form enabled them to receive feedback once this thesis was completed.

Twenty-two questionnaires were completed, with two rejections and one non-response. Interviews were carried out during field trips. Answers were entered onto an Excel spreadsheet and subsequently transferred into Statistical Package for the Social Science (SPSS). The results from each question were analysed in a table.

There were 20 permanent residents and 2 holiday residents living within the Waimarama boundary. Landholdings ranged from 1.56 hectare to 2630ha. Eleven residents had rain gauges and four recorded the amount of precipitation from $650-800 \mathrm{~mm}$, depending on where they lived. The highest rainfall recorded was $(800 \mathrm{~mm})$ at the holiday park which is situated alongside the Puhokio Stream. The park suffered severe flooding (Figure 6.1) when the stream rose three metres above its banks (Table 2). 


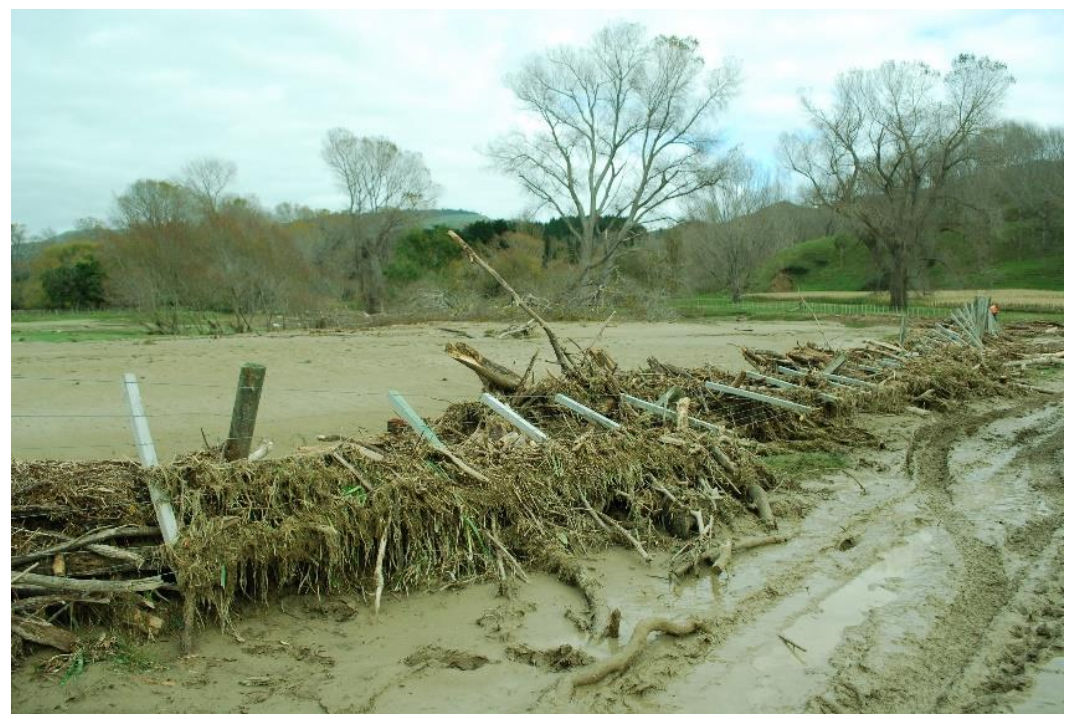

Figure 6.1: Siltation of agricultural land, fence damage with flood debris across the Pukokio Valley. McNeur photo

The holiday park lost land through stream bank collapse, from flooding and serious loss of fruit trees and chickens. Mud/silt was $30 \mathrm{~cm}$ deep after the storm. The owners continue to have ongoing drainage problems. The local general store also recorded storm volume at approximately $800 \mathrm{~mm}$ over 48 hours, but was fortunate to remain relatively damage free.

The main damage caused by the storm was serious land loss through soil slips for 19 properties (shallow slips up to one metre depth), while seven farm properties reported building, fencing and minimal animal loss. One farmer lost 11 cattle in one slip. Economic damage was recorded by 18 of the 22 respondents and 16 of those claimed insurance. Only 13 residents suffered significant financial loss and 11 were recovering financially.

The storm caused damage not only to buildings and fences but also to grazing land (Figure 6.2 montage) thereby reducing animal feed and carrying capacity. Some farmers were forced to reduce stock numbers until ground cover stabilised significantly to allow herd increases. Vegetation regeneration took nearly 18 months before slips showed signs of recovery (Figures 6.3 and 6.4). 

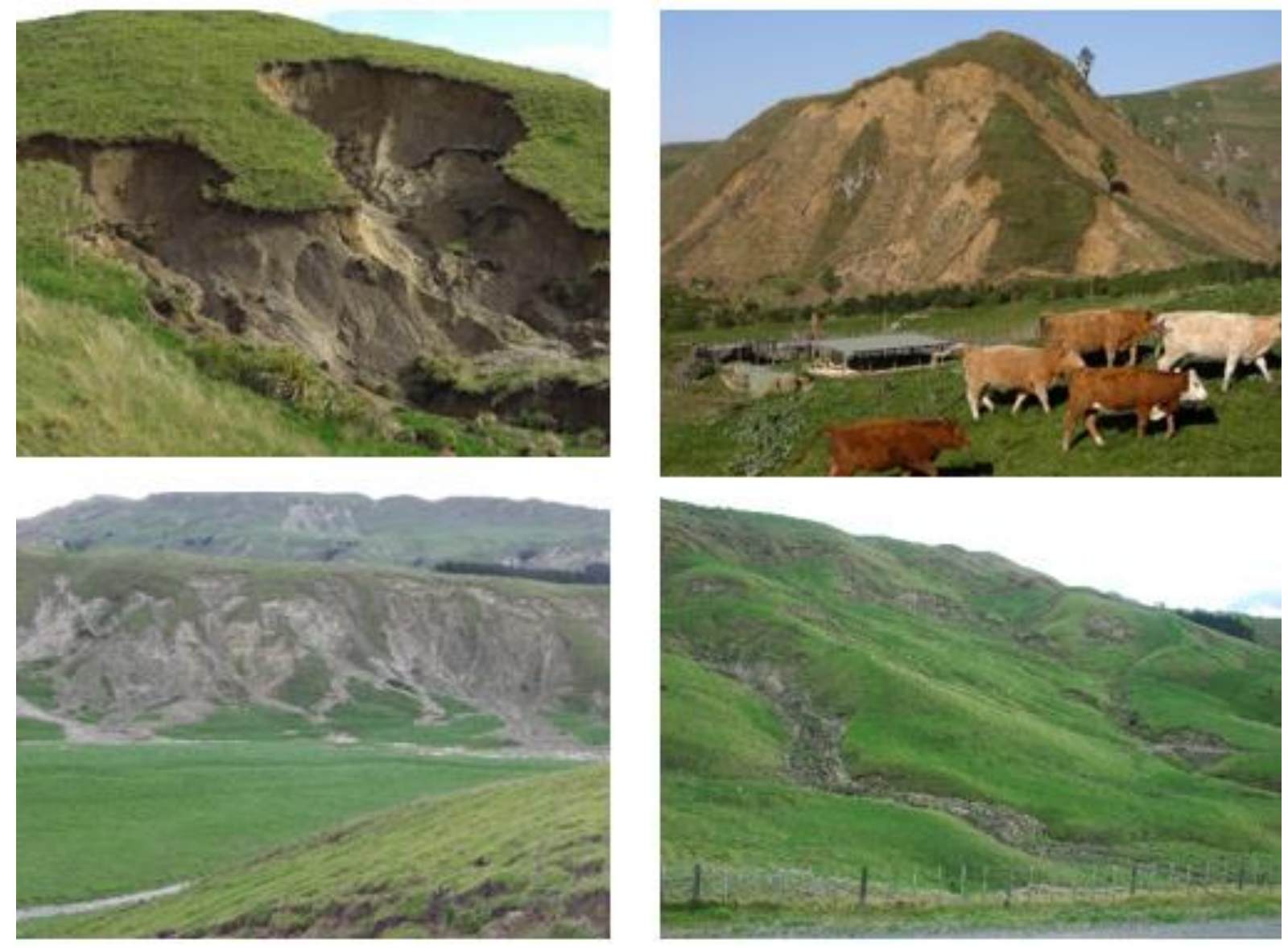

Figure 6.2: Top left: large translational slip, McNeur. Top right: Hakakino, serious land cover loss, McNeur. Bottom left: multiple translational slips, McNeur. Bottom right: Debris flow and translational slips, Author

The Waimarama Mw4.5 earthquake happened during a critical period of the storm when precipitation had increased in intensity and Puhokio Stream had begun flooding. Although the earthquake was widely felt within the valley it was the following morning when the full extent of the storm and slips became obvious. 


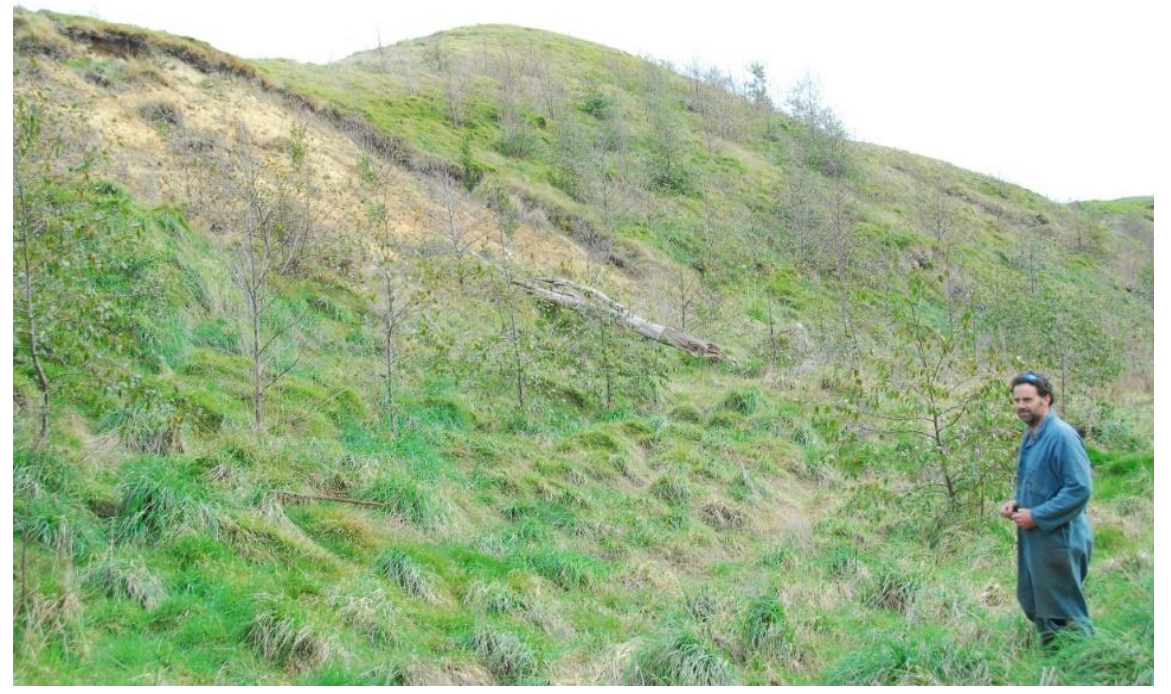

Figure 6.3: Mitigation planting

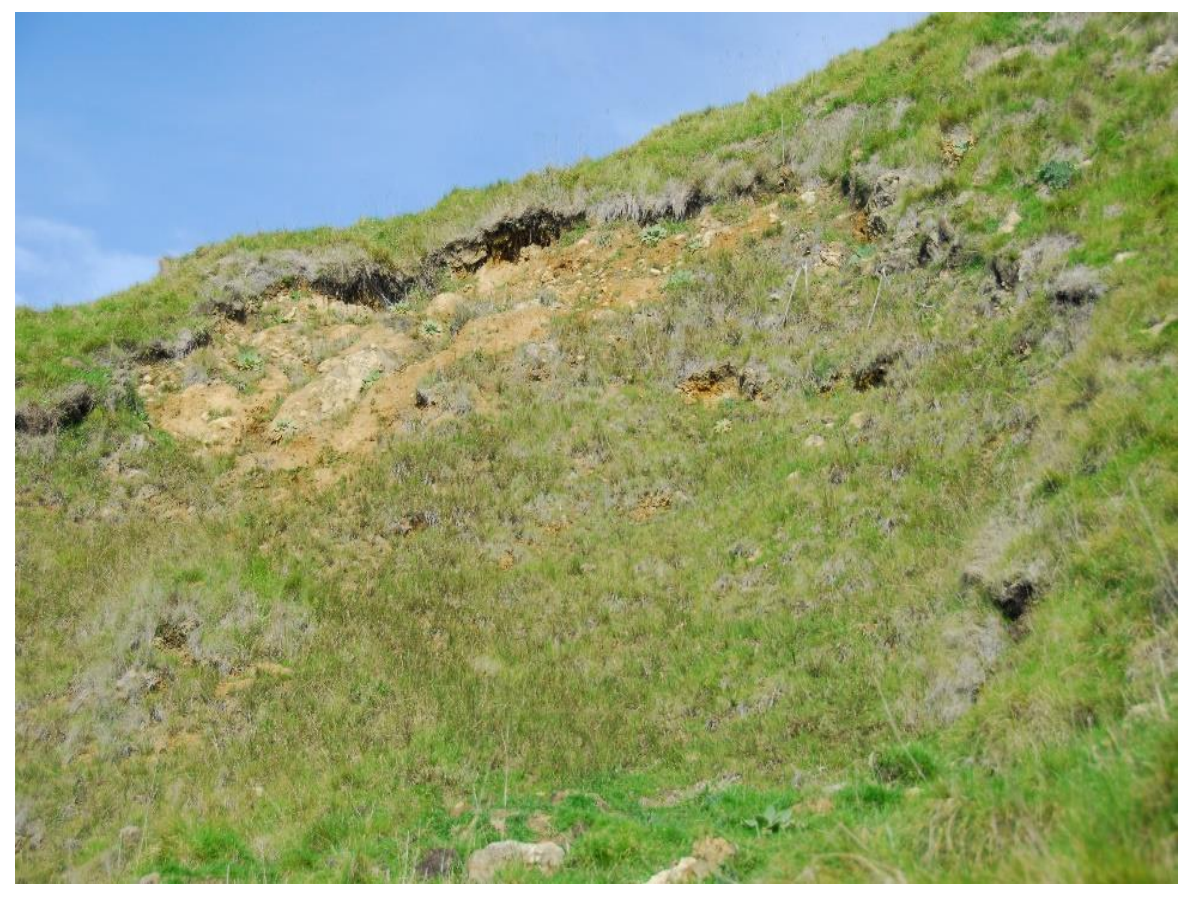

Figure 6.4: 18 months after first visit, regrowth signs very noticeable 
Table 4: Table of questions with Frequency and percent references

\begin{tabular}{|c|c|c|c|c|}
\hline QUESTIONS & $\begin{array}{r}\text { Frequency } \\
\text { yes }\end{array}$ & $\begin{array}{r}\text { Frequency } \\
\text { no }\end{array}$ & $\begin{array}{r}\% \text { Yes } 22 \\
\text { answers }\end{array}$ & $\begin{array}{r}\% \text { No } 22 \\
\text { answers }\end{array}$ \\
\hline \multicolumn{5}{|l|}{ Type of property } \\
\hline Permanent resident & 20 & 2 & 90.9 & \\
\hline Holiday resident & 2 & 20 & 9.1 & \\
\hline Rain gauge & 11 & 11 & 50 & 50 \\
\hline Record volume & 10 & 12 & 45.5 & 54.5 \\
\hline Rain volume & 4 & 18 & 18.2 & 81.8 \\
\hline Previous records & 2 & 20 & 9.1 & 90.9 \\
\hline Stock loss & 7 & 15 & 31.8 & 68.2 \\
\hline Fencing loss & 19 & 3 & 86.4 & 13.6 \\
\hline Ground cover loss & 19 & 3 & 86.4 & 13.6 \\
\hline Economic damage & 18 & 4 & 81.8 & 18.2 \\
\hline Insurance claims & 16 & 6 & 72.7 & 27.31 \\
\hline Financial loss & 13 & 9 & 59.1 & 49.9 \\
\hline Financial recovery & 11 & 11 & 50 & 50 \\
\hline Stock capacity & 10 & 12 & 45.5 & 54.5 \\
\hline Ongoing problems & 13 & 9 & 59.1 & 49.9 \\
\hline Mitigation & 15 & 7 & 68.2 & 31.8 \\
\hline $\begin{array}{l}\text { *Storm intensity In-De- } \\
\text { RS }\end{array}$ & 6 - In & $16-\mathrm{Rs}$ & 72.7 & 27.3 \\
\hline *Slips In-De-Rs & 6 - In & $11-\mathrm{Rs}$ & 27.3 & 50 \\
\hline *Slips In-De-Rs & $4-\mathrm{De}$ & & & 18.2 \\
\hline *Stock losses In-De-Rs & 4 - In & $11-\mathrm{Rs}$ & 18.2 & 50 \\
\hline *Stock losses In-De-Rs & $6-\mathrm{De}$ & $1-\mathrm{Na}$ & 27.3 & 4.5 \\
\hline \multicolumn{5}{|l|}{ Areas of property failure } \\
\hline Hillslope & 16 & 72.7 & & \\
\hline Streambank & 1 & 4.5 & & \\
\hline Stable slopes & 4 & 18.2 & & \\
\hline **Local or agency help & 15 & 7 & 68.2 & 31.8 \\
\hline \multicolumn{5}{|l|}{ In $=$ Increase } \\
\hline \multicolumn{5}{|l|}{ De $=$ Decrease } \\
\hline Rs $=$ Remain the same & & & & \\
\hline
\end{tabular}

Ten farmers reported that stock capacity was increasing due to land recovery, and 13 reported ongoing problems with continuous slope movement. Mitigation work of re-fencing, digging drainage channels, and planting trees was being undertaken by 13 respondents. Two groups began replanting soon after the storm. One group had achieved some success in restoring a large slip that had caused damage to several properties and homes. Regrowth over their slip area had covered almost all of the exposed face. A community of several houses along the coastal strip north of Waimarama Township was inundated by a large slip from the hill behind it. This slip enveloped one house, carrying on through from the back to the front of the house and rendering 
it uninhabitable, and continued on flooding close neighbours properties. This community worked together and replanted the slip and slope with quick growing natives. Two years on little evidence of the damage is visible (Figure 6.5). None of the residents had ever encountered such a storm and agreed that working together had given them the satisfaction of restoring their properties.

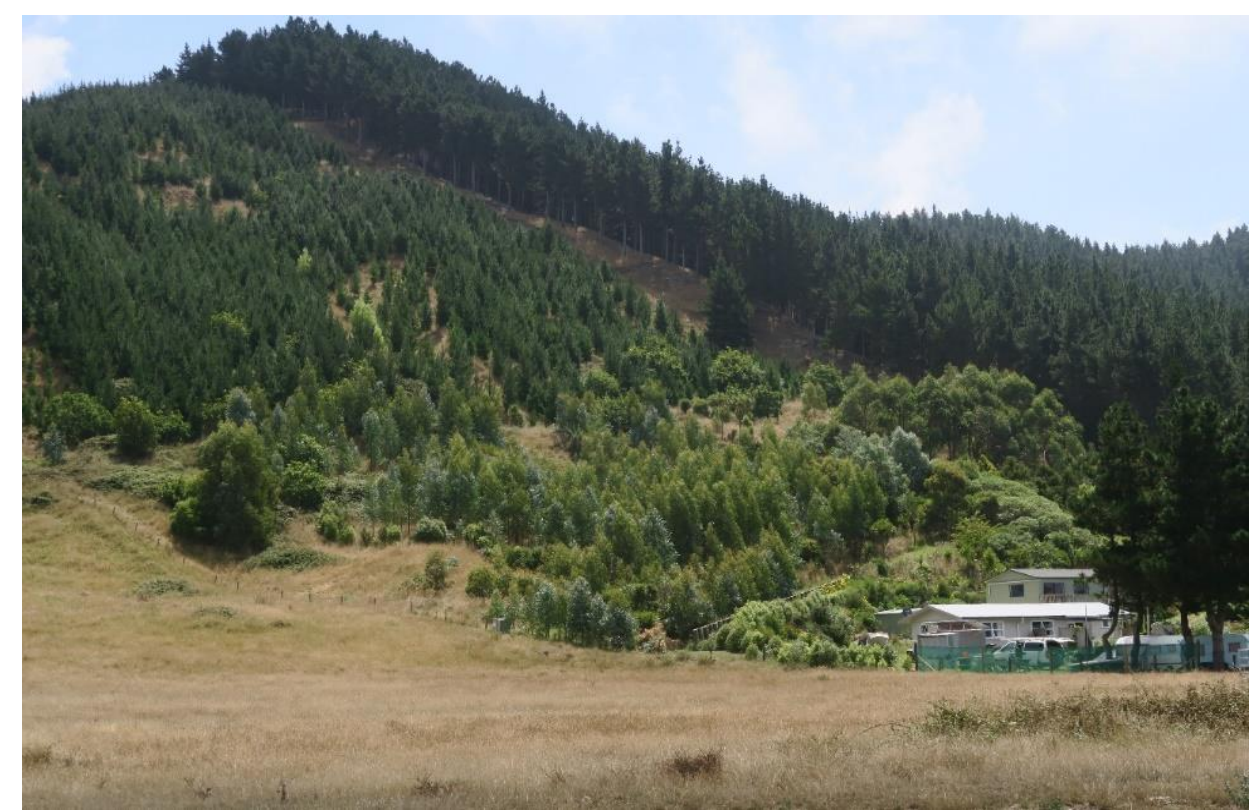

Figure 6.5: New tree plantings by the coastal community have all but removed traces of the slip that damaged houses and gardens $3-4 \mathrm{~km}$, north of Waimarama

Storm intensity since April 2011 had not shown any increase and this was recorded by 16 negative answers. Slip intensity was recorded by 11 landowners who observed that some of their slips were showing slow movement, six residents indicated an increase in slip movement and four commented that there had been no further slip movement. The main area was land loss due to hillslope failure as noted by 16 yes answers and one recorded streambank failure. The Puhokio Stream still requires clearing from fallen trees that could potentially dam in a future storm.

Asked if they had received any help from outside sources, 15 respondents answered yes while seven indicated no.

Collection of the questionnaire information was reserved till this author visited the area either on a sample collecting or questionnaire trip, usually during late morning on weekdays or all day weekends. Visiting was generally carried out as cold-calls (no previous introduction) and when requested to return, a time was arranged. Seven of the 22 interviews were arranged through introductions from previous participants. Interviews were generally 20-30 minutes with some up to an hour including refreshments. Voice recording was not used and discussion was kept to the 
questionnaire and what the information was for. The attitude towards the survey was very positive with offers to revisit at a later date to view ground cover progress.

It was identified that there was poor Regional Council help, but that Taskforce Green was extremely helpful, as was EQC and the local community. Local contractors (Angels) were at the top of the list (Figure 6.6) while general repair and maintenance was carried out by each of the landowners and farmers, e.g. installing new fence line (Figure 6.7).

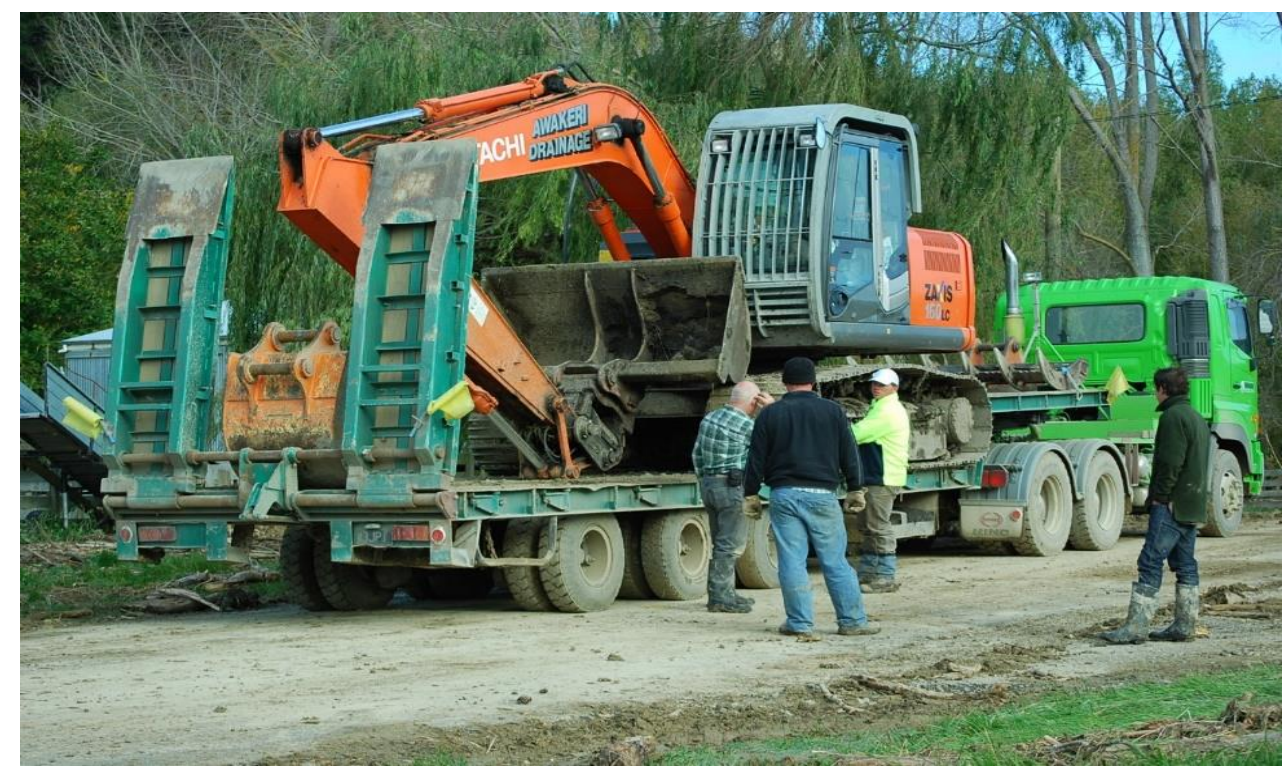

Figure 6.6: Local contractor to the rescue, recognised as a helping Angel. Photo McNeur

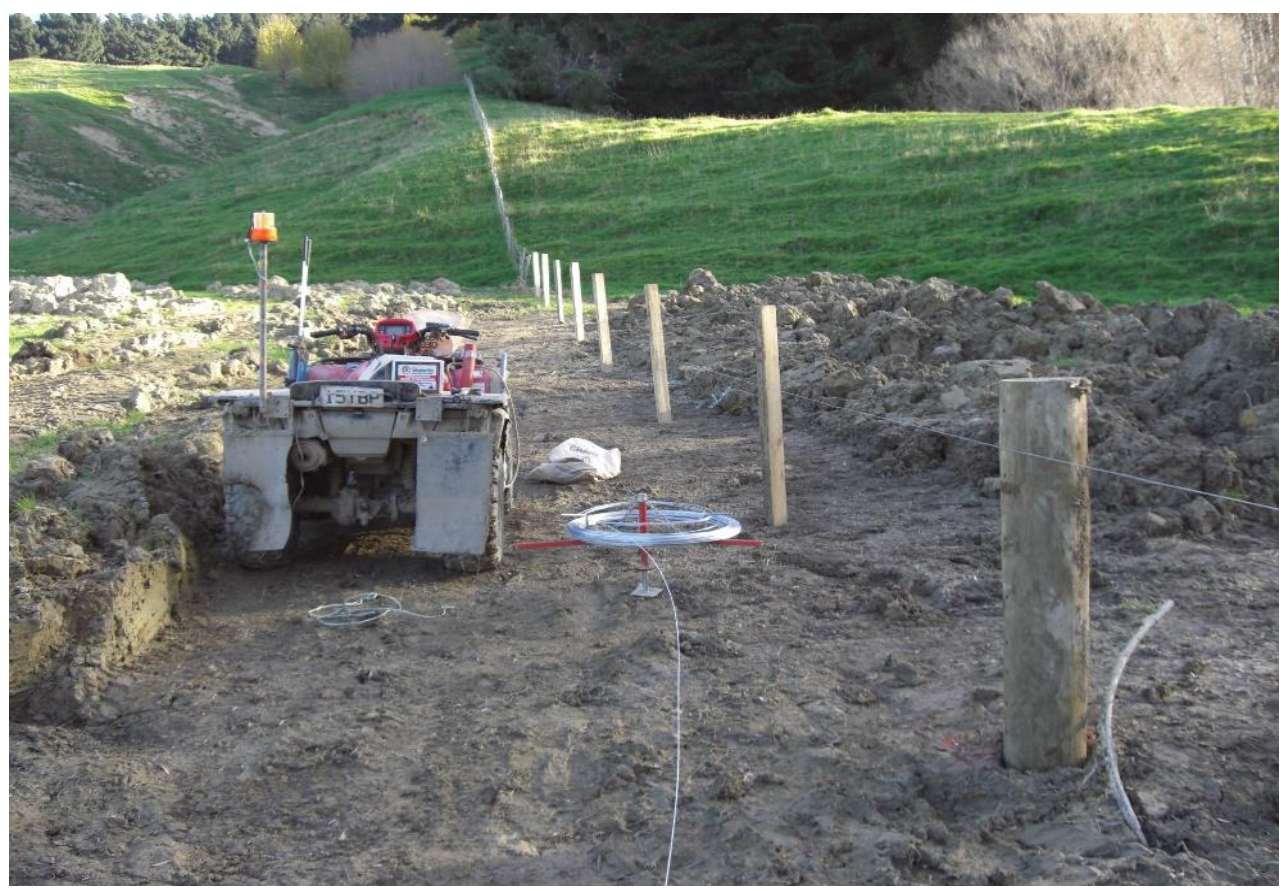

Figure 6.7: Replacing damaged fence line. Photo McNeur 
A field trip in December 2016 to observe slip rehabilitation showed promising signs of regrowth. All measured slips showed good to medium regrowth except those exposed at altitude on northwest facing slopes, while those in protected areas showed best regrowth results (Figure 6.8) and (Figure 6.9) slow recovery on eroded slopes.

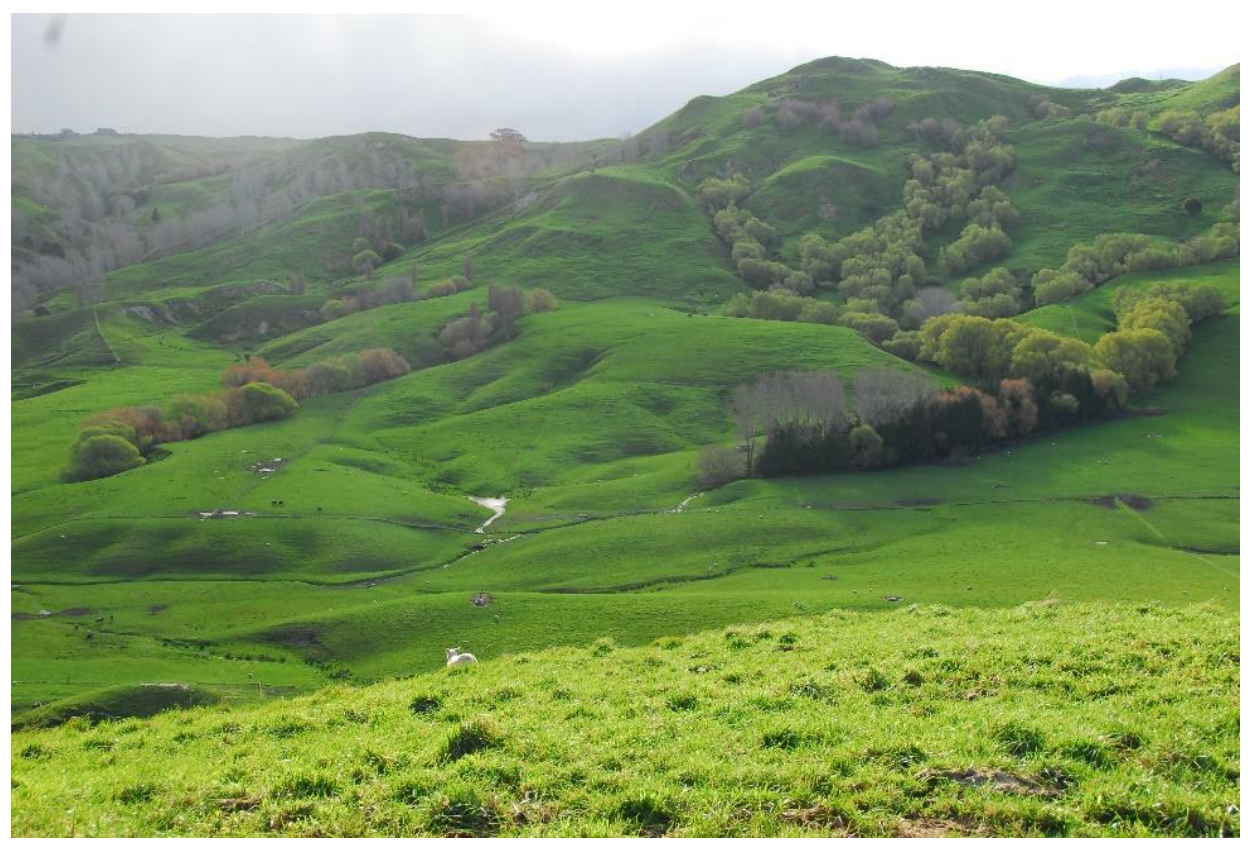

Figure 6.8: Rehabilitated farmland, ploughed and resown, adjacent farm west of main Puhokio Valley

Due to the infrequency of such events the response to the question, of whether storms have increased, decreased or remained the same, the common answer was "the same". However, residents also generally agreed that some slips had increased in size due to continued slope movement.

There will be further slip problems when heavy or continuous precipitation follows a period of wet weather, after which those slips with regolith fractures above and on the side of the head scarp are more likely to fail than those without fractures. The movement of stock on wet slopes, cattle in particular, is more likely to dislodge or break the surface soil allowing water seepage to generate mass movement at a future date (Blaschke et al., 2000).

It is noticeable that very little aerial re-seeding has been used, only over the severest scarred slopes, with natural regeneration of grasses and weeds re-colonising the slips. Mitigation, would require fertilising for grass regrowth and aerial sowing with ground covering grasses, such as white clover, perennial ryegrass and brown top (Charlton, 2008) and planting of soil holding trees (willows and poplars) (Thompson and Luckman, 1993). When discussing mitigation the 
author was told on some occasions that the costs were not recoverable, due to reduced stock units and having to buy in feed because of storm damage and ground cover loss. Insurance was expected to cover some mitigation recovery in new plant and equipment, buildings and fencelines. Hillslope recovery to economic stock production will eventually return when landslides consolidate and become regrassed.

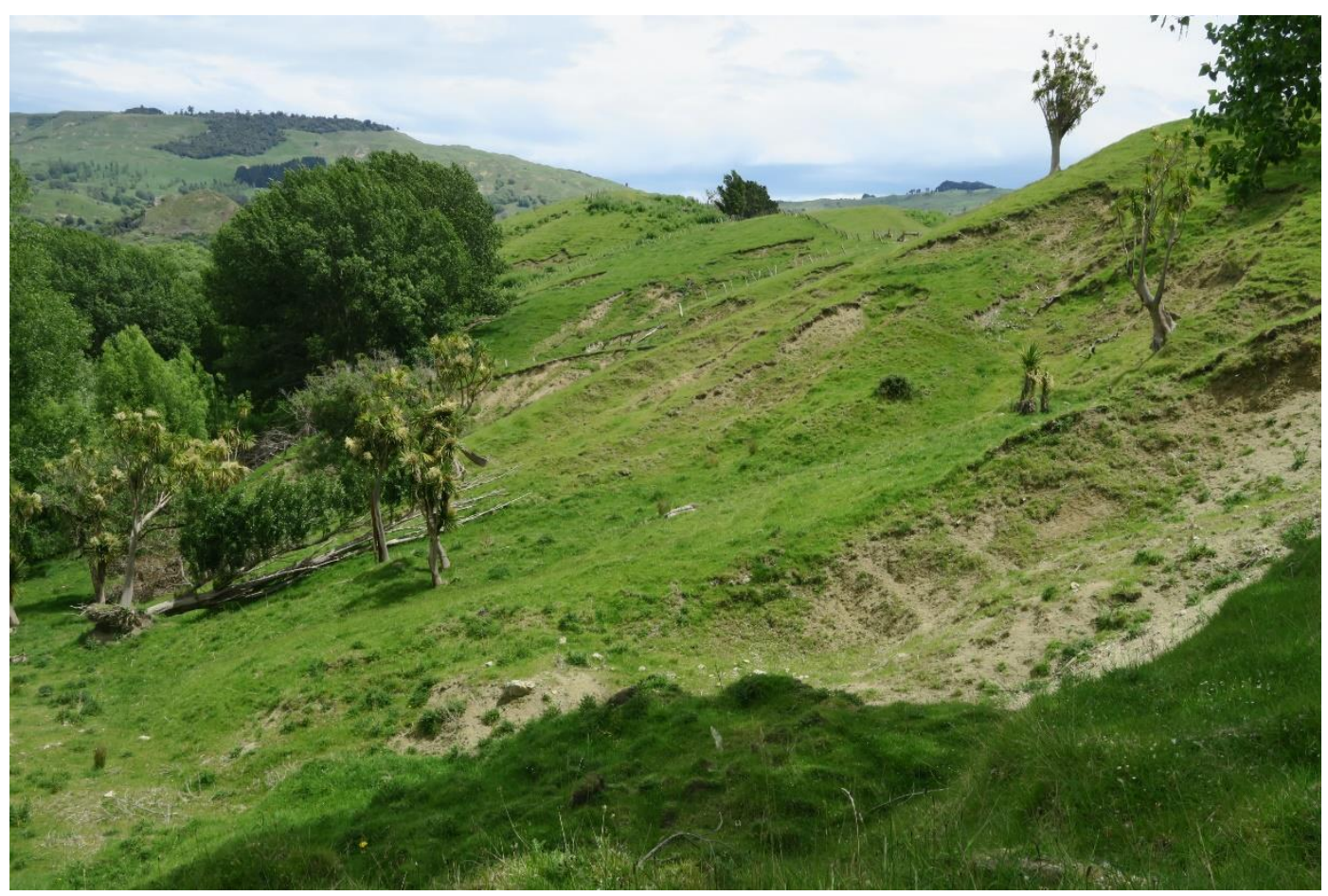

Figure 6.9: Landslides showing slow recovery, west facing slopes west of Puhokio Valley

The estimated cost of lost ecosystem services from topsoil loss due to landslides triggered in the 2011 Hawke's Bay storm was NZ\$10M (Dominati et al., 2014). However, the ongoing ecosystem services costs calculated for the following 20 years if taken into account, could reach NZ\$146M. An update to the NZ\$10M figure by Dominati et al. (2014) is NZ\$50M as recognised by GNS Science (Rosser et al., 2017).

Estimates of the national annual cost associated with landslides in New Zealand is NZ\$250 $\$ 300 \mathrm{M} / \mathrm{yr}$ (Page et al., 2015). These figures are regarded as minima due to incomplete nature of landslide data and reporting (Rosser et al., 2017).

\section{Other surveys in New Zealand and Overseas}

A survey by Smith et al. (2011) into the consequences of the February 2004 Manawatu floods provides perceptions and responses from participants showing how they individually, the community generally, and local and government agencies responded to one of the worst 
rainstorm events to impact on the Manawatu/Wanganui region. The storm was referred to as a once in a 100-year event. In the aftermath of the floods a number of investigative researches were carried out by Environmental Management Services Limited (2004) and the (Management, 2004).

In the Manawatu case a questionnaire survey including face-to-face interviews was conducted with farmers and others closely associated with the floods and aftermath. Themes and questions were prepared from literature related to community pre-paredness (Paton and Johnston, 2006) and discussions with MAF officials and other experts. A total of 39 farm households were interviewed as well as 17 individuals, who were directly involved in the management of the recovery programme that included representatives from local government, aid agencies and police (Smith et al., 2011).

Knowledge gained from these investigations was added to that of previous recovery programmes that included Hurricane Bola on the east coast in 1988 (Marden and Rowan, 1993) and a later storm event that occurred in the Manawatu region in 1994 (Brooks et al., 2002; Glade, 1998; Page et al., 1994; Preston and Crozier, 1999).

It has been suggested by (Easterling, 2007; Pachauri and Meyer, 2014) that global warming may increase the frequency and magnitude of future climate extremes, and there is an urgent need to understand better community response, and to integrate this understanding into policy.

Approaches to the management and mitigation of disasters during most of the $20^{\text {th }}$ century were organised top-down and conducted for, and not with, the communities affected (Allen, 2006; Cannon, 1994; Pearce, 2003; Smith et al., 2011). Technocratic solutions were responses that attempted to control nature or alleviate losses after the event, including large-scale engineering works aimed at forming embankments, river channel modifications, reservoirs and river flow control (Smith et al., 2011). Tobin (1999) inferred that the restoration of the local community to a state of normalcy, although an understandable objective, often led to a continued cycle of disaster-damage-repair-disaster (Smith et al., 2011).

Interestingly, Cannon (1994, p. 13) argued that 'hazards' are natural and in general disasters are not, and should not be seen as the inevitable outcome of a hazards impact. This distinction focuses on outcomes of particular hazards that vary depending on where, when, how and to whom they occur. Disasters invariably exhibit social, economic and political, as well as environmental characteristics. Researchers have now begun to concentrate on the ways different societies, communities or individuals are more or less 'vulnerable' to the effects of natural hazards. The concept of vulnerability has come to be seen as one of the key tools for explaining 
the social and spatial variability of disasters (Alexander, 1997; Bankoff et al., 2004; Smith et al., 2011).

The Manawatu floods of February 2004 were the largest emergency management event in New Zealand for 20 years, and was the first incident to occur under the new civil defence legislation (Management, 2004). Flooding occurred over large areas of the Manawatu and Wanganui district, including areas that had never flooded in living memory. A regional civil defence emergency was declared after several district councils declared local emergencies (Environmental Management Services Limited, 2004; Smith et al., 2011).

The economic cost of the Manawatu event in 2004 from a survey by MAF (2008) was estimated at NZ\$157M. The cost included structure and infrastructure, stock and crop losses and ongoing production loss (MAF, 2008).

The rural residents were particularly affected from a combination of vulnerability to property damage (flooding, high winds and landslides) including breakdown in communication. Many rural people were unaware of impending flooding until too late to move equipment and stock. Over 2000 farm properties experienced flood damage (Smith et al., 2011; Ward, 2005).

Financially and economically, the losses accumulated from the disaster were extremely high and disruptive. From the loss of stock through drowning, fencing, buildings and agricultural land, and siltation and landslips, the downtime from production and destruction of farm equipment and residences totalled an estimated cost to dairying of NZ\$24M, and to forestry NZ\$29M (Council, 2004; Smith et al., 2011).

An interesting perception from this survey (Smith et al., 2011) showed that some respondents believed there is a hierarchy within the farming/rural community with sheep/cattle farmers at the top, followed by dairy farmers, employees and lastly the unemployed. There is another group - hobby farmers that are excluded from the general farming community, due to their differing values and priorities towards perceived excessive expectations of external assistance. Some hobby farmers felt neglected in the aftermath of the floods (Smith et al., 2011).

The interviews showed a common theme of answers where repeated references were made to the ways that rural communities were changing with an increasing focus on 'town' as the centre of activity for farmers and others, and showed a considerable shift away from the immediate farm neighbourhood from a generation ago (Smith et al., 2011). 
The survey found that those living in low-lying areas were more likely to have made some type of preparation, or more likely to be aware of possible flooding, while for some of those living in the hills, the event was unprecedented, and the households were ill-prepared.

The small resident's beach community at Waimarama experienced severe regolith penetration onto their properties caused by a hillslope collapsing. There was a well organised communal response to clear away the debris, and residents spoken to during the survey commented on how pleased they were that everyone pitched in, afterwards holding a celebratory barbeque.

One of the main problems that many respondents had not anticipated was the level of isolation that endured for several days. This isolation was a result of many farmers high level of reliance on mobile phones, and expectations that communication is now 24/7. Few farms in rural areas had radio transmitters and those that did failed due to lack of batteries. It was also noted that those who relied on mobile phones were unaware that when power was lost their phones were inoperable (Smith et al., 2011).

It was found that those interviewed had decided to stay on after the flood, had found the cleanup time consuming, and had found the effort gave little time for social activities and placed a significant strain on personal relationships. Financial resources also were required for rebuilding infrastructure, which added pressure to debt servicing that would otherwise have been used for business growth. A noted health issue from some individual farmers were the symptoms of stress, including an inability to sleep when it rained, and crying when recalling the trauma involved (Smith et al., 2011).

It was argued by many respondents that aid agencies, especially those organised at regional or national level, lacked local knowledge and understanding of the area. They suggested that the official flood response was top-down, and that local initiatives were stymied in some areas by bureaucracy further up the chain (Smith et al., 2011).

Following are some quotes that apply to officialdom interference, when help is the major requirement:

"The community response for helping out was overwhelming and the council just seemed to get in the way. An example: they closed off the road into the valley which prevented relatives and friends who were trying to help from entering."

"Many officials had all trained 'city-ised' knowledge but this could not replace the local knowledge and experience which was often ignored." 
"The beauracracy was way over the top. For example: many people were stopped from coming into town with their shovels as there were OSH/ Occupational Safety and Health issues."

"When government officials came they simply got in the way of the effort. Their systems of process defy all kinds of common sense, which farmers have about their land and stock." (Smith et al., 2011).

Such accounts reinforce the views of researchers including (Pearce, 2003), who show the importance of social capital in hazard mitigation and the need for public participation in disaster planning and recovery. These accounts suggest, there is a significant disconnect between government and farmers in their expectations of response, notably in distinctions made by many farm house-holds between knowledge and expertise - either as something that is gained through experience of the locality, or as a 'trained "city-ised" knowledge' which commonly is viewed as inappropriate in practice (Smith et al., 2011).

While the 2004 Manawatu flood clearly exposed the vulnerability of rural communities, it forced people to re-think what, or, more correctly, who, constitute their community. In certain cases, this revealed a complete breakdown of community involvement (Smith et al., 2011).

The 2011 storm at Waimarama, forced residents to collect rainwater, as the water-main pipe was broken at the same time road access was closed when the main bridge into the village became damaged and unusable. Road access was also closed due to landslides and flooding. Power and lighting was cut and a helicopter was used for emergency patient transport (Research, 2011).

Patankar and Patwardhan (2016) surveyed the effects on households and small businesses of the uninsured losses due to a major flood event in the city of Mumbai, India. Climate-related hazards have a huge physical, economic and social impact that can have long-term negative consequences for development and poverty alleviation. To assess and measure these impacts it is essential to formulate a needs-based adaption for disaster risk management policies. While most impact assessment studies generally focus on economic impacts measured either through insured losses associated with private capital, or through insured and uninsured losses associated with public infrastructure such methods fail to reflect the losses suffered by the informal sector includes households and small commercial establishments, as these are mostly uninsured, and detailed information on impacts is either unavailable or difficult to obtain (Patankar and Patwardhan, 2016). 
Insurance industry figures for the number of meteorological, hydrological and climatological loss events (disasters) worldwide between 1980 and 2013 has increased from an annual average of 250-800, while the overall estimated losses have increased steadily from US\$70 billion in 1980 to US\$400 billion in 2011 (Munich Re., 2014). These losses have been calculated at 2013 values and adjusted for inflation, based on the consumer price index for each country. Losses from disasters between 1980-2012 worldwide show that a significant share of them (about 75\% or US $\$ 310$ billion) is uninsured (Munich Re., 2014) and that in poor and inadequately insured economies, based on calculations from the Munich Re database, only $7 \%$ of the overall losses (US\$13.8 billion) were insured in 1980-2009 at 2012 values (Munich Re., 2013). This shows a significant insurance deficit among poor and developing economies which imposes almost the entire burden of impacts of the weather on their people (Patankar and Patwardhan, 2016). Where there is a large informal economy, the penetration of insurance for life and non-life products, including that for physical assets, is minimal or non-existent. The share of the developing countries in the world's non-life insurance market is only 10\%. The insurance density in OECD countries in 2007 was \$2517 as against South Asia with a density of \$67.8 (UNCTAD, 2007), (Insurance density is the total premium income per person in a country's population). The insurance density for India for non-life insurance was \$10.5 in 2012 and insurance penetration was 0.78 in 2012 (IRDA, 2013b), (Insurance penetration is the ratio of premium underwritten in a given year to the Gross Domestic Product (GDP) (UNCTAD, 2007). Insurance density and penetration are the two indicators of the extent of insurance coverage in any country (IRDA, 2013a). These results suggest that the absence or inadequacy of insurance coverage, turns most losses related to weather events or disasters into out-of-pocket expenses for the citizens in the developing world (Patankar and Patwardhan, 2016).

The importance of insurance was highlighted during the survey at Waimarama where residents who lost buildings or other property, such as farm implements, fences and personal effects were adequately covered, although insurance companies required current receipts or age of equipment lost. During the survey all residents had insurance.

Uninsured losses, especially in the developing world, need to be assessed as they form the largest part of the total losses in case of weather events (Munich Re., 2013). It is critical to assess the losses suffered by the largely uninsured communities in the developing world to understand the full implications of the extreme weather events for them, understand their vulnerability, and help devise suitable adaption strategies that will minimise such losses in the future. On 26 July, 2005, Mumbai experienced an extreme precipitation event that led to unprecedented floods, massive 
damage, loss of life and property and affected the economic and social services adversely (Patankar and Patwardhan, 2016).

An India Meteorological Department (IMD) weather station, located in the western suburb, recorded $944 \mathrm{~mm}$ precipitation (this was $45 \%$ of the annual average rainfall for Mumbai). A previous recorded heavy rainfall of $570 \mathrm{~mm}$ in Mumbai was on $5^{\text {th }} \mathrm{July,}$ 1974. A number of estimates were put forward in the aftermath of the floods to understand the extent of the damage, there were 50,000 residential and 40,000 commercial buildings partially damaged. An unofficial figure quoted by the Indian Merchants Chamber (IMC) put the losses at Indian Rupees (INR) 50 billion or US\$1.1B (Maharashtra, 2005). Munich Re, using the standard methodology of insurance density, population density and nature of the region affected, and extrapolation, estimated the total losses at US\$5B (including insured losses of US\$770M) for the Mumbai floods (Jha et al., 2011; Munich Re., 2011). Ranger et al. (2011) carried out a detailed exercise of estimating the total direct damages of 2005 floods. Combining the total insurance value (TIV) estimated for different property types with the average mean damage ratios, the simulated direct losses, including infrastructure, were estimated in the range of US\$690-1910M (Patankar and Patwardhan, 2016).

Patankar and Patwardhan (2016) stated that the total losses calculated by (Munich Re (2011) and Ranger et al. (2011) were based on exposure maps and assumptions concerning population and insurance density, but they had not included any information on the nature and magnitude of losses of households or small businesses in their estimates. Patankar and Patwardhan (2016) emphasised that the results from their survey added value for a detailed understanding of the nature and magnitude of the losses associated with household and small businesses. The primary data collected from their survey and used for this estimation was to show the vulnerability of those sections of the population who did not have insurance, or social security, or had very limited means to carry the burden of losses resulting from floods (Patankar and Patwardhan, 2016).

Globally, natural hazards levy an "environmental tax" on society, according to Pike et al. (2003), and the burden is increasing worldwide. There was little change from insurance losses ascribed to human actions from 1970-1992. Losses to extreme weather disaster increased from US\$3.9 billion per year in the 1950s to US\$40 billion in the 1990s (Pike et al., 2003).

Two comparable empirical studies with detailed estimates of losses for households were undertaken after the German Federal State of Saxony floods (Meyer and Messner, 2005) and London floods (Chatterton et al., 2008), where both used similar categories of damages to 
buildings and household goods (appliances and assets). Those studies found that the percentage of household losses in the total estimated losses from floods were 33\% in Saxony, and 38\% in London and for Mumbai households their losses were about $22 \%$ which agreed with estimates by Patankar and Patwardhan (2016).

The above three accounts of extreme weather events resulting in landslides and flooding shows there is a need to recognise that there is no one size fits all. Each of the above events occurred without a pattern or pre-determined place. However the Munich data show a continuing increase in hydrological and meteorological events. Disasters happen, and the resulting clean-up is carried out by the communities affected.

The questionnaire was applicable and non-invasive into the privacy of the recipients and proved a worthwhile exercise. Although a slightly rearranged set of questions would have provided more information on a greater range of economic and financial outcomes, including attitudes towards government and regional authorities.

The interviews conducted by Smith et al. (2011) following the 2004 Manawatu/Wanganui floods showed that most of the residents interviewed were disappointed with the beauracratic attitude from some government officials, who seemed to take safety concerns too seriously when none were apparent. Their use of authority seemed inconsistent to the community affected. The required approach needs to be diplomatic and sympathetic, and not need a heavily beauracratic when some people may have just lost everything and are grieving over their loss.

While government and regional authorities have the safety of the communities to contend with, it is apparent that community closeness is worth further investigation. There are many issues that can have a lasting effect on a community's well-being, where specialists in physical and psychological services may be required, as noted by Patankar and Patwardhan (2016) in the Mumbai survey.

Although the questionnaire had only 22 recipients it covered a wider area than the field work undertaken in Te Apiti Road. The strongest evidence from verbal discussion was how everyone affected had collectively helped their neighbours. This bears out the conclusions by Smith et al. (2011) from the Manawatu survey. 


\section{Chapter 7: Conclusions}

This study followed a high precipitation event and the collapse of weakly-bedded marine sediments, which generated hundreds of shallow landslides over a wide area of the North Island East Coast. The storm path spread from Kairakau in the south and extended to Ocean Beach in the north, with Waimarama between. Globally, landslides by any name, have the same ending, transport of regolith downslope. Landslides reconfigure landform morphology, whether in the high mountains, in the high mountains, farmed slopes, or agricultural land that are subjected to long periods of precipitation or cyclonic weather. It is regolith lithology that determines saturation levels, which may cause slope failure over time.

The exact magnitude of the Waimarama storm remains unknown, due to the lack of operational local weather stations. It was noticeable when collating rainfall volume, that many local weather stations had been discontinued, although a wider regional precipitation amount was available and used, including volume readings from local residents. Precipitation between $650-800 \mathrm{~mm}$ over 48 hours caused hillslope saturation and eventually multiple landslides.

If this incident had been the first of its kind, it would be regarded as a major disaster. However, within New Zealand there have been multiple examples of these one off storms, high precipitation, or lengthy periods of rain, where land has become saturated and collapsed, leaving open scars, in many cases too numerous to count over geographically restricted areas. Many of these multiple land collapse issues began when the first Polynesian migrants arrived 700-800 years ago and became exacerbated upon arrival of the first European migrants. Pristine forests were exchanged for animal production farming, agriculture, residential, industrial and carriage ways. Once the root systems had decayed from the denuded forests, landslides during major rainfall events almost became the norm. Many geomorphic scientists have spent lifetimes contributing to the knowledge of landslides and why they occur; it often comes down to slope angle, aspect and weak regolith (Blaschke et al., 2000; Brooks et al., 2002; Galve et al., 2015; Preston and Crozier, 1999). The common drivers of landslides are weather, climate, tectonics and gravity. Anthropogenic influence through forest clearing, vegetation removal, introduction of grazing animals, and habitation needs are the greatest threat to landform collapse.

The North Island of New Zealand has areas that are marine based sediments with a weak lithology structure which is more prone to collapse under lengthy periods of precipitation or extreme weather events. These marine mudstones, siltstones and sandstones were deposited 
offshore and tectonically uplifted to form coastal ranges. Soil formation in these settings is shallow - 50cm $-1 \mathrm{~m}$ generally - and on slopes of $15^{\circ}-25^{\circ}$ where most landslides are generated.

The hillslopes of the east coastal regions of the Wairarapa, Hawke's Bay and Gisborne, including inland Manawatu to Wanganui and inland north east of New Plymouth, have shallow marinebased regolith sediment mixed with volcanic tephra overlying marine bedrock of sandstone, siltstone/mudstone. These areas are prone to high precipitation events where multiple landslides have occurred in the past.

The laboratory research included liquid limit, plastic limit and specific gravity. There were a variety of results from all three experiments. These variations were due to factors of different locations, landslide groups and regolith mixtures.

Tests indicated a higher liquid limit for the A horizon of $88.5 \%$ and low of $40.2 \%$ while the B horizon had a high liquid limit of $85.7 \%$ and low of $18.8 \%$. The liquid limit range for the $\mathrm{C}$ horizon was $85.2 \%$ and low of $22.4 \%$. The highest reading for plastic limit was A horizon $48.4 \%$ and low of $22.4 \%$; B horizon $51 \%$ and low $17.1 \%$. The $\mathrm{C}$ horizon high is $43 \%$ and low of $16.1 \%$. Specific gravity had a wide range of results that fluctuated within a band of $1.72 \mathrm{~g} / \mathrm{cm}^{3}$ and 1.28 $\mathrm{g} / \mathrm{cm}^{3}$. The results from laboratory testing indicate that all horizons were prone to failure, and that the $\mathrm{C}$ horizon was the most likely to fail first due to saturation.

The DEM when loaded with all field and Google Earth measurements, provided an overall indication of where the majority of slips were oriented, and where on hillslopes they occurred. The landslide pattern showed that south-east $135^{\circ}$ to east $90^{\circ}$ and west $270^{\circ}$ through to north $360^{\circ}$ were over represented for land loss through landslides. The valley orientation is generally south-west - north east while the slopes are facing in the dominant weather patterns of west, north-west and east, south-east. Where a valley ridge is bisected by a river, there are some hillslopes oriented towards the south, south-west and north, north-east. All aspects had hillslope failure.

74.7 percent of landslides occurred on slope inclination of $15-25^{\circ}$ and covered 40.9 percent of land area. Least affected were slopes $5-10^{\circ}$ the land area being 55.5 percent and recorded 12.7 percent of landslides. Land area of 3.5 percent at $30-40^{\circ}$ had a high slope failure of 12.6 percent. The highest recorded number of landslides 66.4 percent occurred at an elevation of $60-80 \mathrm{~m}$ which represented 66.4 percent of land area. Land area of 22.8 percent at an elevation of $20-40 \mathrm{~m}$ recorded 7 percent of landslide activity and at 200-340m which covers 12.8 percent land area had 26.3 percent of slope failure. 
These hillslope results show a consistency that has been observed and researched by other New Zealand studies (Crozier, 2005a, 2010; Crozier et al., 1980; Glade, 2003; King and Blakemore, 1977; Lambert et al., 1984; Page et al., 2000), indicating that marine regolith when saturated for long periods or by extreme events, will eventually collapse, forming multiple landslides in a region where marine sediments occur. There are many landslides caused through earthquakes and recorded by (Dadson et al., 2004; Hovius et al., 2011; Jibson, 2011; Parker et al., 2015).

While there was an earthquake during the height of the storm, this study made note only that it occurred, and may have contributed to some landslides, however the weak regolith was already under extreme conditions, so further study of the earthquake was not included in this research. There was also the possibility that the earlier precipitation (as recorded by K. McNeur), over previous weeks, was retained as antecedent moisture in the soil and could have contributed to quicker saturation, thereby increasing the potential for hillslopes to collapse sooner rather than later.

A survey was undertaken to record the local communities' involvement with each other and their response to how they managed damage to their properties, or help from local and government agencies. Responses were varied, ground cover loss was the most dominant factor with 19 residents declaring that they had had some land movement, while 16 residents recorded hillslope failure as their major issue with land loss. Flooding of some properties and loss of access from the valley during the storm peak also affected some households. In general, 13 residents indicated they had a financial loss through severe land loss, 18 residents recorded economic loss from damaged buildings, equipment and fences, and had animals relocated or feed brought in to accommodate pasture loss. Eleven residents recorded financial recovery up to this survey taking place, with insurance as a help in some economic recovery.

The community were very helpful in clearing away damage and silt from flooding. Task Force Green was considered the most active, helping to repair damage, while EQC was another organisation recorded as very helpful financially. There were earthmoving contractors who cleared blocked waterways and silt from roadways, and a presence from the local and regional councils. There were a few residents who considered the councils could have provided more resources for moving stock and animal feed.

Previous studies have usually been of an independent nature, either field observation, questionnaire surveys or model type use. This study introduced a combination of field observations, laboratory soil analysis and questionnaire to formulate a comprehensive data base that is open to additional or collective research from other extreme events. Should it be necessary 
to compare results then the system is already available. The main theme of this thesis was to combine field observations and laboratory research, with a personal approach via a questionnaire. This research has confirmed that marine sediment under extreme precipitation will collapse forming multiple shallow landslides. Laboratory analysis showed that all horizons are subject to landsliding, that the $\mathrm{C}$ horizon above the bedrock is most susceptible to fail first. This is due to less tolerance to high water content. All aspects had landslides, however, some hillslopes were less tolerant to extreme weather than others, mainly because of their location on the slope and slope angle.

Mitigation is a key to contain landslides, and there are many options: including revegetation, fencing, woodlots, or land retirement, and stock reductions. Some have economic advantages.

There are three important findings from this research. First, laboratory testing and soil analysis provided evidence that weak horizon $\mathrm{C}$ regolith, when situated above an impervious bedrock with slope angles of $15-25^{\circ}$ and in an aspect of E, SE, W, NW, and North, is highly likely to collapse and form shallow landslides. Rainfall induced landslides can affect wide areas on even moderately steep slopes. Second, field surveys should be actioned as soon as possible after the event as important information may be lost due to following precipitation and animal movement. Third, follow up community surveys are needed to gain a clear understanding of what communities require, i.e. restoration of storm damage, better communication, infrastructure services and available agencies for help. Local communities have built-in resilience and are capable of dealing with such catastrophic events given a sufficient level of support. 


\section{References}

Aaheim, A., Romstad, B., and Sælen, H., 2010, Assessment of risks for adaptation to climate change: The case of land-slides. Mitigation and Adaptation Strategies for Global Change, v. 15, no. 7, p. 763778.

Aleotti, P., and Chowdhury, R., 1999, Landslide hazard assessment: summary review and new perspectives: Bulletin of Engineering Geology and the Environment, v. 58, no. 1, p. 21-44.

Alexander, D., 1997, The study of natural disasters, 1977-97: some reflections on a changing field of knowledge: Disasters,, v. 21, no. 4, p. 284-304.

Allen, K., 2006, Community -based disaster preparedness and climate adaptation: local capacity building in the Philippines: Disasters,, v. 30, no. 1, p. 81-101.

Amanti, M., Casagli, N., Catani, F., D'Orefice, M., and Motteran, G., 1996, Guida al censimento dei fenomeni franosi e alla loro archiviazione: Miscell Serv Geol d'It, no. 7, p. 109.

Antrop, M., 2003, Development of European landscapes: Landscape Urban Plan, no. 67, p. 1-8.

Bain, J. A., 1971, Plasticity chart as an aid to the identification and assessment of Industrial clays: Clay Minerals no. 9, p. 17.

Bankoff, G., Frerks, G., and Hilhorst, T. e., 2004, Mapping Vulnerability: Disasters, Development and People: Earthscan, London.

Basher, L., Botha, N., Dodd, M., Douglas, G., Lynn, I., and Marden, M., 2008, Hill country erosion: a review of knowledge on erosion processes, mitigation options, social learning and their long term effectiveness in the management of hill country erosion: Landcare Research Contract Report

Bates, R. J., and Jackson, J. A., 1980, Glossary of Geology, 2nd edition: American Geological Institute, USA.

Bauer, E. E., 1960, Spec. Tech. Pub: Am. Soc. Test. Mat, no. 254, p. 160-167.

Baver, L. D., Gardner, W. H., and Gardner, W. R., 1972, Soil Physics John Wiley, New York, v. 4th ed., 498 p. p.:

Benda, L., 1990, The influence on debris flows on channels and valley floor in the Oregon Coast Range, U.S.A.: Earth Surface Processes and Landforms, v. Vol. 15, p. pp. 457-466.

Benda, L., and Dunne, T., 1987, Sediment routing by debris flows. In Beschta, R. L., Blinn, T., Grant, G. E., Ice, G. G., Swanson, F. J. (Editors) Erosion and Sedimentation in the Pacific Rim.: International Association of Hydrological Sciences (IAHS), v. Vol. 165, no. pp. 213-223.

Blaschke, P. M., Trustrum, N. A., and De Rose, R. C., 1992, Ecosystem processes and sustainable land use in New Zealand steeplands.: Agric Ecosyst. Environ., v. 41, p. 153-178.

Blaschke, P. M., Trustrum, N. A., and Hicks, D. L., 2000, Impacts of mass movement erosion on land productivity: : Progress in Physical Geography, v. 24, no. (1),, p. 21-52.

Bochet, E., Garcia-Fayos, P., and Poesen, J., 2009, Topographic thresholds for plant colonization on semiarid eroded slopes: Earth Surf Process Landf, no. 34, p. 1758-1771.

Böll, A., Burri, K., Gerber, W., and Graf, F., 2009, Long-term studies of joint technical and biological measures: For Snow Landsc Res, v. 82, no. 9, p. 9-32.

Boussabaine, A., and Kirkham, R., 2004, Whole life-cycle costing: Risk and risk responses: Wiley, Chichester, p. 268.

Bradshaw, J. D., 1993, A review of the Median Tectonic Zone: terrane boundaries and terrane amalgamation near the Median Tectonic Line.: New Zealand Journal of Geology and Geophysics, no. 36, p. $117-125$.

Bromhead, E. N., and Ibsen, M. L., 2007, An Overview of Landslide Problems in the British Isles, with Reference to Geology, Geography and Conservation, in Sassa, K., Fukuoka, H., Wang, F., and Wang, G., eds., Progress in Landslide Science: Berlin, Heidelberg, Springer Berlin Heidelberg, p. 13-25. 
Brooks, S. M., Anderson, M. G., and Collison, A. J. C., 1995, Modelling the role of climate, vegetation and pedogenesis in shallow translational hillslope failure: Earth Surface Processes and Landforms, $v$. 20, no. 3, p. 231-242.

Brooks, S. M., Crozier, M. J., Glade, T. W., and Anderson, M. G., 2004, Towards Establishing Climatic Thresholds for Slope Instability: Use of a Physically-based Combined Soil Hydrology-slope Stability Model: pure and applied geophysics, v. 161, no. 4, p. 881-905.

Brooks, S. M., Crozier, M. J., Preston, N. J., and Anderson, M. G., 2002, Regolith stripping and the control of shallow translational hillslope failure: application of a two-dimensional coupled soil hydrology-slope stability model, Hawke's Bay, New Zealand: Geomorphology, v. 45, no. 3-4, p. 165-179.

Brown, W. J., 1983, The changing imprint of the landslide on rural landscapes of New Zealand: Landscape Planning, v. 10, no. 3, p. 173-204.

Brown, W. J., 1991, Landslide Control on North Island, New Zealand: Geographical Review, v. 81, no. 4, p. 457-472.

Brunetti, M. T., Luino, F., Vennari, C., Peruccacci, S., Biddoccu, M., Valigi, D., Luciani, S., Cirio, C. G., Rossi, M., Nigrelli, G., Ardizzone, F., Palma, M. D., and Guzzetti, F., 2013, Rainfall Thresholds for Possible Occurrence of Shallow Landslides and Debris Flows in Italy. In: M. SchneuwlyBollschweiler et al. (eds.), Dating Torrential Processes on Fans and Cones.: Advances in Global Change Research, no. 47.

Brunetti, M. T., Peruccacci, S., Rossi, M., Luciani, S., Valigi, D., and Guzzetti, F., 2010, Rainfall thresholds for the possible occurrence of landslides in Italy: Nat. Hazards Earth Syst. Sci., v. 10, no. 3, p. 447-458.

Brunsden, J., and Thornes, J. B., 1979, Landscape sensitivity and change.: Transactions of the Institute of British Geographers (new series), v. 4, no. (4), p. 463-484.

Campbell, D. A., 1951, Types of soil erosion prevalent in New Zealand.: Union Géodesique et Géophysique Internationale-Association Internationale d'Hydrologie Scientifique-Assemblée Générale Bruxelles 1951 -- Tome II. pp. 82-95.

Cannon, T., 1994, Vulnerability analysis and the explanation of "natural" disasters. In A. Varley (ed.) Development and Environment Disasters, p. 13-30.

Canuti, P., Casagli, N., Ermini, L., Fanti, R., and Farina, P., 2004, Landslide activity as a geoindicator in Italy: significance and new perspectives from remore sensing.: Environ Geol, v. 45, no. 7, p. 907919.

Carrara, A., 1982, Cartografia tematica, stoccaggio ed elaborazione dati. In: atta del Convengo Conclusivo P.F. Conser. Suolo, Sottopr.: Fenomeni Franosi, Relazione Generale, v. 9-10 giugno 1982, no. Roma, p. 265-281.

Catane, S. G., Abon, C. C., Saturay Jr, R. M., Mendoza, E. P. P., and Futalan, K. M., 2012, Landslideamplified flash floods-The June 2008 Panay Island flooding, Philippines: Geomorphology, v. 169-170, p. 55-63.

Cavaille, P., Dommanget, F., Daumergue, N., Loucougaray, G., Spiegelberger, T., Tabacchi, E., and Evette, A., 2013, Biodiversity assessment following a naturality gradient of riverbank protection structures in French prealps rivers: Ecol Eng, no. 53, p. 23-30.

Charlton, D., 2008, Pastures - Pastures for different livestock: Te Ara - the Encyclopedia of New Zealand, (accessed 7 April 2018).

Chatterton, J., Viavattene, C., Morris, J., Penning-Rowell, E., and Tapsell, S., 2008, Delivering benefits through evidence: the costs of the summer 2007 floods in England, Environment Agency, Government of UK. .

Chen, X.-L., Liu, C.-G., Chang, Z.-F., and Zhou, Q., 2016, The relationship between the slope angle and the landslide size derived from limit equilibrium simulations: Geomorphology, v. 253, p. 547550.

Choi, K. Y., and Cheung, R. W. M., 2013, Landslide disaster prevention and mitigation through works in Hong Kong: J Rock Mech Geotech Eng, no. 5, p. 354-365. 
Chowdhury, R. N., and Flentje, P., 1998a, A landslide database for landslide hazard assessment. In: Workshop on Landslide Hazard Assessment - Progressing from Qualitative to Quantitative Approaches, Wollongong February 8-9, 1998.

Corcoran, M. K., Peters, J. F., Dunbar, J. B., Llopis, J. L., Tracy, F. T., Wibowo, J. L., Simms, J. E., Kees, C. F., McKay, S. K., Fischenich, J. C., Farthing, M. W., Glynn, M. E., Robbins, B. A., Strange, R. C., Schultz, M. T., Clarke, J. U., Berry, T. E., Little, C. D., and Lee, C. D., 2011, Initial research into the effects of woody vegetation on levees: Engineer Research and Development Centre, Washington, DC.

Costanza, R., D'Arge, R., Faber, S., Grasso, M., Hannon, B., Limburg, K., Naeem, S., O'Neill, R., Paruello, J., Raskin, R. G., Sutton, P., and Van den Belt, M., 1997, The value of the world's ecosystem services and natural capital: Nature, no. 387, p. 253-260.

Cotton, C. A., 1968, Mountains. In Fairbridge, R. W.: The Encyclopaedia of Geomorphology. Rheinhold, New York.

Council, H. R., 2004: Palmerston North, Manawatu.

Craig, R. F., 2004, Craig's soil mechanics, 7th edn: London, p. 464.

Crozier, M. J., 2005a, Multiple-occurrence regional landslide events in New Zealand: Landslides, v. 2, no. 4, p. 247-256.

Crozier, M. J., 2005b, Multiple-occurrence regional landslide events in New Zealand: Hazard management issues. Landslides, v. 2, no. 4, p. 247-256.

Crozier, M. J., 2010, Landslide geomorphology: An argument for recognition, with examples from New Zealand: Geomorphology, v. 120, no. 1-2, p. 3-15.

Crozier, M. J., Eyles, R. J., Marx, S. L., McConchie, J. A., and Owen, R. C., 1980, Distribution of landslips in the Wairarapa hill country: New Zealand Journal of Geology and Geophysics, v. 23, no. 5-6, p. 575-586.

Crozier, M. J., Gage, M., Pettinga, J. R., Selby, M. J., and Wasson, R. J., 1992, Stability of hillslopes, p. pp. 63-90.

Cruden, D. M., and Brown, W. M., 1992, Progress towards the World Landslide Inventory. : In: Proc 6th Int Symp on Landslides, Christchurch, no. 1, p. 59-64.

Dadson, S. J., Hovius, N., Chen, H., Dade, W. B., Lin, J. C., Hsu, M. L., Lin, C. W., Horng, M. J., Chen, T. C., Milliman, J., and Stark, C. P., 2004, Earthquake-triggered increase in sediment delivery from active mountain belt: Geology, no. 32, p. 733-736.

Dalrymple, J. B., Blong, R. J., and Conacher, A. J., 1968, A hypothetical nine unit landsurface model: Zeitschrift für Geomorphologie, no. 12, p. 60-76.

De Rose, R. C., 2013, Slope control on the frequency distribution of shallow landslides and associated soil properties, North Island, New Zealand: Earth Surface Processes and Landforms, v. 38, no. 4, p. 356-371.

Diemont, W. H., Smiet, A. C., and Nurdin, 1991, Re-thinking erosion on Java: Netherlands Journal of Agricultural Research, no. 29, p. 183-192.

Dominati, E. J., Mackay, A., Lynch, B., Heath, N., and Millner, I., 2014, An ecosystem services approach to the quantification of shallow mass movement erosion and the value of soil conservation practices: Ecosyst Serv, no. 9, p. 204-215.

Douglas, M., 1990, Risk as a forensic resource: Daedalus, v. 119, no. 4, p. 1-16.

Dymond, J. R., Ausseil, A.-G., Shepherd, J. D., and Buettner, L., 2006, Validation of a region-wide model of landslide susceptibility in the Manawatu-Wanganui region of New Zealand: Geomorphology, v. 74, no. 1-4, p. 70-79.

Easterling, W. E. e. a., 2007, Food and fibre and forest products'. In M.L. Parry et al. (eds.) Climate Change 2007: Impacts, Adaptation and Vulnerability. Contribution of Working Group II to the 'Fourth Assessment Report of the Intergovernmental Panel on Climate Change: Cambridge University Press, Cambridge, p. 273-313.

Environment, M. f. t., 2008.

$-, 2012$.

Eyles, G. O., 1983, The distribution and severity of present soil erosion in New Zealand: NZ Geographer, v. 39 , no. 1 , p. $12-28$. 
Eyles, G. O., 1985, New Zealand land resource inventory erosion classification, in Authority, N. W. a. S. C., ed., Water and Soil Directorate,

Ministry of Works and Development, p. 61.

Fattet, M., Fu, Y., Ghestem, M., Ma, W., Foulonneau, M., Nespoulous, J., Le Bissonnais, Y., and Stokes, A., 2011, Effects of vegetation type on soil resistance to erosion: relationship between aggregate stability and shear strength: CATENA, no. 87, p. 60-69.

Frei, M., Boll, A., Graf, F., Heinimann, H. R., and Springman, S., 2003, Quantification of the influence of vegetation on soil stability., Proceedings of the International Conference on Slope Engineering: Hong Kong, China, p. 872-877.

Galve, J. P., Cevasco, A., Brandolini, P., and Soldati, M., 2015, Assessment of shallow landslide risk mitigation measures based on land use planning through probabilistic modelling: Landslides, $v$. 12, no. 1, p. 101-114.

Geertsema, M., Highland, L., and Vaugeouis, L., 2009, Environmental Impact of Landslides, in Sassa, K., and Canuti, P., eds., Landslides - Disaster Risk Reduction: Berlin, Heidelberg, Springer Berlin Heidelberg, p. 589-607.

Glade, T., 1998, Establishing the frequency and magnitude of landslide-triggering rainstorm events in New Zealand: Environmental Geology, v. 35, no. 2, p. 160-174.

Glade, T., 2003, Landslide occurrence as a response to land use change: a review of evidence from New Zealand: CATENA, v. 51, no. 3-4, p. 297-314.

Gray, D. H., and Leiser, A. T., 1982, Biotechnical Slope Protection and Erosion Control, in Reinhold, V. N., ed.: New York, p. 271.

Gray, D. H., and Sotir, R. B., 1996, Biotechnical and soil bioengineering slope stabilisation: a practical guide for erosion control: Wiley, USA.

Guthrie, R. H., and Evans, S. G., 2007, Work, persistence, and formative events: The geomorphic impact of landslides: Geomorphology, v. 88, no. 3-4, p. 266-275.

Gyssels, G., Poesen, J., Bouchet, E., and Li, Y., 2005, Impact of plant roots on the resistance of soils to erosion by water: a review: Prog Phys Geogr, no. 29, p. 189-217.

Hales, T. C., Ford, C. R., Hwang, T., Vose, J. M., and Band, L. E., 2009, Topographic and ecologic controls on root reinforcement: J Geophys Res, no. 114:F03013.

Hawley, J. G., and King, M., 1978, Landslips on some seasonally dry hill country soils in New Zealand, Report to the Soil Conservation and Rivers Control Council: Wellington.

Haywick, D. W., Lowe, D. A., Beau, A. G., Henderson, R. A., Carter, R. M., , 1991., Pliocene-Pleistocene (Nukumaruan) lithostratigraphy of the Tangoio block, and origin of a sedimentary cyclicity, Central Hawke's Bay, New Zealand.: New Zealand Journal of Geology and Geophysics, v. 34, p. 213-225.

Hennrich, K., and Crozier, M. J., 2004, A hillslope hydrology approach for catchment-scale slope stability analysis: Earth Surface Processes and Landforms, v. 29, no. 5, p. 599-610.

Hicks, D. M., Shankar, U., McKerchar, A. I., Basher, L., Lynn, I., Page, M., and Jessen, M., 2011, Suspended Sediment Yields from New Zealand Rivers.: Journal of Hydrology (New Zealand), v. 50, no. 1, p. 81-142.

Hovius, N., Meunier, P., Lin, C.-W., Chen, H., Chen, Y.-G., Dadson, S., Horng, M.-J., and Lines, M., 2011, Prolonged seismically induced erosion and the mass balance of a large earthquake: Earth Planet. Sc. Lett., v. 304, p. 347-355.

Hungr, O., Evans, S. G., Bovis, M. J., and Hutchinson, J. N., 2001, A review of the classification of landslides of the flow type: Environ Eng Geosci, v. 7, no. 3, p. 221-238.

Hungr, O., Leroueil, S., and Picarelli, L., 2013, The varnes classification of landslide types, an update: Landslides,, v. 11, no. (2), p. 167-194.

Hutchinson, J. N., 1968, Mass movement. In: Fairbridge R. W. (ed) Encyclopedia of geomorphology. Reinhold Publishers, New York, pp 688-695.

IRDA, 2013a, Annual report 2012-2013: Insurance Regulatory and Development Authority India.

-, 2013b, Annual report 2012-2013. Insurance Regulatory and Development Authority India.

Jaboyedoff, M., Baillifard, F., Couture, R., Derron, M.-H., Locat, J., and Locat, P., 2005, Coupling kinematic analysis and sloping local base level criterion for large slope instabilities hazard assessment - a 
GIS approach: Landslide Risk Management - Hungr, Fell, Couture \& Eberhardt (eds). Taylor \& Francis Group, London, ISBN 041538043 X.

Jaboyedoff, M., Ballifard, F., Couture, R., Locat, J., and Locat, P., 2004b, New insight of geomorphology and landslide prone area detection using DEM. In: Lacerda et al. (eds). Landslides Evaluation and stabilisation: 199-205 Balkema.

Jaboyedoff, M., Ballifard, F., Philippossian, F., and Rouiller, J.-D., 2004a, Assessing fracture occurrence using "weighted fracturing density": a step towards estimating rock instability hazard.: Natural Hazards and Earth System Sciences, no. 4, p. 83-93.

Jakob, M., and Hungr, O., 2005, Debris-flow hazards and related phenomena: Springer, Germany, p. 739. Jastrow, J. D., Miller, R. M., and Lussenhop, J., 1998, Contributions of interacting biological mechanisms to soil aggregate stabilization in restored prairie: Soil Biol Biochem, no. 30, p. 905-916.

Jha, A., Lamond, J., Bloch, R., Bhattacharya, N., Lopez, A., Papachristodoulou, N., Bird, A., Proverbs, D., Davies, J., and Barker, R., 2011, Five feet high and rising: cities and flooding in the 21st century, in East Asia and Pacific Region. Transport, E. a. U. S. D. U., The World Bank ed.

Jiao, R., Herman, F., and Seward, D., 2017, Late Cenozoic exhumation model of New Zealand: Impacts from tectonics and climate: Earth-Science Reviews, no. 166, p. 286-298.

Jiao, R., Seward, D., Little, T. A., and Kohn, B. P., 2014a, Thermal history and exhumation of basement rocks from Mesozoic to Cenozoic subduction cycles, central North Island, New Zealand: Tectonics, no. 33, p. 1920-1935.

Jiao, R., Seward, D., Little, T. A., and Kohn, B. P., 2014b, Thermal history and exhumation of basement rocks from Mesozoic to Cenozoic subduction cycles, central North Island, New Zealand, 1920$1935 \mathrm{p}$.

Jibson, R. W., 2011, Methods for assessing the stability of slopes during earthquakes - a retrospective: Eng. Geol., v. 122, p. 43-50.

Kamp, P. J. J., 1992, Tectonic Architecture of New Zealand. In Landforms of New Zealand, Second Edition, Edit by J. M. Soons and M. J. Selby, 1992. Longman Paul 1992. pp.1-30. 531 pages.

Kerr, D., and Bishop, G. D., 1971, Hawke's Bay Region. National Resources Survey, Part IV. Compiled by The Town and Country Planning Division, Ministry of Works. A. R. Shearer Government Printer, Wellington, New Zealand

King, M., and Blakemore, S. D., 1977, Wairarapa hill country storm damage 1977.

King, P. R., 2000, Tectonic reconstructions of New Zealand: 40 Ma to the present: N.Z. J. Geol. Geophys, v. 43, no. 4, p. 611-638.

Kirton, A. H., 1989, Government and agricultural technology: New Zealand Agricultural Science, no. 23, p. 2-4.

Körner, C., 2003, Alpine plant life - functional plant ecology of high mountain ecosystem, 2nd edn.: Springer, Heidelberg.

Kremen, C., williams, N. M., Aizen, M. A., Gemmell-Herren, B., LeBuhn, G., Minckley, R., and Ricketts, T. $\mathrm{H} ., 2007$, Pollination and other ecosystem services produced by mobile organisms: a conceptual framewortk for the effects of land-use change: Eco Lett, no. 10, p. 299-314.

Kuzovkina, Y. A., and Volk, T. A., 2009, The characterization of willow (Salix L.) varieties for use in ecological engineering applications: co-ordination of structure, function and autecology: Ecol Eng, no. 35, p. 1178-1189.

Lacasse, and Vanier, 1999, Durability of building materials and components 8: Durability of building assemblies and methods of service life prediction, Service Life and Durability of Materials and Components, Volume 1: Ottawa, NRC Research Press, p. 898.

Lal, R., and Stewart, B. A. e., 1990, Soil degradation, New York: Springer.

Lambert, M. G., Trustrum, N. A., and Costall, D. A., 1984, Effect of soil slip erosion on seasonally dry Wairarapa hill pastures: New Zealand Journal of Agricultural Research, v. 27, no. 1, p. 57-64.

Le Bissonnais, Y., 1996, Aggregate stability and assessment of soil crustability: I. Theory and methodology: Eur J Soil Sci, no. 47, p. 425-437.

Le Heron, R. B., and Roche, M. M., 1985, Expanding exotic forestry and the extension of a competing use for rural land in New Zealand: Journal of Rural Studies no. 1 p. 211-229. 
Lee, J. M., Bland, K. J., Townsend, D. D., and Kamp, P. J. J., 2011, (Compilers) Geology of the Hawke's Bay Area. Institute of Geological \& Nuclear Sciences 1:250,000 Geological Map 8. Gns Science, Lower Hutt, New Zealand.

Leroi, E., 1996, Landslide hazard - Risk maps at different scales: objectives, tools and developments. In: Proc VII Int Symp Landslides, Trondheim, June,1996, no. 1, p. 295-300.

Litchfield, N., and Berryman, K., 2006, Relations between postglacial fluvial incision rates and uplift rates in the North Island, New Zealand: J. Geophys. Res. , v. 111, no. F02007.

Loreau, M., Naeem, S., Inchausti, P., Bengtsson, J., Grime, J. P., A., H., and Wardle, D. A., 2001, Biodiversity and ecosystem functioning: current knowledge and future challenges: Science, no. 294, p. 804-808.

Lynn, I. H., and Eyles, G. O., 1984, Distribution and severity of tunnel gully erosion in New Zealand: NZ Journal of Science, no. 27, p. 175-186.

Maharashtra, G. o., 2005, Maharashtra floods 2005. Relief and Rehabilitation Department

Management, M. o. C. D. a. E., 2004, Review of the February 2004 Flood Event, in Management, M. o. C. D. a. E., ed.: Wellington.

Marden, M., and Rowan, D., 1993, Protective value of vegetation on Tertiary terrain before and during cyclone Bola, East Coast, North Island, New Zealand: New Zealand Journal of Forestry Science, no. 23, p. 255-263.

Marden, M., and Rowan, D., 2015, The effect of land use on slope failure and sediment generation in the Coromandel region of New Zealand following a major storm in 1995: New Zealand Journal of Forestry Science, v. 45, no. 1, p. 1-18.

Martha, T. R., Roy, P., Govindharaj, K. B., Kumar, K. V., Diwakar, P. G., and Dadhwal, V. K., 2014, Landslides triggered by the June 2013 extreme rainfall event in parts of Uttarakhand state, India: Landslides, v. 12, no. 1, p. 135-146.

Mather, A. S., 1980, The changing perception of soil erosion in New Zealand: Geogr J, no. 148, p. 207218.

Mazzoccola, D. F., and Hudson, J. A., 1996, A comprehensive method of rock mass characterization for indicating natural slope instability: Quarterly Journal of Engineering Geology, no. 29, p. 37-56.

McCaskill, L. W., 1973, Hold this land: A history of soil conservation in New Zealand: A H and A W Reed, Wellington, New Zealand.

Mclvor, I., Sloan, S., and Pigem, L. R., 2014, Genetic and environmental influences on root development in cuttings of selected Salix and Populus clones - a greenhouse experiment: Plant and Soil, this issue.

Meyer, V., and Messner, F., 2005, National flood damage evaluation methods: a review of applied methods in England, the Netherlands, the Czech Republic and Germany: UFZ Discussion Papers 21.

Mickovski, S. B., and van Beek, L. P. H., 2009, Root morphology and effects on soil reinforcement and slope stability of young vetiver (Vetiveria zizanioides) plants grown in semi-arid climate: Plant Soil, no. 324, p. 43-56.

Miller, D. J., 1995, Coupling GIS with physical models to assess deep-seated landslide hazards: Environmental \& Engineering Geoscience, no. 1, p. 263-276.

Miller, R. C., 1986, Review of soil conservation progress 1970 to 1985: Wellington: NWASCA.

Mitchell, S. J., 2013, Wind as a natural disturbance agent in forests: a synthesis: Forestry, no. 86, p. 147157.

Mitsch, W. J., and Jorgensen, S. E., 2004, Ecological engineering and ecosystem restoration: Wiley, New York.

Moir, J. L., Scotter, D. R., Hedley, M. J., and Mackey, A. D., 2000, A climate-driven, soil fertility dependent, pasture production model: New Zealand Journal of Agricultural Research, no. 43, p. 491-500.

Montgomery, D. R., and Dietrich, W. E., 1994, A physically-based model for the topographic control of shallow landsliding: Water Resources Research, no. 30, p. 1153-1171.

Montgomery, D. R., Sullivan, K., and Greenberg, H. M., 1998, regional test of a model for shallow landsliding: Hydrological Processes, no. 12, p. 943-955. 
Montrasio, L., Valentino, R., and Losi, G. L., 2011, Shallow landslides triggered by rainfalls: modeling of some case histories in the Reggiano Apennine (Emilia Romagna Region, Northern Italy): Natural Hazards, v. 60, no. 3, p. 1231-1254.

Moran, W., 1989, Sectoral and statutory planning for rural New Zealand. Rural land-use planning in developed nations. ed. Cloke, P. J.: London, Unwin-Hyman, p. 238-263.

Mortimer, N., 2004a, New Zealand's Geological Foundations: Gondwana Research, v. 7, no. 1, p. 261272.

-, 2004b, New Zealand's geological foundations: Gondwana Res., v. 7, no. 1, p. 261-272.

Mosley, M. P., 1980, Mapping sediment sources in a New Zealand mountain watershed: Environ Geol, no. 3, p. 85-95.

Munich Re., 2011, Natural catastrophe know-how for risk management and research: NatCatSERVICE. Munich Reinsurance Group, Munich.

-, 2013, Topic natural hazards: NatCatSERVICE. Munich Reinsurance Group, Munich

-, 2014, Loss events worldwide 1980-2013: NatCatSERVICE. Munich Reinsurance Group, Munich.

Nadim, F., Kjekstad, O., Peduzzi, P., Herold, C., and Jaedicke, C., 2006, Global landslide and avalanche hotspots Landslides, no. 3, p. 159-173.

Norris, J. E., Stokes, A., Mickovski, S. B., Cammeraat, E., van Beck, R., Nicoll, B. C., and Achim, A. e., 2008, Slope stability and erosion control: Ecotechnological solutions: Springer, The Netherlands.

O'Loughlin, C. L., 1984, Effectiveness of introduced forest vegetation for protection against landslides and erosion in New Zealand's steeplands. , in In: O'Loughlin, C. L. a. P. A. J., ed., Symposium on Effects of Forest Land Use on Erosion and Slope Stability: East-West Center, University of Hawaii, p. $275-280$.

Pachauri, R. K., and Meyer, L. A. e., 2014, Climate Change 2014: Synthesis Report. Contribution of Working Groups I, II and III to the Fifth Assessment Report of the

Intergovernmental Panel on Climate Change [Core Writing Team,. IPCC, Geneva, Switzerland, $151 \mathrm{pp}$.

Page, M. J., Carey, J. M., Rosser, B. J., Ries, W., and Townsend, D. B., 2015, Reconnaissance report on landsliding caused by the 19-20 June 2015 rainstorm in the Taranaki-Wanganui-Manawatu region: GNS Science Report 2015/47.

Page, M. J., Trustrum, N. A., and Dymond, J. R., 1994, Sediment budget to assess the geomorphic effect of a cyclonic storm, New Zealand: Geomorphology, v. 9, no. 3, p. 169-188.

Page, M. J., Trustrun, N. A., and Gomez, B., 2000, Implications of a century of anthropogenic erosion in Gisborne-East coast region of New Zealand: Geographer, v. 56, no. 2, p. 13-24.

Paine, R. T., 1995, A conversation on refining the concept of keystone species: Conserv Biol, no. 9, p. 962-964.

Parker, R. N., Hancox, G. T., Petley, D. N., Massey, C. I., Densmore, A. L., and Rosser, N. J., 2015, Spatial distributions of earthquake-induced landslides and hillslope preconditioning in the northwest South Island, New Zealand.

Parry, M. L., Canziani, O. F., Palutikof, J. P., van der Linden, P. J., and Hanson, C. E., 2007, Climate Change 2007: Impacts, Adaption and Vulnerability.

Patankar, A., and Patwardhan, A., 2016, Estimating the uninsured losses due to extreme weather events and implications for informal sector vulnerability: a case study of Mumbai, India: Nat Hazards no. 80 , p. 285-310.

Paton, D., and Johnston, D., 2006, eds. Disaster Resilience -An Integrated Approach. Charles C. Thomas, Springfield, IL.

Pearce, L., 2003, Disaster management and community planning, and public participation: how to achieve sustainable hazard mitigation: Natural Hazards, v. 28, no. 2-3, p. 211-228.

Peploe, B. A., Hamilton, D. H., and Black, D., A., 1982 Pouhokio-Wainongoro Catchment Control Scheme.

Pettinga, J. R., 1980, Geology and Landslides of the Eastern Te Aute District, Southern Hawkes Bay [PhD: Auckland University, $602 \mathrm{p}$.

-, 1982, Upper Cenozoic Structural history, coastal Southern Hawkle's Bay, New Zealand: New Zealand Journal of Geology and Geophysics, v. 25, p. 149-191.

Phillips, C. J., Marden, M., and Suzanne, L. M., 2014, Observations of root growth of young poplar and willow planting types: New Zealand Journal of Forestry Science, v. 44, no. 1, p. 1-12. 
Pike, R. J., Howell, D. G., and Russell, W., 2003, Landslides and Cities' An Unwanted Partnership: Graymer Earth Science in the City, p. 187.

Plieninger, T., Hochtl, F., and Spek, T., 2006, Traditional land-use and nature conservation in European rural landscapes: Environ Sci Pol, v. 9, no. 4, p. 317-321.

Pohlen, I. J., 1971, Soils of Hawke's Bay Region New Zealand. Department of Scientific and Industrial Research. reprinted from National Resource Survey Pat VI - Hawke's Bay Region. Compiled by Town and Country Planning Division, Ministry of Works.

Pohlen, I. J., and Congdon, N. B., 1971, Soils and their relation to land use, Hawke's Bay Region: Town and Country Planning Division, Ministry of Works.

Pollen, N., and Simon, A., 2005, Estimating the mechanical effects of riparian vegetation on streambank stability using a fiber bundle model: Water Resources Research., no. 41, W07025.

Post, W. M., and Kwon, K. C., 2000, Soil carbon sequestration and land-use change: processes and potential: Glob Chang Biol, no. 63, p. 317-327.

Postel, S., and Thompson, B. H., 2005, Watershed protection: capturing the benefits of nature's water supply services: Nat Res Forum, no. 29, p. 98-108.

Preston, N. J., and Crozier, M. J., 1999, Resistance to shallow landslide failure through root-derived cohesion in east coast hill country soils, North Island, New Zealand: Earth Surface Processes and Landforms, v. 24, no. 8, p. 665-675.

Pulford, A., and Stern, T., 2004, Pliocene exhumation and landscape evolution of central North Island, New Zealand: The role of the upper mantle: J. Geophys. Res., no. 109 p. F01016.

Rackham, O., and Moody, A., 1992, Terraces in: Berit Wells B (ed) Agriculture in ancient Greece: Acta Instituti Atheniensis regni Sueciae, v. IN 4, no. XLII, p. 123-130.

Regional Council, H., 2004, Storm: Civil Emergency - Storm and Flood Report, Horizons Regional Council, Palmerston North.

Research, L., 2012.

Research, N. I. o. W. a. A., 2011, April, 2011 Hawke's Bay flooding, 2011-04-25: Extreme event catalog.

Resources, W. S. D. o. N., 2010, Forest Practices GIS Spatial Data Sets. Available from http://www.dnr.wa.gov/BusinessPermits/Topics/ForestPracticesApplications/Pages/fp gis sp atial data.aspx. Accessed 27 may 2011.

Rogers, N. W., and Selby, M. J., 1980, Mechanisms of shallow translational sliding during summer rainstorms, North Island, New Zealand: Geografiska Annaler, no. 62A, p. 11-21.

Romana, M. R., 1993, A geomechanical classification for slopes: Slope mass rating. In J. A. Hudson (Editor), Rock testing and site characterization: 576-600: Pergamon Press, Oxford, United Kingdom.

Rosser, B., Dellow, S., Haubrock, S., and Glassey, P., 2017, New Zealand's National Landslide Database: Landslides no. 14, p. 1949-1959.

Rosser, B. J., and Ross, C. W., 2011, Recovery of pasture production and soil properties on soil slip scars in erodible siltstone hill country, Wairarapa, New Zealand: New Zealand Journal of Agricultural Research, v. 54, no. 1, p. 23-44.

Rouiller, J.-D., Jaboyedoff, M., Marro, C., Philippossian, F., and Mamin, M., 1998, Pentes instables dans le Pennique valaisan. Matterock: une méthodologie d'auscultation des falaises et de détection des éboulements majeurs potentiels. Rapport final du PNR31. VDF, Zürich.

Sassa, K., Tsuchiya, S., Ugai, K., Wakai, A., and Uchimura, T., 2009, Landslides: a review of achievements in the first 5 years (2004-2009): Landslides, v. 6, no. 4, p. 275-286.

Sato, H. P., Hasegawa, H., Fujiwara, S., Tobita, M., Koarai, M., Une, H., and Iwahashi, J., 2007, Interpretation of landslide distribution triggered by the 2005 Northern Pakistan earthquake using SPOT 5 imagery: Landslides, no. 4, p. 113-122.

Schneider, P. P., 2002, The distribution of sediment resulting from a major landslide event [BSc (Hons) Research Project in Physical Geography]: Victoria University of Wellington.

Schuster, R. L., and Highland, L. M., 2007, Overview of the effects of mass wasting on the natural environment.: Geological Society of America, Environmental \& Engineering, v. 8, p. 25-44.

Schwarz, M., Feller, K., and Thormann, J. J., 2013, Entwicklung und Validierung einer neuen Methode für die Beurteilung und Planung der minimalen Schutzwaldpflege auf rutschgefährdeten 
Hängen. [Final report to the Wald-und Holzforschungsfonds].Bern: Swiss Federal Office for the Environment FOEN

Schwarz, M., Phillips, C., Marden, M., Mclvor, I. R., Douglas, G. B., and Watson, A., 2016, Modelling of root reinforcement and erosion control by 'Veronese' poplar on pastoral hill country in New Zealand: New Zealand Journal of Forestry Science, v. 46, no. 1, p. 4.

Shaw, C. C., and Johnson, D. A., 1995, Slope Morphology Model Derived from Digital Elevation Data. Proceedings 1995 Northwest Arc/Info Users Conference. Coeur d'Alene. ID. Oct 23-25. 13pp.

Sidle, R. C., and Ochai, H., 2006, Landslide: Processes, Prediction and Land Use.: Water Resources Monograph 18, Washington, DC: American Geophysical Union.

Sidle, R. C., Pearce, A. J., and O'Loughlin, C. L., 1985, Hillslope stability and land use: Water Resources Monograph Series 11, AGU, Washington, D.C., no. 11, p. 140.

Singleton, P. C., Trotter, P., Widdowson, J., and Korte, C., 1988b, Cyclone Bola: 2. Alpha 64: Wellington, Department of Scientific and Industrial Research.

Slovic, P., 1987, Perception of risk: Science, no. 236, p. 280-235.

Smale, M. C., McLeod, M., and Smale, P. N., 1997, vegetation and soil recovery on shallow landslide scars in Tertiary hill country, East Cape region, New Zealand: New Zealand Journal of Ecology, v. 21, no. 1, p. 31-41.

Smith, W., Davies-Colley, C., Mackay, A., and Bankoff, G., 2011, Social impact of the 2004 Manawatu floods and the 'hollowing out' of rural New Zealand: Disasters, , v. 35, no. 3, p. 540-553.

Sorensen, J. H., Ericksen, N. J., and Mileti, D. S., 1975, Landslide Hazard in the United States: a Research Assessment, Prog Technol., Environ. Man Monogr, University of Colorado.

Sparling, G., Ross, D., Trustrum, N., Arnold, G., West, A., Speir, T., and Schipper, L., 2003, Recovery of topsoil characteristics after landslip erosion in dry hill country of New Zealand, and a test of the space-for-time hypothesis: Soil Biol Biochem, no. 35, p. 1575-1586.

Stokes, A., Atger, C., Bengough, A. G., Fourcaud, T., and Sidle, R. C., 2009, Desirable plant root traits for protecting natural and engineered slopes against landslides: Plant and Soil, no. 324, p. 1-30.

Stokes, A., Douglas, G. B., Fourcaud, T., Giadrossich, F., Gillies, C., Hubble, T., Kim, J. H., Loades, K. W., Mao, Z., Mclvor, I. R., Mickovski, S. B., Mitchell, S., Osman, N., Phillips, C., Poesen, J., Polster, D., Preti, F., Raymond, P., Rey, F., Schwarz, M., and Walker, L. R., 2014, Ecological mitigation of hillslope instability: ten key issues facing researchers and practitioners: Plant and Soil, v. 377, no. 1, p. 1-23.

Stokes, A., Sotir, R. B., Chen, W., and Ghestem, M., 2010, Soil-bio-and eco-engineering in China, past experience and present priorities: Ecol Eng, no. 36, p. 247-257.

Terranova, R., 1984, Aspetti geomorfologici e geologico-ambientali delle Cinque Terre: rapporti con le opere umane (Liguria orientale): Studi e Ricerche di Geografia, no. 7, p. 39-90.

-, 1989, II paesaggio costiero agrario terazzato delle Cinque Terre in Liguria: Studi e Ricerche di Geografia, v. 12, no. 1, p. 1-58.

Terranova, R., Zanzucchi, G., Bernini, M., Brandolini, P., Campobasso, S., Faccini, F., and Zanzucchi, F., 2006, Geologia, geomorfologia e vini del Parco Nazionale delle Cinque Terre (Liguria, Italia): Bollettino della Societa Geologica Italiana Spec, p. 115-128.

Thomas, V. J., and Trustrum, N., 1984, A simulation model of soil slip erosion., p. pp. 213-229.

Thompson, R. C., and Luckman, P. G., 1993, Performance of biological erosion control in New Zealand soft rock hill terrain: Agroforestry Systems, v. 21, no. 2, p. 191-211.

Toll, D. G., Lourenco, S. D. N., Mendes, J., Gallipoli, D., Evans, F. D., Augarde, C. E., Cui, Y. J., Tang, A. M., Rojas, J. C., Pagano, L., Mancuso, C., Zingariello, C., and Tarantino, A., 2011, Soil suction monitoring for landslides and slopes: Q J Eng Geol Hydrogeol, no. 44, p. 23-33.

Trezzini, F., Giannella, G., and Guida, T., 2013, Landslide and Flood: Economic and Social Impacts: Margottini, C. et al. (eds): Landslide Science and Practice, v. 7.

Trustrum, N. A., and De Rose, R. C., 1988, Soil depth-age relationship of landslides on deforested hillslopes, Taranaki, New Zealand: Geomorphology, v. 1, no. 2, p. 143-160.

Uhlemann, S., Smith, A., Chambers, J., Dixon, N., Dijkstra, T., Haslam, E., Meldrum, P., Merritt, A., Gunn, D., and Mackay, J., 2016, Assessment of ground-based monitoring techniques applied to landslide investigations: Geomorphology, v. 253, p. 438-451. 
UNCTAD, 2007, Trade and development aspects of insurance services and regulatory frameworks. United Nations, New York and Geneva

Van Kraayenoord, C. W. S., 1976, Plant materials for erosion control: NZ Agric Sci v. 10, no. 1, p. 29-33.

Van Kraayenoord, C. W. S., and Hathaway, R. L., 1986, Plant Materials Handbook for Soil Conservation, Principles and Practices, in Development, M. o. W. a., ed., Volume 1: New Zealand, p. 295.

Varnes, D. J., 1978, Slope movement types and processes. In: Schuster, R. I., Krizek, R. J (eds) Landslides, analysis and control, special report 176, Transportation research board, National Academy of Sciences, Washington, DC pp. 11-33

Vaugeois, L. M., 2000, SLPSTAB: Modeled Slope Stability Screen. Prepared by the Washington Department of Natural Resources, Olympia, WA. Available from: http://www.dnr.wa.gov/BusinessPermits/Topics/ForestPracticesApplications/Pages/fp gis spatial da ta.aspx. Accessed 13 June 2011.

Vaugeois, L. M., and Shaw, S. C., 2000, Modelling Shallow Landslide Potential for Watershed Management. 2000 ESRI User Conference Proceedings. Available from http://proceedings.esri.com/library/userconf/proc00/professional/papers/PAP310/p310.htm. Accessed 30 Dec. 2011.

Wagner, A., Leite, E., and Oliver, R., 1988, Rock and debris-slides risk mapping in nepal - A user-friendly PC system for risk mapping, In Landslides. In Bonnard, C. (Ed.) Proceedings of the 5th International Symposium on Landslides, Lausanne, Switzerland 10-15 July 1988: 1251-1258. Balkema, Rotterdam.

Walker, L. R., and Shiels, A. B., 2013, Landslide ecology: Cambridge University Press, Cambridge.

Ward, C., 2005, The floods of 2004 - looking back'. R M update. 16 (February): http://www.maf. govt.nz/mafnet/publications/rmupdate/rm16/rm-february-2005.pdf (accessed on 29 November 2010). p. 5.

Whitehouse, I., 1978, A century of erosion recovery: Soil Water, v. 14, no. 5, p. 10-14.

Whittaker, K. A., and McShane, D., 2012, Comparison of slope instability screening tools following a large storm event and application to forest management and policy: Geomorphology, v. 145146, p. $115-122$.

Wilkinson, A. G., 1999, Poplars and willows for soil erosion control in New Zealand: Biomass \& Bioenergy, no. 16, p. 263-274.

Willbanks, T. J., Romero Lankao, P., Bao, M., Berkhout, F., Cairncross, C., Ceron, J.-P., Kapshe, M., MuirWood, R., and Zapata-Marti, R., 2007, Industry, settlement and society. In: Parry, M. L., Canziani, O. F., Palutikof, J. P., van der Linden, P. J., Hanson, C. E. (eds) Climate change: Impacts, adaption and vulnerability.

Young, A., and Saunders, H., 1986, Rates of surface processes and denudation. in Abrahams, A. D., editor.: Hillslope processes, Boston, MA; Allen and Unwin,, p. 3-27.

Zanetti, C., 2010, Caracterisation du developpment des systemes racinaires ligneux dans les digues [PhD Thesis: Universite de Provence.

Zieher, T., Perzl, F., Rössel, M., Rutzinger, M., Meißl, G., Markart, G., and Geitner, C., 2016, A multiannual landslide inventory for the assessment of shallow landslide susceptibility - Two test cases in Vorarlberg, Austria: Geomorphology, v. 259, p. 40-54.

Ziemer, R. R., 1981, Roots and the stability of forested slopes: IAHS-AISH, no. 132, p. 342-357. 


\section{Appendix}

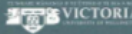

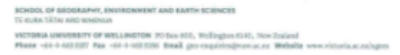

Physical Geography Field Research 2012

Alby Frampton

Research Questions -

Associated with field studies of land slips in the Waimarama Valley, East Coast, Hawke's Bay.

Interpreting the social and economic cost to farmers and residents of the Waimarama Valley weather bomb, April 26 and 27, 2011.

These questions and answers will be used in conjunction with the study of the landslips to show how the effect of the extreme weather community

All names will be kept anonymous, unless signed permission is received

SITE:

Address:

Area:

Owner or Manager:

Farm:

Size/hectares:

Local Business:

Permanent Resident:

Holiday Resident:

\section{ES VICTORIA}

QUESTIONS

1 Do you keep a rain gauge? yes/no

2 Did you keep a record of the storm rain volume yes/no

3 Do you have rain records of previous storms yes/no

What impact did the storm have -

A On your stock

B Fencing

C Ground cover loss

D Economic damage (buildings, fencing, trees, etc)

E Insurance - claims, payments

F Financial loss - business

G Financial recovery

H Stock carrying capacity

I Ongoing problems 


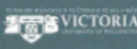

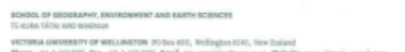

J What is being done to retain or stop further soil loss?

\section{Perception:}

In your opinion have storms increased/decreased/or remained the same

In your opinion have the slips increased/decreased/remained the same

In your opinion have your losses increased/decreased/ remained the same

Which parts of your property are most prone to failure

Did you receive any help from the local Council, Government or any other agency?
स्:

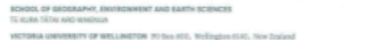

Consent Form:

please tick appropriate box

1 | have been provided with adequate information relating to the nature and objectives of this research project, I have understood that information and have

been given the opportunity to seek further clarifications or explanations.

2

confidential and reported only in an aggregated/non-attributable form, or

3 I consent to information or opinions being attributed to me [reference to persona opinion may be used within the text of the thesis or as a tribute in the

acknowledgements]

I understand that the information thave provided will be used only for this

research project and that any further use will require my written consent.

5

this research is completed he information oblained ton me will be destroyed.

6 Do you wish to review the interview notes and/or receive a feedback

summary

The results from this research will be used for publication in academic or professiona journals, dissemination at academic or professional conferences and a deposit of the research paper (thesis) in the University Library (student research). Permission granted:

Signature: 